\title{
PERSPECTIVES OF MUSLIM HUSBANDS' ROLES IN WOMEN'S HEALTH AND CANCER IN INDONESIA
}

BY

RESTUNING WIDIASIH

A thesis submitted to the Victoria University of Wellington

in fulfilment of the requirements for the degree of

Doctor of Philosophy in Nursing

Victoria University of Wellington

2017 


\begin{abstract}
In developing countries such as Indonesia, women face many health issues, including cancer. Social, cultural and economic factors are known barriers to women accessing health services and achieving a good health. Studies in Indonesia suggest that husbands' support may influence women's health behaviour, including women in breast and cervical screening and treatments. However, little is known in Indonesia about husbands' roles in women's health, including illness prevention, early detection, and treatment of women's cancer. The main objectives of this study were to uncover Muslim husbands' roles and perspectives regarding women's health and women's cancer, and to establish whether there were different perspectives of husbands' roles related to geographical location, age or other social, health or cultural characteristics. This study used an Islamic ontological approach. The Basic Model of Religiosity and Health, the Health Belief Model, and the Help-Seeking Behaviour and Influencing Factors Framework theories informed data collection. A descriptive exploratory methodology was used. Methods included focus groups with 11 groups ( $n=73)$ of married Muslim men, and interviews with married Muslim women $(n=20)$ and health professionals $(n=10)$ from rural and urban areas of West Java province, Indonesia. Data were analysed using two techniques: the Comparative Analysis for Focus Group and the Comparative Analysis for Interviews. The findings revealed that Islamic teaching has an extremely significant position for Muslims husbands in guiding them in their family's roles. Muslim husbands were very involved in women's health and cancer. These roles were influenced by internal and external factors. Husbands' significant roles in women's health include maintaining women's health and facilitating health treatments. However, they have a limited role in disease prevention, and early detection of women's cancer. Muslim husbands' limited health literacy of women's cancer was a significant barrier in rural and downtown areas. This study's findings contribute to a new perspective on religion as a vital influence and driver of health and health behaviour in nursing theory. There is a need for Indonesian nursing practice to incorporate a cultural safety approach to caring for Muslim husbands and wives, and for nurses to ensure men are more fully informed about women's health. This study identified the need for improvements in health services and a reform of the health system especially in improving husbands' knowledge and awareness of women's cancer, and the
\end{abstract}


dissemination of information about women's cancer services, especially in rural and downtown areas. Additional health education programmes including some that target men's health literacy are required alongside improvements in health services, especially women's cancer services.

Keywords: Muslim husbands, roles, Islamic teaching, breast and cervical cancer, women's health, cancer screening, and treatments. 


\section{Dedication}

I dedicate this research to my beloved father H. Subur Widadi, S.Pd, who passed away on May $30^{\text {th }}, 2016$. He had a dream that one of his children would obtain a doctoral degree. I hope I have accomplished his dream and he is happy with this achievement. We are separated in different worlds, but your spirit is always in my heart, and your kindness will be forever remembered. 


\section{Acknowledgements}

In accomplishment of this journey, I offer my sincere gratitude and appreciation to my primary supervisor Dr Katherine Nelson for her patience in guiding me to finishing this study. I feel blessed to have had her as my first supervisor. She provided significant comment and advice for my thesis and was always accessible, communicative, and understanding. She also supported and motivated me in my unhappy times, especially when my father passed away.

I am also thankful to my secondary supervisor Dr Joan Skinner for her valuable advice, especially with my study's proposal. She also provided comments on the final draft of my thesis and her significant advice ensured effective linkages between the chapters.

Special acknowledgment to Helen Barnard who taught me better academic English.

My greatest gratitude goes to the New Zealand Ministry of Foreign affairs and Trade through the NZ ASEAN Award that provided support and funding for me during my journey. Thank you for assisting me to accomplish my dream, and to have overseas study experience and enhance my knowledge about research and women's health that will be useful for me to improve women's health in Indonesia. My family and I are very grateful for this opportunity. We learned a lot of positive things in New Zealand such as communicating with people from different cultural backgrounds and experiencing the education system.

I would like to thank the people in the Faculty of Graduate Research (FGR) and Faculty of Humanities and Social Science for facilitating my study processes from enrolment to the final stage of my thesis, and for providing the opportunity to publish it and present it in international conferences. The FGR programmes and guidelines were very helpful in completing this doctoral study.

I also acknowledge the academic staff of the Graduate School of Nursing, Midwifery, and Health for providing me with support and facilities during my study. 
My profound gratitude to the nursing faculty of the Universitas Padjadjaran, Bandung, Indonesia. Especially to the previous Dean, Mamat Lukman and also $\mathrm{Hj}$ Helwiah Ropi for your guidelines and support for this study leave. I am also grateful to the current Dean, Dr Kusman Ibrahim who fully supported my data collection stage and the extension of my study leave.

My appreciation to all the participants who volunteered to make this study possible: the pre-test participants from the Indonesia Muslim Community in Wellington, friends from the Indonesian Students Association Wellington (PPIW), and research participants from Komplek Perumahan Bojong Koneng Makmur, Warga RT 11 Babakan Sari, Warga Kelurahan Sukapura, Warga Jangraga, Warga Kertajaya, Warga Mangunjaya, PUSKESMAS Ahmad Yani, PUSKESMAS Sukasari, PUSKESMAS Parigi, PUSKESMAS Padaherang, PUSKESMAS Mangunjaya, and Rumah Sakit Hasan Sadikin Bandung. Special thanks to all the community leaders from the six areas above whose facilitation made the data collection possible.

My utmost gratitude to my husband, Anjung Darajat, for his continuous support and encouragement throughout the years. A special thank you for accompanying me to New Zealand and understanding my ups and downs during the journey of my study. Special thanks to my children Saffan Firdaus, Rafa Azka Ulinnuha, and Unzila Silmi Kaffah for their support, understanding, and love. Finally, my profound thanks to my mother Nur Khodijah, older sister Welas Rarasati, younger brother Toha Mahiru Masfu, parents-in-law, relatives, colleagues, and friends in Indonesia and New Zealand.

Jazakumullah Khairan Katsiran (Thank you). 


\section{Table of Contents}

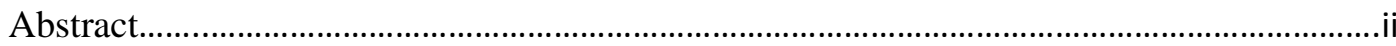

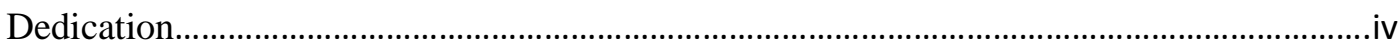

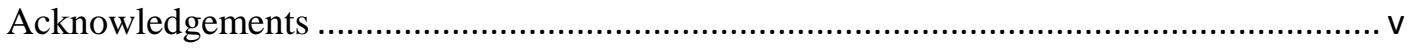

Table of Contents …………………….......................................................................... vii

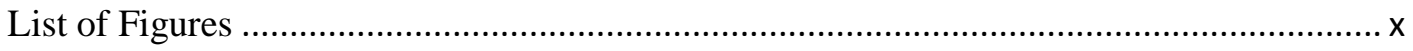

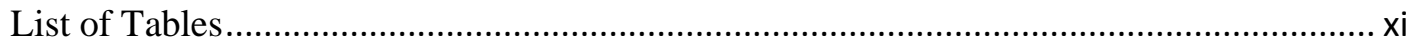

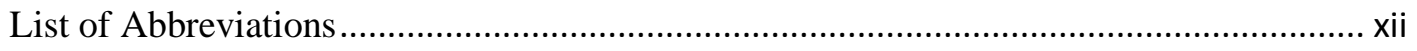

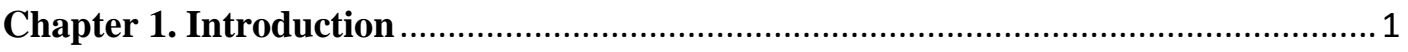

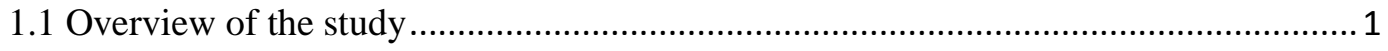

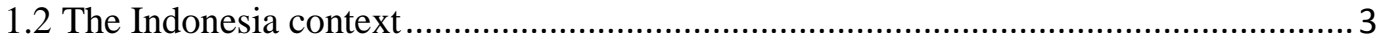

1.3 Researcher's experience of health services in Indonesia ............................................15

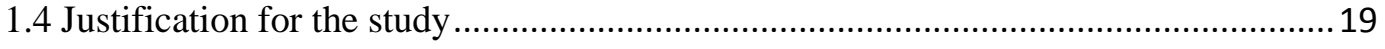

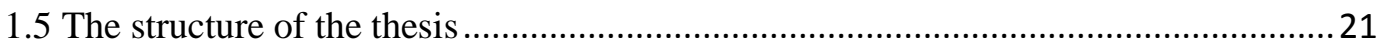

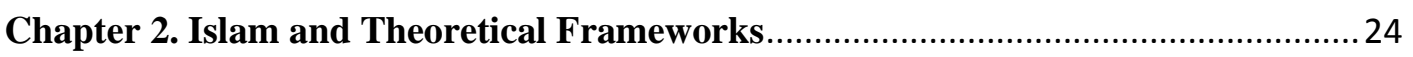

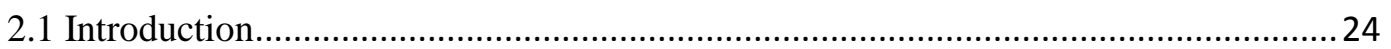

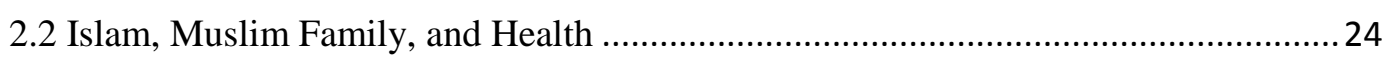

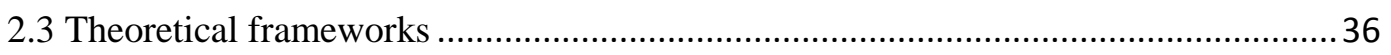

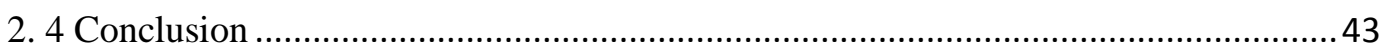

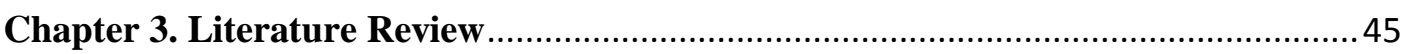

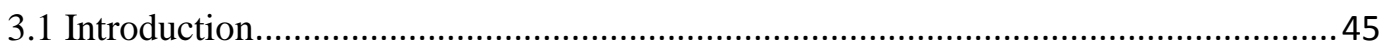

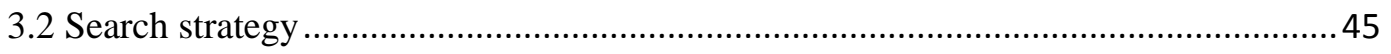

3.3 Factors that influence women's health behaviour........................................................ 48

3.4 Husbands' involvement in women's health behaviour ..............................................67

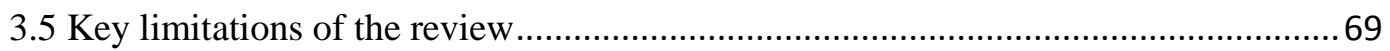

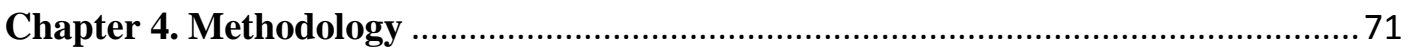

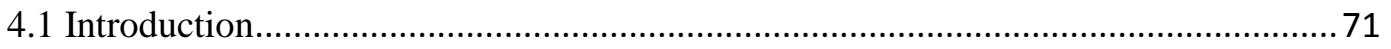

4.2 The philosophical paradigm of the study ............................................................ 71

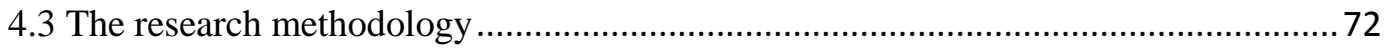

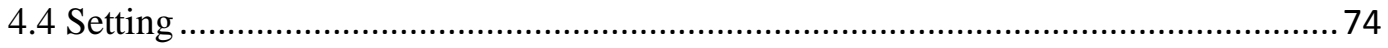

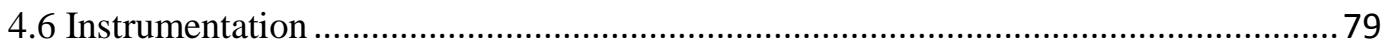

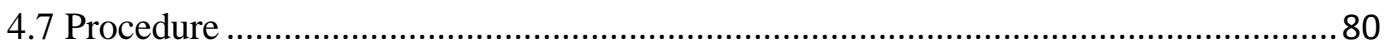

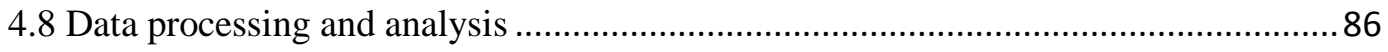

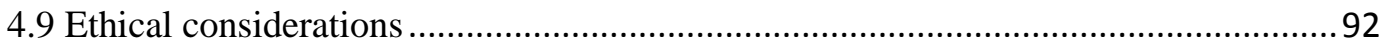

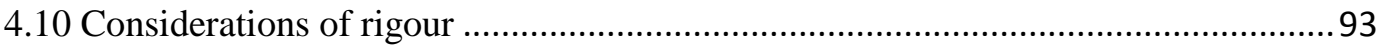


Chapter 5. Men's Perspectives of Their Roles in Women's Health and Cancer .........96

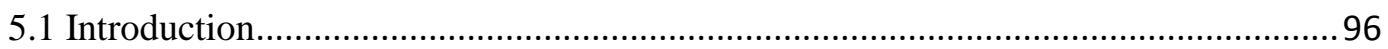

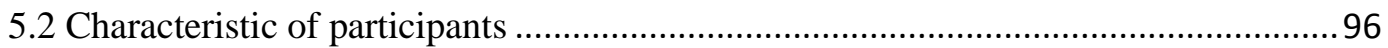

5.3 Islamic teaching shapes husbands' roles in women's health and cancer ....................99

5.4 Husbands' roles are primary in many aspects of women's health and cancer ...........103

5.5 Experience and knowledge influences husbands' perceptions, and awareness of

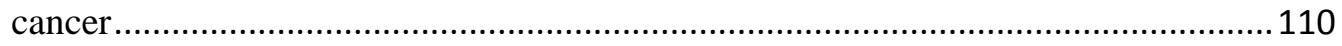

5.6 Barriers exist in husbands' roles in women's health and cancer .............................115

5.7 Husbands power and powerlessness reflects health services context ......................120

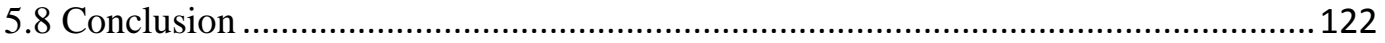

\section{Chapter 6. Women's Perspectives of Muslim Husbands' Roles in Women's Health}

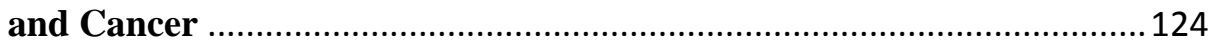

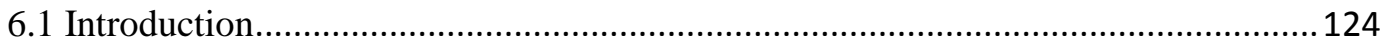

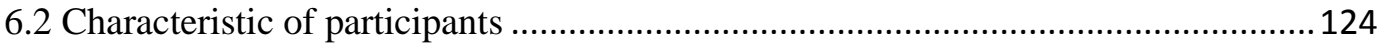

6.3 Islamic teaching impacts on husbands' actions in women's health and cancer........125

6.4 Husbands have extensive roles in supporting family health .....................................129

6.5 Family circumstances and social support influence Muslim husbands' roles in

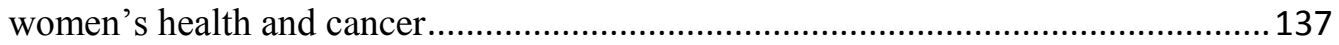

6.6 Husbands' health literacy influence their roles in women's health .......................... 140

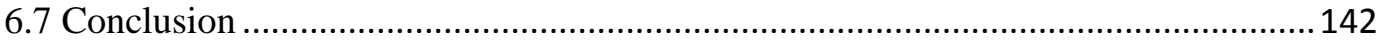

\section{Chapter 7. Health Professionals' Perspectives of Muslim Husbands' Roles in}

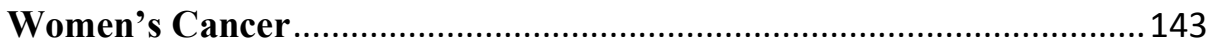

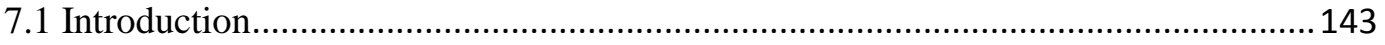

7.2 Characteristic of participants ................................................................................ 143

7.3 Contextual factors influence husbands' behaviour in women's health and cancer...144

7.4 Women's health conditions influence husbands' actions ........................................ 152

7.5 Family and health services impact on women's health decision ..............................156

7.6 Level of health literacy affects husbands' actions in women's health and cancer....161

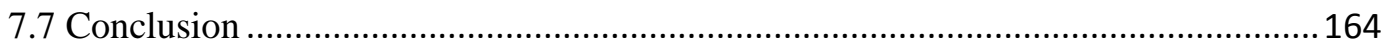

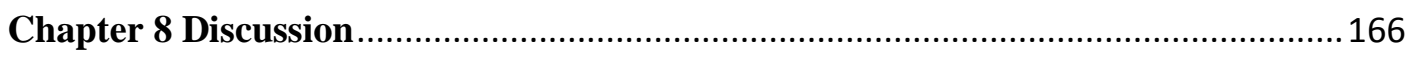

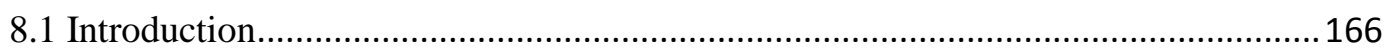

8.2 Islamic teachings influence husbands' roles in women's health and cancer ............168

8.3 Husbands have multiple and variable roles in women's health and cancer...............173

8.4 Personal, family and health service factors influence husbands' roles and experiences

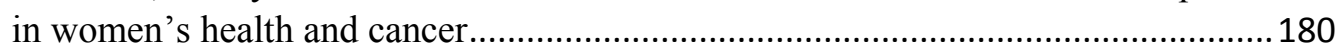

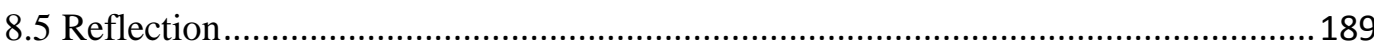


8.6 Study Limitations

8.7 Implications and recommendations for nursing.................................................... 193

8.8 Implications and recommendations for the Indonesia health system ...................... 195

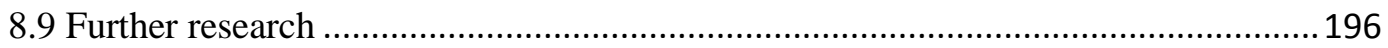

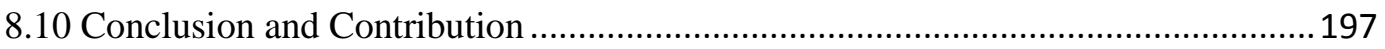

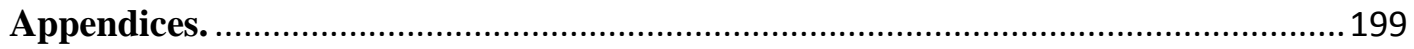

Appendix 1: Introductory letter form supervisor ....................................................... 199

Appendix 2: Recommendation letter from Dean of Nursing Faculty, Universitas Padjadjaran for site permissions to BKBP West Java Province ...............................200

Appendix 3: Site permission letter from BKBP West Java Province .............................. 201

Appendix 4: Site permission letter from BKBP Bandung city ......................................2202

Appendix 5: Site permission letter from BKBP Pangandaran district ..............................203

Appendix 6: Example of focus group guide used for Muslim men ..................................204

Appendix 7: Example of interview guide used for Muslim women .................................206

Appendix 8: Example of interview guide used for health professionals ........................208

Appendix 9: Example of demography survey ...............................................................210

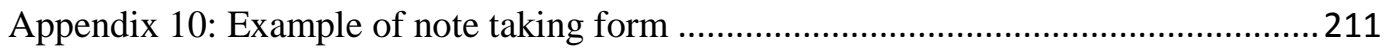

Appendix 11: Example of pre-test focus group guide used for Muslim men .................2213

Appendix 12: Example of pre-test interview guide used for Muslim women ................. 215

Appendix 13: Example of pre-test of Socio-demographics survey ................................217

Appendix 14: Example of pre-test of qualitative survey of women's knowledge ...........218

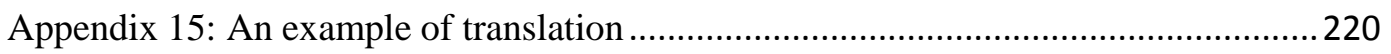

Appendix 16: Ethics approval from Human Ethic Committee Victoria University of

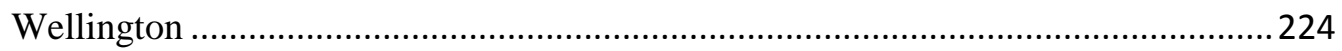

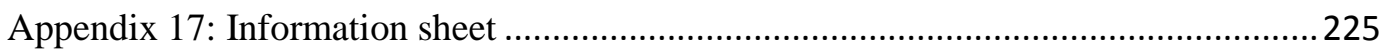

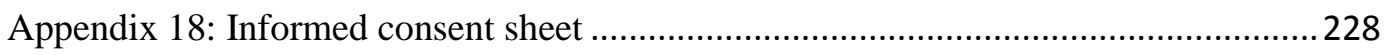

Appendix 19: Example of the moderator agreement for pre-test...................................230

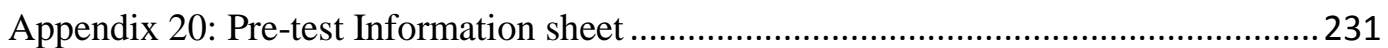

Appendix 21: Example of the informed consent for pre-test.........................................234

Appendix 22: All instrument in Bahasa Indonesia ......................................................235

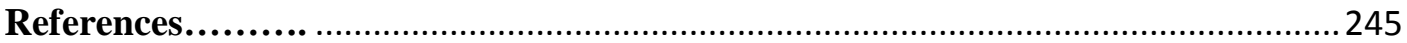




\section{List of Figures}

Figure 1. Map of Indonesia.

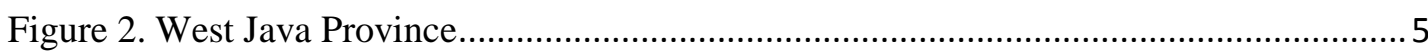

Figure 3. Hierarchy of Indonesian government and health services .................................... 7

Figure 4. The framework for exploring Muslim husbands' roles in women's health and

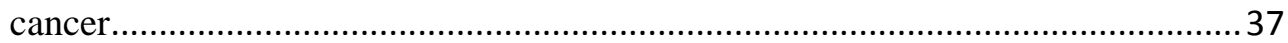

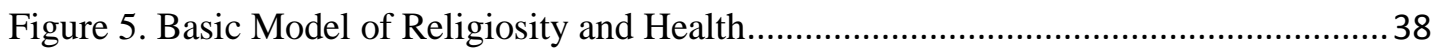

Figure 6. Help-Seeking Behaviour and Influencing Factor Framework ............................... 42

Figure 7. Key findings of Muslim husbands' roles in women's health and cancer................166

Figure 8 . The relationship between Islamic teaching and Muslim's religiosity and spirituality

Figure 9. Muslim husbands' roles in women's health and cancer ...................................174

Figure 10. Factors that influence Muslim husbands' roles in women's health and cancer ... 180 


\section{List of Tables}

Table 1. Number and types of health service in Indonesia 2009-2011 ................................ 8

Table 2. Number of cancer cases in RSKD hospital from 2003 to 2007 ..............................13

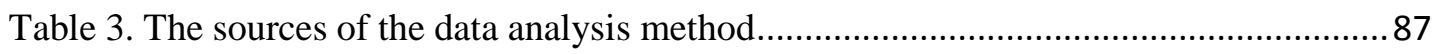

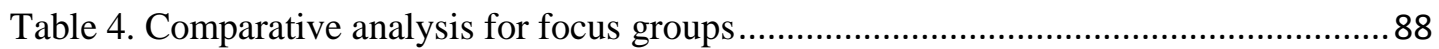

Table 5. The example of analysis steps from precoding to coding using software.................90

Table 6. Comparative analysis for interviews ..................................................................... 91

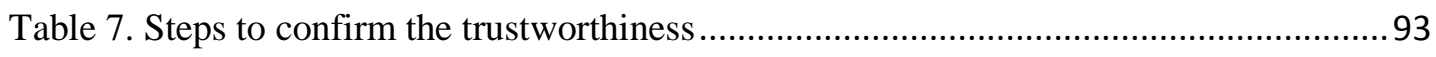

Table 8. Characteristics of focus group participants in urban areas.......................................97

Table 9. Characteristic of focus group participants in rural areas........................................98

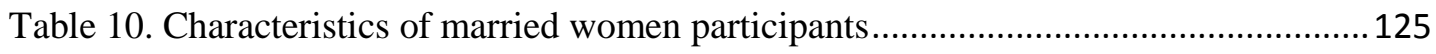

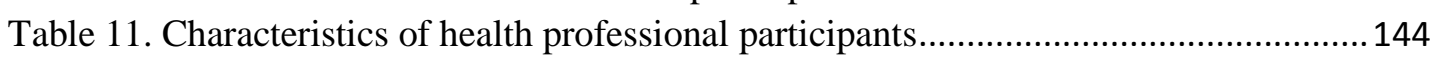

Table 12. Categories and themes from three data sources ...................................................168 


\section{List of Abbreviations}

ACTION

BKBP

BMMRS

BMRH

BPJS

BPOM

BSE

CANR

CBE

CD

FACT-G

FCP

FST

GHRI

HIV/AIDS

HBM

HEC

HPM

HPLP II

HPP

HPV

HSBIFF

CAF

CAI

KKNM

JAMKESMAS

MDGs

ME

MHRWH
Asean Cost in Oncology

Badan Kesatuan Bangsa dan Politik (National Politics Unity and Public

\section{Protection)}

Brief Multidimensional Measure of Religiousness/Spirituality

Basic Model of Religiosity and Health

Badan Penyelenggara Jaminan Sosial (Social Security Agency)

Badan Pengawas Obat dan Makanan (Food and Drug Board Agency)

Breast Self-Examination

Content Analysis in Nursing Research

Clinical Breast Examination

Communicable Disease

Functional Assessment of Cancer Therapy in General

Female Cancer Programme

Family System Theory

General Health Index

Human Immunodeficiency Virus/Acquired Immunodeficiency

Syndrome

Health Belief Model

Human Ethics Committee

Health Promotion Model

Health Promotion Lifestyle Profile II

Health Promotion Programme

Human Papilloma Virus

Help-Seeking Behaviour and Influencing Factors Framework

Comparative Analysis for Focus Group

Comparative Analysis for Interview

Kuliah Kerja Nyata Mahasiswa (A community service program for students)

Jaminan Kesehatan Masyarakat (Community health insurance)

Millennium Development Goals

Middle Eastern

Muslim Husband's Roles in Women's Health 
Ministry of Health

MSG

Mono Sodium Glutamate

NCD

Non-Communicable Diseases

NGOs

Non-Government Organisations

NSDAW

Non-Seventh-Day Adventist Women

OBGYN

Obstetrics and Gynaecology

PBI

Penerima Bantu Iuran (Beneficiaries)

PUSKESMAS Pusat Kesehatan Masyarakat (Primary Health Centres)

PHC Primary Health Centre

PKK

Pembinaan Kesejahteraan Keluarga (Family welfare movement)

POSKESDES Post Kesehatan Desa (Village Health Post)

POSYANDU Post Pelayanan Posyandu (Community Health Post)

P2TP2A Pusat Pelayanan Terpadu Pemberdaan Perempuan dan Anak

(Women and children's empowerment services)

QUAGOL Qualitative Analysis Guide of Leuven

RISKESDES Riset Kesehatan Dasar (Agency of Health Research and Development did basic health research)

RSKD Rumah Sakit Kanker Dharmais (National Cancer Centre)

R/S Religiosity/Spirituality

RW Rukun Warga (Community Association)

SDAW Seventh-Day Adventist Church Women

SPM Standart Pelayanan Minimal (Minimum standard services)

TSE Testicular Self-Examination

UMI Umat Muslim Indonesia (Indonesian Muslim Association)

VIA Visual Inspections with Acetic Acid

WHO World Health Organisation

YKI Yayasan Kanker Indonesia (Indonesia Cancer Foundation) 


\section{Chapter 1. Introduction}

\subsection{Overview of the study}

Women worldwide, particularly from developing countries, including Indonesia, face many health issues. The top 10 women's health issues include cancer, reproductive health, maternal health, human immunodeficiency virus (HIV), sexually transmitted infections, violence against them, mental health, noncommunicable diseases, being young, and getting older (Bustreo, 2015). The World Health Organisation (WHO) identified socio-cultural factors as one of the barriers to women accessing high-quality health services and achieving the best level of health (World Health Organization, 2017c). This factor is related to religion, ethnicity, gender roles, tradition norms, values, beliefs, socio-economic status, and social support and networks (Hernandez, 2006; Shaluhiyah, 2007; United Nations Population Fund, 2011). Engagement with religion is a considerable factor in new forms of women's health programmes as $84 \%$ of the world's population has an affiliation with religion or tradition (United Nations Population Fund, 2016).

Islam, the second largest religion worldwide impacts on all aspects of women's health. According to The Holy Quran, maintaining women's health is one of Muslim husbands' responsibilities. For example, a Muslim husband should take care of his wife by providing her needs, pampering her, accompanying and protecting her, and taking action when she faces health issues (The Holy Quran surah Al Baqarah verse 233, An Nisaa verse 34, Tahrim verse 6). Muslim husbands are likely to have important influences on women's health behaviour, and this is particularly relevant in Indonesia as the majority of Indonesians are Muslim (Suryanto, 2013).

Studies in Indonesia found that factors which influence women's participation in cancer screening were family - mainly husband - economic factors, accessibility to health services, the roles of health providers, social culture, and women's motivation (Aqni, 2013; Hasbiah, 2004; Marlina, 2013; Ningrum, 2012; Nurhasanah, 2008; Ompusungu, 2012; Rahma, 2012; Tresnawati, 2012; Wahyuni, 2011; Wijayanti, 2011; Yuliwati, 2012). Several studies assessed husbands' involvement in perinatal periods, family planning, and cancer (Anggraeni \& Benedikta, 2016; Arkiang, 2016; Kim et al., 2012; Kusmindari, Zinaida, Pasmawati, \& Saputra., 2016; Marlina, 2015; Musyriqoh, 2013; Pratami, 2016; Setiadi, 2015). However, no study 
has focused on Muslim husbands' views of their role as the majority of studies applied a quantitative approach. As a result, information about the detailed roles of husbands and factors that influence their role in women's health and cancer is limited.

Cancer, including women's cancer, kills 8.8 million people every year, mostly in low and middle-income countries (World Health Organization, 2017). Cancer is an immense problem in Indonesia, especially for women (Kementerian Kesehatan Republik Indonesia, 2010). An Indonesian national referral hospital specialising in cancer in 2007 found that two-thirds of all cancer cases they diagnosed were women's cancer such as breast, cervical and ovarian cancer (LitBang Rumah Sakit Kanker Dharmais, 2012). The Indonesian Ministry of Health via the Directorate General of Non-Communicable Diseases has developed national screening programmes as part of cancer control. However, Indonesian studies have found that women's participation in cancer screening and treatment is low (Ekanita \& Khosidah, 2013; Kim et al., 2012; Lantu \& Saraswati, 2013; Pusat Komunikasi Publik, 2013).

Muslim husbands have broad responsibilities to their wives, and these include the influence they have on their wives' health behaviour. I assume that the influence of Muslim husbands' roles in their wives' health, especially cancer, is real. However, information about their involvement in women's health is limited, especially their actions in improving their wives' health, including cancer. Also, the reasons for their behaviour, expectations of women's health services, and views of women's cancer are limited.

This research, therefore sought to, within an Islamic framework, examine the role husbands play in their wives' health with a particular focus on cancer. Taking a qualitative descriptive exploratory approach, 11 focus groups of men shared their own experiences. It was followed by interviews with 20 wives and 10 health professionals. In this thesis, I use the terms "men, spouse, and husbands" interchangeably to refer to the Muslim husbands who shared their roles in their wives' health. Other terms used are "women, wife" which denote Muslim married women, and "health professionals" which refers to nurses, doctors, and midwives. This study will refer to breast and cervical cancer as women's cancer, and the term "roles" denotes Muslim husbands' behaviour and actions. 
Women's cancer in Indonesia was seen as the initial lens through which to focus the study. The husbands in the study had little experience of women's cancer. A few men from urban and rural areas who had experience or knowledge of women's cancer shared how this influenced their awareness of women's cancer. The depth and richness of the men's data, however, was about their roles in protecting and promoting women's health in general and this developed as the central part of the study. For example, husbands' roles in promoting women's health were revealed and the husbands also shared their roles on general health issues such as taking and accompanying their wives to health services when they were sick.

This study used comparative analysis to identify perspectives of husbands' roles in women's health from the three sources: men, women, and health professionals. This analysis method was useful to assess whether husbands' roles differed by geographical backgrounds, age, income levels, and cancer experiences. The study's settings were rural and urban areas of West Java province, Java Island, Indonesia. This chapter now provides an overview of the Indonesian context, including geographical areas, socio-cultural influences, and health services. And then followed by the justification for the study, introduction to the researcher, a description of the study's purposes, and an outline of the thesis.

\subsection{The Indonesia context}

This section describes the Indonesian context, including the geography, sociocultural context, and health system. This information describes the different health facilities and infrastructure between urban and rural areas. It also describes culture and beliefs that influence Indonesians, and the Indonesian government's processes when it develops health services.

\subsubsection{Geography of Indonesia}

Indonesia is a democratic country and the largest archipelago in the world (17,508 islands). It has six official religions which are Islam, Christian, Catholic, Hindi, Buddhist, and Kong $\mathrm{Hu}$ Chu. Islam at $87.1 \%$ has the greatest number of followers (Suryanto, 2013) and the country has the largest Muslim population worldwide (PewResearch Center, 2012). This low-middle income country has the fourth largest population in the world (252,200,000 in 2014); 49.75\% of whom are women), and it is multicultural with 1128 tribes (Sinaga, 2012). Indonesia is 
positioned on the equator and share land borders with Malaysia, Timor Leste, and Papua New Guinea. It is divided into 34 provinces (Kementerian Kesehatan Republik Indonesia, 2012). A map of Indonesia is presented in Figure 1. The arrow on the map points to the geographical region where the study was carried out.

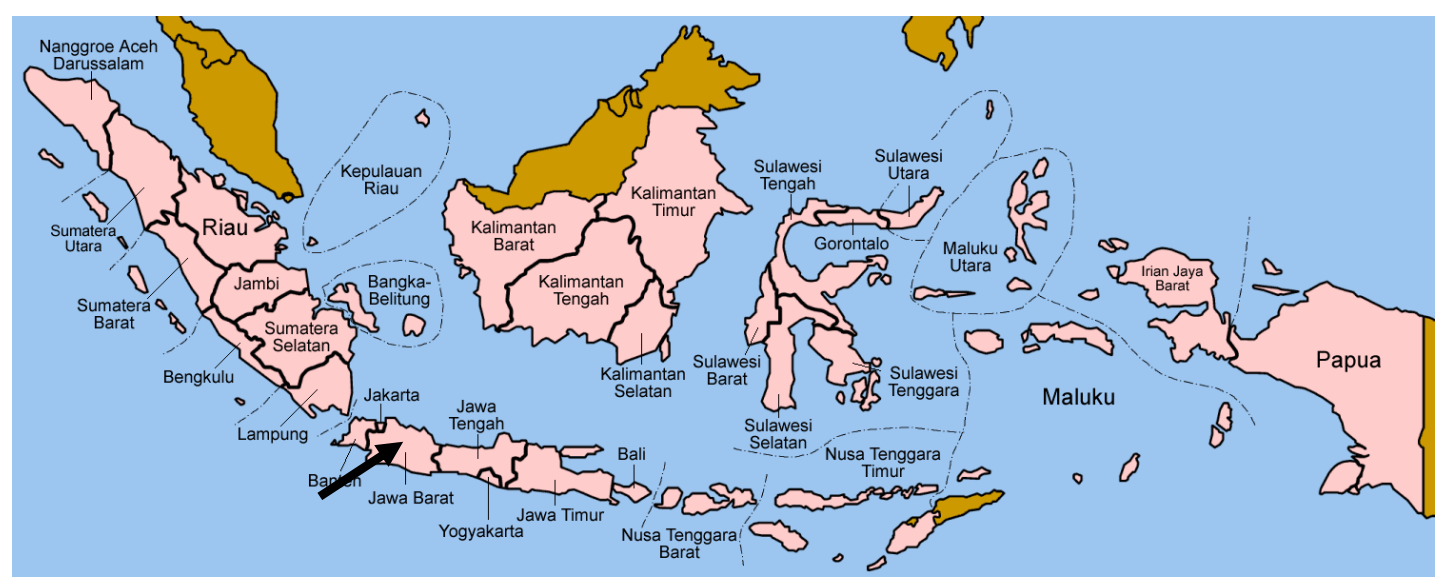

Figure 1. Map of Indonesia

Source: http://www.wikiwand.com/ms/Senarai_provinsi_Indonesia. Reproduced with permission.

The map shows five large islands and groups of small islands. The majority (56.93\%) of the population lives on Java Island. There are six provinces in Java, including Banten, Jakarta, West Java, Central Java, DI Yogyakarta, and East Java. A map of the West Java (Jawa Barat) province where this research was conducted is presented in Figure 2.

West Java province has 27 districts and the largest population with $18.25 \%$ of the total Indonesia population; 97\% of its citizens are Muslim. The capital of this province is Bandung district. Data, for this study, were collected in the Bandung and Pangandaran districts (both are indicated by a black arrow in Figure 2). Bandung is located in the centre of West Java while the Pangandaran district is located in the rural and border areas of West and Central Java.

Indonesia's population is dispersed, with some areas highly populated and others sparsely populated. This population issue affects the economy's equitable distribution and has created health challenges. These challenges include limited health facilities, a lack of health regulations, insufficient health workers, and considerable disease, including tropical, communicable and non-communicable diseases (NCD). Stroke is the NCD that kills most people, followed by cancer 
(Kementerian Kesehatan Republik Indonesia, 2012). The challenges are described in the following section about the overview of the health system.

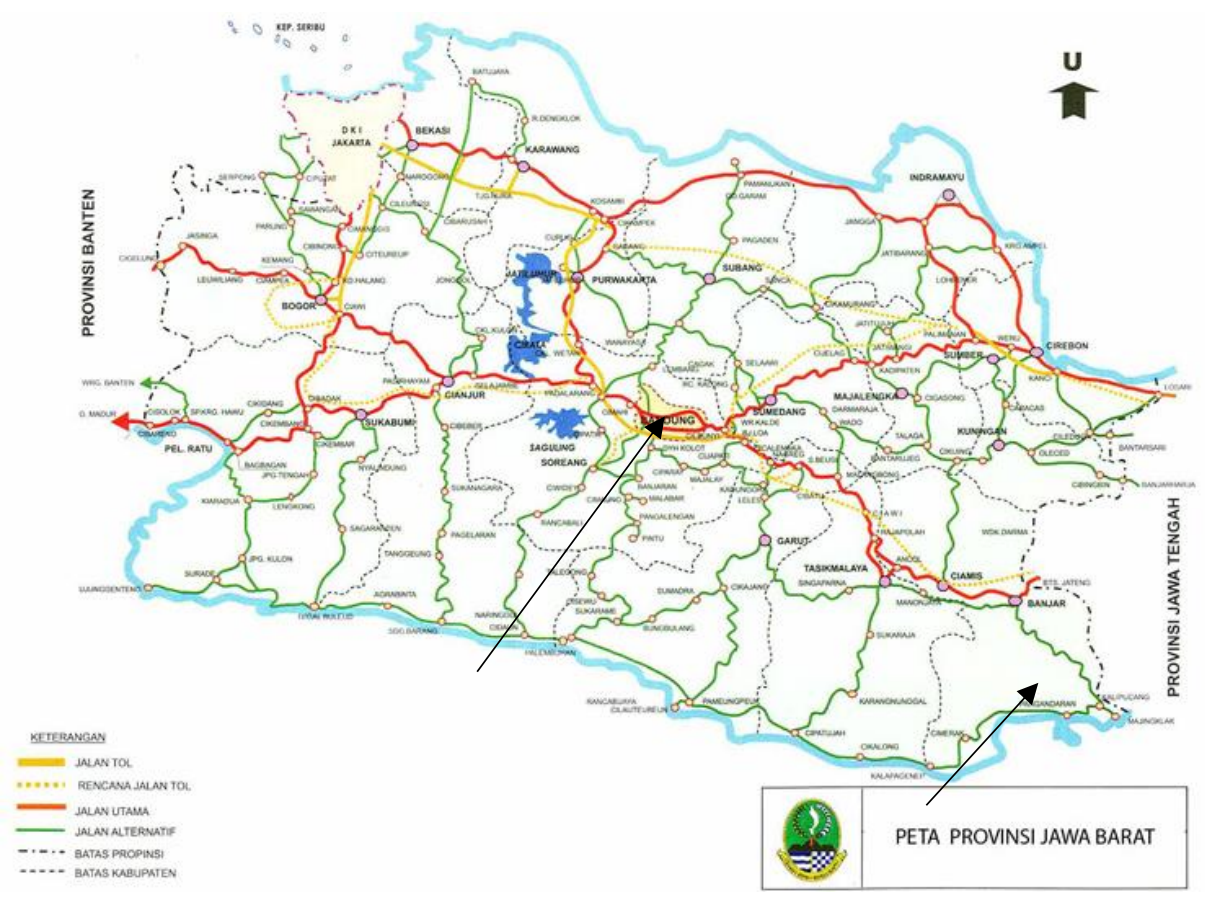

Figure 2. West Java Province

Source http://www.jabarprov.go.id/index.php/pages/id/99. Reproduced with permission.

\subsubsection{Overview of the health system in Indonesia}

This section presents information about health services and system priorities in Indonesia, and also describes women's health services and programmes. It will be apparent that the health system in Indonesia is still developing and this could impact on citizens' health services, including women's health services. These include changes to the health priorities programmes as well as changes in the country's leaders, insufficient health services and health professionals, limited data about women's health, including cancer, and issues related to cancer screening and funding.

\section{Indonesia health development system priorities}

The Indonesian health system is managed by the Ministry of Health (MOH) under the direction of the President of the Republic of Indonesia. With regard to women's health, there is also the involvement of the Ministry of Women's 
Empowerment and the Children Protection Programme which focuses on violence against women and trafficking cases. The health system priorities in Indonesia are written in the MOH's strategic plan 2015-2019 (Kementerian Kesehatan Republik Indonesia, 2015). These include improving health services such as mothers and children's services, disease control, increasing accessibility and quality of health services (especially in the rural, border, and poor areas), expanding government health insurance, health services, and ensuring there are sufficient health professionals, medicines and vaccines available. In addition, the $\mathrm{MOH}$ has specific targets named the Standard Minimum of Services (SPM) (Kementerian Kesehatan Republik Indonesia, 2016). The targets include: fulfilling minimum service standards for pregnancy, postpartum women, neonatal and children under five years, and screening for citizens from 15 years. Screening in this target includes breast and cervical screening. Further standards cover people with hypertension, diabetes, mental problems, tuberculosis, and HIV.

Changes in government leaders responsible for health have impacted the implementation of many programmes. At times, a programme is not disseminated to all areas of Indonesia, the target is not achieved, or the programme is replaced with another health programme. For example, the "Alert Village" (a programme that focuses on improving community awareness of maternal health) programme was part of the five-year strategic plan in the period 2004-2009. The implementation of the programme was not completed and did not cover all villages. In 2008, the new $\mathrm{MOH}$ renamed the programme "the Healthy Village", which provided wider services. Changes in health leaders also have the potential to improve women's health. For example, the current Minister of Health changed the SPM targets in 2016. In 2008, there was no target for women's cancer screening, but this has been included in 2016 (Kementerian Kesehatan Republik Indonesia, 2016).

\section{Health services}

There are six levels of health service in the government's hierarchy. These include referral hospitals at the national level; public and private hospitals at the provincial and district levels; primary health care (PUSKESMAS) in the subdistricts; health posts (POSKESDES) in the villages; and community health posts 
(POSYANDU) with each village commonly having 4-6 community groups. Figure 3 shows the Indonesian's government hierarchy and types of health services.

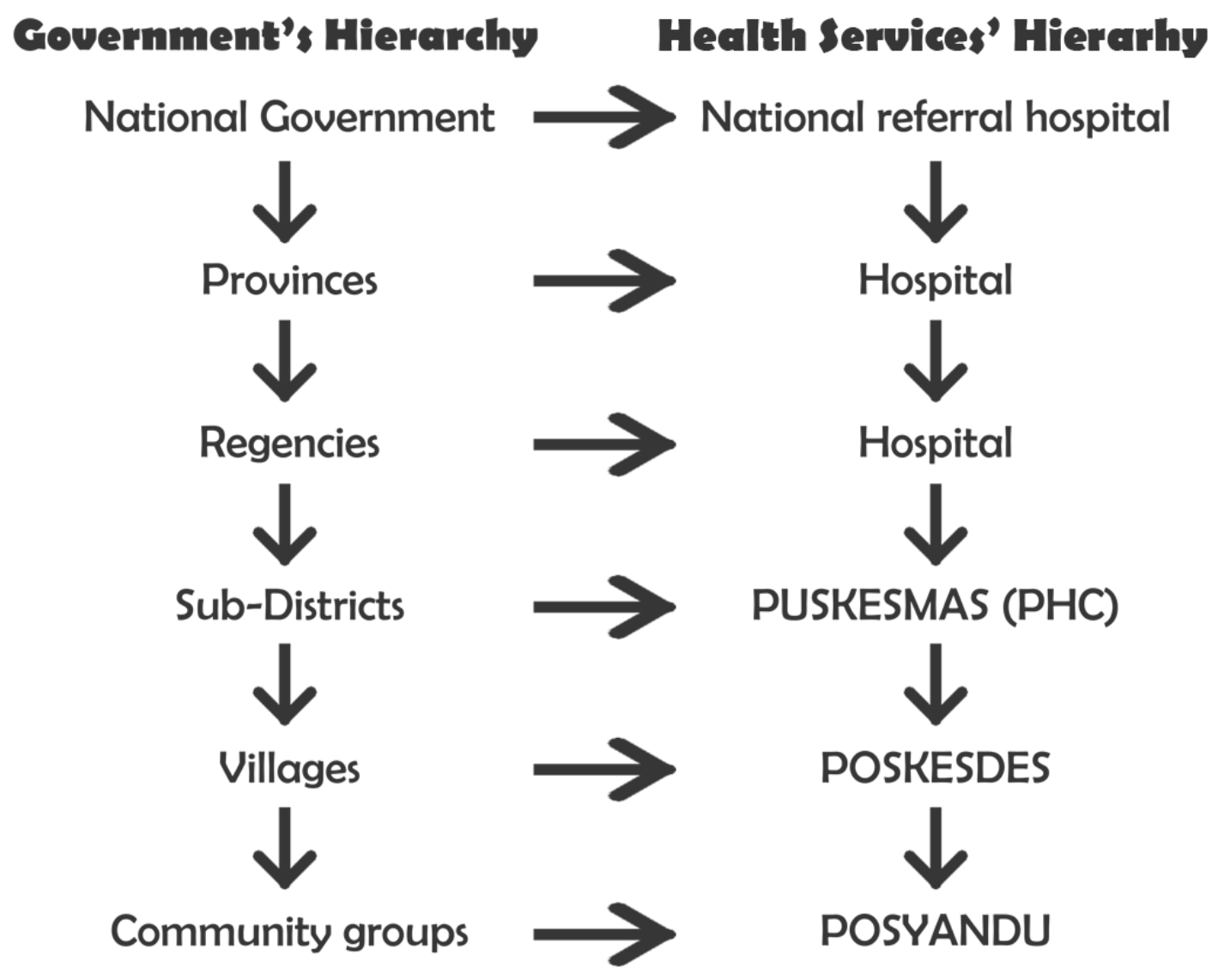

Figure 3. Hierarchy of Indonesian government and health services

Each health service has targets and provides specific services that are written in the $\mathrm{MOH}$ regulations. For example, the $\mathrm{MOH}$ regulation 128/MENKES/SK/II/2004 is about PUSKEMAS's (Kementerian Kesehatan Republik Indonesia, 2004) main targets. The PUSKESMAS targets are mothers and children's health; health promotion; environmental health; family nutrition; prevention and eradication of the communicable diseases; and cures. This health service has the potential to improve the community's health; however, some issues have been identified, in particular, those relating to the quality of services and a shortage of qualified health workers (Purnomo, 2009). Human resources are issues in the health system in Indonesia, especially in rural and isolated areas (Husain \& Soetjipto, 2006). The number of health facilities increased from 2009 to 2014 (Table 
1). This table shows that the number of private hospitals increased markedly from 2011 to 2014.

Table 1. Number and types of health service in Indonesia 2009-2011

\begin{tabular}{|l|r|r|r|}
\hline Health Services & \multicolumn{1}{|c|}{$\mathbf{2 0 0 9}$} & \multicolumn{1}{c|}{$\mathbf{2 0 1 1}$} & \multicolumn{1}{c|}{$\mathbf{2 0 1 4}$} \\
\hline POSYANDU & 266,827 & 268,439 & 289,635 \\
\hline POSKESDES & 22,650 & 53,152 & 58,917 \\
\hline PUSKEMAS & 2704 & 3019 & 3378 \\
With inpatient facilities & 6033 & 6302 & 6353 \\
Without inpatient facilities & & & \\
& 755 & 826 & 930 \\
HOSPITAL & 768 & 895 & 1478 \\
Public & & & \\
Private & & & \\
\end{tabular}

Sources: Profil Data Kesehatan tahun 2011, and Data dan informasi: Profil kesehatan tahun 2014, Kementerian Kesehatan Republik Indonesia

Health services focus on four main services; health promotion, prevention, treatment, and rehabilitation. In actuality, the main service focus in the majority of hospitals is treatment. For example, in Liwa public hospital, located in Lampung Province, health promotion services and facilities are minimal. This hospital does not have a department of Health Promotion in the structure of the hospital organisation. It does not have an annual budget for health promotion programmes, and has limited human resources in health promotion, and minimal health promotion plans (Suryana, 2010). Furthermore, health promotion services are not optimal in the Adam Malik hospital in Medan, North Sumatra province, because there is no clear assessment process before and after health promotion (Hakim, Heldy, \& Fauzi., 2013).

According to descriptions of the main focus of services in PUSKESMAS and hospitals in Indonesia, it is likely that women's cancer screening services are not the priority.

According to the head of the Directorate General of Non-Communicable Diseases, as part of the $\mathrm{MOH}$ structure, this directorate has developed four programmes for cancer control, including prevention, early detection, surveillance of epidemiology, and information especially for cervical and breast cancer (Putri, 2012). This directorate developed breast and cervical screening programmes that 
require collaborating with cross-sectoral institutions. These institutions include local government, non-government organisations, and professional organisations. A pilot project programme for early detection of cervical cancer was developed in 2008 (Pusat Komunikasi Publik, 2013). However, there is limited information about the implementation of this pilot nationally or about programmes that were developed by the Directorate General of NCD. The cancer screening programmes appear to be ad hoc; however, women should have cancer screenings regularly. It is uncertain, why cancer control target programmes, especially women's cancer screening, are not a required in health service programmes. As a consequence, health services are likely to play passive roles. They tend to wait until women take the initiative to come to health services when abnormal signs are found. No study has examined the relationship between the increasing number of health services in Indonesia and the quality of women's health services, especially cancer prevention, screening, and treatment. Limited early detection services, in particular, women's cancer screening, may hinder women's action and awareness of cancer screening.

\section{Funding of health services}

Hospital fees for women's cancer screening and treatment vary and depend on several factors. For example, private health services are commonly more expensive than public services and not all people have health insurance. The government established Badan Penyelenggara Jaminan Sosial (BPJS), a social security programme including health on $1^{\text {st }}$ January 2014. This programme declared that every citizen should enrol in this health insurance programme by 2019. In 2017, the number of citizens who had registered was $175,229,402$ or $70 \%$ of the population (Departemen Komunikasi Eksternal dan Hubungan Masyarakat, 2017). There is also a private insurance service, which targets people with middle and higher incomes, but there is no clear data about the number who have registered with it (Eric, 2016).

The BPJS covers many health services, including screening and treatment for breast and cervical cancer (Informasi BPJS, 2016). Women can obtain free cancer screening and treatment when they are registered with BPJS. However, a study developed by Asean Cost in Oncology (ACTION) in Indonesia found that $70 \%$ of patients with cancer passed away and many faced financial problems after 12 months of therapy, and $24 \%$ of cancer therapy fees were not covered by BPJS. The findings 
also report that families looked for financial support from many sources, including from other families (40.9\%), the local government (17.3\%), and loans (10.4\%); others generated income by selling personal assets (13.7\%), moving home (4.3\%), or delaying hospital payments (3.8\%) (Maharani, 2016). Further, women who do not have BPJS insurance needed to spend approximately 50.000-750.000 IDR (\$NZ 575) for a Pap smear, depending on the type of health facility (Arya, 2016). For Indonesian, especially women from rural areas and low income, the Pap smear cost is expensive. Many issues regarding the implementation of this new health insurance programme have been reported (Dewan Perwakilan Rakyat Republik Indonesia, 2016). For example, citizens faced problems with limited health services. A result of this is a patient can spend hours waiting for health services, and there is also minimal dissemination of information about services and procedures. However, the government-funded health insurance is one way to guarantee and improve citizens' health because it covers an individual's medical treatment, disease prevention and recovery (Australian Indonesia Partnership of Health System Strengthening, 2015).

\section{Traditional health services in Indonesia}

Traditional health care has been practiced in Indonesia since $722 \mathrm{BC}$ and is an Indonesian heritage (Shinoda, 2016). According to the Director of Public Health in the Department of Health, about 280,000 traditional healers and 30 specialisations in traditional Indonesian healing are recorded. Currently, there are 30,000 species of plants in Indonesia, and 950 of them have healing functions that can be developed for the welfare of the people (Idward, 2012). These traditional medicines include: mind and body interventions such as hypnotherapy, yoga and doa (Islamic meditation); services such as acupuncture, acupressure, and aromatherapy; manual healing such as shiatsu and massage; pharmacology and biological therapies, for example, medical herbs; diet for the promotion of health or the prevention of illness; and ozone therapy (Kementerian Kesehatan Republik Indonesia, 2007).

Even though modern health services have been developed in Indonesia, many people also use traditional medicines. The National Social Survey shows that in $2001,57.7 \%$ of Indonesians applied self-therapies for their diseases and $31.7 \%$ used traditional medicines. In the following three years, the percentage of Indonesians applying self-therapies increased to $72.44 \%$ and $32.87 \%$ used traditional medicines 
(Idward, 2012). Traditional services are regulated (Ministry of Health regulation number 23/1992 and 36/2008), and the government has delegated control of the production and consumption of herbs for medicine to the Food and Drug Board Agency (BPOM). No national data that specifically reports on the proportion of women with breast and cervical cancer who used traditional therapies have been compiled. However, a few studies have found that traditional medicines were used by women diagnosed with cancer. A study in Jakarta of 34 patients with cervical cancer, in a centre of a national cancer referral hospital, found that $61.8 \%$ used herbal medicines (Radji, Aldrat, Harahap, \& Irawan, 2010). Similar findings were found in a qualitative study of six women with breast cancer in a referral hospital in Yogyakarta. This latter study found that patients consumed herbs, traditional painkillers, and other types of alternative therapies, even though they knew that those alternative therapies would not help (Ginting, 2014).

It is not known what influences people with cancer to use traditional therapies in Indonesia and who in a family is involved in the decision. A study that assesses family's perceptions, especially husbands' perceptions about women's cancer, has yet to be done. Their perceptions may impact on their wives' health-seeking behaviour, especially in Muslim couples.

\section{Women's health in Indonesia}

Indonesia's women's health development system, data, targets, and services mainly focus on maternal health (pregnancy, labour, and postpartum) as mandated by the National Strategy for Health Development (Kementerian Kesehatan Republik Indonesia, 2015) and the SPM (Kementerian Kesehatan Republik Indonesia, 2016). For the past 10 years, the Indonesian government has focused more on maternal health, as Indonesia participated in the Millennium Development Goals (MDGs) agreement, and one of the MDG's goals was reducing maternal mortality. However, Indonesian women also face other health problems, such as increasing reproductive health diseases and cancer, reduced family planning participation and a rise in violent incidents against women. The barriers to reproductive health faced by Indonesian women are discrimination against unmarried women and girls; sexual abuse, restrictions on married women's and girls' reproductive choices; and other 
impediments to sexual and reproductive rights (Amnesty International, 2010). As a result, a comprehensive picture of women's health is limited.

With regard to women's access to and participation in health services, there is limited specific information available on health care uptake such as screening and treatment for breast and cervical cancer. The government uses the frequency of pregnancy and postpartum check-ups as an indicator to measure women's access to, and participation in health services. Further, the government encourages pregnant women to visit health services at least four times during their pregnancy, however the data gathered indicates that women's access to health services varies by province (Balitbangkes Kementerian Kesehatan RI, 2013). This may be influenced by geographical, social, and economic factors, as the data shows provinces located near the centre of government have more developed health facilities and infrastructure than other provinces. There is a need for more comprehensive research into women's access to health services.

\section{Breast and cervical cancer services in Indonesia}

This section provides data related to women's cancer in Indonesia. Breast and cervical cancer are the two most common cancers among women in Indonesia and the world (Stewart \& Wild, 2014). The actual numbers of women with breast and cervical cancer are not known in Indonesia as there is no national cancer registry (Menteri Kesehatan Republik Indonesia, 2010). According to the MOH (2012), cancer cases were dominated by women's cancer. Of all cancers, $30 \%$ were breast cancer and $24 \%$ cervical cancer. The $\mathrm{MOH}$ reported that the prevalence of cancer in women is higher than that of men with 5.7 per 1000 women and 2.9 per 1000 men developing cancer (Pusat Komunikasi Publik, 2012). Women's cancer is preventable, detectable, and treatable; however, only a limited number of women participate in cancer screening in Indonesia, and women who are diagnosed with cancer tend to present to hospital in the advanced stages (Desanti, Sunarsih, \& Supriyanti., 2010). The most effective method to prevent cervical cancer is the HPV vaccination, and the high-quality methods to detect cervical cancer are cytology and Pap smear (Kessler, 2017). Mammography is the only effective method of breast cancer screening that has proven. However, breast self-examination is one method that is commonly used to detect breast cancer in low-middle income countries, but 
this method is no longer considered effective for early diagnosis. No particular method has been introduced for breast cancer prevention; rather women need to adopt a healthy lifestyle to reduce their breast cancer risk factors (World Health Organization, 2017a).

The sources of women's cancer information in Indonesia are limited. I found information from two sources. The first is the research department of the "Rumah Sakit Kanker Dharmais" (RSKD) Jakarta, a national referral cancer hospital that developed a pilot project for a cancer registration system. This referral hospital collated cancer prevalence and incidence data from 2003 to 2007 (LitBang Rumah Sakit Kanker Dharmais, 2012). The pilot project by the RSKD hospital found that more than two-thirds of women's cancer cases were in the reproductive system (breast cancer, cervical cancer, ovarian and corpus uteri). Table 2 presents the number of cancer patients based on gender in the RSKD hospital. The second is a report from the Agency for Health Research and Development which conducted basic health research (RISKESDES) in 2013 and published the findings in the Journal of Health Data and Information (Pusat data dan informasi, 2015). The data showed that women's cancers were dominant, their incidence was higher than men's cancers, and the number of female patients had increased.

Cancer is identified as one of the main causes of mortality in Indonesia; however, limited health programmes have been developed by the Indonesian government, and as a result, there is a lack of women's response to the cancer programme, including screening.

Table 2. Number of cancer cases in RSKD hospital from 2003 to 2007

\begin{tabular}{|l|r|r|r|}
\hline Year & \multicolumn{1}{|c|}{ Men (\%) } & \multicolumn{1}{c|}{ Women (\%) } & \multicolumn{1}{c|}{ Total } \\
\hline 2003 & $604(36.5)$ & $1049(63.5)$ & 1653 \\
\hline 2004 & $595(35.5)$ & $1079(64.5)$ & 1674 \\
\hline 2005 & $718(34.0)$ & $1392(66.0)$ & 2110 \\
\hline 2006 & $802(33.8)$ & $1569(66.2)$ & 2371 \\
\hline 2007 & $781(32.7)$ & $1606(67.3)$ & 2387 \\
\hline Total & $3500(34.0)$ & $6695(66.0)$ & 10195 \\
\hline
\end{tabular}

Source: Registrasi kanker berbasis Rumah Sakit di Rumah Sakit Kanker Dhamais 20032007, LitBang Rumah Sakit Kanker Dharmais, 2012 (LitBang Rumah Sakit Kanker Dharmais, 2012). 
Table 2 illustrates that the number of cancer cases has steadily increased, especially for women from 2003 to 2007, while the number of male cancer patients has fluctuated. In addition, female patient numbers were two times higher than male. Budget restrictions have meant that registration systems do not yet apply to other hospitals, and the RSKD hospital has not continued the project (LitBang Rumah Sakit Kanker Dharmais, 2012). In addition to the pilot study, the RSKD reported their services related to cancer prevention and early detection from 2010 to 2014 . They provided health education about cancer screening for women in hospital and the community (Sabrida, 2015). Regarding cancer screening, they provided services including mammography and Pap smears. Further, the RSKD research showed that the number of screenings by women in outpatient services was higher than the number of women who visited the services in 2010-2014. This increase is because of a growing and increasing awareness among women of cancer and, because of this, women often had more than one type of screening. An example of this is a record of women who visited the policlinic for both a Pap smear and a mammography (Sabrida, 2015).

The RISKESDES (2013) found that neoplasm diseases are reported as seventh in the top 10 mortality causes in Indonesia, and cancer's prevalence was 1.4 per 1000 citizens (Wahidin, 2015). The RISKESDES (2013) found that East Java, Centre Java, and West Java provinces were estimated as having the third highest number of breast and cervical cancer (Pusat Data \& Informasi, 2015). In 2010, breast cancer was the most common hospitalised women's cancer $(28.7 \%)$ followed by cervical cancer $(12.8 \%$ ) (Wahidin, 2015). Perhaps this is because of the increasing awareness among women of breast cancer and when women found breast abnormalities they visited health services immediately (Sabrida, 2015).

Even though cancer control is not the main priority in health development, the Indonesian government is committed to improving women's participation in the early detection of cancer. It has developed a national programme for breast and cervical cancer screening. In 2008, the previous first lady, Ani Yudhoyono, launched a national programme of breast and cervical cancer screening. This was followed by a pilot programme for the early detection of cervical cancer in six districts, run by the MOH. In 2014, the programme's progress report revealed that the number of PUSKESMAS involved in the pilot programme was 1986 totalled 9,422, and 904,099 women participated (total target 35,000,000 women). The pilot project faced 
some problems such as the lack of community information and community awareness and myths (Widianto, 2013). In 2015, the current first lady, Iriana Jokowi, established the same programme as the former first lady with the same method of screening, the visual inspection with acetic acid (VIA) test and the Clinical Breast Exam. The target of this programme from 2015 to 2019 is $50 \%$ of Indonesian women age 30-50 years attend breast and cervical screening. This programme's activities include socialisation and training for trainer providers, cadres, and health professionals. It also includes surveillance, monitoring, and evaluation (Wahidin, 2015). From the 2008 pilot project, an evaluation found that husbands were one of the barriers women faced when accessing cancer treatments (Kim et al., 2012). However, information about the current programme's progress report was not located. Perhaps, this is because it is still in the implementation stage, and the updated data of women's health behaviour in screening, factors, and barriers that may influence women's participation in screenings has not as yet been collated.

\subsection{Researcher's experience of health services in Indonesia}

I was motivated to undertake this study due to my experience as a nurse educator and a community women's health activist. As a nurse educator in maternity nursing for 12 years in Indonesia, I was responsible for supervising groups of students in clinical areas of maternity services for a minimum of six months. These service areas included outpatient services (policlinic of obstetrics and gynaecology [OBGYN]), delivery rooms, and inpatient services (postpartum wards and gynaecology rooms). In the latter, students often cared for women with cancer. When I supervised students in hospitals, mostly in a national referral hospital, I had interactions with female patients who faced different health issues, and I found differences in women's and their family's behaviour when they were sick. For example, pregnant women who visited the hospital were only those at risk who were referred by the village midwife. In addition, patients who visited the policlinic of obstetrics and gynaecology were mostly women aged 50 years or older with cancer and who were accompanied by family members, or they presented for a Pap smear because several cancer signs and symptoms had been detected by health professionals in the PHC or private practices. The women who were admitted to the OBGYN ward were mostly women who had advanced stages of cancer. 
Commonly, patients present to a referral hospital in two ways. Firstly, patients present to public or private hospitals because they feel unwell. Secondly, patients visit hospitals with a referral letter from a PUSKESMAS or the private services (midwife, nurse, doctor, or clinic). Patients who come to the health services do not need to make an appointment. Every patient takes a queue ticket from the hospital front desk for their registration. At this desk, patients provide some documents for administrative requirements to get second queue ticket based on their symptoms. For example, a woman with vaginal bleeding will get a queue ticket to visit the policlinic (outpatient services) of Obstetrics and Gynaecology. There is limited time for registration, as the front desk's opening hours are from 8 am to $11 \mathrm{am}$, the policlinic's opening hours vary, a national referral hospital opens from 9 am to $4 \mathrm{pm}$, and referral hospitals at district level open from 9 am to $2 \mathrm{pm}$.

Patients who are hospitalised are referred by the policlinic or the hospital's emergency services. The inpatient wards are divided into several classes of services: VIP class, first class, second class, and third class. Patients' room class depends on their insurance, or if they have money, they can choose the class. The lowest class is commonly for low-income people or government-insured poor citizens. In the ward, patients should be accompanied by their family members because health professionals rely on the family members to provide some services. These include buying medicines from the hospital's pharmacy, taking a blood sample to a laboratory, or looking for blood for transfusion. Unfortunately, only a small number of rooms provide accommodation for patients' families, usually in the VIP class. Patients' families, especially those from rural areas, need to rent accommodation and spend considerable amounts of money when a family member is hospitalised. It is likely that a patient and family from rural areas face many challenges when their family member is hospitalised in a referral hospital.

I found limited health education programmes delivered by health professionals, including discharge planning in both inpatient and outpatient services. I also observed that the majority of services focused on curative procedures, and I wondered why most women attended the hospital for screening only after they found abnormalities. Further, the hospital management usually asked students participating in the hospital's fieldwork programme to deliver health education to hospital visitors. The hospital provides topics for health education. For example, a cancer screening offered in the OBGYN inpatient services, seemed out of place given most 
women who were at the hospital had cancer symptoms and had come for therapy. I assumed there was a missing link in primary prevention activities (health education about screening) for breast and cervical cancer that impacts on women only visiting health services after they have found abnormal symptoms, for example, vaginal bleeding. Information about screening is only available in the hospital or other health services, and as healthy women do not attend these, they do not obtain this vital information. Another health service I frequently supervised in was a PUSKESMAS. One of the foci in this health service was women's health, especially maternal and reproductive health, which was managed by midwives. The main target of health programmes in women's health areas was to reduce maternal mortality, so midwives mainly focused on women who were pregnant or postpartum. There were some health prevention and disease control services in the PUSKESMAS, but their focus was on preventing tropical diseases such as tuberculosis and dengue fever. There was limited attention given to cancer prevention and early detection, or on other women's health issues.

I also worked in community services with a non-government organisation which focused on women's health. The closer I came to the women, the more I learned about their limited understanding of health prevention, including health education or screening. In the community health posts (POSYANDU) women can access health information from health professionals. However, these services target children under five and their mothers. I reflected on whose responsibility it is to improve women's health in adolescence, unmarried women, married women without children, and older women. I also thought about how rural women obtained health services, including health prevention services, because they faced barriers such as geography, economics, and accessibility to health services because cancer screening services are provided by hospitals located in district capitals and are often far from their homes. From these experiences, I recognised the need for a model for women's health promotion and prevention services that focused on women's reproductive health for all ages in urban and rural areas.

I am interested in women's reproductive health promotion and prevention. This is for several reasons; first, women's reproductive health, in general, has not been a priority of women's health development, because the priority is women's health in maternal periods. The second reason is health services in Indonesia are more focused on treatment and rehabilitation services rather than health promotion 
and illness prevention. I read references from several sources such as Indonesian government official reports of health development from 1997 to 2012, government policies, studies from non-government organisations, the WHO data and reports, and studies about women's health in Indonesia, including breast and cervical cancer. From these reports and previous studies, I found that NCDs such as cardiovascular diseases, cancer, chronic respiratory diseases, and diabetes, are the diseases that kill most people in many low and middle-income countries, including Indonesia. Stroke is the NCD that kills the most people in Indonesia, and this is followed by cancer (Kementerian Kesehatan Republik Indonesia, 2012). The actual number of cancer cases is not known; however, data from a national referral hospital specialising in cancer diseases in Jakarta found that two-thirds of all cancer cases they diagnosed were women's cancer (LitBang Rumah Sakit Kanker Dharmais, 2012). These women's cancers are preventable, detectable via early diagnosis, and are treatable. However, female participation is low in the government's cancer screening and treatment programmes. Furthermore, many factors influence women's health behaviour, including social support from the family, especially husbands. It is likely that husbands have important roles in women's health in Indonesia.

I was predominantly interested in exploring more about husbands' roles in women's health, including the prevention, early detection, and treatment of women's cancer in the Muslim community. At the commencement of this research, I assumed that Muslim husbands are one of the main influencing factors in women's health behaviour because Muslim couples have a strong bond as directed in Islamic teachings, and married Muslim women believe that to become a good Muslim they need to follow Allah and their husbands. A husband's responsibilities to his wife and family are written in the Holy Quran and are shown by the Muslim prophet Muhammad [two main guidelines for Muslim]. It is likely a Muslim husband is the main source to help women improve their health, including cancer. However, studies into husbands' behaviour, views, and understanding of women's cancer, including illness prevention, early detection, and treatment are limited. It is also not known whether Muslim husbands from different backgrounds, such as where they reside, their education, or economic level, have different perceptions and behaviours towards women's health. Even though Muslim husbands' responsibilities to women are clearly written in the two Islamic guidelines, there are possibilities that men have 
different perceptions of their religious teaching, or they may implement them differently, and these may influence their roles in women's health, including cancer.

\subsection{Justification for the study}

The MOH, via the Directorate General of Disease Prevention and Control and the Indonesia Cancer Foundation (YKI), declared that the prevention and treatment of women's cancer are the main priority of their health programmes (Indonesia Cancer Foundation, 2014; Menteri Kesehatan Republik Indonesia, 2010). In 2008, these institutions carried out a pilot project for the early detection of women's cancer in the Karawang district and the West Java province. This project was a collaboration involving the $\mathrm{MOH}$, Jhpiego, a non-profit health organisation affiliated to Johns Hopkins University, USA, and the Ford Foundation (Kim et al., 2012). Breast self-examination (BSE) and VIA methods were chosen by the $\mathrm{MOH}$ as the recommended interventions for screening for women's cancer because both techniques require few tools, are low cost and can be delivered easily by health providers. However, four years after both screening techniques had been introduced nationally, few Primary Health Centres (PHCs) had introduced the screening. As a consequence, only a few women participated in the cervical screening programme (Pusat Komunikasi Publik, 2013). Women's participation generally in cancer screening and treatment in Indonesia is low (Ekanita \& Khosidah, 2013; Kim et al., 2012; Lantu \& Saraswati, 2013).

Several factors are known to influence women in Indonesia for participating in screening and treatment of cancer. Studies found that husbands are one factor that influences women's engagement in screening, prevention, and treatment (Aqni, 2013; Tresnawati, 2012; S. Wahyuni, 2011; Yuliwati, 2012). It is possible that husbands have an influence women's behaviour because they are closest to Muslim married women. The close relationship between husband and wife in Islam is written in the Surah Al Baqarah verse 187 as follows: "They are clothing for you and you are clothing for them". Because of the relationship, they complement and influence each other in positive or negative behaviour, including health behaviour.

From an Islamic perspective, the husband has full responsibility of caring for and protecting his family members, and he has an important role in decision making as it relates to giving consent for health treatment (K. Ibrahim, 2009). The influence 
of a Muslim husband may also be related to women's religiosity, as religiosity is one factor that influences health behaviour (Masters, 2008; O'Mahony \& Hegarty, 2009). Muslim women believe that a virtuous woman is a woman who obeys Allah and her husband as noted in the Holy Quran surah An Nisaa verse 34. The Muslim husband is likely to have a significant influence on his wife health behaviour. However, no study in Indonesia has focused specifically on Muslim husbands' actions and behaviour in women's health and cancer. Previous studies have indicated that husbands were one of some influencing factors in women's health behaviour. However, there are limited details and explanations of husbands' actual influence and behaviour, as the studies mostly used a quantitative approach. In addition, the information about the extent husbands are involved, and in what areas they are involved in women's health, including cancer, is not known. This study was designed to provide some of this missing information. It explores Muslim husbands' roles in women's health and breast and cervical cancer, including prevention, early detection, and treatment.

The main objectives of this study were to:

1. Uncover Muslim husbands' roles in women's health, and breast and cervical cancer, including prevention, early detection, and treatment.

2. Explore women's perspectives of Muslim husbands' roles in women's health, and breast and cervical cancer, including prevention, early detection, and treatment.

3. Explore health professionals' perspectives of Muslim husbands' roles in women's health, and breast and cervical cancer, including prevention, early detection, and treatment.

4. Identify whether there are different perspectives of husbands' roles related to geographical location, age or other social, health or cultural attributes.

The study's findings contribute to health knowledge and practices in four main ways: first, they provide fundamental knowledge and information about the influence of Islamic teachings on Muslim husbands' roles in women's health and cancer, including prevention, early detection, and treatment. This finding contributes to nursing theory related to religion. Secondly, the findings contribute information to Indonesia's programmes concerning the role husbands can play in women's cancer, including prevention, early detection, and treatment. The third contribution is to 
nursing research methodology by showcasing ways of using the qualitative descriptive exploratory approach with a comparative analysis and collecting data from Muslim husband groups by a Muslim woman researcher. Lastly, this study will be useful to other Muslim countries about married men's knowledge and actions towards women's cancer.

\subsection{The structure of the thesis}

This thesis consists of eight chapters. Chapter 1 has presented information about the study's background, including an overview of breast and cervical cancer, in Indonesia, the Indonesian government system, geographical settings, population, citizens' religions, and the country's income. This chapter also introduced my background and experience and why it guided my interest in this study's topic. Finally, it provides an overview and explanations as to why the aim of this study is Muslim husbands' roles in women's health and cancer, and the expected contribution of the study to nursing knowledge, research, health services, and communities.

Chapter 2 provides information about Islam and the theoretical frameworks. In the Islamic section, this chapter provides an overview of Islam and how this influences health and family life. The second section describes the other theories informing this study. These are the Basic Model of Religiosity and Health theory, the Health Belief Model, and the Help-Seeking Behaviour and Influencing Factors Framework. The significance of using an Islamic ontological framework is explained, and the influence of the theories provided.

Chapter 3 presents the literature review relevant to my study. This review includes a description of factors that influence men and women's health behaviour in general health and women's cancer. These factors include knowledge and information; perception, awareness and attitude; religion and beliefs; cultural norms and psychology; social, demography, and economy; and health services. In addition, literature about men's involvement in women's health and cancer is presented.

Chapter 4 presents the methodology of descriptive exploratory research that I used and details the research design. Design features include the settings, the three types of participants who were recruited to participate in the study, the pre-test and the multiple methods used, procedures, the comparative data analysis, ethical considerations, and how rigour was addressed. 
Chapter 5 presents the findings from the 11 focus groups of married Muslim men. The chapter describes the socio-demographic characteristics of the participants and presents five themes that emerged from the analysis. The themes which are 'Islamic teaching shapes husbands' roles in women's health and cancer', 'husbands' roles are primary in many aspects of women's health and cancer', 'experience and knowledge influences husbands' perceptions and awareness of cancer', 'barriers exist in husbands' roles in women's health and cancer', and 'husbands' power and powerlessness reflects health service context'. Each theme includes explanations and participants' quotes.

Chapter 6 reports on the findings from the 20 interviews conducted with married Muslim women. Following a description of the participants, the four themes that emerged from the analysis of the data from women's interviews are presented. The themes include 'Islamic teaching impacts on husbands' actions in women's health and cancer', 'husbands have extensive roles supporting family's health', 'family circumstances and social support influence Muslim husbands' roles in women's health and cancer', and 'husbands' limited health literacy influences their roles in women's health'. Each theme includes explanations and participants' quotes.

Chapter 7 presents the findings from the interviews of 10 health professionals regarding Muslim husbands' roles in women's health and cancer. The health professionals included physicians, nurses, and midwives, who took part in the interviews. The four themes that emerged are 'contextual factors influence husbands' behaviour in women's health and cancer', 'women's health conditions influence husbands' actions', 'family and health services impact on women's health decision' and 'level of health literacy affects men's actions in women's health and cancer'.

Chapter 8 presents the discussion of the findings. This chapter begins with the triangulation of themes from the three data sources; men, women, and health professionals. A discussion of the three category headings that emerged follows. The category headings are 'Islamic teachings influence husbands' roles in women's health and cancer', 'husbands have multiple and variable roles in women's health and cancer', and 'personal, family and health service factors influence husbands' roles and experiences in women's health'. The areas of the theoretical frameworks and literature related to the findings are then examined. This is followed by the implications of the findings to the health services. Finally, the conclusion of this study, including a reflection on the research processes, and implications and 
recommendations for the health services, nursing practice, the development of the health system, and for future research are described. The recommendations were developed in light of the characteristics of Muslim communities in Indonesia. 


\section{Chapter 2. Islam and Theoretical Frameworks}

\subsection{Introduction}

This chapter outlines the ontological and philosophical position of this research which used an Islamic ontological approach and was undertaken by an Islamic researcher. It describes the basic frameworks of the Islamic faith in relation to the question, research approach, data gathering, analysis and the interpretation of the findings. As this study takes an Islamic ontological position, this chapter also includes a description of my perspectives on my Muslim faith with some reflections on how this has impacted on the way this research has unfolded. The chapter begins with an overview of Islamic teachings related to Muslim husbands' roles in women's lives. This is followed by an introduction to the theoretical lenses that informed this study. The most significant of these is the Basic Model of Religiosity and Health (BMRH) theory. Other theories include the Health Belief Model (HBM) and the Help-Seeking Behaviour and Influencing Factors Framework (HSBIFF).

\subsection{Islam, Muslim Family, and Health}

Islam originates from an Arabic root word sa-la-ma which means peace, safety, security, or to submit (Maqsood, 2012; Stacey, 2008). Islam is a monotheist religion and part of the Abraham poetic religions. God is Allah, and believers believe that Allah is the One and is incomparable as written in the Surah Al Ikhlas verses 1-4: "Say, He is Allah who is one, Allah the eternal refuge, He neither begets nor is born, nor is there to Him any equivalent". Islamic believers are called Muslims. Muslims believe that the prophet Muhammad (peace be upon them) is Allah's last messenger. Allah said in the Surah Al Ahzab verse 40: "Muhammad is not the father of [any] one of your men, but [he is] the Messenger of Allah and last of the prophets. And ever is Allah, of all things, Knowing". Muslims believe there were other Allah messengers before Muhammad, around 25 prophets are written in the Holy Quran, these include Adam, Noah, Abraham, Moses, and Jesus. All messengers were human beings, and no one had sovereignty of Allah.

Many aspects of Islam guide Muslims' behaviour as individuals, and as community and family members. I am not a scholar of Islam, so I provide only a small part of Islamic teaching. This includes the husband-wife relationship, their 
roles as spouses and parents, women's position in the family, and family health. The Holy Quran (Allah's commandments) with thematic indexes and Hadith (the collected sayings of the Prophet Muhammad) are the two main material sources for this section. From these Islamic teachings, I accept that Muslim husbands' roles in family health, especially their wives' health, are authentic. They apply their roles as part of the husband-wife relationship and its influence on women's health outcomes. However, it is possible that in the application of their roles, men's behaviour differs. Several factors could underpin this and may include different interpretations of Islamic teaching or the influence of socio-cultural characteristics.

There are two basic frameworks of Islam; they comprise the six basic Islamic beliefs and the five pillars of Islam (Ibrahim, 1997). These include the individual's broad responsibilities to Allah as the creator and their responsibilities to other humans. The frameworks further explain the meaning of family and Muslims' roles and responsibilities as husbands, wives, and parents. Finally, I present the Islamic teachings regarding health which guide Muslims' behaviour in maintaining and solving health issues, including family's health.

\subsubsection{Overview of Islam}

Muslims follow the Islamic teachings as written in the Holy Quran (Al-Hilali \& Khan, 1998) and the Hadith (Khan, 2011). The content of the Holy Quran includes knowledge about God, Islamic law, Muslim practices, reward and punishment, and a history of Jesus, Moses, Noah, and Abraham, the prophets. The Holy Quran also provides guidelines for community relationships, and science information, for example, embryology, economy, astronomy, and health. The Hadith is attributed to the last messenger of Allah, the Prophet Muhammad, and indicates his words, actions, and behaviour.

The six basic Islamic beliefs are as follows: belief in Allah, belief in the angels, belief in the Holy Quran, belief in the prophets and messengers of Allah, belief in the Day of Judgment, and belief in Al-Qadar (divine predestination). Belief in Al-Qadar means Muslims believe that Allah knows everything and that He has documented and recorded everything. Allah has control of everything good and bad and is the only creator of everything. Further, Muslims believe that Allah is the centre of everything as written in the Surah Al An'am verse 162: “Say, Indeed, my 
prayer, my rites of sacrifice, my living and my dying are for Allah, Lord of the worlds".

Al-Qadar divides into two categories: unconditional and conditional predestination. The former category means Allah provisions or provides, and nothing can be done to change it and includes the date of birth and death. Muslims believe that everybody has their own date for death and it is unconditional, and it can come at any time, without people knowing. The latter is a predestination that can be changed by human effort (Ibrahim, 1997). Muslims also believe that sickness or health is from Allah but humans are able to overcome their illnesses by intervening or changing their behaviour. They may choose to visit medical or alternative services. The choice individuals can influence their personal beliefs or family or community considerations and goals. These different choices align with my understanding that it is acceptable and possible in Islam to have different ways to achieve goals in areas of conditional predestination. For example, people can move from being poor to being rich, and from sadness to happiness.

The second fundamental framework is the five pillars. These are Muslim's testimony (Shahada) that there is no true god but Allah, and Muhammad is the messenger of Allah. The pillars involve performing prayers five times a day facing Qiblah (Makkah city), Zakat (charity to the needy), fasting during Ramadhan (the ninth month in the Islamic months, based on the lunar cycle), and taking part in the Hajj (pilgrimage to Makkah) (Ibrahim, 1997). This fundamental framework is a Muslim starting point as an Islamic believer. Islam differs from other religions and includes the above as individual responsibilities. Also, people's roles as part of the community are outlined. These are being charitable, and taking care of others and family. These fundamentals describe the comprehensiveness of Islamic teaching for Muslims' live. Muslims should not only focus on themselves but also need to socialise and show empathy to others. Islamic teaching is not just dogma but is a way of life that guides Muslims' daily behaviour in all aspects of their lives. In this context, Muslims connect with others, including husband-wife relationships. For couples in a close relationship, it is possible that they influence each other in many aspects of life, including health behaviour. Following is a discussion of Muslim families and members' roles within the family. 


\subsubsection{Muslim families}

\section{The family and marriage in Islam}

A family in Islam is a fundamental unit in society. A marriage between a man and a woman is the only way to establish a family in Islam because sex outside of marriage is not allowed, and there is no concept of homosexuality or celibacy in Islam. A marriage is a halal way (permitted by Islamic law) for a man and a woman to have sex (Doi, 2015). The aims of marriage in the Holy Quran are that couples complement one another, and live in peace as is written in the Surah Ar Ruum verse 21:

And of His signs is that He created for you from yourselves mates that you may find tranquillity in them, and He placed between you affection and mercy. Indeed in that are signs for people who give thought.

In verse 187 in the Surah Al Baqarah, the close relationship between a man and a woman in a married relationship is written as follows: "They are clothing for you, and you are clothing for them".

In Islam, getting married is not mandatory. A recommendation for Muslims, is sunnah (an Islamic teaching practice based on the Prophet Muhammad's saying, and is part of the worshipping of Allah) (Usamah, 2013). An Islamic scholar, Sheikh Ahmad Kutty argues that a marriage could be mandatory under some conditions, including if a man or woman is afraid that if they are not married, they would Zina (have sex before marriage) (Kutty, 2004). A marriage is legal in Islamic law when it fulfils the requirements, including the marriage aqd (contract), mahr (a gift for the woman), witnesses, and announcing this happy news to the public (Triutomo, 2014). It is likely a marriage is the starting point of bonding between a man and woman in Islam, as they become close and take care of each other.

\section{Muslim husbands' and wives' responsibilities}

When a Muslim becomes a husband or a wife, they have responsibilities to the family. Many of the responsibilities of Muslim husbands and wives are written in the Holy Quran and Hadith. For example, a mother provides breastmilk for her baby, and the father provides food and clothes, as stated in the Surah Al Baqarah verse 233: 
Mothers may breastfeed their children for two complete years for whoever wishes to complete the nursing [period]. Upon the father is the mother's provision and their clothing according to what is acceptable. No person is charged with more than his capacity. No mother should be harmed through her child and no father through his child. And upon the [father's] heir is [a duty] like that [of the father].

Husbands must live with their wives correctly and courteously. In fact, Allah tells us that if a man dislikes something about his wife, he should bear with it as Allah may have placed a lot of good in it. This is written in the surah An Nisa verse 19. A Muslim wife's responsibilities are accepting her husband's money, being patient, accepting of his respect and obeying him.

Men are the protectors/guardians and maintainers of women, because Allah has given the one more than the other, and because they support them from their means. Therefore/so the righteous women are devoutly obedient (to the husband) and guard in (the husband's) absence what Allah would have them, guard. (An Nisa verse 34)

As a protector, Muslim husbands should remind their wives and daughters to cover their aurat (women's body parts that are not allowed to be seen by others) as cited in the surah At Tahrim verse 6:

O Prophet, tell your wives and your daughters and the women of the believers to bring down over themselves [part] of their outer garments. That is more suitable that they will be known and not be abused. And ever is Allah Forgiving and Merciful.

In addition, the surah An Nur verse 31 explains that the only people who are permitted to see women's bodies are the Muhrim.

And tell the believing women to reduce [some] of their vision and guard their private parts and not expose their adornment except that which [necessarily] appears thereof and to wrap [a portion of] their headcovers over their chests 
and not expose their adornment except to their husbands, their fathers, their husbands' fathers, their sons, their husbands' sons, their brothers, their brothers' sons, their sisters' sons, their women, that which their right hands possess, or those male attendants having no physical desire, or children who are not yet aware of the private aspects of women. And let them not stamp their feet to make known what they conceal of their adornment. And turn to Allah in repentance, all of you, $\mathrm{O}$ believers that you might succeed.

Muslims believe in life after death. Muslim husbands' responsibilities are broad, they not only protect and maintain women and families in the world but they are also responsible for the family in the akherat (of life after death).

O you who have believed, protect yourselves and your families from a Fire whose fuel is people and stones, over which are [appointed] angels, harsh and severe; they do not disobey Allah in what He commands them but do what they are commanded. (At Tahrim verse 6)

Further, besides the Holy Quran commands, the prophet Muhammad provided a model as to how Muslim husbands should behave toward their wives. This includes pampering, treating them kindly, respecting and supporting them, ensuring their privacy, and trusting them in all aspects of life (Hadad, 2007).

In Indonesia, when a Muslim couple marries, husbands read a Sighat Ta'liq (agreement between husband-wife) as part of the Government of the Republic of Indonesia's policy through the Ministry of Regulation Edict No.3, 1953. The content of this agreement includes the following points: when a husband leaves his wife for two years or more without any communication, fails to provide material support for three months, perpetrates domestic violence, or ignores his wife for six months she has recourse to report him to the Religious court, and the court will penalise him, and the woman has the right to divorce. This agreement in Indonesian law is aimed to protect the wife from the husband's violations.

From the descriptions of men and women's responsibilities in the family, it is clear that both men and women have different responsibilities. Men are the main 
protectors of the family, including his wife. Islam also provides extensive opportunities and equality for women. For example, a Hadith narrated by Abu Dawood, hadith 2578: Muhammad's wife Aisha rode horses and raced with him. Sometimes she won, and Muhammad said they are equal (Hussain, 2012). I believe a liberal perspective should be taken when interpreting Islamic teaching. The message from this teaching is that husbands and wives should collaborate in developing the family with equal roles. The husband-wife roles in the Holy Quran are provided as advice, and it is better for Muslims to follow these; however, in particular circumstances, a husband-wife can swop their roles. This is not a sin, but a part of maintaining the family's welfare.

I am aware many people think that in Islam, men are more powerful and dominant in a family. Maybe people think that Islam is identical with a Saudi Arabian culture where the religion spread for the first time. Moreover, history reveals that before the period of the Prophet Muhammad, women of all ages were intimidated and undervalued in Saudi Arabia. This is demonstrated in Arabian families who felt shamed when they had a daughter, and so they buried her alive (AlMubarakfuri, 2011).

One aspect of Islamic teaching, particularly before Allah, is to save women and give them an equal position with men. Many Hadiths of the Prophet Muhammad explain how he positioned women as equals. The Prophet collaborated with his wife in developing businesses (Al-Mubarakfuri, 2011). It is likely that Islam has two standards of treating women, protecting as well as empowering them. This may be because all verses of the Holy Quran and Hadith have asbabun nuzul (histories or reasons why these verses and Hadith are revealed). However, many factors could influence Muslim men and women's behaviour and may impact believers' application of Islamic teaching.

\section{Muslim parents' responsibilities}

Parents have an honoured place in Islam. They have the right to be respected by their children and should be responsible for their children. Parents' responsibilities to children are physical, moral, and spiritual. Muslims' responsibilities as parents are written in the Holy Quran and Hadith. The father's responsibilities are providing clothes, food, facilities, formal and moral education, religious knowledge, guidance when choosing a partner, and marrying his daughters 
to a Muslim man. Many surahs in the Holy Quran explain parents' responsibilities. For instance, Surah Luqman verse 13-19 consists of examples of how a father should teach his son morality regarding respecting parents and others, protecting the earth from destruction, and teaching Islamic practices, including praying five times a day.

From Hadith scholars, there are several Hadith which explain how parents, especially the father, should be involved in taking care of children. An example of this is a Hadith reported by Abi Dawud (Allah be pleased with them both) that stated that the Messenger of Allah (Allah bless him and give him peace) said: "Whoever has a child, he should give him/her a good name and teach him/her how to read and write. And when he/she matures, he should marry him/her off. When he/she matures and the father does not marry him/her off, then if the boy/girl commits a sin, the sin will be on the father (Khan, 2011). Fathers and daughters are likely to be very close according to a Hadith narrated by Al-Bukhari 3437 "Fatima (Prophet Muhammad's daughter) is part of me. Whatever pleases her, pleases me and whatever angers her, angers me" (Khan, 2011). Muslim parents' responsibility is to take care of the children. Fathers have the greater responsibility, to provide for his children from birth until marriage. After marriage, a father's responsibilities to his daughter passes to her husband. A Muslim woman is likely to be protected and cared for continuously by men in her life, whether by her father or her husband. This situation may be advantageous because their material and safety needs are provided. On the other hand, it may impact women's independence, autonomy, and empowerment, for example, a wife relies on her husband for everything. There is the possibility that husbands may treat women differently to their fathers, as husbands may have different interpretations of their responsibilities.

A Muslim mother's responsibilities are as broad as the fathers. Their primary roles are giving birth, breastfeeding, taking care of the baby, and playing the role of the first teacher at home. Muslim women's positions are precious, as the Prophet Muhammad said (narrated by an-Nasa'i 3104) "Paradise lies under your mother's feet" (Khan, 2011). A Hadith narrated by Al-Bukhari claimed "a companion asked the Prophet, "Who deserves my good treatment most?" "Your mother", said the Prophet. "Who next?" "Your mother". "Who next?" "Your mother". "Who after that?" "Your father". These two Hadith describe the noble position of women in Islam (Khan, 2011). 
A mother and father are likely to share their responsibilities in the family. They collaborate as partners to manage their family, especially taking care of and educating the children. The Holy Quran and Hadith write about equality between men and women in many aspects, including spiritually, socially, economically, and politically. For example, Allah will accept Muslims' prayers whether they are men or women, as written in the Holy Quran Surah Ali Imran verse 195. In addition, when an Arabian tribe's culture was to reject female babies and bury them alive, Islam, via the Holy Quran Surah 81 verses 8-9, and surah 16 verses 58-59, criticised this and considered it a criminal action.

As men and women in a Muslim family share and collaborate, there is the possibility that they influence one another. There was a need to involve married women's information in this study as they have an equal position in a family, and balanced information relating to husbands' roles in a family, especially related to women's health and cancers, needed to be obtained.

\subsubsection{Health from an Islamic perspective}

This subsection elucidates health and diseases related to Islamic beliefs. It also provides Islamic guidelines for Muslims' actions in maintaining health and treatment when they are sick and summarises Islam as a comprehensive religion that covers all aspects of human life, including health. Islamic guidelines for health may be useful for Muslim husbands when they support women's health, and their support may vary depending on individual or family choice. Other factors like therapists and health facilities may also be influenced.

Humans live in a dynamic world. People face ups and downs in their lives. For example, happiness can be followed by sadness, and health by illness. Muslims believe that Allah will cure the diseases as written in the Surah As-Shu'ara verse 80: "And when I am ill, it is He who cures me", and a Hadith from Prophet Muhammad narrated by Al-Bukhari 5678 "There is no disease that Allah has created, except that He also created its remedy" (Khan, 2011). Islam has a comprehensive approach to health and views it as a balanced condition between the physical and mental. Islam also provides healings to maintain and treat all aspects of health (Hussain, 2012; Stacey, 2008).

Maintaining physical health as part of health promotion is mentioned in the Holy Quran and Hadith. For example, personal hygiene according to Surah Al 
Maidah verse 5: including cleaning teeth and washing hands, face and feet five times before prayers. In addition, healthy food and eating management are also written in the Holy Quran, such as not overeating and drinking (Al A'raf verse 31). Eating is part of a person's needs (Al Baqarah verse 233), eat the good things (Al Baqarah verse 172; Taha verse 81); and fast (Al Baqarah verse 183) (Assad, Niazi, \& Assad, 2013). In Islamic law, all foods are halal (lawful) except pork, intoxicants (alcohol and drugs), and animals improperly slaughtered. Further, the Prophet Muhammad provided examples related to the body's fitness. In a Hadith narrated from Hazrat Ibn Umar, Prophet Muhammad said to teach your children swimming, archery, and horse riding. These verses and a Hadith related to physical health are examples of how Islam is concerned with maintaining men's and women's physical health.

Islamic doctrine states that Muslims who are faced with health issues should seek treatment. The Hadith describes the importance of seeking treatment, as narrated by Usamah ibn Shuraik:

Hadith Tirmidhi: O Allah's Messenger! Should we seek medical treatment for our illnesses?' He replied: 'Yes, you should seek medical treatment, because Allah, the Exalted, has let no disease exist without providing for its cure, except for one ailment, namely, old age. (Pathan, 2003)

Allah's command in Surah Ar-Ra'd verse 11 states: "Indeed, Allah will not change the condition of a people until they change what is in themselves". The two commandments describe that Muslim people need to be proactive to solve health issues by maintaining health and looking for treatments when they are sick, and believe Allah will help them.

General health in Islam is defined as an integrated system consisting of four elements, including mind (Aql), body (Qalb), self (Nafs), and soul/spirit (Ruh) (Laher, 2014). Mental health (mind, self, and spirit) problems appear as anxiety, stress, depression, and other negative mental conditions. The Holy Quran provides an approach for mental illness treatment (Abdel-Khalek, 2011). It mentioned some surah and verses that are useful to help or improve mental health. For example, advising people to stay positive and hopeful when they face problems that make them feel depressed. These are written in the Surah Yusuf verse 87: "And never give up hope of Allah's soothing Mercy: truly, no one despairs of Allah's soothing Mercy, 
except those who have no faith". This holy book also provides reminders that suicide is prohibited as inscribed in the Surah An-Nisa verse 29: " [do not] kill (or destroy) yourselves, for surely God has been Most Merciful to you”. Muslims should be optimistic during hard times as they will pass, as written in the Surah Ash-Sharh verse 5: "So, verily, with every difficulty, there is a relief".

Muslims believe all problems in the world, including health, need to be surrendered to Allah because they are a test from Allah that will increase their Taqwa (piety to Allah). If we can deal with and return all problems to Allah then $\mathrm{He}$ will help us.

And we will surely test you with some fear and hunger and a loss of wealth and lives and fruits, but give good tidings to the patient, who, when disaster strikes them, says, "Indeed we belong to Allah, and indeed to Him, we will return.” (Al Baqarah verses 155-156)

The Holy Quran is complemented by a Hadith from the Prophet Muhammad who said: "No person suffers any anxiety or grief, and says this supplication but Allah will take away his sorrow and grief, and give him in their stead joy". Allah provides rewards for people who are ikhlas (accepting) of their destiny. These Surah and Hadith explain that people who have risks in their lives will face problems physically or mentally. Anticipating these problems, Allah provides information and warnings about health in the Holy Quran and Hadith. Muslims who understand and learn the two Muslim main guidelines would be healthier than others.

Islam provides healings that were practiced by the Prophet Muhammad. Some healings use the Holy Quran as a medium for treatment. For example, reciting Surah Al Fatihah and drinking water to reduce fever, doing Ruqya (Islamic prayer formulas) to comfort their minds, and other medical actions to treat physical health issues. Methods of healing are written in many books. For example, Healing With The Medicine of The Prophet recommends some therapies for physical health problems. The therapies include curing fever, headaches, tonsillitis, diarrhoea, dropsy, constipation, skin rashes, heart problems, treating epilepsy and wounds. In addition, this book describes how the Prophet Muhammad did cupping, cauterisation, and puncturing of veins. 
Health is one aspect Islam is concerned with, and it has a comprehensive approach to humans' health systems. Being healthy is a conditional predestination that needs human efforts, and Allah recommends that Muslims should search for treatments when they have health issues. These teachings are guidelines for Muslims' health, even though in their actual application, it is acceptable if they differ in health actions as many factors could influence humans' health behaviour.

\subsubsection{My position and assumptions as an Islamic woman researcher}

I am Muslim, and I believe that Islamic teaching is true, and its contents of orders, prohibitions, and warnings aim for rahmatan lil 'alaimin [blessing for the whole world and its content]. I grew up in a conservative Javanese Muslim family, in which my parents, especially my father, applied Javanese cultural values that were influenced by the Buddhist religion and Islamic teaching. My family history shaped my perceptions of the roles and behaviour of fathers, mothers, and children in families; the father is fully responsible for his family's needs. He is the protector and the main decision-maker in the family and the mother stays at home and takes care of family members, and children should follow whatever parents' advice. My perceptions of family members' roles changed when I studied at university, learned more about Islam, and I had my own family. As an Islamic couple, my husband and I collaborate and share family responsibilities. Even though we are both employed; my husband is the main income earner, he provides for all the family needs. Regarding our children's education, we approach and educate our children based on their ages as per the Prophet Muhammad guidelines. I play more roles in my family's health than my husband; perhaps it is influenced by my background as a nurse. He respects my decisions related to health.

From my life history, I learned that people might have different interpretations of Islamic teaching and these appear in their behaviour. I accept that men in my family are my protectors and have a role protecting my safety. As a Muslim woman researcher, I believe that exploring Muslim husbands' roles in women's health and cancer is acceptable and does not go against Islam. I had clear aims in my study, but I was aware that other Muslims might not agree with me, especially related to my data collection processes as I wanted to explore men's perspectives. The study design meant that Muslim men who I had no family relationship with, would have to interact with me. I was aware that some Muslim men might not interact with a 
woman who was not a family or relative. To address this issue, I developed strategies to approach Muslim men's communities. The details of these are in the methodology chapter.

According to the two basic Islamic frameworks, men and women have large roles in the family. I believed that Muslim husbands' roles in women's health would exist as described in the Holy Quran and Hadith but that husbands' applications of their roles in women's health may vary because they are allowed to act in various ways to obtain a better condition. Husbands may apply for their roles as the religious teaching states, apply them differently, or modify them. Their behaviour may be influenced by family needs and social backgrounds.

The Islam ontological approach was used in conjunction with other theories. Next, I describe the spirituality and religiosity theoretical frameworks that also informed this research.

\subsection{Theoretical frameworks}

This section presents the main theories that informed this study. Theoretical frameworks are important because they guide what should be examined to address the concepts and answer the research question (Aydemir, Özkeskin, \& Akkurt, 2015). The theories guided the form and content of the data gathered to enable a description of Muslim husbands' roles related to their wives health (Ajzen, 1991).

To obtain a picture of Muslim husbands' roles in women's health, no single theory was applicable to this study as Maxwell (2013) comments; no theory can explain everything. A theory that is relevant to one area will not be applicable to other areas. The main theory that informed this study was the Basic Model of Religiosity and Health (BMRH) theory. This theory argues that religiosity and spirituality influence health outcomes. The BMRH theory has had limited use in research and because I did not know whether Islamic beliefs influenced husbands' actions, I also used the Health Belief Model (HBM) and the Help-Seeking Behaviour and Influencing Factors Framework (HSBHIFF) to guide the study. The linkage between the Islamic ontological approach and the theoretical frameworks in this study is illustrated in Figure 4. 


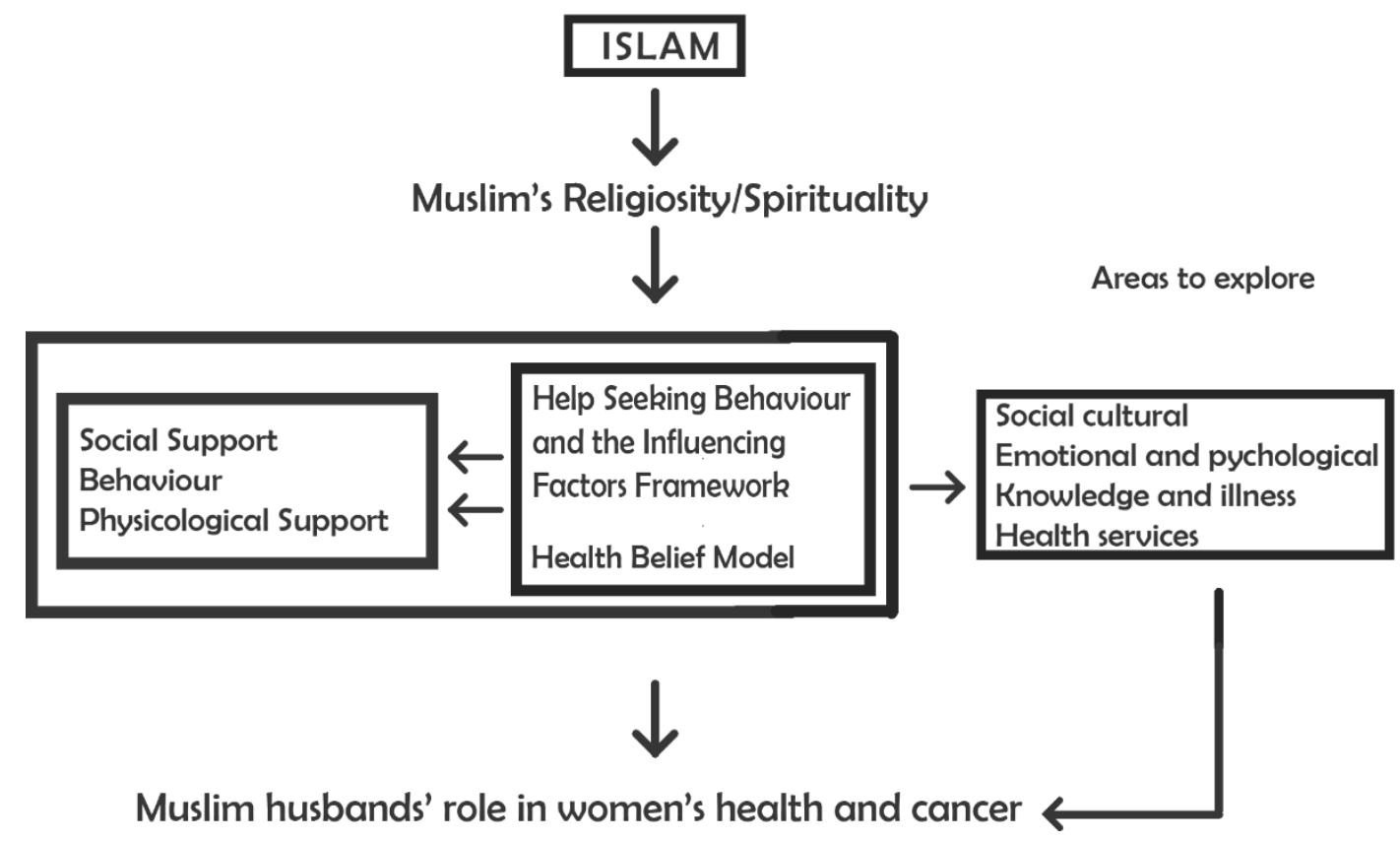

Figure 4. The framework for exploring Muslim husbands' roles in women's health and cancer

The main aim of this study was to uncover Muslim husbands' roles in women's health, and cancers, including prevention, early detection, and treatment. According to the BMRH theory, there is a relationship between religiosity/spirituality and health outcomes. Religiosity/spirituality in this study focused on Muslims' beliefs which is Islam. Muslim husbands' belief of Islam may affect their roles in women's health and cancer. The three theories: BMRH, HBM, and HSBIFF were integrated to address the study objectives related to three areas. The first area emphasises socio-cultural dimensions which involved assessing sociodemographic characteristics and other aspects such as family (in particular husbands), beliefs, and community members. This dimension also covered the decision-making and problem-solving processes in women's health, the roles of husbands and other family members in these processes, the effect of health problems on family functions, and expectations of the health services. The second area focuses on the men's emotional and psychological response related to actual or potential cancer diagnosis, motivating factors that encourage women's positive health behaviour, and their understandings of barriers and benefits regarding prevention and treatment of diseases, including women's cancers. The third area captures the men's 
understanding of women's cancer, risk factors, prevention, symptoms, treatment methods, therapies and alternative therapies, and their perceptions of the cancer severity and roles of treatments.

\subsubsection{The Basic Model of Religiosity and Health}

The BMRH was developed by Kevin Master (2008), a Professor of Psychology at the University of Colorado, Denver. This model was developed based on scientific evidence related to the relationship between religion and health. Masters (2008) framework states that religiosity/spirituality (R/S) has direct and indirect effects on health outcomes and is facilitated through social support, behaviour, and psychological factors. This model was developed based on assumptions of the mechanism of how religion and health are pertinent to people physiologically and biologically. The mechanism is that religious teaching practices are related to health and include avoiding alcohol, and the early detection and treatment of disease. In addition, religious teaching affects people's psychology, religious rituals and practices, emotional control, psychological and physical functions, and hereditary factors. Masters illustrated his framework figuratively (Figure 5).

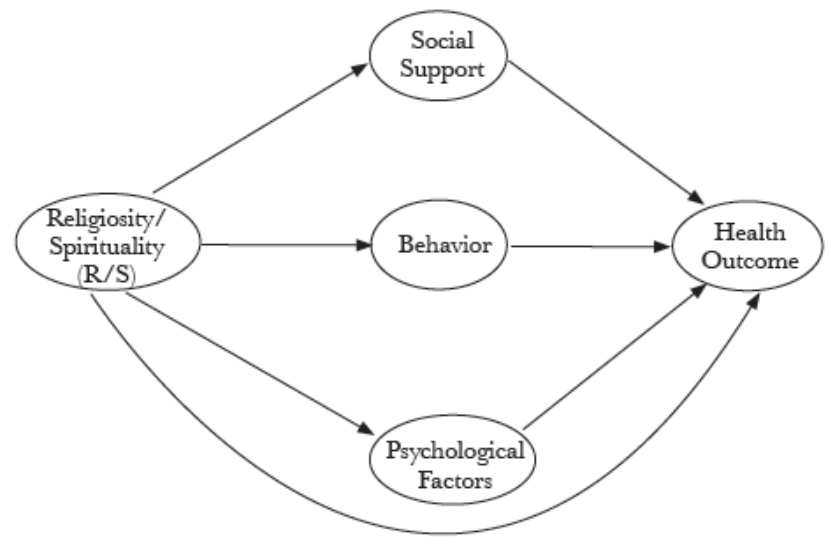

Figure 5. Basic Model of Religiosity and Health

Source: Masters, K. S. (2008). "Mechanisms in the relation between religion and health with emphasis on cardiovascular reactivity to stress.", Research in the Social Scientific Study of Religion, 19, p. 05. Reproduced with permission.

Masters argues his model has three main pathways. The first pathway is the $\mathrm{R} / \mathrm{S}$ - Behaviour-Health Outcomes. This pathway proposes that people behave in particular ways, including restricting their diets and other activities which impact 
their health outcomes. People's behaviour varies and differs as do the variety of health outcomes and these influence their quality of life and mortality. The second pathway is the R/S - Social Support-Health Outcomes which proposes that R/S shape social support which impacts on health outcomes. Social support factors are the diagnosis of serious diseases, genetics, sex, age, and ethnicity. The third is the $\mathrm{R} / \mathrm{S}$ influence psychological factor which impacts health outcomes (for example, R/S factors may increase hope and optimism as well as anxiety). Each component pathway is multidimensional and may result in a positive or negative influence on health outcomes.

Even though limited studies have used the BMRH as a framework, those that applied it have found a relationship between R/S and health behaviour. For example, Hooker, Masters, and Carey (2014) assessed R/S and health behaviour in college students from a multidimensional perspective. Park et al. (2017) examined R/S in behavioural medicine, and Jordan, Masters, Hooker, Ruiz, and Smith (2014) looked at the implication of R/S for health and well-being. Hooker et al.'s (2014) study of 266 undergraduate students with an average age of 18.6 years who were: Catholic (68\%), Protestant (19\%), Jewish (16\%), Buddhist (3\%), other (3\%), Muslim (1\%), Hindu (1\%), or No religion (11\%) found that R/S variables were strongly related to health behaviour. These variables included experiential, comforting, faith, personal spirituality, support from a religious community, private and negative religious practices interaction, and organisational religiousness. The health behaviour variables included safety-related activities (using seat belts and avoiding alcohol when driving), adequate sleep, substance use (alcohol and smoking behaviour), and physical activities. Even though only $1 \%(n=26)$ of participants were Muslim, the study confirmed that this model is applicable to Muslim communities, including my study.

I used the BMRH as the main theory because there were links between the three pathways of this theory and my study. The religiosity in my study is related to Islamic teaching, a religion followed by the majority of Indonesians. According to the BMRH theory, Islamic beliefs could impact health behaviour via social support, behaviour, and psychological factors. Muslim from different social backgrounds such as rural-urban, and older-younger, may have different health behaviours. Social support also means income levels, education, beliefs, and people and communities, including family members, community and religion leaders, and friends. 
The second is the behaviour factor. This is influenced by religious teachings which guide Muslim husbands' involvement in women's health. Their behaviour may vary; husbands could follow their religious teaching, contradict it or modify it. This variety of behaviour influence women's health behaviour, especially related to cancer prevention, screening, and treatment. Lastly, the psychological and physical factors provide guidelines and recommendations for Muslims when they face health issues. Some factors, such as serious diseases, could impact psychologically or physically on women and affect their health outcomes. My study was expected to provide evidence of how Islamic beliefs influence and impact on health behaviour. I applied the HBM to obtain more data about participants' perceptions of Muslim husbands' roles and women's cancer. To obtain broad information about social support areas and Muslim husbands' behaviour, I also used the HSBIFF theory.

\subsubsection{Health Belief Model}

I considered this model was useful as it supports the main theory that people's perceptions of health, cancer prevention, screening, and treatments impacts behaviour. The Health Belief Model (Hayden, 2009) was developed by the USA Public Health Service in the 1950s as a method to elucidate medical screening programmes, especially for tuberculosis. The main concept of this model is that health behaviour is governed by personal beliefs or perceptions about health problems and approaches to reduce the occurrence of illness. The HBM consists of seven concepts including four main concepts and three additional concepts. The four main concepts: perceived seriousness, perceived susceptibility, perceived benefits, and perceived barriers, and three additional concepts include cues to action, motivating factors, and self-efficacy. The following paragraphs summarise the concept of HBM.

The above seven concepts include the perceived seriousness of a disease and explains a person's perceptions about the severity of diseases. Their perceptions are influenced by their level of medical knowledge, and beliefs about the disease's effect on his/her life. The second is the perceived susceptibility and reflects the individuals' belief about how their behaviour can be a risk to their health. The more people understand how susceptible they are to a particular health event the more effort they will make to reduce their risk. The combination of perceived seriousness and 
perceived susceptibility results in a perceived threat. People's perception of the real risk of a serious disease effects behaviour changes. Third is the perceived benefit, people will adopt a new health behaviour if they believe it will help them.

The fourth concept is the perceived barriers. These state that people have difficulty changing or adopting new behaviour because of the burdens they perceive change will place on them. This concept is an individual's views of her/his barriers to adopting new health behaviour. The fifth is the modifying variables which are those things in people's lives that can be modified, enabling changes in behaviour from unhealthy to healthy behaviour. A key aspect of this is motivation. People's behaviour is modified by culture, education levels, experiences, skills, and motivation. The sixth concept is the cues of action which describes how an individual's behaviour can be influenced or changed by social or interpersonal factors. The factors include people, the media, an ill family member, advice from others, a reminder letter from health services, or a warning sentence on a product. Lastly, the self-efficacy concept explains that someone can adopt new behaviour if they have confidence.

Many studies have used this model as a framework. They include studies of health promotion and cervical cancer screening. For example, a cross-sectional survey of 202 Korean immigrant women in the USA who had participated in screening found that the HBM was useful for explaining women's health behaviour regarding breast cancer screening (Lee, Stange, \& Ahluwalia, 2014). Based on Lee et al.'s (2014) study, I believed the HBM theory would be applicable to my study because their study had some similarities to mine, including focusing on women's cancer, and assessing behaviour.

The seven concepts of HBM guided me in conceptualising the interviews and focus group guidelines. The area of questions identified from the HBM framework including questions about participants' view of disease severity, personal health behaviour, treatments, the motivation for health behaviour, and their view of social influences on their behaviour. These physical or psychological perceptions may influence men and women's health behaviour. The following subsection presents the third theory the HSBIFF utilised in this research. 


\subsubsection{Help-Seeking Behaviour and Influencing Factors Framework}

This framework was developed based on the integration of an empirical study and theoretical review. The theoretical literature that informed this framework was the judgement to delay model (Facione, 2002), and the common sense model of selfregulation of health and illness (Leventhal, 2003). The framework posits that knowledge and beliefs, habits, health services' systems, effective responses, and relationship constraints influence women's health-seeking behaviours. In addition, other factors that influence health-seeking are abnormal symptoms and psychological distress, including fear, worry, and anxiety. From theories and empirical studies, O’Mahony proposed the HSBIFF.

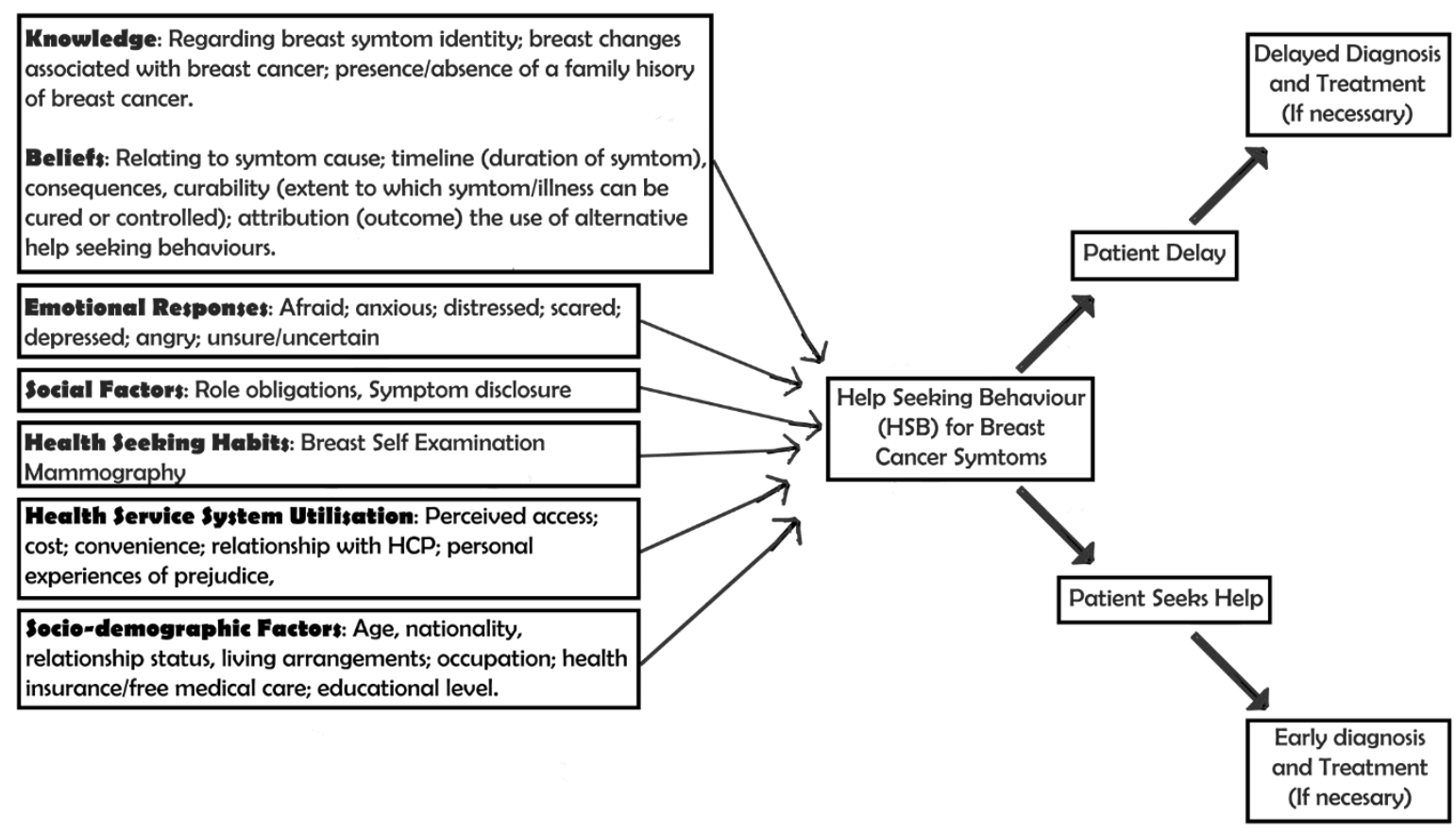

Figure 6. Help-Seeking Behaviour and Influencing Factor Framework

Source: O'Mahony, M. et al. (2013). Shedding light on women's help-seeking behaviour for selfdiscovered breast symptoms. Eur J Oncol Nurs, 17(5), 632-639. doi:10.1016/j.ejon.2013.03.012. Reproduced with permission.

This framework consists of six concepts. The first is knowledge and beliefs about the symptoms of the disease, the duration of illness, side-effects, the treatment method, the control method and alternative therapies or prayer, explain why people seek or do not seek help. Second, the psychological factors of fear, anxiety, worry, uncertainty, and depression motivate people to seek help. The third is the social factor which describes that an individual's role as a husband or wife influences their 
help-seeking behaviour. Fourth, people adopt health-seeking habits, including preventative actions and health service engagement such as visiting a doctor for treatments. The fifth concept explains how the utilisation of health services is related to accessibility, health insurance, economics, and a perception of health services. Lastly, sociodemographic factors such as age, nationality, and relationship status influence behaviour.

Research, to date, has used each of these concepts and the framework in isolation. With regard to the HSBIFF framework, O'Mahony (2013) conducted a correlational and a descriptive qualitative survey of 499 women who attended the breast clinics of two urban hospitals in Ireland. This study aimed to describe women's help-seeking behaviour and its association with influencing factors of breast self-examination. The study found the factors influencing women to delay health-seeking behaviour were knowledge, ignoring symptoms, beliefs, and fear. Moreover, the HSBIFF provided a useful guide to identify the barriers and contributing factors of health-seeking behaviour (O'Mahony, Hegarty, \& McCarthy, 2011; O'Mahony, McCarthy, Corcoran, \& Hegarty, 2013).

The six concepts of the HSBIFF framework complement the three factors of the main framework, the BMRH theory. I used this framework to support the BMRH theory because the HSBIFF provides detailed components for assessing the social factors of knowledge, socio-demographic, beliefs and others that influence behaviour such us health services' facilities and accessibilities. These concepts were also useful as a fundamental guide in gathering data related to husbands' and wives' behaviour. I further used this theory to frame the research instrument, in particular, the social demographic survey and the focus group and interview questions: the utilisation of women's health services and their expectations of these services.

\section{4 Conclusion}

Two basic Islamic frameworks present the fundamental beliefs for Muslims' lives as they are relevant and closely correlated to this study. The first is Muslims' belief in conditional predestination which means that they need to strive to obtain the best outcomes in all aspects of their lives, although these may differ. The second is their roles as members of the broader society and within their families, both of which are detailed in the Holy Quran and Hadith. Ontologically, Muslim husbands' roles in 
women's health are based on Islamic teaching and might vary as they are influenced by many factors. The fundamental Islamic frameworks show that Islamic teachings influenced every step of this study. These include developing the questions, deciding the study approach, collecting data, analysing, and discussing findings.

Three theoretical lenses framed this study. The main theory was the Basic Model of Religiosity and Health which was useful for uncovering the fundamental knowledge about the relationship between religiosity and health behaviour. The Health Belief Model and the Help-Seeking Behaviour and Influencing Factors Framework complemented and supported the BMRH. They were used to guide the exploration of participants' perspectives of husbands' roles in women's health, and cancer what may influence their roles. 


\section{Chapter 3. Literature Review}

\subsection{Introduction}

This literature review aimed to identify key aspects underpinning the research questions, and provide the context for this study's design, methodology, analysis and interpretation. The literature sources are divided into four country categories including Western, non-Western countries, Muslim-dominated countries, and Indonesia. The literature review is organised under two headings. These are factors that impact on women's health behaviour generally and on cancer in particular, and secondly husbands' behaviour related to women's health and cancer. The factors included knowledge and information, perceptions, attitudes, religion/spirituality, beliefs, awareness, health services, society and culture, economics, demography, experience, and psychology. The literature also highlights husbands' roles in women's health and cancer, including supporting women's health and making health decisions. The chapter is divided into four headings. The first presents the search strategy to find the relevant references based on specific keywords. Next, the findings of the review are presented under two headings. Finally, the limitations of the literature which includes the areas examined in this research.

\subsection{Search strategy}

The search used the PubMed, CINHAL plus, Google Scholar, and Portal Garuda computerised databases. Keywords in English and Bahasa Indonesia identified relevant studies published in international and Indonesian journals. The search was limited to humans, the English, and Indonesian languages, and studies published from 2006 to 2016. Keywords included men/husband/spouse/partner, women, Muslim, roles/actions/behaviour, health promotion, prevention, treatment, breast cancer, and cervical cancer. Booleans such as AND and OR were used as necessary.

Articles from various international journals provided useful insights related to husbands' behaviour and actions in women's health and cancer from Western, nonWestern countries, other Muslim countries, and Indonesia. Even though Indonesian articles were limited, these articles were important in illustrating women's health 
situations in Indonesia, including women's health issues and services. The Indonesian literature also provided information related to research methodology often applied by Indonesian researchers.

The literature from four country categories identified factors that influence men and women's health behaviour, including cancer screening. Twenty four studies from Western countries including the USA, England, Canada, and Ireland investigated influencing factors in health behaviour from different ethnic groups, minority groups, and immigrants. The three most influencing factors in health behaviour were health services, social factors including family and ethnic groups, and knowledge and belief (Ackerson \& Gretebeck, 2007; Allen et al., 2014; Benjamins, Ellison, Krause, \& Marcum, 2011; Bowen et al., 2013; Carreno, Vyhmeister, Grau, \& Ivanovic, 2006; Casciotti \& Klassen, 2011; Dempsey \& Davis, 2006; Dillard, Couper, \& Zikmund-Fisher, 2010; Friedman, Hemler, Rossetti, Clemow, \& Ferrante, 2012; Gonzales, Harding, Lambert, Fu, \& Henderson, 2013; Granek \& Fergus, 2012; Keating, O'Malley, Murabito, Smith, \& Christakis, 2011; Lor, Khang, Xiong, Moua, \& Lauver, 2013; Ma et al., 2012; Marlow, McGregor, Nazroo, \& Wardle, 2013; McAlearney et al., 2012; Ndukwe, Williams, \& Sheppard, 2013; O'Mahony \& Hegarty, 2009; O'Mahony, McCarthy, Corcoran, \& Hegarty, 2013; Potrata, 2011; Reid-Arndt \& Cox, 2010; Tan, Moldovan-Johnson, Gray, Hornik, \& Armstrong, 2013; Torres, Erwin, Trevino, \& Jandorf, 2013; Underhill, Lally, Kiviniemi, Murekeyisoni, \& Dickerson, 2012; Waller et al., 2009; L. Watts et al., 2009).

The 14 studies from non-Western countries, including South Africa, Kenya, Israel, Taiwan, India, Mexico, Barbados, and Estonia, found that knowledge, health services, social factors, and awareness were the most common factors influencing health behaviour (Augusto, Rosa, Cavalcanti, \& Oliveira, 2013; Birhanu et al., 2012; Bowen et al., 2013; Chang et al., 2013; Christian \& Guell, 2015; Kivistik, Lang, Baili, Anttila, \& Veerus, 2011; H. Y. Lee, Stange, \& Ahluwalia, 2014; Lu, Lin, \& Lee, 2010; Maree \& Wright, 2010; Park, Song, Hur, \& Kim, 2009; Satitvipawee, Promthet, Pitiphat, Kalampakorn, \& Parkin, 2009; Tiwari \& Kishore, 2011; Villafuerte, Gomez, Betancourt, \& Cervantes, 2007; Winkler, Bingham, Coffey, \& Handwerker, 2008). The 15 Muslim-dominated countries' studies conducted in Malaysia, Qatar, Iran, Pakistan, Arab Saudi, Kuwait, and Turkey found that knowledge, beliefs, and social factors were the three most influential factors in 
health behaviour (M. Al-Amoudi \& H. S. Abduljabbar, 2012; Al-Naggar, Bobryshev, Abdulghani, Rammohan, \& Al-Jashamy, 2012; Babu et al., 2011; Baheiraei, Mirghafourvand, Charandabi, \& Mohammadi, 2013; Banning, Hafeez, Faisal, Hassan, \& Zafar, 2009; Donnelly et al., 2013; Duran, 2011; El-Hammasi, Samir, Kettaneh, Al-Fadli, \& Thalib, 2009; Farooqui et al., 2013; Harandy et al., 2010; Kumar, Shaikh, Khalid, \& Masood, 2010; Norsa'adah, Rahmah, Rampal, \& Knight, 2012; Rosmawati, 2010; Taha, Al-Qutob, Nystrom, Wahlstrom, \& Berggren, 2012; Yusoff, Taib, \& Ahmad, 2011). From the 22 Indonesian studies, the factors influencing health behaviour included knowledge (Artiningsih, 2011; Dewi \& Arma, 2013; Maharsie, 2012; Puspitasari, Indrawati, \& Pujiati., 2012; Saraswati, 2009; Sulistiowati \& Sirait., 2014; Yanty \& Vidi., 2013), women's attitudes and motivation (Anugraheni, 2010; Desanti, Sunarsih, \& Supriyanti., 2010; Ningrum, 2012), and social-cultural and health services (Amalia, 2015; Aqni, 2013; Hasbiah, 2004; Kim et al., 2013; Ompusungu, 2012; Sarihati, 2013; Tresnawati, 2012; S. Wahyuni, 2011; Yuliwati, 2012). Another factor was physiological (Fauziah, 2016; Misgiyanto \& Susilawati., 2014; Sudaryanto, Mahmudah, \& Sukraeny, 2016). The Indonesian literature mostly assessed women's knowledge, and attitudes to health behaviour. Only a few studies researched the influence of beliefs, religion, cultural norms, economic, and socio-demographic factors on health behaviour.

Studies that gathered information about husbands' involvement in women's health and cancer were limited. Western studies found that men were involved in women's general health (Kim, Chopik, \& Smith, 2014) and cancer screening (Trevino, Jandorf, Bursac, \& Erwin, 2012). In addition, three studies from nonWestern countries (Israel, Mexico, South Africa) identified husbands' roles in women's health, particularly with regard to breast and cervical cancer (HassonOhayon, Goldzweig, Dorfman, \& Uziely, 2014; Maree, Mosalo, \& Wright, 2013; Thiel de Bocanegra, Trinh-Shevrin, Herrera, \& Gany, 2009). Only three studies about men's behaviour in women's health were found in Muslim-dominated countries (Egypt, Jordan) (Hamdan-Mansour, Malkawi, Sato, Hamaideh, \& Hanouneh, 2016; Ohashi et al., 2014; Taha, Al-Qutob, Nystrom, Wahlstrom, \& Berggren, 2013).

In Indonesia, several studies have been conducted into men's participation in women's health, including husbands' support during breastfeeding (Pratami, 2016), family planning (Kusmindari, Zinaida, Pasmawati, \& Saputra., 2016; Setiadi, 2015), 
and cancer screening (Aggraeni, 2016; Arkiang, 2016; Kim et al., 2012; Marlina, 2015; Musyriqoh, 2013). None of these studies included Muslim husbands in the sample criteria, three used a qualitative approach, and only two studies were published in English, the rest were in the Bahasa Indonesia language.

The literature search presented important understandings about various factors that influence women's health behaviour generally and towards cancer, particularly the husband factor and their involvement in women's health. This search also provided an awareness of the limited and superficial literature exploring men's behaviour in women's health, especially in Indonesia. The review of the literature supported the design and methodology for this study.

\subsection{Factors that influence women's health behaviour}

The literature identified 12 influencing factors in women's health behaviour. In presenting these factors, I have categorised the factors into six sub-headings based on factors that have a similar meaning. The six sub-headings include knowledge and information; perception, awareness, and attitude; religion and beliefs; cultural norms and psychology; social-demographic and economics; and health services.

\subsubsection{Knowledge and information}

Limited health literacy in Indonesia, and in Muslim-dominated and nonWestern countries was a dominant factor that influenced women's health behaviour generally including cancer. Christian and Guell (2015) conducted interviews with 14 female patients between the ages of 20 and 60 years in the Caribbean who had a low uptake of screening. The thematic content analysis found four themes. One was women who had little knowledge of the aim of Pap tests. However, studies from Muslim-dominated countries including Kuwait, Qatar, Malaysia, and Iran found that women had extensive knowledge of cancer. Women were reported to understand the risk factors for cervical cancer, the screening methods, and prevention programmes in their countries (Donnelly et al., 2013; El-Hammasi et al., 2009; Montazeri et al., 2008; Rosmawati, 2010). A cross-sectional quantitative analysis study of 550 men who attended the outpatient clinic of the King Abdul Aziz hospital in Jeddah, Saudi Arabia (S. M. Al-Amoudi \& H. S. Abduljabbar, 2012) found that the majority of 
men had limited health knowledge and $90 \%$ did not know the importance of mammography for women.

The correlation between the level of knowledge and women's health behaviour was found in several studies from Indonesia (Aqni, 2013; Artiningsih, 2011; Lantu \& Saraswati, 2013; Maharsie, 2012; Murtini, 2012; Puspitasari et al., 2012). Aqni's (2013) study investigated the delaying factors that influenced 23 women with advanced cancer and 23 with an early stage of cancer following cervical cancer screening. This case-control study used Chi-square and logistic regression to analyse the findings. The analyses found that knowledge and other factors, including fear, family support, and health service accessibility, influenced women to participate in cancer screenings. The influence of health knowledge to women's health behaviour was also indicated in other descriptive quantitative studies in Indonesia (Hasbiah, 2004; Ningrum, 2012; Ompusungu, 2012; Tresnawati, 2012; Yuliwati, 2012). Knowledge is identified as a factor that had a significant influence on health behaviour in Indonesia; however, there is limited detailed information about participants' knowledge of women's health behaviour as studies mainly applied the quantitative approach. Study findings were primarily reported in proportion and categories. For example, knowledge categories were high, medium, and low without explanation of the meanings of each category.

Studies from Western countries also found that limited knowledge was a factor that influenced health behaviour, especially for ethnic minorities such as African and underserved groups (Ackerson \& Gretebeck, 2007; Ndukwe et al., 2013) study examined the level of knowledge and awareness of breast and cancer screening among 38 African-born immigrant women in the USA. The data was collected by two methods: interviews with key informants of the African Women's Cancer Awareness Association, and two focus groups comprising African immigrant women, one group aged 20-29 and the other aged 40-70. The interviews revealed that levels of education, age and having insurance were important factors to obtaining cancer information and awareness, while the focus groups reported limited knowledge contributed to a lack of awareness and low attendance at screenings. Other reasons given were fear, religious and cultural issues, and concerns related to privacy because of physical exposure during procedures.

Limited health literacy was indicated in a comparative study in Chile, conducted in two different religious groups of women: Adventist $(n=18)$ and non- 
Adventist ( $\mathrm{n}=18$ ) (Carreno et al., 2006). The study assessed the impact of health promotion programmes on behaviour in relation to the health-promotion lifestyle profile based on the Pender model. The result confirmed that health promotion programmes improve women's health-promotion lifestyle profiles. Similarly, Indonesian researchers developed health education programmes related to cervical cancer screening and then assessed the effectiveness of the programmes to women's health's knowledge. Dewi et al. (2013) investigated the knowledge and attitudes of 72 women, aged between 22 and 63, before and after a Pap smear health promotion programme. This quasi-experimental study analysed the data using the Wilcoxon test. The findings showed an improvement in respondents' knowledge of, and attitudes to, the Pap smear after health education. The health programme methods could be developed in various ways, including mass media. A study in Iran found that women searched for health information via television and radio (Babu et al., 2011).

Health information, for example cancer information, was also found to be important to men and women who were suspected of having cancer or were diagnosed with it (Eheman et al., 2009). They obtained information from several sources including doctors, other health providers, friends, other cancer patients, books, internet, TV, radio, and support groups (Monsonego, Cortes, da Silva, Jorge, \& Klein, 2011; Nagler et al., 2010; Noh et al., 2009; Thorburn, Keon, \& Kue, 2013). Women sought information because they wanted to be informed about women's cancer, i.e., the best treatments, doctors and hospitals and how to manage the sideeffects of therapy (Nagler et al., 2010).

The media, such as the internet, TV, and radio, strongly influence women's views regarding the treatment of cancer. Three studies have described the positive effect of cancer media information influencing women's decision making, enhancing their knowledge of treatment and diagnosis and resulting in them adopting healthy behaviours such as increasing the consumption of fruit and vegetables (Lewis et al., 2012; Nissen, Tsai, Blaes, Swenson, \& Koering, 2013; Radina, Ginter, Brandt, Swaney, \& Longo, 2011). However, patient and family also need to be selective in receiving information from the media because the media can have a negative impact because of its coverage of controversial issues (Weeks, Friedenberg, Southwell, \& Slater, 2012). 
In summary, health knowledge has a pivotal influence on women's health behaviour, especially in Indonesia, other Muslim-dominated countries and nonWestern countries. In addition, many health education programmes developed to address limited health literacy were tested to assess the effectiveness of the programmes. Indonesian studies mostly applied quantitative approaches, focusing only on women as study participants and thus there is a lack of detailed information about respondents' health knowledge. Mass media and electronic sources are useful for raising health awareness. However, people need to be careful with health information provided by media. The impact of these multiple factors on husbands related to women's health and cancer is not known in the Indonesia context.

\subsubsection{Perceptions, awareness, and attitudes}

\section{Perceptions}

Perceptions in this literature review are related to what men and women perceived about women's health issues, including cancer, and the influence of disease perception in health behaviour. A decision study in the USA of 1729 English-speaking adults aged 40 years and older investigated relationships between perceived risk of cancer and behaviour during decision making for breast, colon, and prostate screening (Dillard, 2010). In this study, the participants completed multiple choice questions about perceived risk, information seeking, and informed decisionmaking tendencies. The study found that increasing participants' perception of diseases' risk encouraged them to seek health information and to consult one or more health professionals. Similar findings were shown in a cross-sectional study of 202 Korean women who migrated to the USA. The study aimed to examine the utilisation of mammograms by Koreans about the HBM. Two methods of data collection were applied: a self-administered questionnaire $(\mathrm{n}=101)$ and interviews $(n=101)$. Data were analysed using univariate analysis and hierarchical logistic regression. The analysis found that women who perceived themselves at risk of breast cancer tended to attend the clinical breast examination service. In contrast, women who perceived they were at low risk of breast cancer, did not want to attend this service.

Studies in non-Western countries found that men and women's perceptions of early detection, diseases, and treatments impacted on behaviour. A qualitative approach with semi-structured in-depth interviews of 40 women in Barbados found 
that women understood the importance of Pap smears to detect sexual and reproductive health issues and to make sure their bodies functioned well (Christian \& Guell, 2015). The study showed women had limited understanding about Pap smears; however, they recognised the positive effects of screening. In addition, a study in Ethiopia investigated community members' (men, women, and community leaders) perceptions of cervical cancer and treatment (Birhanu et al., 2012). The study gathered data using 18 focus groups - six of men, six of women, and six of community leaders. The analysis found four themes, two of which were related to the perceptions of cancer causes and two the benefits of treatment. The participants believed that cancer occurred because of God's punishment, and a lack of personal hygiene. In relation to treatments, they shared two different opinions; the majority thought that modern treatments could not help cancer. The participants preferred traditional therapies, and only a few of them thought that modern surgery could help the early stages of cancer.

From studies in Malaysia and Pakistan, two Muslim-dominated countries, several misconceptions about cancer causes were identified. Kumar's (2010) study tested the relationship between knowledge, perception and beliefs, and making treatment decisions. The study involved 230 Pakistani females and males, who filled in a questionnaire in the Urdu language. The questionnaire included questions relating to demography, previous treatment for a disease, myths regarding risk factors, and roles in decision making. The study found that $37.5 \%$ of participants perceived that cancer is related to social habits such as drinking alcohol $(21 / 3 \%)$, not believing in God (5.7\%), past sins, and God's curse. With regard to treatment behaviour, $89.6 \%$ of the participants thought that cancer was potentially curable, $60 \%$ believed that rituals including religious activities will be a cure, and $23.5 \%$ considered a healthy lifestyle prevented cancer. In addition, a study in Malaysia of 25 traditional male therapists found that the majority perceived food and unhealthy lifestyles as the main causes of cancer, and one said it was interference by ghosts. The interviews with healers also found that modern medical treatments were the main advice given to patients who exhibited cancer symptoms. These studies reported that participants' perceptions of diseases were affected by treatment choices.

No study in Indonesia has gathered information relating to the influence of women's perceptions of health behaviour. However, there was a study which 
investigated women with breast cancer risk about breast self-examination (BSE) (Desanti et al., 2010). This cross-sectional study involved 384 women who filled in a questionnaire. The results showed that respondents had negative perceptions of BSE. In fact, $74.4 \%$ perceived no advantages in BSE, and 70.1\% said they faced barriers to doing BSE. No further descriptions from respondents related to barriers and advantages of BSE.

These studies revealed various perceptions of cancer identified from Western, non-Western, and Muslim-dominated countries. Some perceptions of cancer impact on participants' awareness of the importance of cancer screening, while misconceptions of cancer could lead to inappropriate choices of treatments. In addition, compared to other countries' studies, Indonesia's studies related to health perception and the impact on health behaviour were limited. Understanding Indonesia husbands' perceptions of cancer may identify valuable information regarding the behaviour of women.

\section{Awareness}

The awareness of diseases and health procedures, either positive or negative, impacts on women's health behaviour. Women visit health services for screening because they are aware of the importance of early detection to their health. Interviews of 20 women in Indonesia found that the women understood about preventing serious illnesses, so they were willing to visit the health centre for treatments (Kim et al., 2012). Similarly, six focus groups of African-American women in the USA found that increasing women's awareness was the main reason for screening participation and their awareness rose after they had had experience of multiple cancer deaths in their communities (Ndukwe et al., 2013). In addition, a study of 1279 women in Australia using a survey found personal awareness and motivation regarding their health were reasons to participate in cancer screening (Dieng, Trevena, Turner, Wadolowski, \& McCaffery, 2013).

Limited awareness is a factor that could hinder men and women participating in health behaviour. Low awareness of cancer was identified in Malaysia, Turkey, and Saudi Arabia, three Muslim-dominated countries. Norsa'adah's (2012) study collected data from 12 breast cancer patients using interviews with patients who had a history of delayed treatment, consultation, or diagnosis from the East Coast of Peninsular Malaysia. This study found that many participants were not aware of 
cancer-related symptoms and ignored minor symptoms. They thought that cancer would never happen to them. They had no perception of the seriousness of symptoms because they had no pain and they could do their daily activities. Further, they had no abnormal cytology, and several participants were pregnant or in postpartum periods. A cross-sectional study of 550 men in Saudi Arabia found that $42.4 \%$ were not aware of the advantages of BSE for early detection of breast cancer and, as a result, they gave minimum support to their wives for this screening (M. AlAmoudi \& H. S. Abduljabbar, 2012).

Non-Western and Western studies also identified men's low awareness of women's health. Rosser's et al. (2014) assessed the knowledge and attitudes of 110 men in Western Kenya. The awareness questions included five yes or no questions asking participants to answer (yes, no) if they had ever heard of cervical cancer, human papillomavirus (HPV) and cervical cancer screening, such as Pap smears, and visual inspections with acetic acid (VIA). This study found that men had low awareness of the HPV vaccine and cervical cancer (Rosser, Zakaras, Hamisi, \& Huchko, 2014). Other Western and non-Western studies identified of low awareness by different ethnic groups and ages in relation to health-seeking behaviour (Granek \& Fergus, 2012; Kyle, Forbat, \& Hubbard, 2012; Liou, Ling, Feng, Guo, \& Chen, 2009; Waller et al., 2009).

Studies of men and women's awareness showed that awareness is an important factor that could influence either positive or negative action toward health behaviour. Low awareness was identified from studies in Western, non-Western, and Muslimdominated countries. In Indonesia, a few studies have gathered information about men and women's awareness of health, especially women's health and cancer. Understanding more about this is important.

\section{Attitudes}

Studies identified positive and negative attitudes related to health behaviour in Muslim-dominated countries and Indonesia. El-Hammasi et al.'s (2009) study aimed to assess women's knowledge, and attitudes to Pap smears in Kuwait. The study involved 299 women aged 15 years and older who were asked to fill in a questionnaire. The findings were that women were willing to participate in screening programmes and wanted to know more about Pap smears. Other Muslim-dominated country studies, including Malaysia, Qatar, Turkey, and Kuwait, found that 
participants had positive attitudes to early detection and treatment of disease. This included participants paying attention to BSE, and preferring to go to medical services for treatment (Donnelly et al., 2013; Duran, 2011; El-Hammasi et al., 2009; Rosmawati, 2010).

A few studies were conducted in Indonesia to assess women's health attitudes. Amalia's (2015) study investigated husbands' knowledge and attitudes related to their wives' Pap smear. This study involved 105 husbands who filled in a questionnaire, and the data was presented in table format. Findings found that $63.8 \%$ $(\mathrm{n}=67)$ had positive attitudes to Pap smears. However, there was no explanation about the positive and negative attitudes. Other Indonesia studies about health attitudes also provide little-detailed information. The studies reported findings of attitude using the categories of positive and negative or good and poor (Amalia, 2015; Artiningsih, 2011; Lantu \& Saraswati, 2013; Wahyuni, 2013).

Attitudes were a factor that influenced health behaviour. Studies from other Muslim-dominated countries presented participants' attitude clearly, whereas the Indonesian's studies tended to present in categories and lacked descriptions of the meaning of attitude categories. Understanding husbands' attitudes to women's involvement in health and cancer screening maybe useful to increase the number of women having screening for cancer.

\subsubsection{Religion and beliefs}

\section{Religion}

The positive influence of religion/spirituality on health behaviour has been proven in countless literature. Studies indicate that women with a high level of religiosity performed early detection behaviours to cancer screening more frequently than those with a low level of religiosity (Allen et al., 2014; Benjamins et al., 2011; Carreno et al., 2006). Allen et al.'s (2014) explored the roles of Catholic religious teachings and practices of cancer screening knowledge, attitudes, and behaviour among 67 Catholic Latino people in Massachusetts. Eight focus groups were used to collect the data. The analysis found that participants stated that their religious teachings and practices had significant roles and connections to health behaviour. The roles included prayers, which helped them to cope with life stresses, health information and access to health services, material assistance, and support from priests. 
Religiosity/Spirituality (R/S) also enhanced mental health, provided there were social support and activities, and it promoted healthy lifestyles (Banerjee, Strachan, Boyle, Anand, \& Oremus, 2014; Koenig, 2012; Labun \& Emblen, 2007; B. Y. Lee \& Newberg, 2005). Besides the positive effects of R/S, Koenig's (2012) study identified negative influences of R/S on mental health behaviour, for example, aggression, and obsessive practices. Similar trends were shown in Chang et al. (2013) study. They investigated 147 women in Taiwan, 80 of whom were suspected of having breast cancer and 67 were diagnosed with it. Based on the questionnaire answers, this study found that those who had delayed had greater spiritual support than those who did not delay cancer treatment. The participants who delayed their treatment obtained support from their communities, and this helped them to deal with the stress, for example applying religious ceremony as therapy. Another study was related to screening behaviour, a cross-sectional study in India of 100 women ( $n=63$ Hindus, $n=37$ Muslim) was conducted to gather awareness of the various risk factors for cervical cancer and health-seeking behaviour (Tiwari \& Kishore, 2011). The results showed the Muslim women had a higher proportion of abnormal Pap smears. However, there was no further information about specific health behaviour from the two groups of women related to religion in this study.

Different influences of R/S were found in several studies from Muslimdominated countries [Iran, Pakistan, Jordan] such as the influence of Islamic teachings on health behaviour, including early detection and disease treatment. Participants in several of these studies held to their religious beliefs and practices because they were part of their psychological support (Babu et al., 2011; Banning et al., 2009; Harandy et al., 2010; Taha et al., 2012). A study of 39 Iranian women diagnosed at various stages of breast cancer gathered information via in-depth semistructured interviews related to the feelings and attitudes about cancer, coping strategies, and health behaviour after diagnosis. This study found that spirituality was their main source of psychological support. Although participants were upset after the cancer diagnosis, their faith helped them to an early acceptance, and they surrendered their lives to God, who they believed had a plan for their lives, and cancer was a test from God and was God's will (Harandy et al., 2010).

According to the above studies, religiosity/spirituality, including Islamic teaching, have positive and negative effects on health behaviour. Studies about the positive effects of Islamic teaching and practice on health behaviour were conducted 
in several Muslim-dominated countries. Meanwhile, in Indonesia, the largest Muslim population worldwide, has no published data that inform the influence of the Islamic teachings to Indonesians' health behaviour. Given the dominance of this religion in Indonesia, understanding its impacts on health-seeking behaviour is essential.

\section{Beliefs}

Beliefs in this literature review are specifically related to men and women's beliefs in disease causes and therapy preferences. A qualitative study in two clinics in Turkey of 11 women, aged 15-49 who were receiving cancer treatment found they had no Pap smear experience. Three themes were identified related to beliefs, knowledge, and barriers to women seeking treatment. This study's findings revealed that most participants believed cervical cancer is dangerous, they cannot ignore it and they could have taken precautions. In addition, they believed the cervix is the most important organ in women, and that their cancer is a test from Allah and action needs to be taken. A few participants also shared they thought that they did not need to be screened as they believed they only had a small risk of developing cancer as this cancer most commonly affects older women (Duran, 2011). Other studies found that participants' beliefs of terminal diseases, including cancer, is bad luck, the outcome was death, and cancer is a dangerous disease (Ackerson \& Gretebeck, 2007; Duran, 2011; Lor et al., 2013).

Studies from Muslim-dominated countries found that participants believed in traditional or alternative medicines rather than modern treatments (Kumar et al., 2010; Lor et al., 2013; Norsa'adah et al., 2012). Alternative therapies were recommended by Lor et al. (2013) in the USA. The study's objectives were to describe the beliefs, feelings, norms, and external conditions that relate to breast and cancer screening of 16 Hmong women, aged 24-73 years. The study used semistructured questions and a content analysis method. One finding found there was uncertainty among participants' beliefs about cancer treatments; participants were unfamiliar with western treatments and preferred traditional medicine such as "khaws khoob" (spiritual ritual). They believed this would make them better and that modern treatment always included surgery, "cutting", and they thought this only worked temporarily.

These studies described various beliefs related to diseases, early detection, and treatment that influenced participants' choices of health actions. Their beliefs could 
influence positively or negatively women's health behaviour. Several studies showed participants' beliefs encouraged them to seek early detection and treatments, while others showed women preferred to do nothing. From this literature review, I found no Indonesian study that focused on identifying the influence of beliefs on women's health behaviour.

\subsubsection{Culture norms and psychology}

\section{Cultural norms}

Cultural norms, in this literature review, relate to cultural values that influence men and women's health behaviour. Studies in the USA identified the influence of cultural norms on women's health behaviour, especially related to women's reproductive organs. Potrata's (2011) study explored the symbolic meanings of "breasts" that may affect women's late presentations for breast cancer. This qualitative study used semi-structured interviews of 46 complementary, alternative, and religious healers who worked with breast cancer patients. The thematic analysis found that there were two symbolic meanings of breasts. The first was breasts are a symbol of nurturing and maternity. Furthermore, culturally, women are responsible for the full-time care of children and do not have mammograms because of a lack of time. Second, breasts are a symbol of beauty. The healers were of the opinion that women fear and delayed cancer treatment because they wanted to remain "beautiful". This symbolism was believed to be held by all female patients from White, Latino, African, and American cultures.

Different cultural values were also evident in Lor et al.'s (2013) study among women who shared their cultural context about breasts and vaginas in relation to cancer screening. These women had norms including it being culturally unacceptable to show their breasts or genitals to their husbands and children and talking about screening or showing pictures of screening results were culturally inappropriate. As a result, some women preferred to delay screening.

A small study in Indonesia published internationally related to Indonesians' cultural norms that influenced women's health behaviour. The qualitative research using in-depth interviews with four married women from Kebumen, Central Java found that sociocultural norms were a barrier for women's early detection behaviour. Culturally, women believe that they need to follow their husband's advice when they advise delaying screening (Tresnawati, 2012). 


\section{Psychology}

Fear and embarrassment were the two primary psychological conditions identified in this literature review that could affect women's health behaviour, including for women's cancer. Studies in Ireland and the USA found embarrassment, fear of pain, fear of cancer diagnosis, anxiety, worry, distress, uncertainty, and depression were women's psychological feelings to breast cancer screening or therapy (Friedman et al., 2012; O'Mahony et al., 2013). A qualitative descriptive study was conducted in Ireland that involved 10 women, ages 25 to 55 years who had abnormal symptoms such as breast lump, breast pain, and bloody nipple discharge. These symptoms were found by participants before they decided to go to health services. When they found the symptoms, the women were fearful because of what the symptoms could mean, many "freaked out", were upset, had a lot of positive and negative thoughts, were scared and, while waiting for a check-up with the doctor, struggled with trying to be positive, and were in denial. As a result, women delayed seeking help (O’Mahony, 2011).

Studies from non-Western countries found similar psychological feelings after diagnosis of a potentially terminal disease. A quantitative study of 25 women in Bombay, India, found that women were psychologically threatened after a cancer diagnosis (Ramanakumar, Balakrishna, \& Ramarao, 2005). The study explained that women felt the fear of reducing their body function, lacked confidence, feared to die, felt rejected and inferior, was angry and irritated, felt jealous, was labile and often cried, and felt depressed. The spouses also felt psychological changes after the terminal diagnosis. A case study of 20 husbands in Mexico that aimed to identify family characteristics related to utilisation of Pap smear services and barriers found that husbands felt frightened of their wives' symptoms, fear of possible positive tests because what would happen to their children if their mother was sick. They also felt shame related to the Pap smear procedures because of their wives' bodies being seen by others and the possibility that they would be checked by a man (Villafuerte et al., 2007). In addition, Tawari's (2011) study that involved 100 women aimed to assess the distress experienced before Pap smears. The study found women suffered from broad psychology feelings, including anxiety, shyness, and fear of many things, including pain, because of the procedure, the instruments, cancer, and an evil curse. Women also fear social stigma and their communities' reactions, and how the disease will affect their sexual relations. 
Similarly, fear of social stigmatisation was found in an explorative qualitative study of 64 women in Jordan, a Muslim-dominated country (Taha et al., 2012).

Women with cancer tended to hide their disease from society because it is related to a dangerous illness, and patients with cancer thought their disease would affect their daughter's socially. Another study in Pakistan focused on women's emotional feelings to cancer symptoms. It found that feelings included distress, shock, disbelief, upset, and fear of treatment (Banning et al., 2009). Different feelings were identified in 538 women in Qatar who were not participating in CBE and mammograms. In their questionnaires, they stated their main feelings were an embarrassment because a male would examine their breasts, fear of cancer diagnosis and gossip (Donnelly et al., 2013).

A limited study in Indonesia explored women and men's psychological feelings that could influence women's health behaviour related to early detections and disease treatments. A quantitative study in a hospital in Surabaya, Indonesia involved 84 women who visited an oncology policlinic for the first time aimed to identify delaying factors of cancer early detection (Aqni, 2013). The data were analysed using Chi-square test and logistic regression. The study found that fear identified as a delaying factor of women's cancer early detection. However, there was no further information specifically about fear.

In summary, women in Western studies faced personal psychological feelings, and they needed to adapt to it. However, in non-western Muslim-dominated countries studies, women and men's fear was related to social stigma. The literature review also indicated that psychological changes were not only felt by women but also their spouses. However, few studies have explored men's psychological feelings to women's health. There is a need for more worldwide exploratory studies, including in Indonesia, as there is little-detailed information about women and men's psychological feelings in Indonesia regarding women's health that could influence their health behaviour.

\subsubsection{Social, demography, and economy}

\section{Social}

Social influence in this literature review is related to the influence of spouses, children, extended families (mothers, fathers, siblings, and relatives), friends, and community members (community leaders, religious leaders, volunteers, and cadres) 
to women's health behaviour. Husbands and family members were identified as the main social support for women's health in Western countries. Keating et al. (2011) investigated whether screening of breast, prostate, and colorectal cancer is influenced by siblings, friends, spouses, and co-workers' screening behaviour. The study used data from the Framingham Heart Study which involved 2929 women aged 41-70 years, and 2021 men aged 51-70 years in the original cohort. Of the women participants, 597 of them had sisters, 175 had female friends, and 174 had female coworkers, while 337 men had brothers, 154 had male friends, and 99 had male coworkers who enrolled in the Framingham Heart Study. Both women and men were asked the last year they had a stool test and when a sigmoidoscopy had last been performed. Women were asked the year of their last mammogram and men were asked when they had had blood tests for prostate cancer screening. The data were analysed using logistic regression models. The study found that an increasing proportion of women who attended for mammograms had sisters who had also had them. Similarly, an increase in women's colorectal cancer screenings was associated with spouses having attended colorectal cancer screenings. Friends and co-workers' screening behaviour was not associated with respondent screening behaviour. Other Western countries' studies, including the USA and Canada, found husbands and family members provided emotional support, health behaviour role models, and support for decisions to seek treatment (Granek \& Fergus, 2012; Keating et al., 2011; Ma et al., 2012; Torres et al., 2013; L. Watts et al., 2009).

Several studies from non-Western countries, including South Africa, Peru, and Ethiopia, identified the influence of the social environment on women's health. These studies presented the positive influence of friends on screening behaviour, supportive husbands to women's health-seeking behaviour, and also unsupportive husbands because of a cancer diagnosis. Maree and Wright (2010) conducted a doorto-door quantitative survey, aimed at understanding health-seeking behaviour, of 565 women in Tshwane, South Africa. The survey found that $61.3 \%$ of respondents mentioned that their husbands, life partners, or family supported them to seek healthcare when they detected the warning signs. In addition, $20.7 \%$ indicated that permission was needed from parents or husbands. In contrast, focus groups conducted by Birhanu et al. (2012) with six groups of women, men, and community leaders from Ethiopia, found that cervical cancer was sometimes a cause for divorce. Men's behaviour was to ignore their wives, making them less important as people, 
labelling them as a community stigma, and finally divorcing them. The community perceived that women with cervical cancer were associated with having frequent sexual intercourse and multiple sexual partners.

The majority of studies from Muslim-dominated countries, including Malaysia, Jordan, Pakistan, and Iran, found that husbands and family members were the facilitators of, and barriers to, women's health behaviour. Husbands and family members' support included: encouraging the wife to exercise, healthy food, giving advice for screening, taking care when she was sick. Furthermore, family members, especially mothers, reminded them about health activities and supported them when they were diagnosed with cancer (Baheiraei et al., 2013; Banning et al., 2009; Donnelly et al., 2013; Kumar et al., 2010; Rosmawati, 2010; Taha et al., 2012). However, an aspect of Baheiraei et al.'s (2011) findings showed that the husband and family were also a barrier to women's health promotion activities. Their study interviewed 15 women and aimed to gather information about facilitators and inhibitors of health-promoting behaviour among Iranians. The barriers included limited social contact after marriage, family disputes and lack of nutritious food.

Further supportive versus unsupportive behaviour of husbands related to women's cancer was identified in 10 focus groups of women aged 20-65 years in Jordan (Taha et al., 2012). This study found several participants received family and social support about seeking breast healthcare and husbands stood by their wives when they were diagnosed with breast cancer. However, some other men started looking for other women because women with breast cancer were considered to have lost their femininity, or men did not like having a sick wife. In addition, a study in Pakistan found Pakistani women who had abnormal breast signs preferred to hide them from their family to avoid social stigma (Banning et al., 2009).

Quantitative studies in Indonesia found that husbands were a factor that influenced women's health behaviour, especially with regard to family planning (Rafidah, 2012), perinatal periods (Harumawati, 2012), and cervical cancer screening (Aqni, 2013; Hasbiah, 2004; Sarihati, 2013; Wahyuni, 2013). A few qualitative studies found social factors influenced women's health behaviour including husbands, family members, and cadres (Kim et al., 2013; Tresnawati, 2012). Rafidah's (2012) study investigated the influence of husbands on women's participation in family planning. This cross-sectional study involved 63 women respondents who filled in a questionnaire, and the data were analysed using logistic 
regression. The study found two-thirds of the husbands supported women's family planning and $38.1 \%$ opposed it. Rafidah's study provided no further information about the particular support from husbands.

\section{Demography}

Few studies in this literature review identified specific health behaviour of women and men based on whether they lived in rural or urban areas. Both rural and urban women faced different challenges. For example, long distances from health services, or limited facilities. Birhanu's (2012) study using six focus groups of women from two different areas (Addis Abba and Jimma in Ethiopia) found that women living in rural areas faced risks related to health-seeking behaviour. Rural women generally sought treatment when their cervical cancer was at advanced stages, and they were in severe pain. The study also found that rural women must travel long and expensive distances for screening or treatment (Birhanu et al., 2012).

A study from the USA assessed the Quality of Life (QoL) of 46 women from rural areas with various degrees of breast cancer. This study concluded that women needed continued social support and the more remote the rural area, the greater risk of lowered QoL (Arndt, 2010). However, different trends were found in a crosssectional survey of 705 women who lived in the rural areas of North Eastern Thailand. This study aimed to identify the factors associated with BSE performance among Thai women living in rural areas. The findings showed $75 \%$ had performed BSE and 68\% had in-depth knowledge of BSE procedures (Satitvipawee et al., 2009). Contrasting results were identified in an exploratory study of 565 urban black women in South Africa that aimed to explore urban women's understanding of cancer and their health-seeking behaviour. Findings showed that women had a low level of knowledge and understanding of cancer, needed permission for screening, and not all women had money for screening (Maree \& Wright, 2010).

These studies indicate that women living in rural areas are likely to face more challenges than those in urban areas, even though it does not mean that women in urban areas do not have challenges. Those challenges influenced health-seeking behaviour. There has not been a study in Indonesia comparing women or men's health behaviour in relation to these two different living areas. Understanding whether living rurally or in urban areas affects behaviour would be useful for health service. 


\section{Economy}

Financial issues were identified as a factor that could be a burden to women's health behaviour. A cross-sectional qualitative telephone study in the USA of 11 African American, four white, and one Latina women found two themes related to the impact of low incomes. The first was the psychosocial context which included the influence of economic status to patients' decisions for the treatment of diseases. The second was the lack of insurance, as health professionals' services required health insurance. One participant said the doctor did not want to check her as she did not have insurance cover (Bowen et al., 2013). Having a low income was also found to influence women's health behaviour in Ackerson and Gretebeck's (2007) study conducted in African American group resulting in low participation in cancer screening.

Studies in two Muslim-dominated countries, Pakistan and Iran, found similar findings with Western studies. Financial limitations were a burden to health promotion and disease treatment. Baheiraei et al.'s (2013) study of 15 women in Iran found that women wanted to attend Yoga or other exercise lessons, but the price was high. Also, Banning's (2009) study found that the financial issue was a problem that women with a terminal disease like cancer faced. Cancer needs long, and many medical treatments and these impacted on family's savings, and participants reported they lost their breadwinners as their husbands left them. For a single woman, costly cancer treatments were affected by the minimum help provided by relatives or family. In Indonesia, few studies have assessed the influence of low incomes on women's health behaviour; one qualitative study interviewed 20 women and found that the cost of trips to health services was one consideration in delaying treatments (Kim et al., 2012).

\subsubsection{Health services}

This literature review found that health services have a major influence on women's health behaviour. There have been many studies that have discussed the significant influence of health services, including health professionals' behaviour, health facilities, programmes in women's health, and health insurance. This was evidenced in 13 of 23 studies in Western literature; 8 of 14 in non-Western studies 
and 10 of 16 studies in Muslim-dominated countries. In addition, six studies in Indonesia described the impact of health services.

\section{Health professionals'behaviour}

The most influencing factor in women's health behaviour in the literature was health professionals' behaviour. Their behaviour was a motivation as well as a barrier to men and women's actions. Health professionals' behaviour that motivated patients to go for screening was reported in several qualitative studies in Western countries (Lor et al., 2013; Marlow et al., 2013; O'Mahony, Hegarty, \& McCarthy, 2011; Torres et al., 2013). These included: health professional's ability to talk in the patients' mother tongue, a good relationship between patients and health professionals, and good health services enhanced positive views of health professionals' services.

A similar trend in Western studies was found in an exploratory study of 14 Barbadian women. Christian and Guell (2015) explored women's attitudes and knowledge toward cervical cancer screening. Data were gathered by the in-depth interview method and analysed using thematic analysis. Four themes were found, one was health professional roles as the main driving force behind the uptake of screening. Participants shared that they did not understand cervical cancer and the objectives of screening but because of the doctors or nurses' recommendation, they participated in it. Health professionals' recommendations for the early detection of cancer also encouraged women from the Muslim countries of Pakistan, Qatar, and Indonesia to attend screening programmes (Donnelly et al., 2013; Kim et al., 2012; Kumar et al., 2010; Sarihati, 2013). In addition, a literature review of Iranian studies found that the same gender of health professionals was a motivating factor for women's cancer screening (Babu et al., 2011).

In contrast, several studies identified that health professionals' attitudes became burdens for women's health behaviour, including language barriers (Torres et al., 2013), poor communication skills (Augusto et al., 2013; Farooqui et al., 2013; Friedman et al., 2012; Ma et al., 2012; Yusoff et al., 2011), and a lack of health professionals' capabilities in health procedures (Lor et al., 2013). In addition, a study of nine different ethnic minority groups of immigrants in London found women experienced barriers to accessing cancer treatment. These included language, long waiting times for appointments, and difficulties with their work schedules 
(Marlow et al., 2013). Other barriers were the difficulties in understanding the language in cervical cancer leaflets, delays in results, inappropriate times for screening schedules, and limited times for health consultations (Augusto et al., 2013; Thomas, Saleem, \& Abraham, 2005)

\section{Health facilities}

Studies identified some issues in health facilities that influence women's health behaviour. A qualitative study in Indonesia aimed to explore factors that influence women's decisions to have cancer screening and treatment. Twenty-eight health professionals were interviewed, and limited or broken health instruments were identified as a barrier to women attending cancer treatments. This impacted rural women's attendance as considerable costs and time were involved (Kim et al., 2012). Also, the studies from Malaysia and USA identified that limited printed information about screening and ineffective screening equipment with patient obesity were issues that affected patients' health behaviour (Friedman et al., 2012; Norsa'adah et al., 2012).

\section{Health programmes}

Developing health programmes for cancer prevention would be beneficial for women. Studies in England and the USA found that cancer prevention programmes have improved women's awareness and reduced cancer mortality rates (Ackerson \& Gretebeck, 2007; Forster et al., 2014). The prevention programmes in non-Western and developing countries have not been as effective in reducing either the number of new cases or the number of deaths from cervical cancer as women faced burdens including the lack of organisation and inadequate facilities (Winkler et al., 2008).

A study in Indonesia that evaluated a five-year cervical and breast cancer prevention project found that women's uptake of screening had increased, but the proportion was low compared to the target number (Kim et al., 2013). This study was conducted at 17 health centres and provided free cervical screening using the VIA method, health education about BSE, training for health professionals, and facilities for screening located close to the communities. The findings showed that only 40,050 women, $24.4 \%$ of the target population participated in the programme and $83.1 \%$, of those who were VIA positive received cryotherapy. This study recommended that Indonesia change the service model and programme management 
to increase screening coverage. Further health programmes were also recommended to encourage women to participate in health behaviour, including screening and treatment. More information about health services enablers in Indonesia is required.

\subsection{Husbands' involvement in women's health behaviour}

Some husbands supported their wives in their health behaviour while others did not. Support identified in Western, non-Western, Muslim-dominated countries, and in Indonesian studies included: making supportive decisions, providing health information, encouraging women to participate in health education programmes, being positive about health and life and providing financial assistance. Trevino's (2014) study of 163 men from rural Arkansas and New York that aimed to test a community-based breast cervical intervention programme found that men were willing to attend intervention programmes about women's health to enhance their knowledge that could be useful to women's health in the future.

Positive support from spouses, as well as negative spouses' behaviour to women's health, were identified in an exploratory qualitative study of 17 black South African women (Maree et al., 2013), which found men had major influences on the behaviour of women who suffered from cancer. These included encouraging women to go to health services when they had abnormal signs such as vaginal bleeding, helping in their daily activities such as showering them when they had severe health issues and providing financial support. This study also found that some partners did not support women financially, and they married another woman. There was also a similar lack of men's support for women's health detected in several studies from non-Western countries, including Kenya, India, and Mexico. Men's lack of support for family planning, health service visits, and sex education for their daughters was identified (Onyango, Owoko, \& Oguttu, 2010; Saha, Singh, Chatterjee Saha, \& Roy, 2007; Thiel de Bocanegra et al., 2009). A qualitative study of seven males and four females in Kenya that gathered information about men's behaviour found men rarely accompany women to visit health services because it is uncommon and meant that men are being overpowered by women. Moreover, the men never talked to their daughters about reproductive health as taking care of children is mostly the women's responsibility and the father is not expected to discuss sexuality with his daughters (Onyango et al., 2010). 
Studies in Jordan, Malaysia, and Egypt found men were fully supportive of women's conditions and treatments. They took over the household tasks when their wife was sick, and encouraged them to seek treatment. They also accompanied them to medical or alternative treatments, protected them from society's negative views of cancer, and protected their families from the risk of cancer (Ohashi et al., 2014; Yusoff et al., 2011). An exploratory qualitative study of 24 men from Jordan, a Muslim-dominated country, identified husbands' roles in the breast health of female family members. The content analysis found that men encouraged women to seek healthcare, provided advice and money for treatment, accompanied them to health services, and protected their families from genetic risks by avoiding marriage with a girl with a history of breast cancer. One reason men supported women was that of their religious beliefs. The men felt responsible for their families' health and wellbeing as they believed that husbands' responsibilities to family members were a part of worshipping God, and their religion teaches that a wife is precious in the family (Taha et al., 2013).

There are limited studies in Indonesia about husbands' involvement in women's health. Those that have been done found husbands had roles in the breastfeeding period and cancer screening. Pratami (2016) interviewed five husbands whose wives were in the breastfeeding period (6-12 months) and identified three types of support provided by husbands. These included providing information related to breastfeeding, such as types of nutritious food for breastfeeding women, factors that influence breast milk production, and breast milk-stocking methods. Other support was providing food, breast milk pumps, and participating in taking care of the baby. Finally, was husbands' emotional support for their wives; they accompanied their wife at night during breastfeeding, listened to their wife talk about the baby, and motivated her to keep breastfeeding. Contrasting behaviour was identified in Anggraeni's (2016) study. She did a descriptive quantitative study of 30 women to investigate husbands' support in the early detection of cervical cancer. This study found a lack of husbands' support for the screening fee, transportation, and health insurance. In addition, women felt a lack of emotional support from their husbands, including them not paying attention to screening and their health.

The literature contained many instances of support by husbands to enhance women's health, even though a few studies found poor support for women's health 
from their husbands. In studies in Muslim-dominated countries, husbands expressed their particular reasons for supporting their wife, including religion but there have been limited studies exploring these in Indonesia.

\subsection{Key limitations of the review}

Various factors influencing women's health behaviour were identified in many countries, including Indonesia. However, Indonesian studies predominantly investigated the influence of knowledge and attitudes on health behaviour generally, and few explored men and women's perceptions of women's health, and the influence of religion, beliefs, social and cultural norms, and men's psychological response to women's health behaviour and cancer.

The majority of Indonesian studies used a quantitative approach with limited detailed findings and little exploration. This has resulted in limited detailed understandings of the condition people having only superficial or insufficient information to develop health programme. Most studies were conducted in urban areas where men and women can easily obtain information about cancer from many sources. However, few studies, including Indonesian studies have explored how men and women who live in rural and isolated areas obtain information about women's health and cancer.

The literature showed men have important roles for non-Western and Muslim women. However, there were few investigations about how husbands give support to their wives, and husbands' understanding of their roles and responsibilities in supporting their wives' health and cancer, especially in Indonesia. This might be due to the fact that breast and cervical cancer are women's health issues, so studies have mainly focused on women, and only a few researchers have shown an interest in husbands' roles in women's health and cancer.

Understanding the various influencing factors identified from many studies, from an Indonesia perspective is important such as religion, beliefs, psychology, and social and cultural norms. Social support, mainly from spouses, could be a potential factor to improve women's health. Spouses were identified as being pivotal in providing motivation and help women in accessing health services. However, there are limited studies into husbands' behaviour related to women's health and cancer in Indonesia. There is a need for a further in-depth study into men's awareness and 
their involvement in women's health and cancer because their involvement has a significant influence both directly and indirectly, and positively and negatively on women's health.

The positive and negative effects of religion/spirituality were found in many studies in Western, non-Western, and Muslim-dominated countries. Studies of these in Muslim communities found that there are important roles for religion as it plays a significant role in a patient's behaviour to cope with cancer and other severe diseases. In addition, the need for health interventions that integrate Islamic teaching to improve healthy behaviour has been identified. However, to date, there is no study into how Islamic teaching influences Indonesians, especially husbands' roles in women's health. This is particularly imperative as Indonesia has the largest Muslim population in the world and it could have more extensive applications in the Muslim world. 


\section{Chapter 4. Methodology}

\subsection{Introduction}

This chapter presents the methodology of this study which has taken a constructivist, qualitative descriptive exploratory approach. The study aimed to uncover Muslim husbands' roles in women's health and cancer. It examines this from three different groups' perspectives: men, women and health professionals. The data were collected in two districts in the West Java province of Indonesia using focus groups and semistructured interviews. The data were analysed using a comparative analysis for focus groups and interviews, a technique developed as part of the research.

\subsection{The philosophical paradigm of the study}

This study drew upon the constructivist paradigm. The basic assumption of this paradigm is that the social world is subjective and in order (Gibson, 1979). The primary concern of this paradigm is to understand that the social world is subjectively experienced and that explaining this world requires both an understanding of individual consciousness and a frame of reference for the participants. This social world is not a fixed unit but is constructed by people who participate in it (Polit \& Beck, 2014). This paradigm is most useful with qualitative data collection methods (Creswell, 2014; Mackenzie \& Knipe, 2006). The methodological implication of this worldview is that contextual details need to be gathered (Gibson, 1979).

The underlying assumption of this research is that the roles that Muslim husbands play in the health of their wives, including the prevention, screening, and treatment of women's cancer, may have a unique expression which is, as yet, little known and poorly explored. The Islamic ontology in which this research is embedded and the constructivist paradigm in which it is undertaken was adopted enable a unique approach to this exploration. The exploration allowed for a freeflowing and open explanation while at the same time ensuring congruence and relatability back to the strongly Islamic context in which the question was embedded. 


\subsection{The research methodology}

This study used a qualitative descriptive exploratory approach. There are many traditions of qualitative research, including grounded theory, ethnography, and phenomenology. These traditions are increasingly being applied by researchers in the health and social sciences, including nursing studies (Hunt, 2009). However, these qualitative approaches have not always met the needs of nurse researchers as they are not specifically suited to answering questions that will advance nursing theory and nursing science (Thorne, Kirkham, \& Emes, 1997). Nurse researchers have therefore made considerable advances in the development of some qualitative methodological approaches (Thorne et al., 1997). One such methodology is qualitative descriptive research (Sandelowski, 2000; Thorne et al., 1997).

According to Polit and Beck (2014), qualitative description typically focuses on describing people's characteristics, circumstances, and phenomena. This methodology is under debate as some researchers have the opinion that qualitative description does not exist as part of the constructivist approach (Sandelowski, 2010). However, others such as Lambert (2012) believe that qualitative description is a viable and acceptable qualitative research design. The social world has multiple realities, and researchers can modify research questions as new information arises (Polit \& Beck, 2014). The goal of qualitative description is to generate a summarization of everyday events experienced by individuals or groups of individuals (Sandelowski, 2010). An exploratory study begins with a phenomenon about which little is known; and the methods are designed to explore the nature of the phenomenon, manifestations, factors that are related, and factors that led or contributed to it (Polit \& Beck, 2014).

This research adopted the analysis typically used in the qualitative description to search for some group comparisons specifically. Comparative analysis is used in quantitative studies designed to pursue understandings of differences and similarities between two or more subjects or groups (Carpi, 2008). In qualitative research, a comparative approach is used in grounded theory research: constant comparative analysis (Thorne \& Sally, 2000) as an analytical tool to develop theory, and in case studies where there are multiple cases, it can be used to draw out similarities and differences (Yin, 2003). Little is written about using comparison in descriptive research. 
The purpose of this study was to uncover Muslim husbands' roles in women's health and cancer in the Indonesian Muslim community. This included exploring husbands' roles and responsibilities, determining the perceptions of their roles in women's health and cancer, and exploring sociocultural influences. It also aimed to begin the examination of whether or not there may be differences in these roles across geographical locations, age or other social, health or cultural characteristics.

To gain a broad perspective of Muslim husbands' roles, I gathered data from three different sources: Muslim husbands, Muslim married women, and from a variety of health professionals. I then triangulated the data as I wanted to obtain an extensive overview of Muslim husbands' roles which are naturally subjective and which will have multiple realities. I wanted to begin an examination of how women's views compare with those of men. I, therefore, involved Muslim married women. As an extension of this, I was also interested in how the health professionals might view this same issue. Secondly, a design consideration was ensuring rigour, especially related to establishing confirmability of the study in relation to reducing my influence in the analysis of the data (Polit \& Beck, 2014; Shenton, 2004). The triangulation undertaken expanded the study's findings and minimised my influence, rather than establishing some sense of cross-referenced 'truths' about the findings and analysis. The research, therefore, does remain true to the constructivist approach.

The data were gathered using focus groups with married Muslim men and semi-structured interviews with women, and health providers. I used focus groups with the men as they are useful in studies when little is known of a phenomenon as they can result in new ideas and creative concepts. Participants can learn from the discussion and talk freely about the phenomenon of interest (Frasure-Yokley, 2015; Morais, 2010; Stewart \& Shamdasani, 2015).

I used interviews with the women and health providers for several reasons. Firstly, an interview is another way to understand and deeply explore human behaviour (Carter, Bryant-Lukosius, DiCenso, Blythe, \& Neville, 2014) and I aimed to gain information from women and health professionals about husband's actions regarding women's health and cancer. So both focus groups and interviews are suitable for an exploratory study, and combining data from different methods enhances understanding of the phenomenon. Secondly, triangulation in the data collection methods which aimed to bring confirmation of the findings and ensure complete data related to the men's different perspectives of their roles. Thirdly, I 
considered participants' beliefs, especially Muslim women's beliefs, would be related to the Holy Quran, surah Al Baqarah verse 187: "They are clothing for you, and you are clothing for them". This verse explains the close relationship between husband and wife which includes protecting each other such as be exposing their spouse's weakness to others.

\subsection{Setting}

The data were collected in Propinsi Jawa Barat, a West Java province of Indonesia. The study was conducted in this province because the majority of Jawa Barat residents are Muslim (97\%) and therefore it is a Muslim-representative region. This is also the region where I am based at the University of Padjadjaran and facilitating data collection through the University's numerous sector collaborations was convenient for me.

The decision to have urban and rural settings was made because I wanted to know whether Muslim husbands' roles differed where there were different health facilities. The two district sites were Kota Bandung and Kabupaten Pangandaran. Bandung is the capital of the Jawa Barat province and the largest urban area in Jawa Barat. While Pangandaran is a new district of the Jawa Barat province, the infrastructure and facilities are still developing. The following paragraph describes the details of the study sites.

Site 1: The Urban setting, Kota Bandung city has 30 sub-districts, two of which are Cibeunying Kaler and Kiara Condong. I selected these two areas because of accessibility and because they met the urban criteria. From the former sub-district, I chose two villages, Bojong Koneng village, where I live which is representative of a middle-income group, and Babakan Sari village which is a downtown area where mainly people with low incomes live. From the latter sub-district, I chose Sukapura village, which is an area of community nursing fieldwork for the nursing students at my workplace, the Nursing Faculty of the Padjadjaran University. I received permission from the Dean of the Nursing Faculty to use this area as my research site. This village has mixed criteria and includes people of both low and middle incomes. These sub-districts were the locations of the focus groups and the interviews with women. Health professionals' interviews were conducted in the Hasan Sadikin hospital, PHC of Babakan Sari, and PHC of Ahmad Yani. 
Site 2: The rural setting was the Pangandaran district which has 10 subdistricts, one of which is Mangunjaya. I chose Mangunjaya as my study site because it has five villages that all met the criteria of being rural areas according to the Badan Pusat Statistik (the Statistic Centre Bureau) Indonesia. The Camat (sub-district leader) of Mangunjaya informed me that $100 \%$ of the residents in this sub-district are Muslim. Other reasons for choosing Mangunjaya were that it is on the border between West Java and Centre Java, and therefore has two different cultures living together. Also, my colleagues from the Faculty of Nursing were the supervisors of the Kuliah Kerja Nyata Mahasiswa (KKNM), a community service programme for students in this area. These colleagues were available to help me in approaching KKNM students and community leaders. The KKNM students helped me in accessing rural areas, and the community leaders' roles as facilitators in approaching participants.

In the rural setting, I chose five health professionals who worked in five rural health services. They were from three primary health centres (PUSKESMAS), and two of them were from village health posts (POSKEDES). There were no hospital in the rural areas. The highest level of the health services is the PUSKESMAS for subdistricts, and other health services are the POSKEDES and private doctors, nurses, and midwives' services. The three health services were located in the same villages as the focus groups and interview participants, including POSKEDES Jangraga, PUSKESMAS Mangunjaya, and POSKEDES Kertajaya. The other two health services were PUSKESMAS Parigi and PUSKEMAS Padaherang. I chose PUSKESMAS Parigi because it is a referral health service for the Pangandaran district. Finally, I chose PUSKEMAS Padaherang because this health service is the only one near the Mangunjaya sub-district that has had experience of cancer screening services, especially Pap smears, and they invite women from the Mangunjaya sub-district for screening services.

\subsection{Participants}

Participants were recruited using purposive sampling. The inclusion criteria were: Muslim married men and married women and health professionals (aged between 20 and 60 years) living in urban or rural areas. The exclusion criteria were single, widower or widow, and non-Muslim. I had these criteria particularly the 
Muslim/non-Muslim criteria because there are six official religions in Indonesia. Participants were grouped into two age categories; 41 years and over, and 40 years and younger. The age groups were chosen for three reasons. Firstly to address the dynamics in the discussion by having homogeneity of participants (Stewart \& Shamdasani, 2015). The groups took account of the cultural hierarchy in Indonesia between older and younger people. Having a younger and older group would meant that the younger could actively engage in their group discussion. Mixed groups may have limited this because the younger participants may have provided more opportunity to the older participants to share their opinions out of respect for the older participants. Secondly, according to Hasson-Ohayon, Goldzweig, Dorfman, and Uziely (2014) of 300 women and their spouse in two different age categories; 82 middle-aged and younger women (age 54 or younger) found that age influenced the study's result. Thirdly, anticipating an ethical issue, the pre-test informed that the older group shared more knowledge and experience about cancer than the younger group. I was concerned the younger participants may feel ashamed about their lack of knowledge and experience but not be open to share this if they were in a mixed group.

\subsubsection{Recruiting participants}

The first step to approach participants was processing the recommendation letter from my workplace in Indonesia at the Nursing Faculty of the Padjadjaran University. I then sent the letter and other administrative requirements to Badan Kesatuan Bangsa dan Politik (an institution that has legalisation to permit researchers to approach communities) to process my site permission in the province. I needed the permission from the provincial level because I wanted to work in two districts in the West Java province; the Bandung city district and the Pangandaran district. The next step was processing the permission site letters for both districts. Using these permission letters I could access participants in communities and health institutions legally (Appendices 1-5). To access the potential participants, the first step involved engaging the community leaders. In Indonesia, especially in rural and downtown areas, the community leader has a significant role in what happens in their community. They are the representative of the community. As a result, everything that outsiders (non-local) want to do with community members should be first approved by the leader. The leaders have responsibilities to protect and help the 
community in many aspects including health. Even though participants were chosen by a community leader, their participation in this study was voluntary as the consent process occurred after the leader had introduced the participant to me. It is not known whether any person the community leader approached to participate in the study declined participation.

Urban participants. In approaching urban participants, I took several steps. First, I went to the community leader in a downtown area of Babakan Sari village, near my residence. I knew this community leader as we had met several times at community gatherings. I visited him in December 2014 and explained my study. He was very welcoming and willing to help me invite men from the two age groups: 41 plus and up to 40, living near his house. He informed me that I could do a focus group on December $12^{\text {th, }} 2014$ for the older group and on December $20^{\text {th, }} 2014$ for the younger group. He also introduced me to three women from the area to participate in my research. Second, I gained permission from my residential coordinator to involve a group of men from Bojong Koneng, my village. The residential coordinator supported me by providing contact numbers for men 41 years and over, and I then communicated with them via telephone. Nine men agreed, and the focus groups were conducted in January 2015. I also invited a woman neighbour who matched the participant criteria to participate in an interview.

The next focus groups were two groups in Sukapura village. My colleague, who was the clinical instructor of community nursing in this area, helped me to meet the community leader. The community leader permitted me and offered to help by inviting his residents to participate in this study. The focus group was conducted in December 2014 with the younger group of men, and in February 2015 with the older group. The community leader also provided information about three women who were eager to be interviewed based on what the leader's wife had shared about my research. My colleague also introduced me to three women from a middle-income area and to two midwives from two PHCs in the Bandung area, all of whom agreed to be interviewed.

For health provider participants in hospitals, I went to the Hasan Sadikin Hospital a referral hospital for West Java region and a teaching hospital for students from several institutions including the Faculty of Nursing at the Padjadjaran University. Before I commenced study at Victoria University of Wellington, New Zealand, I was a coordinator of students' fieldwork for the Maternity Nursing course 
in the Hasan Sadikin hospital. Initially, I met with the head of the gynaecology and oncology department at this hospital and described my research. She identified two midwives and a nurse specialist in maternity nursing for potential interview. All consented to participate and these interviews took place in the hospital in December 2014 and January 2015.

Rural participants. To approach rural participants, I went to rural areas in the Pangandaran district in January 2015 and stayed for six weeks. Using the permission letter from the BKBP of West Java, I visited the BKBP of the Pangandaran district to process the site permission letter for my data collection. I stayed in Jangraga village, which is part of the Mangunjaya sub-district. I introduced myself to the community leaders from three different villages (Jangraga, Mangunjaya, and Kertajaya). In this sub-district I was accompanied by a KKNM student who was known to them. I explained my purpose and the leaders accepted it and helped me to invite men and women to participate in the study. In rural areas, the community leader has considerable influence in the community. Members of the community would attend an event when invited by the leader. The community leaders in three villages helped me to invite men and women based on the participant criteria, and they also decided the date and venues of the focus groups and interviews.

In choosing five health professionals from rural areas, I had recommendations from the head of PUSKEMAS and the village leaders. I went to three PUSKESMAS and met the heads of these health services. I explained my study aims and discussed the characteristics of health professionals who could participate in my study. They chose one health professional in every PUSKESMAS and introduced them to me. All PUSKEMAS leaders in this sub-district were male, and they chose female health professionals for the interviews. This may have been chosen because women's health professionals manage health programmes related to women's health in the PUSKESMAS. In addition, another two health professionals were chosen based on the leaders of the villages' recommendations, especially for Jangraga and Ketajaya village.

\subsubsection{Final sample}

The total number of participants was 103, including 73 men (11 groups), 20 women, and 10 health providers. Of the 11 focus groups with the men, five were in urban areas, and six in rural areas. The urban groups comprised three groups of men 
41 years or more and two groups of men 40 years or younger. In the urban areas, I also divided the men into two groups - low and middle incomes. These latter groups were identified by the areas in which participants lived. The low income group in urban areas included two groups of the older men and one group of younger men. The middle-income groups in urban areas included one group of the older men and one group of the younger men. In the rural areas, the groups consisted of three groups of men 41 years or more, and three groups of men 40 years or younger. In the rural area, I did not divide participants according to income because their living situations were not significantly different. The details of the participants' characteristic are presented in the findings.

\subsection{Instrumentation}

The development of data collection tools were theoretically informed from the Basic Model of Religiosity and Health (BMRH) (Masters, 2008), the Health Belief Model (HBM) (Hayden, 2009) and the Help-Seeking Behaviour and Influencing Factors Framework (HSBIFF) (O'Mahony \& Hegarty, 2009; O'Mahony, McCarthy, Corcoran, \& Hegarty, 2013). From these theories, I identified areas of questions that would be useful to explore Muslim husbands' roles in women health and cancer, including socio-cultural, emotional and psychological factors, knowledge and illness concepts, and health services.

Five data collections tools were used in this study including a focus group guide, an interview guide for women, an interview guide for health professionals, a social demographic survey for all participants, and a note-taking form (Appendices 6-10). All instruments were developed in English and then translated into Indonesian. The focus group and interview guides had similar topics but the questions were tailored to the particular participant group. Before the tools were finalised, I began by developing the tool for pre-testing which included the social demographic survey, a semi-structured focus group guide for the men, semistructured interview guides for the women and a qualitative survey of women's knowledge (Appendices 11-14). After the pre-test, I evaluated all instruments and made revisions, including removing the women's knowledge tool from data collection. The detailed changes are presented in the pre-test sub-heading. 
This instrument included four main areas of questions. Firstly, I explored men's behaviour in women's health in general and then in cancer. This section of the focus group and interview schedule guided me to gather data about Muslim men's involvement in their wives' health whether the women were healthy or sick. For example, one question asked "What is your involvement in your wife's health?" The interview question for women, for example, "Tell me, the type of role your husband has for your health". Secondly, I gathered information related to socio-cultural factors of husbands that may affect their behaviour. These included their knowledge of women's cancer, beliefs, health services and their experience with cancer. For example, asking participants experience of women's cancer in their family, colleagues, relatives, or neighbours, and the impact of cancer experience on their behaviour. Similar question were asked of women participants. Next, the participants were asked about their understanding and perception of women's cancer. Finally, I explored men's experience and expectation of women's health services, including health programmes for men.

The social demographic survey was developed to gain information about participants' social and demographic backgrounds. This instrument asked participants their age, marital status, education and occupation, number of children, personal and family history related to cancer. The participants filled this survey in before the focus groups or interviews. The note-taking form was developed to help me recall the process and interactions in the focus groups. A novice researcher like myself needed a note instrument that was easy to complete as a record of what happened in the group.

The guides aimed to capture questions and topics that would lead to uncovering husbands' roles from different perspectives about the research question. The content of the data collection tools were approved by both supervisors as tools that would generate credible and dependable information about men's roles in women's health and cancer.

\subsection{Procedure}

\subsubsection{Pre-test}

To anticipate issues regarding the methods in this study, I carried out pre-tests with men and women from the Indonesian Muslim community in Wellington. A pretest is a trial of the instrument to determine whether the instruments are understood 
by participants and do not bias participants' contribution (Polit \& Beck, 2014). The pre-test in this study had objectives that focused on the research instruments, the processes of using them, and who should be the moderator of the focus groups. The objective related to the focus groups and interview guides was to ensure that the nature of the questions was acceptable to Muslim men and that the focus groups and interviews would generate data that would answer the research question. The pre-test also included looking at interview times, numbers of participants in a focus group, and time required for a focus group and ne interview. The objective regarding processes concerned establishing whether a woman could be a focus group moderator. Establishing how Muslim men would respond to a female researcher was important given the different roles of men and women in Islam society that were discussed in Chapter 2.

The focus groups pre-tests were conducted with two groups of New Zealandbased married Muslim men. These participants were recruited with the assistance of the president of the Indonesia Muslim Association (UMI) whom I had contacted, discussed my study with, and asked for his permission to conduct a pre-test. He gave permission and provided the contact numbers of UMI members who met the pre-test criteria including those older and younger than 41, married, living in Wellington, and who might volunteer to participate. Based on the UMI information, I texted 12 potential male participants. Some replied others did not. I followed up my text by meeting those who replied individually to inquire about their availability in the pretest at the UMI monthly event in October 2014. I also arranged for a male $\mathrm{PhD}$ candidate from Indonesia, who was studying at Victoria University, to be a focus group moderator in the pre-test. Preparing this moderator involved familiarising him with the focus group questions, venue and equipment (note-taking form and a taperecorder).

Seven married Muslim men aged 41 years and over, attended and responses of this discussion were tape-recorded. I was the note taker and observer and provided some refreshments before and after the focus group. The focus group schedule was the draft schedule with one additional question concerning the gender of the moderator. The responses to the questions indicated that the schedule would generate appropriate data. This group commented that having a male moderator was good, but a female moderator would be acceptable; the most important thing was that the moderator could communicate effectively with the participants. 
Based on the first pre-test, I was the moderator in the second focus group pretest, and the $\mathrm{PhD}$ student was the note taker. The second group was small, three married Muslim men, aged 40 years and under. The process was quite similar to the first group. The participants also said that the gender of the moderator was not important; the most important thing was that the moderator is familiar with the questions. One participant considered that it is also important for the moderator to have expertise on the topic of the research, namely women's health. Both groups provided a lot of information about Muslim husbands' roles in women's health and cancer. Following the two focus groups, I obtained the perspective of the male $\mathrm{PhD}$ student moderator about the effectiveness of each of the groups for gathering data. He too considered a woman could safely moderate the groups.

I learned some strategies from the pre-test about the roles of a moderator in conducting a focus group. These included: developing questions, managing times, note taking, controlling my questions, and transcribing focus group data. In my opinion, the big group (seven people) was more dynamic and interactive than the small group (three people). I could obtain answers to all the questions from both groups but the small group was less interactive. From this pre-test, I obtained information that showed different experiences between the younger and older participants with regard to women's health. The differences were not only in the way older men took care of their wives but also included their experiences of cancer, especially regarding early detection or treatment. These focus group pre-tests informed the data collection process in Indonesia, such as the number of people in a group, the focus group moderator, the ages of a group, suitable times for conducting a focus group, and that the male participants would want some information about women's cancer.

The pre-test of the interviews with women was conducted with two married Indonesian Muslim women living in Wellington in October 2014. The first woman who was younger than 40 was interviewed at her home, and the second woman who was older than 41 was interviewed at a café. The interviews were approximately 30 45 minutes. The pre-test guided my interview process in Indonesia, including revising the socio-demographic survey, particularly the occupations, and I made a decision to omit the survey about women's cancer knowledge because they took long to fill in. I also felt the first woman who participated in the interviews did not enjoy the interview because she was worried about her answers not being correct regarding 
her knowledge of women's cancer. In the interview pre-tests I gained some insights into how not to question, how to be a good listener, and the importance of remaining silent until people had completed answering a question.

The data from the pre-test were not used in the analysis because the main aim of this pre-test was to a trial focus group and interview methods, and to survey demography and cancer knowledge questions. In addition, Indonesia and New Zealand are different countries and have many differences, including the economies, social culture, the health system, and the health facilities. Women's cancer promotion and prevention programmes in New Zealand are established, for example, there are regular recalls from health services to remind women about screening, and cancer advertisements on television. While Indonesia's health system and facilities are totally different, especially women's cancer services, so Indonesian Muslim husbands who live in New Zealand face different challenges that may influence husbands' roles.

\subsubsection{Data collection in Indonesia}

I am the primary researcher in this study, and for the data collection in Indonesia, I was the moderator for all focus groups and also the interviewer for women and health professionals. Three types of facilitators helped me in the data collection. They were community leaders, and two males - a KKNM student and a family member. The community leaders were facilitators in approaching participants. Their roles included identifying the potential participants in rural and downtown sites, contacting them, providing venues, and deciding focus groups or interview dates and times. The leaders have significant roles in Indonesia, especially in rural and downtown areas. They are facilitators between the Indonesia government and citizens for many programmes. For example, in the health area, when the government launches a new health policy, the government officers invite community leaders to a meeting where the policy could be introduced to them, and then the leaders inform the communities. Other roles of community leaders are as helpers and advisors when communities face problems or need advice, such as when a patient needs to go to a referral hospital in the city, and the patient's family is confused about administrative procedures, transportation, or even finances. The leaders are chosen by local communities, and are representative of those communities; some are local government officers others are religious leaders. 
I hired a male student as my note taker when I gathered data in rural areas. He was a student who joined the KKNM programme. He arrived and started the KKNM two weeks before my data collection. He was familiar with the road conditions, especially damaged roads, routes to connect one village to another, areas with high risk of crime because there are insufficient lights on the roads, and he was accepted by rural communities, as KKNM students develop and manage community services. I needed the student's help because this was the first time I had visited and stayed in these rural areas. I did not know the roads, the safety and the culture of people in this sub-district. I thought I needed an assistant to help me if unexpected situations happened on my trip or during the discussion process. I chose him as my guard because in Indonesian culture, student and teacher relationships are like children and parents and I believed he would help and protect me if something happened. Finally, a family member, my husband, was also part of my study team. He helped me in five focus groups as the note taker in urban areas.

To address the study' objectives, the final semi-structured focus group and interview guides covered topics about Muslims' husband's roles in women's health and cancer. Topic areas included husbands' involvement in their wives' general health and health's issues, experiences and knowledge of breast and cervical cancer, women's health services expectation, and actions or potential actions in women's cancer. Every topic included prompts that aimed to stimulate participants to be active involved in providing opinions in focus groups or interviews (Appendices 6-7).

In summary, the data collection in Indonesia involved the following steps:

1. I visited the community leaders to discuss accessing participants for the focus groups and the interviews in rural and downtown areas and visited the resident coordinator for the middle-income groups. The community leaders helped me to access residents because they knew their community, and they also invited the participants while the resident coordinator provided the phone numbers of the potential participants.

2. I negotiated the times and places for the focus group and interviews with community leaders. The rural venues included four focus groups in four community leaders' houses and two in "Balai Desa" (a village office). The interviews with the rural women were held in the POSYANDU Jangraga $(n=4)$, 
Kuwu's (people called the village leader in Kertajaya) house $(n=4)$ and at Balai Desa Mangunjaya $(n=2)$. The interviews with the rural health professionals were held in the midwife's house in Jangraga village, and a POSKESDES for the midwife from Kertajaya. Other health professionals' interview sites were PHC Mangunjaya, PHC of Padaherang, and PHC Parigi.

In urban areas, I conducted five focus groups, three of which were in three community leaders' houses, and two were in Balai $R W$ (a community centre). The women's interviews were conducted mostly in participant's houses, and the health professional's interviews were in the Hasan Sadikin hospital, PHC of Babakan Sari, and the PHC of Ahmad Yani.

3. The data collection processes for the focus group included explaining the study to the participants, asking for their agreement, and obtaining their informed consent. The participants filled in the sociodemographic survey before each focus group. I was the moderator for all focus groups $(n=11)$. The duration of the audio-taped focus groups was approximately 60-90 minutes, and they were conducted in the Indonesian language. After the data collection was completed, many participants asked about the signs, symptoms, causes, prevention, early detection, and therapy for breast and cervical cancer. In anticipation of this (from my pre-test experience), I distributed pamphlets about these diseases that I had obtained from the Hasan Sadikin hospital. I also provided food and a mug as a gift.

4. The process of women's interviews included introducing myself to participants, explaining the study's aims, and asking for their informed consent. This interview was intended as an individual interview. However, because I respected the Muslim's belief that a husband or wife are not normally allowed to talk about their family relationships to a stranger I offered participants the opportunity to have somebody accompanying them. Eight of the 20 women preferred a peer interview (two women in an interview). Before interviews, participants filled in the sociodemographic survey. The audio-taped interviews were approximately 30-60 minutes. When the interview was 
completed, I provided food and a goodie bag with an NZ logo as a gift to each participant.

5. When interviewing health professionals I employed the same steps as the women's interviews. Health professionals preferred an individual interview. The interview took approximately 60-90 minutes. After the interview I also provided refreshments and a gift for the participants.

6. Following each focus group and interview, I wrote a summary of the data. The summaries included my evaluation of the process of the focus groups and interviews. For example, time management, participants' responses to the questions, and interview strategies. I also discussed with the note taker about the process of the focus group and checked whether the process aligned with the information sheet, and the focus group guide.

\subsection{Data processing and analysis}

The analysis process commenced with each focus group and interview being transcribed by me. The transcriptions were in the Indonesian language, and I translated them into English (Appendix 15). The primary supervisor read all the English translation as part of peer checking. Considering the huge volume of data, that both focus groups and interviews were used, the low level of interpretation in the descriptive exploratory approach, and the limited study time, no member checking or back translation was used in the data analysis. The sociodemographic survey data were collated into five tables that are presented in the relevent findings chapter. Two tables contained the participants' characteristics from the urban areas, two from rural areas, and one from the health professionals. The details of the focus groups were focused on their family situations, and the health professionals' information was coded relating to their professional roles. Details included the number of participants in each focus group, their ages, number of children, years of marriage, personal or family history of cancer, education, and occupation.

Three sources informed the data analysis methods for the focus groups and interviews: F. Rabiee's recommendation (Rabiee, 2004), the Qualitative Analysis Guide of Leuven (QUAGOL) (Dierckx de Casterle, Gastmans, Bryon, \& Denier, 
2012), and Content Analysis in Nursing Research (CANR) (Graneheim \& Lundman, 2004). Most researchers combine some sources in data analysis to make it applicable to their study (Green \& Thorogood, 2004). In this study, integration of sources was useful in supporting the data analysis process because the details for each step complement each other. The steps of data analysis of these three sources are summarised in Table 3.

Table 3. The sources of the data analysis method

\begin{tabular}{|c|c|c|}
\hline F.Rabiee's recommendation & QUAGOL & CANR \\
\hline $\begin{array}{ll}\text { Eight steps } \\
\text { 1. Words } \\
\text { 2. Context } \\
\text { 3. Internal consistency } \\
\text { 4. Frequency } \\
\text { 5. Intensity of comments } \\
\text { 6. Specificity of responses } \\
\text { 7. Extensiveness } \\
\text { 8. } & \text { Big picture }\end{array}$ & $\begin{array}{l}\text { 1. Preparation for coding } \\
\text { - Rereading of interviews } \\
\text { - Narrative interview } \\
\text { report } \\
\text { - From narrative to } \\
\text { conceptual interview } \\
\text { - Fitting-test of } \\
\text { conceptual interview } \\
\text { scheme } \\
\text { - Constant comparison } \\
\text { process } \\
\text { 2. Undertake coding using } \\
\text { a qualitative software } \\
\text { program } \\
\text { - Draw up list of concepts } \\
\text { - Coding process back to } \\
\text { the "ground" } \\
\text { - Analysis of concepts } \\
\text { Extraction of the } \\
\text { essential structure } \\
\text { Description of the } \\
\text { results }\end{array}$ & $\begin{array}{l}\text { The steps of content } \\
\text { analysis of interviews } \\
\text { 1. Meaning unit } \\
\text { 2. Codes } \\
\text { 3. Subcategories } \\
\text { 4. Category } \\
\text { 5. Theme }\end{array}$ \\
\hline
\end{tabular}

The procedures of these three sources have similarities in the steps of qualitative data analysis, including precoding processes, coding, and formulating themes. However, each provides different details and explanations for each step of analysis. For example, F. Rabiee's recommendation describes details of the steps of focus group data analysis especially with regard to the precoding process; however, this source has no clear step that informs the connection between focus group data with the research questions which the QUAGOL has. The QUAGOL involves a software program in the coding process which was suitable for this study because the study contained massive amounts of data (Dierckx de Casterle et al., 2012). In 
addition, the F. Rabiee's recommendation is not suitable for individual interview data as her framework tends to evaluate the group interactions based on the transcribed text.

\subsubsection{The analysis of focus group data}

The analysis method for focus groups was developed based on two sources: the F. Rabiee recommendation and the QUAGOL. Some modifications of these approaches were applied in this study. Some steps from each of the two sources were integrated, to form the analysis process which I named the Comparative Analysis for Focus Group (CAF). Table 4 describes the steps in the CAF process.

Table 4. Comparative analysis for focus groups

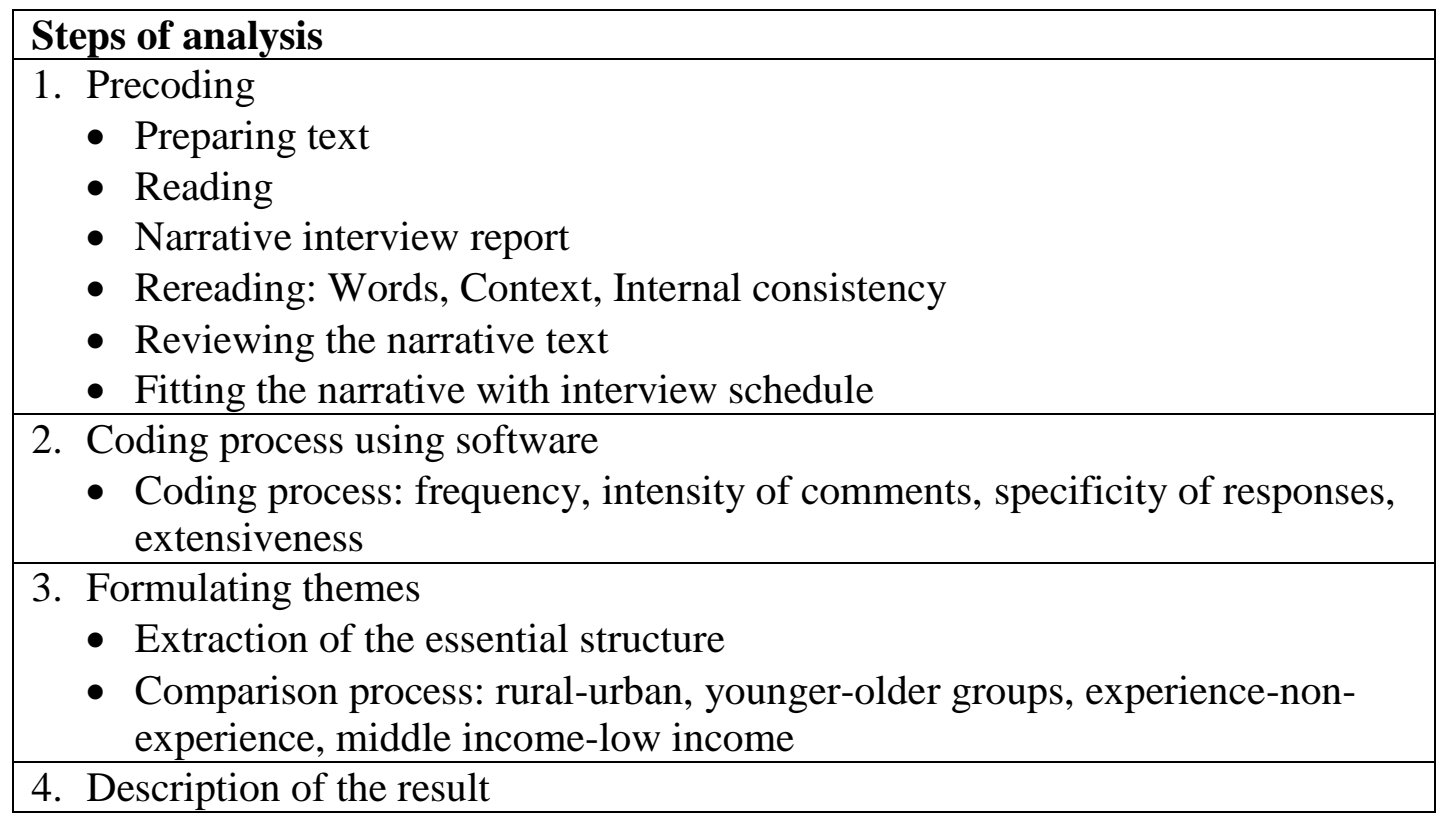

The analysis is divided into four main steps: precoding, a coding process using software, formulating themes, and descriptions of the results. The precoding step included preparing text such as the printed text and pencils, reading the text a minimum of three times for each transcription and marking participants' meaningful comments, and writing a summary of the text report in my own words. The written summary was based on participants or groups' main ideas. Next, I reread the text to ensure that I had paid attention to participants' significant words, understood the context behind participants' comments, and reviewed the consistency of these comments. The final step before moving to the software program involved fitting the 
text to the interview schedule. In this step, I made three types of files. The first was a file for each group's answers by question. Next, I developed files for the urban and rural groups. These contained the questions and answers from all the urban and rural participants. Thirdly, I categorised the focus group questions and included the participants' comments for each category. For example, comments in response to "Please share what your involvement was in your wife's health generally" were filed under the category men's behaviour. I then printed these files and used them for the coding using the software program. The precoding processes were useful for me to understand the contents of each group's text, and they provided a general picture of the differences in the information between the urban and rural participants.

The next step was coding, using the software program, NVivo 10. In this process, I used files from the pre-coding step and entered the categories from them as nodes. I read participants' comments for each category and coded and developed sub-nodes for similar ideas: according to frequency, the intensity of comment, specificity of responses, and extensiveness. Table 5 presents an example step of analysis from precoding to coding using software NVivo 10.

The third step was formulating themes. I printed nodes and sub-nodes from the NVivo 10 program, and then read and analysed them. I grouped these into four groups: men's actions, health services-related issues, influencing factors (such as information, education), and communication. This process also included extraction of the essential structure, and comparison of data based on the rural-urban areas, younger-older groups, experience-non-experience, and middle and low incomes. 
Table 5. The example of analysis steps from precoding to coding using software

\begin{tabular}{|c|c|c|c|c|c|c|}
\hline No & Name & $\begin{array}{l}\text { Page } \\
\text { Lines }\end{array}$ & Quotes & NVivo Node & Subnodes & $\begin{array}{c}\text { Sub- } \\
\text { subnodes }\end{array}$ \\
\hline 1 & $\mathrm{XX1}$ & $2 / 70$ & I took her to the doctor & \multirow[t]{3}{*}{$\begin{array}{l}\text { Men's } \\
\text { actions in } \\
\text { women's } \\
\text { health }\end{array}$} & \multirow[t]{3}{*}{$\begin{array}{l}\text { Actions } \\
\text { because of } \\
\text { wife's } \\
\text { health } \\
\text { problems }\end{array}$} & $\begin{array}{l}\text { Visiting } \\
\text { health } \\
\text { services }\end{array}$ \\
\hline & & $88-89$ & $\begin{array}{l}\text { For me, when my wife } \\
\text { was sick, I asked her, } \\
\text { would you prefer a } \\
\text { "Mantri" (a registered } \\
\text { nurse, commonly a } \\
\text { man) or a doctor? And } \\
\text { if she answered "wait } \\
\text { a moment", it was up } \\
\text { to her, she was the } \\
\text { patient who feels the } \\
\text { symptoms. }\end{array}$ & & & $\begin{array}{l}\text { Empowering } \\
\text { women }\end{array}$ \\
\hline 2 & $\mathrm{XX} 2$ & $2 / 73$ & $\begin{array}{l}\text { I took her to the } \\
\text { hospital, eeh I mean } \\
\text { the doctor } \\
\text { But if her symptom was } \\
\text { mild, such as body } \\
\text { sore, I did massage. }\end{array}$ & & & $\begin{array}{l}\text { Visiting } \\
\text { health } \\
\text { services } \\
\text { Traditional } \\
\text { therapy }\end{array}$ \\
\hline
\end{tabular}

4.8.2 The analysis of interview data

The steps for the analysis of the interview data were similar to the focus groups analysis. The method was informed by the CANR and QUAGOL methods of qualitative data analysis. I chose the CANR because it is appropriate for analysing data with low levels of interpretation, including descriptive exploratory study (Vaismoradi, Turunen, \& Bondas, 2013), and it is suitable for analysing a study that has not been extensively explored (Green \& Thorogood, 2004). The QUAGOL, on the other hand, is useful for managing enormous amounts of data. Data from the interviews were reasonably large, because the interviews were with 20 women and 10 health professionals. Therefore, steps from CANR and the QUAGOL were combined for analysis of the interview data. The process for this analysis was named the Comparative Analysis for Interviews (CAI). Table 6 shows the steps of the CAI analysis process. 
Table 6. Comparative analysis for interviews

\begin{tabular}{|l|}
\hline Steps of analysis \\
\hline 1. Precoding \\
- Rereading \\
- Meaning unit \\
- Narrative interview report \\
- Reviewing the narrative text \\
- Fitting the narrative with interview schedule \\
\hline 2. Codes \\
- Coding process using software \\
- Sub categories \\
- Category \\
\hline 3. Formulating themes \\
- Comparing between rural and urban, and other cultural attributes \\
\hline 4. Description the result \\
\hline
\end{tabular}

The CAI process is divided into four main steps including precoding, coding using software, formulating themes, and descriptions of the results. The precoding steps include rereading the interview transcriptions several times to discern the main idea and then notice the units' meanings. I read each transcription three or four times and marked the meaning unit, and then I wrote summaries in Bahasa Indonesia for each. The contents of each summary included general views of each transcription and the details of participants' answers based on the semi-structured guide. The next step was a review of the narrative text to enhance my understanding of the participants' information. The final step of precoding fitted the narrative with the interview schedule. I developed two types of files: a file of the contents of each woman and each health professional's questions and their answers at the interviews; files containing data of urban and rural group. The questions and answers from all urban or rural participants were included in these files. I then printed these files and used them for coding processes using the software program.

The second step was to code the data using the NVivo 10 software and to group the data into subcategories and categories. I began with the urban data and continued with the data from the rural areas. The third step was formulating the themes by reading and analysing the subcategories and categories. This process also includes the comparison of data based on the rural and urban areas and cultural characteristics. Finally, presenting the finding themes. 


\subsubsection{Integrating findings themes}

The final step was to triangulate all the study's findings. I collected all the themes from the three data sources and integrated them. These became the main categories. There were five themes from the husband participants, four from the women participants, and four from the health professionals. I analysed the similarities and differences amongst the themes and grouped them into three categories because of the partial interrelationships of themes each of the 13 themes had its characteristic. For example, the influence of society and culture on Muslim husbands' behaviour category emerged from the themes that were a part of the influencing Islamic sociocultural teaching on shaping men's behaviour (men's theme). Islamic teaching impacts on men's actions in women's health (women's theme), and sociocultural factors (for example, age, occupations, religiousness) influenced men's behaviour in women's health behaviour (health professionals' theme). I was unable to make these one theme because men and women did not mention age or occupation as factors that shape their behaviour.

\subsection{Ethical considerations}

Ethical considerations aim to protect participants' right from any harm. For example, embarrassments, emotional confusion, or ignoring confidentiality (Creswell, 2014; Grbich, 1999; Polit \& Beck, 2014). Ethical approval was obtained from the Human Ethics Committee (HEC) of Victoria University, Wellington (Appendix 16, HEC, 21192). Several information sheets were designed to protect participants (Appendix 17). These provided clear information about this study and were a way to protect participants and ensure they understood the data collection processes. The information sheets addressed the support that could be given if people got distressed in the interviews and described that the confidentiality of people including if they named any third parties, such as family members, health professionals or patients would be protected.

Informed consent (Appendix 18) was obtained from all focus group and interview participants prior to their participation in the study. Although many of the husbands and wives participating in the research came via the community leader, I had checked that it was their choice to participate. Similarly, the health professionals whose employer put them forward could also decline from consenting. Participating 
in this study was voluntary, and interview participants were informed that they were able to withdraw at any time up to the analysis process. In the focus groups, the men were made aware that while they could withdraw during the group interviews, the information they had already shared would remain part of the group's data. Further, the consent explained that the researcher would keep the data confidential. To address confidentiality, I also developed a moderator's confidentiality form during the pre-test (Appendix 19).

In presenting these study findings, I managed confidentiality of participants by changing their groups and names to initials. For example, A1, A means he is from the Babakan sari group, 1 means his XX. It also applied for women and health professionals participants. The details characteristic of participants are presented on chapter 5, 6, and 7. The details of the focus groups and participants' opinions were not shared with the community leaders.

\subsection{Considerations of rigour}

This study applied Lincoln and Guba's quality criteria (Creswell, 2014; Houghton, Casey, Murphy, \& Shaw, 2013; Lincoln, 1985; Polit \& Beck, 2014). Their four criteria for developing trustworthiness are credibility, dependability, confirmability, and transferability. Table 7 summaries the actions taken to affirm trustworthiness in the study.

\section{Table 7. Steps to confirm the trustworthiness}

\begin{tabular}{|l|l|}
\hline Credibility & $\begin{array}{l}\text { Prolonged engagement, audio-taping and verbatim } \\
\text { transcription, saturating data, member checking, data cleaning, } \\
\text { peer review }\end{array}$ \\
\hline Dependability & $\begin{array}{l}\text { Careful documentation, member checking, stepwise } \\
\text { replication, inquiry audit }\end{array}$ \\
\hline Confirmability & $\begin{array}{l}\text { Careful documentation, development of a codebook, peer } \\
\text { review of triangulation data sources, inquiry audit }\end{array}$ \\
\hline Transferability & $\begin{array}{l}\text { Saturation data, documentation of quality-enhancement } \\
\text { efforts, thick, vivid description }\end{array}$ \\
\hline
\end{tabular}

Credibility is related to internal validity, and also the completeness of data from different perspectives (Lincoln, 1985; Polit \& Beck, 2014; Shenton, 2004). I wanted to make sure that my study's instrument and data collection processes worked as I had planned. This included developing trust with the participants, tape recording all the processes of data collection, note taking, discussing with note takers 
to clarify and evaluate the data collection processes, using quotations to support the analysis and discussions with supervisors as peer reviews.

The second criterion was dependability which relates to reliability (Lincoln, 1985; Polit \& Beck, 2014; Shenton, 2004). In this study, I had 11 focus groups, 20 female and 10 health professional interviewees. I ensured that each of the focus group processes were similar. I also ensured this applied to the interviews. I did focus group and interview process pre-tests on preparing and practising as a moderator and interviewer respectively. I evaluated and discussed the pre-tests with my supervisors and made some changes to the data collection procedures. I followed the data collection procedures and guidelines, documented appropriately for each focus group and interview, was accompanied by the same note taker for each area, and reported and evaluated these processes to my supervisor periodically via email. In addition, the data analysis from precoding to themes was documented in Word and NVivo files. The processes and changes of data analysis were all documented.

The third aspect is confirmability. The aspect is related to the objectivity of a study and the data (Lincoln, 1985; Polit \& Beck, 2014; Shenton, 2004). To reduce my influence, I gathered data about husbands' roles in women's health and cancer using triangulation of data sources which is men, women, and health professionals. I reported and discussed with my supervisors every focus group and interview process. My supervisors checked and read the focus group transcriptions, and we worked together regularly to analyse the data. Transferability in this study means to make the study's characteristics and processes clear so that others can determine whether they are applicable to their setting (Lincoln, 1985; Polit \& Beck, 2014; Shenton, 2004). I have provided data collection procedures, clear inclusion and exclusion criteria of participants, focus groups and interview guidelines for the moderator, and information about the study throughout this chapter.

\subsection{Summary}

As information about Muslim husbands' roles relating to women's health and cancer is limited, I applied a descriptive exploratory methodology using focus groups and interviews for this research. This methodology and these methods are suitable for uncovering a phenomenon about which little is known or understood.

Participants in research can be purposively selected, which for this research involved recruiting participants from urban and rural settings. Engagement by rural 
participants was dependant on the community leader's involvement, whereas in the urban areas, especially among the middle-class groups, the researcher could contact people directly.

All instruments were useful for the data collection processes. The information sheet, informed consent form and semi-structured questions guided the focus group and interview process. The note-taking form guided the transcription process, and Breast and Cervical Cancer pamphlets were useful for covering participants' questions about both cancers. Pretesting of focus groups and interviews were beneficial to the data collection process in Indonesia. From the pre-test, I obtained appropriate guidelines for data collection, and more confidence to guide the community focus groups and ask questions in interviews. Several steps from existing tools for the data analysis of the focus groups and interviews were combined. This integration aimed to support the analysis of the data from different methods of data collection and was appropriate for the study's objectives. The right of participants in this study was protected, and trustworthiness of this research was confirmed. 


\section{Chapter 5. Men's Perspectives of Their Roles in Women's Health and Cancer}

\subsection{Introduction}

This chapter describes the findings from the 11 focus groups of married Muslim men. The study's findings of the interviews with married Muslim women are presented in Chapter 6, and those from the interviews with the health professionals are reported in Chapter 7. The focus groups were undertaken in urban and rural areas to address the following objectives: 1) to uncover Muslim husbands' roles regarding women's health and cancer, and 2) to identify whether there are differences in understandings, perceptions and expectations related to geographical location, age or other social, health or cultural characteristics. The first section of this chapter introduces the characteristic of participants. This is followed by presentation of the five themes that emerged from the Muslim husbands' data. The final section presents a conclusion.

The five themes emerged from the data analysis of all groups of men. These themes are illustrated by men's quotes based on the comparative analysis of focus group data. The comparison included urban and rural, older and younger, those who have and have not had experience of cancer, and middle and low-income groups. The themes are: 1) Islamic teaching shapes husbands' roles in women's health and cancer; 2) Husbands' roles are primary in many aspects of women's health and cancer; 3) Experience and knowledge influences husbands' perceptions and awareness of cancer; 4) Barriers exist in husbands' roles in women's health and cancer, and 5) Husbands' power and powerlessness reflects health service context.

\subsection{Characteristic of participants}

Seventy-three men attended one of 11 focus groups; each group comprised 5-8 participants. The groups originated from urban and rural areas. None of the men had been diagnosed with cancer, but 11 had a family history of cancer. The urban groups included men from middle incomes who lived in an elite residential area and men on low-incomes who lived in slums areas. Table 8 describes the characteristics of participants from urban areas, and Table 9 those for rural areas. 
Table 8. Characteristics of focus group participants in urban areas

\begin{tabular}{|c|c|c|c|c|c|c|c|c|c|}
\hline No & Group & Age & $\begin{array}{c}\text { Child } \\
\text { no }\end{array}$ & $\begin{array}{c}\text { Years } \\
\text { Married }\end{array}$ & $\begin{array}{l}\text { History } \\
\text { Cancer }\end{array}$ & $\begin{array}{c}\text { Friends } \\
\text { with } \\
\text { cancer }\end{array}$ & $\begin{array}{l}\text { Family } \\
\text { Cancer }\end{array}$ & Education & Occupation \\
\hline 1 & A1 & $>41$ & 3 & 37 & No & No & No & ES & Handyman \\
\hline 2 & $\mathrm{~A} 2$ & $>41$ & 3 & 30 & No & No & Sister & JHS & Employee \\
\hline 3 & A3 & $>41$ & 2 & 35 & $\mathrm{No}$ & No & No & JHS & Jobless \\
\hline 4 & A4 & $>41$ & 2 & 38 & $\mathrm{No}$ & No & No & ES & Handyman \\
\hline 5 & A5 & $>41$ & 3 & 38 & No & No & No & $\mathrm{ES}$ & Handyman \\
\hline 6 & A6 & $>41$ & 2 & 37 & No & No & No & $\mathrm{ES}$ & Handyman \\
\hline 7 & A7 & $>41$ & 3 & 40 & No & No & No & $\mathrm{ES}$ & Handyman \\
\hline 8 & E1 & $>41$ & 1 & 20 & No & Yes & No & UN & Government Officer \\
\hline 9 & $\mathrm{E} 2$ & $>41$ & 5 & 19 & No & Yes & Relatives & UN & Businessman \\
\hline 10 & E3 & $>41$ & 2 & 25 & No & Yes & Sister & UN & Employee \\
\hline 11 & E4 & $>41$ & 4 & 10 & No & Yes & Relatives & UN & Employee \\
\hline 12 & E5 & $>41$ & 3 & 15.5 & No & Yes & Relatives & UN & Businessman \\
\hline 13 & E6 & $>41$ & 2 & 13 & No & Yes & No & UN & Employee \\
\hline 14 & D1 & $>41$ & 2 & 31 & No & Yes & No & SHS & Government Officer \\
\hline 15 & D2 & $>41$ & 5 & 24 & No & Yes & No & SHS & Handyman \\
\hline 16 & D3 & $>41$ & 4 & 30 & No & Yes & No & JHS & Employee \\
\hline 17 & D4 & $>41$ & 5 & 24 & No & Yes & No & $\mathrm{ES}$ & Businessman \\
\hline 18 & D5 & $>41$ & 2 & 30 & No & Yes & No & JHS & Businessman \\
\hline 19 & D6 & $>41$ & 2 & 17 & No & Yes & No & SHS & Employee \\
\hline 20 & D7 & $>41$ & 2 & 20 & No & Yes & No & SHS & Employee \\
\hline 21 & D8 & $>41$ & 3 & 32 & No & Yes & No & JHS & Employee \\
\hline 22 & B1 & $\leq 40$ & 3 & 12 & No & No & No & SHS & Employee \\
\hline 23 & B2 & $\leq 40$ & 1 & 3 & No & No & No & SHS & Employee \\
\hline 24 & B3 & $\leq 40$ & 1 & 4 & No & Yes & Relatives & SHS & Employee \\
\hline 25 & B4 & $\leq 40$ & - & 10 & No & Yes & No & UN & Employee \\
\hline 26 & B5 & $\leq 40$ & 2 & 13 & No & Yes & No & SHS & Employee \\
\hline 27 & $\mathrm{C} 1$ & $\leq 40$ & 2 & 10 & No & Yes & No & UN & Government Officer \\
\hline 28 & $\mathrm{C} 2$ & $\leq 40$ & 3 & 8 & No & Yes & No & UN & Government Officer \\
\hline 29 & $\mathrm{C} 3$ & $\leq 40$ & 3 & 10 & No & Yes & Relatives & UN & Employee \\
\hline 30 & $\mathrm{C} 4$ & $\leq 40$ & 2 & 8 & No & Yes & Relatives & UN & Government Officer \\
\hline 31 & $\mathrm{C} 5$ & $\leq 40$ & 2 & 11 & No & Yes & Relatives & UN & Government Officer \\
\hline 32 & $\mathrm{C} 6$ & $\leq 40$ & 2 & 10 & No & Yes & No & UN & Government Officer \\
\hline
\end{tabular}

Note: ES (Elementary School) JHS (Junior High School) SHS (Senior High School) UN (University)

A1-7: >40 Babakansari B1-5: <40 Babakansari C1-6: <40 Sukapura

D1-8: $>40$ Sukapura E1-6: $>40$ Bojong Koneng Makmur

Table 8 shows there was a difference between the older and the younger groups in relation to the number of children, years married, education, and occupation of the men. In terms of children, the older groups had more children (range 1-5) than the younger groups (range 0-3). The older groups had been married for an average of 26.9 years (range 10-40), while the younger groups had been married an average of nine years (range 3-13). In addition, the education level of the men in the older groups ranged from elementary school $(n=6)$ to the university. All participants in the younger groups had attended senior high school, and the majority had graduated from university. The level of education was related to the men's occupations. The majority of men who attended the elementary school were handymen, while the men who graduated from senior high school or higher, worked 
as businessmen, employees, or as government officers. All except one were

employed. The younger groups' occupations were not as varied as the older groups.

The majority were employees, and the rest were government officers. Table 9

presents the characteristics of participants from rural areas.

Table 9. Characteristic of focus group participants in rural areas

\begin{tabular}{|c|c|c|c|c|c|c|c|c|c|}
\hline No & Group & Age & $\begin{array}{c}\text { Child } \\
\text { no }\end{array}$ & $\begin{array}{c}\text { Years } \\
\text { Married }\end{array}$ & $\begin{array}{l}\text { History } \\
\text { Cancer }\end{array}$ & $\begin{array}{c}\text { Friends } \\
\text { with } \\
\text { Cancer }\end{array}$ & $\begin{array}{l}\text { Family } \\
\text { Cancer }\end{array}$ & Education & Occupation \\
\hline 1 & F1 & $>41$ & 1 & 37 & No & Yes & No & JHS & Farmer \\
\hline 2 & $\mathrm{~F} 2$ & $>41$ & 3 & 33 & No & Yes & No & ES & Farmer \\
\hline 3 & F3 & $>41$ & 1 & 30 & No & Yes & No & ES & Farmer \\
\hline 4 & F4 & $>41$ & 3 & 13 & $\mathrm{No}$ & Yes & No & ES & Farmer \\
\hline 5 & F5 & $>41$ & 2 & 16 & No & Yes & No & SHS & Employee \\
\hline 6 & F6 & $>41$ & 2 & 24 & No & Yes & No & ES & Farmer \\
\hline 7 & F7 & $>41$ & 2 & 23 & No & Yes & No & ES & Farmer \\
\hline 8 & F8 & $>41$ & 2 & 19 & No & Yes & Wife & SHS & Employee \\
\hline 9 & $\mathrm{H} 1$ & $>41$ & 2 & 25 & No & Yes & No & ES & Farmer \\
\hline 10 & $\mathrm{H} 2$ & $>41$ & 2 & 31 & $\mathrm{No}$ & Yes & $\mathrm{No}$ & SHS & Employee \\
\hline 11 & $\mathrm{H} 3$ & $>41$ & 2 & 24 & No & Yes & No & JHS & Farmer \\
\hline 12 & $\mathrm{H} 4$ & $>41$ & 1 & 23 & No & Yes & No & SHS & Employee \\
\hline 13 & H5 & $>41$ & 2 & 25 & No & Yes & No & JHS & Farmer \\
\hline 14 & H6 & $>41$ & 1 & 32 & No & Yes & Relatives & JHS & Farmer \\
\hline 15 & $\mathrm{H} 7$ & $>41$ & 3 & 32 & No & Yes & No & UN & Government Officer \\
\hline 16 & $\mathrm{~J} 1$ & $>41$ & 2 & 32 & No & Yes & No & UN & Employee \\
\hline 17 & $\mathrm{~J} 2$ & $>41$ & 2 & 23 & No & Yes & No & SHS & Employee \\
\hline 18 & $\mathrm{~J} 3$ & $>41$ & 2 & 25 & No & Yes & No & SHS & Employee \\
\hline 19 & $\mathrm{~J} 4$ & $>41$ & 2 & 29 & No & Yes & No & SHS & Employee \\
\hline 20 & $\mathrm{~J} 5$ & $>41$ & 2 & 26 & No & Yes & No & SHS & Employee \\
\hline 21 & J6 & $>41$ & 3 & 26 & No & Yes & Relatives & SHS & Employee \\
\hline 22 & G1 & $\leq 40$ & 1 & 6 & No & No & No & SHS & Businessman \\
\hline 23 & G2 & $\leq 40$ & 2 & 10 & No & No & No & SHS & Businessman \\
\hline 24 & G3 & $\leq 40$ & 2 & 8 & No & No & No & SHS & Employee \\
\hline 25 & G4 & $\leq 40$ & 1 & 2 & No & No & No & JHS & Businessman \\
\hline 26 & G5 & $\leq 40$ & 0 & 4 & $\mathrm{No}$ & No & $\mathrm{No}$ & UN & Employee \\
\hline 27 & G6 & $\leq 40$ & 1 & 7 & No & No & No & JHS & Employee \\
\hline 28 & G7 & $\leq 40$ & 2 & 7 & No & No & No & SHS & Employee \\
\hline 29 & I1 & $\leq 40$ & 0 & 1 & No & Yes & No & UN & Businessman \\
\hline 30 & $\mathrm{I} 2$ & $\leq 40$ & 3 & 21 & No & Yes & No & ES & Businessman \\
\hline 31 & $\mathrm{I} 3$ & $\leq 40$ & 2 & 7 & No & Yes & No & UN & Government Officer \\
\hline 32 & $\mathrm{I} 4$ & $\leq 40$ & 1 & 6 & No & Yes & No & SHS & Employee \\
\hline 33 & I5 & $\leq 40$ & 1 & 2 & No & Yes & No & SHS & Farmer \\
\hline 34 & I6 & $\leq 40$ & 2 & 6 & No & Yes & No & SHS & Employee \\
\hline 35 & $\mathrm{I} 7$ & $\leq 40$ & 0 & 1 & No & Yes & No & SHS & Employee \\
\hline 36 & $\mathrm{~K} 1$ & $\leq 40$ & 3 & 8 & $\mathrm{No}$ & Yes & $\mathrm{No}$ & UN & Employee \\
\hline 37 & $\mathrm{~K} 2$ & $\leq 40$ & 2 & 11 & No & Yes & No & JHS & Farmer \\
\hline 38 & K3 & $\leq 40$ & 2 & 10 & No & Yes & No & SHS & Employee \\
\hline 39 & K4 & $\leq 40$ & 1 & 4 & No & Yes & No & UN & Employee \\
\hline 40 & $\mathrm{~K} 5$ & $\leq 40$ & 1 & 5 & No & Yes & No & UN & Employee \\
\hline 41 & K6 & $\leq 40$ & 1 & 5 & No & Yes & No & SHS & Employee \\
\hline
\end{tabular}

Note: ES (Elementary School), JHS (Junior High School), SHS (Senior High School), UN (University)
F1-8: >41 Jangraga
H1-7: >41 Kertajaya
J1-6: >41 Mangunjaya
G1-7: <40 Jangraga
I1-7: <40 Kertajaya
K1-6: <40 Mangunjaya

Table 9 shows there was a considerable difference between the men in the older and younger groups related to education. The majority of men from the 
younger groups attended senior high school or university; one man had attended only junior high school and another only elementary school. While the older participants had various education levels, around a half of them $(n=9)$ attended senior high school, six attended elementary school, and only two men graduated from university. There was also a large difference in men's occupations between the older and younger groups. The main occupation of the older groups was farming, and only small numbers worked as employees or government officers. Whereas the majority of younger participants worked as employees or were businessmen, and just two were farmers. None of the participants had had cancer, and only three had a family history of cancer. However, many participants, mainly from Mangunjaya and Kertajaya villages, were familiar with breast and cervical cancer because many women from these villages suffered from these cancers. Further, the older groups had been married longer (average 27.4 years) than, the younger groups (average 6.3 years). The next five sections presents the themes that emerged from the analysis.

\subsection{Islamic teaching shapes husbands' roles in women's health and cancer}

The husbands' fundamental beliefs influenced their roles in women's health, including cancer. Participants shared that Islamic teaching guides them in building a family and choosing health professionals. This religious teaching influenced the husbands' perception of women's cancer, their actions when their wives were sick, and how they thought they would act if their wives were ever diagnosed with cancer. This theme consists of four foci: how Islamic teaching guides husbands' roles, how Allah has a role in women's health, including cancer, the importance of reminding women to surrender their diseases to Allah, and that husbands should follow Islamic rules when choosing health professionals for their wives.

According to the data comparison, there are similarities and differences among the groups about their Islamic values related to women's health behaviour and cancer. The majority of participants from urban and rural groups used some Islamic terms when they expressed their opinions about women's health and cancer, for example, Alhamdulillah (All praise belongs to God), and Nauzubillah (I seek refuge with Allah). The first term, Alhamdulillah is to thank Allah for something good, "My wife has hypertension, Alhamdulillah her blood pressure is normal now, she checked it yesterday" (A3). Nauzubillah is a Muslim expression used when a person 
is shocked by something; "Naudzubillah, but if it happens [women cancer], I would ask the nearest health provider for advice and solutions" (I3). These terms show how Muslim men connect to Allah in their happiness and sadness.

Both older and younger husbands from rural and urban areas shared that as Muslim husbands, they have roles and responsibilities in the lives of women and other family members. Their responsibility is to take care of the family in all aspects of life, including health. Sakinah mawaddah wa rahmah [an Arabic term which means happiness, give affection to each other, and reciprocal compassion] was an Islamic teaching, shared by several participants, that guide them in building a family. The following statement reflects participants' opinions of Islamic values, "The main value for this is sakinah mawaddah wa rahmah. That is my main guideline. There is a term sakinah which means we have to take care of our wives, in both health and illness" (B5). In addition, husbands were aware that their responsibilities as the head of the family are wide and have extensive meaning. These responsibilities are not only related to providing for their family's physical needs but also their psychological needs. “A husband's responsibilities are wide, not only to provide money but also other needs, such as feeling comfortable, feeling safe, and providing a peaceful environment for family members; children and wife" (C4). Some husbands also considered that they have the responsibility to take care of their families in both health and illness in Dunia [the world]. This includes preparation for Akhirat [life after death]. Fulfilling their promise to Allah and applying their role as an Iman [head of the family].

Older husbands from urban areas perceived that cancer is a test from Allah, and Allah gives this disease to women because breast cancer patients are mostly women. They also believed that God would cure the disease. A participant from an urban area also commented that a disease in their family was a test from God or that they were sinful. "I often think about the causes, are they because of my sins or a test from God?" (A3). Another urban participant shared a scientific view about the causes of cancer:

I read about cancer, sorry I forgot the source. It explained that the cause of cancer is unknown, and $80 \%$ of it is given, not because of lifestyle or other causes...it occurs because the cells in our body split imperfectly or quickly. It is just unlucky. (E5) 
Older husbands from rural areas related their opinions about Allah having a role in women's health. Even though they had uncertain understandings related to what caused cancer, the majority believed that Allah would help them because this disease comes from him so it can be given back to him. "I believed that my God is the only one who can cure this disease, and the doctor is only a facilitator to help us recover from a disease" (J2). Other participants did not consider that Allah alone could cure cancer; people needed to help Allah by making maximum efforts. A participant from a rural area said: "I believe, as humans, we have to strive, but the final result depends on our God" (J3). These older groups' opinions demonstrate that husbands remind women to surrender to Allah when afflicted with diseases, as well as seeking treatments. An older participant from a rural area whose wife had cancer shared that he often told his wife to submit her illness to Allah as part of involving Allah in her health, and spoke of motivating and supporting her to keep praying to Allah because he believed Allah would help her recover.

Compared to older participants, fewer younger participants shared Allah's roles related to women's health. When Allah's roles were shared this was often in conjunction with health services or treatment: "I believe, if we have a disease that God provides medicines, so he is the one who will take the disease from our body...You should believe it, inshaallah [a hope term from Arabic] God will help us" (B4). Another participant from the same group shared he was aware that there is a possibility that cancer treatment would be ineffective. "If the cancer cannot be cured, I will tell her that everything comes from God. Return to him, and keep praying” (B5). The data indicates that men have opinions of how Allah has a role, including curing this disease. They also believed that as human beings they need to take actions and give maximum effort to solving the health problem.

The majority of younger participants from rural and urban areas explained how they chose health professionals for their wives based on Islamic teaching. The data revealed husbands' tendency and preference to take their wives to female health professionals, especially when the problems were related to their wives' female body parts, for example, breast and vagina. One of their reasons is that Islamic teaching prohibits others looking at their wife's aurat (women's body) unless they are muhrim (family members who are allowed to see the woman's body). The husbands 
not only wanted to protect their wives but they also wanted the best services from health professionals without any religious obstacles. "Personally, it was because of my religious teaching and wanting a good quality service for my wife. I mean the female doctor could assess my wife's health conditions maximally” (C2). Another participant from a rural area also mentioned about muhrim rules in Islam. "A male doctor is not her muhrim, whatever the reasons are" (K6). However, some older husbands from urban and rural areas shared that the gender of the doctor was not important, and said that the most important thing is the doctor's skills. The husbands had different opinions about the doctor's gender; some were quite strict about not allowing a male doctor to see their wife's private parts while others were not, and considered a male doctor could help their wives health.

In terms of cancer experience, there was no major significant difference between the men's groups who had cancer experience in the family (group E and B) about how Islamic beliefs influence their views of women's health and cancer. Several participants from both groups shared that they believed God would provide a cure for every disease, including cancer.

I think cancer is a dangerous disease, so go to the doctor first. On the other hand, keep praying and supporting are also important. Inshaallah [hope] if there is a disease God provides medicines. All diseases are coming from God, so we give back to him, he will help us. (E4)

In summary, Islamic teaching is important for Muslim husbands in applying for their roles in women's health and cancer. They are responsible for their wives as part of their commitment as head of the family based on religious guidelines. Responsibility for their wives' lives is the main reason for participants from rural and urban groups to be involved in their wives' health. The participants also believed God gives an illness, including cancer, but he also provides the medicines, so it was important to keep close to Allah when their wives were sick. In addition, participants, especially those in the younger groups, thought about the gender of the health professionals who took care of their wives. Most preferred female doctors because of their Islamic beliefs. Islamic teaching was revealed as being part of the Muslim husband's way of life as many Islamic terms were used when sharing 
opinions in the group discussions. The following section presents the husbands' roles in women's health and cancer.

\subsection{Husbands' roles are primary in many aspects of women's health and cancer}

This finding identified different aspects of Muslim husbands' roles in women's health, including cancer. These roles are diverse and include: maintaining women's and family's health, having cancer screening, and dealing with their wives' health problems. The husbands used different approaches to deal with their wives' health, including collaborating with external sources. They offered no information about their roles in the prevention of women's diseases, including women's cancer, such as vaccination or health education.

\subsubsection{Maintaining women's health}

This finding explains how husbands support their wives in maintaining their health. This includes: material and psychological support, and helping their wives in their daily activities. Participants from urban and rural areas mentioned the types of material sources they provide such as health insurance, healthy food, money, and access to sport facilities. Most husbands from rural areas and those on low incomes in urban groups provided health insurance from Jamkesmas and BPJS - government insurance organisations. Some of them had no insurance, as paying for health insurance hard for rural people because they are mostly farmers or employees with low incomes.

For low-income people like us, commonly we choose class 3 the cheapest price of health insurance, for people who are frequently hospitalised. For example, my neighbour who had kidney, uterus and prostate surgery was registered with BPJS which was useful for them, but for general people, I mean healthy people, paying health insurance monthly is hard, so Pa Kadus [the community leader] did not push us to join BPJS. It is voluntary for people who have money and think insurance is crucial for them. (F7) 
Husbands from middle-income groups provided private insurance and extra nutritious food for their families. Their aims for providing insurance for their families included getting free medical services, including medical check-ups. "Fortunately, we have health insurance in the Borromeus Hospital, so every month we do a medical check-up" (E4). They also considered that "All family members take supplements routinely, like a multivitamin tablet for kids, or honey for us" (C4). They provided vitamins and supplements to maintain their children and wife's health.

Both the younger and the older participants were also aware of the importance of healthy food for their families and activities to maintain women's health. They advised that their wives avoided junk food and chemical products, and return to traditional and organic food. "I am disciplined about food. I don't allow my family, wife or kids, to buy food from street vendors. I especially keep an eye on my children's meals. All the food we have is homemade and we eat three times a day, with snacks and fruit" (C5). A participant from a rural area shared about his wife's activities outside the home as support for her health.

I knew that one of her hobbies is dancing so I give my permission for her to go to the sub-district office for free aerobic exercise every Thursday. Nowadays aerobic movements are similar to dancing. I am supporting her, Alhamdulillah [thank God] she is healthy, even though a little bit obese. I also allowed her to visit her daughter in West Papua so that she could refresh her mind. (H6)

Participants also reported their psychological support for their wives. This support varies and includes making their wife happy and comfortable, and being responsive to their family's problems. Both urban and rural participants shared some actions they took to make their wives happy, including providing them free time, taking the family on outings, and giving presents. "Sometimes we go for refreshments. Even though I am only a farmer, when there is a night market in the sub-district, we go there together; my wife and my children" (F6). However, in terms of family planning programmes, few participants from either urban or rural areas mentioned them, and their information was limited. They shared that for contraception services, wives made the decision and went to a midwife or female doctor by themselves.

To maintain women's health, participants with low incomes, including rural 
participants, and downtown groups shared that they helped with household tasks, such as dishwashing, cleaning the house, and taking care of the children. Some also said that they helped their wives as part of their daily activities. "Even though I arrive from work at night, I help her to clean house every day to assist her to keep healthy. Sure we have to support her physically and spiritually" (D3). Helping with household tasks was not common for participants from middle-income groups. Middle-income families mostly have nannies or cleaners to help them. In addition, a participant from a rural group shared that after he married he controlled his unhealthy behaviour in order to promote his family's health. "I am a cigarette addict. I try to avoid smoking in the bedroom. I smoke outside the house or occasionally in the living room" (K6). Both rural and urban husbands provided various support to maintain their family's health. However, they performed their support differently. Middle-income husbands tended to provide facilities to support their wives' health. On the other hand, low-income husbands provided limited facilities but offered help around the house.

\subsubsection{Facilitating cancer screening}

Most husbands knew a little about screening for cancer, and some husbands knew a lot. Across the groups, three methods of women's cancer screening were shared by participants; Pap smears, breast self-examination, and mammography. Participants' behaviour to screening varied. The husbands from middle-income groups supported their wives by providing money or insurance and accompanying them to the health services for screening, "The main point if it is for her health, I give my support, for example, she needs pap smear test or another medical checkup" (E2). A younger husband from a downtown area said he knew about Pap smears from the company wall information, and asked his wife to do that, but his wife refused because she was busy with the baby. Even though urban groups were more likely to understand cancer screening, a few husbands from younger groups shared they delayed sending their wives for screening because they did not think she had any abnormal signs or symptoms related to cervical cancer. "I advised her to go for Pap smear soon if there is abnormal vaginal discharge, for example, whitish or bleeding" (C2). Another husband from the same group had similar thoughts “Actually, I know, [now] we don't need to wait until symptoms occur. It is compulsory not to wait, but with no symptoms, I do nothing" (C1). On the other 
hand, the majority of participants from rural areas had never thought about prevention and early detection of women's cancer. However, a rural husband who had a relative with breast cancer shared his awareness of cancer risks in his family, and so he advised his daughter to have blood checks. He did not know about women's cancer screening, but he thought the blood test would help.

\subsubsection{Helping wife with health issues and cancer}

Participants from both areas and age groups shared their active roles in response to their wives' health issues. They undertook various actions including listening to their wives when they talked about their symptoms, observing their symptoms, providing temporary help, and discussing and taking them for treatments. Husbands from urban and rural groups reported that they assessed their wives' health problems before taking actions to resolve the health problem. They identified their wives' health problems by listening to their complaints. "When she felt unhealthy, she kept repeating her health problems" (H2). Husbands would then ask their wives, how they felt, or they would observe the symptoms. And then the actions taken were based on the signs and symptoms of the illness, and the consequences of their actions on their wives' health. In addition, an urban man whose wife had a history of heart attacks expressed he increased his attention to his wife when she was ill.

I am a busy man, but if it is an urgent condition, I have to go home immediately and not ignore it. So it depends on ourselves, our intentions and if we care for our wives, we should spend our time with her, like that. (C6)

Other urban participants shared other types of attention, including returning home from work immediately, especially in an emergency situation, providing full attention, taking care of their wives, and making them feel comfortable.

Men from urban and rural areas shared that they carried out some actions to help their wives with mild health problems. These actions included applying traditional therapies and providing home medicines. Traditional therapy included giving a massage, such as rubbing and reyek [prone position, someone steps along their backs]. However, one participant from a rural area shared that he would not support his wife going to others for a massage because he was worried about the side effects of it. "I never took her to a masseuse because I was afraid of dislocation or 
that she would get worse because of massage" (I6). Another type of traditional therapy that some men reported providing herbal drinks to help their wives' health issues, especially when the issue was related to their personal organs, as commented:

I had the experience of my wife suffering from white vaginal discharge. I know that 'Daun Sirih' [the betel leaf] can help 'women's problem', so I asked her to boil it in water and drink it before going to the doctor, Alhamdulillah [thank God] the problem was solved with that leaf. $(\mathrm{F} 2)$

The husbands from rural areas in both the older and younger groups mentioned that herbal drinks were also important for women to maintain their health. Another action some husbands took was providing home medicines. This involved buying medicines such as paracetamol or other pain killers from the local shop for their wives to take. "When my wife had hip pain, I first suggested she buys medicines; pain killers from the small shops. If the pain killers could handle her pain that was okay" (B2). Providing and giving home medicine to their wife is very likely a habit for the majority of participants. However, a few husbands from both areas avoided medicines from the local shop and would take their wife directly to the doctor when she faced health issues.

Husbands took their wives for therapies when the home medicines do not work. There were two types of therapies, including health services and alternative therapies such as Saman or herbs therapies. Most participants from the urban areas with middle incomes went to referral hospitals or private health services with their wives. As mentioned by a participant from an urban area, "When she had health problem symptoms I rarely suggested she take home medicines. We mostly visited the hospital" (C3). Low-income urban participants visited the PHC, small clinics, and public hospitals. Rural participants shared that they preferred to take their wives to the PHC, alternative therapies and private health services (a practising doctor, registered nurse, or a midwife) as there are no hospitals in rural areas. In addition, a participant from a rural area shared his choices related to health treatment for his wife, "I would quickly take her for therapy. Here in Java, like me, when Ifelt unhealthy last month, I went to the medical service first to see a doctor, the second I visited 'kesepuhan' [Javanese term for a therapist, typically a herbal therapists] (H3). These data indicate that husbands' actions to address their wives' health problems are 
numerous, and are based on the women's health conditions and other factors, including lifestyle and culture. For mild symptoms, men preferred to solve them by themselves, such as massage, rubbing, or home medicines, but they would send their wives to health services or alternative therapies when the health problems were more severe.

\subsubsection{Empowering women}

In supporting women's health, husbands also empower women. The empowerment activities include discussions about health problems, including cancer, making decisions for treatments, and sharing health knowledge of a particular disease. These actions were shared by participants from both areas. A man from a rural group shared "For me, when my wife was sick, I asked her, and would you prefer to visit a 'Mantri' [a registered nurse, commonly a man] or a doctor? And when she answered 'wait a moment', so it's up to her, she decides it" (F7). Also addition, an urban participant shared that he encouraged his wife to become more independent when visiting the hospital, and to be aware of abnormal signs and symptoms in her body.

\subsubsection{Involving other sources to support women's health}

Husbands, particularly from rural areas, engaged other sources to support their wives' health. This finding identified husbands' actions to involve other people who are close to them to provide solutions or give opinions with regard to their wives' health problems. The data indicated that family members, including parents, relatives, children and community leaders, and religious leaders, are sometimes also involved in women's health. Participants from rural areas, in particular, younger husbands, mentioned that parents: father or mother-in-law, family members are important for them to discuss their wives' health issues, including reproductive issues and serious diseases. "The decision was the result of a discussion among me, my wife, and parents because my wife's disease was severe, I thought I needed to talk to her parents" (G3). Parents helped husbands, particularly those who were younger, with decision making and financial support. However, one participant from a different younger rural group shared that even though he had disclosed details about his wife's illness with her parents, they did not influence his actions for his wife. In addition, relatives are another source for men to talk to about their wives' health. 
Information gained in the data showed it is common in a big family for one family member to have a more dominant role than others, and it is considered he/she should handle their family's health problems. However, other men considered they should know what is happening.

Besides the husband, relatives also influence the family decisions. For example, a family with five children, where one is more dominant because of age, education, or affluence is relied on to make family decisions. Commonly, she or he is the second person after the husband in the decision-making processes. My neighbour who suffered from breast cancer, sorry to say, her nipple was cut off, her brother shouted to her husband, saying 'why did you not tell me? (K5)

For older rural groups, adult children can also be involved in their mother's health. Husbands empower their adult children to participate in their mother's health, including making a health decision and helping parents when they face health problems.

I have a son. He has married actually. When my wife or I faced health problems, I called him. Commonly, he would say that I should go to the hospital immediately. If he says that we need to go the hospital, we follow his advice. We go to the hospital, so he decides it for us. (F3)

Another older participant from a different rural group shared his experience when his 60 -year old wife needed back surgery. He talked to his daughter, and the surgery was cancelled because his daughter did not agree with it. In contrast, younger children (aged 10-18 years) are expected to help with household tasks.

The Kadus [community leader] is another source whom husbands approach regarding their wife's health, particularly in rural groups. The Kadus considered he was asked for advice as the community believes he has a better understanding than they do about health service procedures, especially the JAMKESMAS (the Indonesia government insurance subsidies). Husbands discuss their wife's health with the Kadus because they think he is a person who can help them, especially with regard to fees and sometimes in decision making. "In my area, Sindang, for example, even 
though a patient only needs to go to the PUSKESMAS, she is waiting for the Kadu, because she wants cheap fees or free services if possible” (J4). Beside community leaders, participants from the same group mentioned that they talk to an ajengan [preacher] about their wives' health and ask for a blessing. "Yes, ma'am many people followed 'the ajengan' advice, including me, because they would send 'doa' [praying to God] for us" (J2). Even though husbands believed in ajengan, most of them preferred to solve their wives' health problem by attending health services and getting the health professionals' advice.

Husbands' roles in women's health are significant. They apply their roles in many aspects of women's health and cancer, including health promotion, early detection, facilitating arrangements for treatment, and involving family, relatives, community and religious leaders. Husbands provide broad support for their wives' health, including material and psychological support. Rural husbands especially, collaborate with other sources to improve women's health. Husbands have pivotal roles in women's health and cancer; however, the findings show a lack of husbands' roles in illness prevention and screening. Both old and young rural husbands are likely to face more challenges than urban husbands. Several of these challenges are related to women's cancer screening information, health services in a referral hospital, and financial issues. As a result, they need support from others, including parents, children, relatives, and community leaders when they apply their roles to their wives' health.

\subsection{Experience and knowledge influences husbands' perceptions, and awareness of cancer}

There were different levels of knowledge between husbands who had and had not had experience with cancer. Participants who had cancer experience shared their understanding of cancer, including signs, treatments, preventions, early detections, and risk factors. While participants who had not had experience of cancer, reported their lack of understanding of cancer and asked questions about causes and treatments. The findings showed that husbands' knowledge of women's cancer shaped their perceptions and awareness of cancer. Husbands from urban and rural areas perceived that cancer is a fatal disease, and their experience of cancer affected 
their awareness of it. They paid more attention to women's cancer, if they had had experience of it in their family, relatives, neighbours or colleagues.

The socio-demographic data revealed that the number of men who had any experience of cancer in their family was small (16\%). However, most groups (10 of 11) had neighbours with cancer. Even though most participants had female neighbours with cancer, they had limited information about women's cancer, as these cancer commonly occur in women's private parts and are not talked about.

The experience shaped husbands' understanding of women's cancer. The majority of participants had no clear understanding of cancer. "For rural people like us, we did not know the difference between tumours and cancer. It was not discussed socially. Rural people thought that a lump is a cancerous tumour, so we have little health education about it" (I7). Some men from urban and rural groups were also uncertain about the definition of cancer and its causes, and others associated this disease as given by God, and they felt confused about this disease. Those who knew something about cancer shared what they thought were the causes of cancer, including smoking, genetics, food, water, and husbands' behaviour. However, many were unsure about their opinions, "Smoking is also one of the cancer causes, right?" (G1).

A participant from an urban area whose relative had cancer described cancer based on his reading of an article, "The cells in our body split imperfectly and are uncontrolled" (E5). Yet, he also believed that cancer is a disease from God: "It is just unlucky. People say that it is given, so if it is given, it would be difficult to solve" (E5). The few participants who had family members, relatives, or colleagues with cancer described symptoms of breast and cervical cancer explicitly, including a white discharge from the vagina, a lump in the breast, redness, a smelly and itchy breast, and gangrene in the breasts. The descriptions were sometimes graphic: " $M y$ mother in law's neighbour, who was old, had many maggots on her breast, and it was smelly. She passed away a month ago" (I2). Participants from rural and urban areas including downtown areas who had no cancer experience had limited understanding about the signs and symptoms of breast and cervical cancer and were keen to learn. "Could you explain it to us? I heard from TV about breast and cervical cancer, but I have not seen women who suffer from these cancers" (B5).

Cancer stages and treatments were also discussed by men who had cancer experience. Rural men mentioned different terms to describe the stages of cancer, 
including the early, late, and advanced stages, but could not describe the differences between early and advanced stages of cancer specifically. In contrast, descriptions of cancer shared by middle-income men in the urban groups who had experience of cancer were that, mostly, women with cancer who visited health services were in the advance stage. "As I know, most cancers found in late stadiums 3 or 4, and rarely found in the early stadium 1. I think, if it's found in the early stage, then the doctor can treat it" (C6). A rural participant had an understanding about cancer treatments, including surgery, radiotherapy, chemotherapy, and palliative care because he helped his neighbour when she went for cancer treatments.

My neighbour had breast cancer. We referred her to the Margono Hospital in Central Java where she had radiotherapy several times, but it was in the advanced stage, and the doctor could not help her. At the end, she passed away. (I7)

Men who had family members with cancer or who supported women receiving cancer therapy were aware of the risk factors, including genetic, food contents such as Mono Sodium Glutamate, and men's sexual behaviour.

I think the genetic factor has a big influence in my family as several have had severe cancer and I have a history of cancer in my mom's family. My grandma had cancer. I think it was cervical cancer and she passed away because of this. Then my aunty passed away because of ovarian cancer, and some relatives died of breast cancer. (C2)

A rural participant who had accompanied his niece for cancer treatments said how cancer killed her and he wanted to protect his family from cancer. Even though he did not know how to prevent cancer he reminded men of his family to protect women from cancer by being sexually responsible.

My niece suffered from breast cancer; she said the first symptom was a small lesion in her breast. I have a daughter and grandchildren and I am worried husbands would suck their breasts and injure them. If they do not care, it would stimulate breast cancer, but what would happen if I forbid their 
husbands to suck their breasts? Honestly, I am afraid because of my niece's experience. Lucky me, I don't have teeth anymore, so I avoid sucking my wife's breast. (H6)

Participants, especially from the rural groups reported that they did not know how to detect and prevent cancer. In the focus groups, they asked me what cancer is and wanted me to explain causes, therapies, and prevention methods.

Men from different groups offered diverse opinions with regard to the nature of breast and cervical cancer, and these were influenced by their experiences. They described cancer as a deadly disease because most women they had known with it had died and it was difficult to treat even though the women had gone to an international hospital, as noted: "In this village, around 10 women suffered from breast cancer, and only one recovered" (J4). In addition, participants highlighted that women's behaviour, a family history of cancer, and some perceptions of it such as a low expectation of recovery or that it is difficult to prevent were reasons they thought it was dangerous. "Sometimes this disease came suddenly, then in only a few days it changed and become severe. The change was so fast" (E3). Participants also talked about their fears when they compared cancer with other diseases.

Like that Ma'am, I am scared when someone talks about cancer. For example, I asked Pak XX [Mr XX], what are your health problems? If he answers I have a problem with my hip, I don't find it unusual, but if he answers cancer, I feel different, scary scared Ma'am. (A1)

A different perspective was shared by a man who had experience in managing his family with cancer. He focused on the expensive fees of cancer treatments.

Previously the surgery fee was 3.5 million rupiah [\$NZ 350], I don't know the latest prices. Chemotherapy was 2.5 million rupiah [\$NZ 250] each, and the patient needed six treatments. We can count on it. Then radiotherapy was 750 thousand rupiah [\$NZ 75], and the patient needed it around 35 times. It depends on cancer's stage. (J6) 
Men from rural and urban groups considered that cancer is a fatal disease for women because it is a deadly disease, dangerous, scary, and costly. The men who had cancer experience in their community tended to share the dangers of cancer and their fear of this disease. Those who had experience of a family member with cancer also talked about the financial expense.

Participants with close experience of cancer shared that they were not aware of their wives, daughters, or relatives' health. They spoke of encouraging women in their extended family to ask about every problem related to their health and not to be shy to share it. In addition, they would also assist if a woman needed to go to the hospital for a medical check-up or screening.

I paid attention to my wife and children, especially my children. I have two daughters, and I am more concerned about their health, especially after I saw the side effects of chemotherapy. My friend lost her hair after several chemotherapy treatments, and her skin was burned. I felt scared and was also sorry to see that. It affected me, and I should have paid more attention because I know many women with severe cancer. (E3)

Rural participants from Kertajaya, a village in which many women had had cancer, reminded each other about women's health in the focus group. Communicating with their spouse and being aware of their health, especially when the health problem related to the breast and vagina, were considered important. "If the sign is related to her personal parts [breast or vagina], don't delay taking your wife to the doctor" (H3). In addition, cancer seemed scary for the participants who had helped their relatives or a neighbour with cancer. One man who had experience of multiple cancers in his extended family perceived that causes of cancer were family-related, and he advised his extended family to check blood types, even though he did not know the aim of this action. A different concern for a few men were avoiding chemical ingredients in food. These men (from urban and rural areas) preferred to eat organic vegetables and fruits because they believed that chemical substances could stimulate cancer.

Because my neighbour had breast cancer, I suggested to my wife to keep clean [her personal part] and then to avoid the chemical ingredients $A, B, C, D$ when 
cooking and that it is better to cook using the traditional methods and ingredients. (H5)

Further, participants shared that their roles in women's health were necessary, because they considered it as part of their responsibility as a husband, "A husband should protect his family: wife and children from all life's aspects such as health" (B1). They also wanted to learn more about cancer so it would help them to protect their wives and help them make appropriate decisions if their wives faced cancer. "I need and hope there would be an education programme about it because I have a limited understanding of all women's diseases" (K3). The husbands were aware that they needed health information to improve their roles in women's health, including cancer.

In summary, men have various levels of knowledge of cancer. The more involvement they had had with cancer, the more they understood about cancer. The men perceived cancer differently based on their experience. The data also revealed that men's experience of cancer encourages them to be aware of their family and it influenced their actions. Those men with experience of cancer in their family or workplace were motivated to pay more attention to their wives and daughters' health. Furthermore, the experience of cancer made them aware that they needed more information about it in order to participate in their wives' health as part of their responsibilities as head of the family. Experience and knowledge shaped men's perceptions of, and behaviour towards, cancer. The following section presents barriers faced by men when they applied for their roles.

\subsection{Barriers exist in husbands' roles in women's health and cancer}

The data revealed barriers exist in relation to husbands' roles in women's cancer, including a lack of cancer information, burdens to utilise the provided health services, women's health behaviour, and financial problems. These barriers occurred in rural and urban groups with low incomes. Men, especially from rural areas, shared their difficulties in obtaining information about breast and cervical cancer. A rural participant who was a smoker shared that he knew a cancer term from a cigarette package. Another rural participant shared, "There was no information about cancer from the health providers in this village. What should we do? There were no 
solutions or suggestions, nothing" (J2). Some urban participants said they learned a little about women's cancer from newspapers, the internet, pamphlets in hospitals, television, and friends. Participants from urban areas used a variety of information sources. However, none indicated that they obtained information from health providers.

Participants indicated that their preferred sources to help them with cancer information were the internet, print, television or radio, discussion forums with health professionals, premarital programmes, health events, and health information from community leaders. Participants from urban areas preferred using technology more than those in the rural areas.

Personally, information from social media is easy to access nowadays in the internet era. I can open and read some information from the internet in my break time. It is easier to me than going to a health education event, because my work times are uncertain. (B3)

The men from rural areas preferred direct interaction with health professionals, as noted: "For health information, health providers can share with us at the village meeting. Then I will inform my residents, a community leader in level RT [neighbourhood] or $R W$ [community organisation], and also during a weekly or monthly religious meeting” (F8).

The participants mentioned their disappointment that there were limited health education programmes provided by the government with regard to women's cancer. As a man from an urban area who lives in a downtown area shared: "For me as a handyman, I don't have information sources, especially about health information because there are no clear programmes from the government that I can access" (B3). Participants from rural areas also complained about the lack of programmes, especially with regard to illness prevention or early detection of cancer. They said the main focus were curative. Participants reported their hope for cancer education programmes from the government.

Like this Ma'am, we don't know about cancer. We are lay people here, and when somebody had a lump then people said it was cancer. People did not 
understand about cancer. There is no cancer information in this rural area.

(I2)

Participants from middle-income groups from urban areas shared the only government programme which they were familiar with was the "Alert Husband" antenatal programme. This is a programme advising husbands how they can support their pregnant wife. Most participants from urban and rural areas did not know how they could be involved in women's health, particularly cancer prevention and early detection.

The men participants also spoke of the burden in utilising health services. They described related health services from different aspects, including health care regulations, facilities, health professionals, and the processes of services and their difficulties when they wanted to participate in their wives' health. Some expressed that they cannot be involved in women's health because hospital regulations do not support men, as mentioned by a participant from an urban area:

It is good that men should be involved in their wives' health, but based on my experience, men were not allowed to enter the women's assessment room. The hospital system does not support men when they want to know their wives' condition. (C6)

The discussion clearly indicated that men want to participate in their wives' health but were not supported by health professionals to do so. In addition, some men from downtown areas complained about barriers to health facilities and accessibility, including the limited number of beds in hospitals and the limited of referral hospitals.

When my wife was sick, and the doctor suggested she is hospitalised, unfortunately, there was no room available in the hospital. We needed to book the room first, and then paid the down payment. Truthfully, this is real. I face many problems accessing health services. (D3)

Another participant from the same area said the hospital was too full with patients from the whole of West Java province areas such as Majalengka, Garut, Plumpang, 
and Bandung. He wanted the government to build new hospitals in every sub-district because the Hasan Sadikin hospital is very crowded, and also build a PHC at the village level.

Participants also shared their concern relating to the complicated processes of the health services, especially the administration requirements in public hospitals.

When the health professionals in the PHC advised me to refer my daughter to a hospital, I needed to collect many administrative requirements, including a supporting letter from the community leader in our region. After all the requirements were completed, I went to the PHC to take the referral letter. Those processes took half a day. After that, I went to the hospital in a hurry because I needed to take a queue ticket. In a day the hospital provided around 100 tickets for a policlinic in the inpatient service, but because there were so many patients, unfortunately when I arrived at the hospital all the tickets had been taken. Why is everything so complicated? We follow all the government policies, but the service is always complicated. (A3)

The complicated process was also noted by community leaders from downtown urban and rural areas. A community leader from a downtown area commented that for somebody who does not have the JAMKESMAS card, they need to have a BPJS card, and to process both cards is quite frustrating. He helped the community as best as he could, but when the sick people go to a public hospital, the services were poor and the administrative processes were frustrating. As a result, men who have money preferred sending their wives to non-government health services. Many husbands preferred to go to the speciality clinic in their workplaces, have alternative therapies, or palliative care for their families. They do this because they are accessible, and the doctors are friendly, ask questions and discuss their wife's disease freely. The same was said by some men who took their wives to alternative services. They wanted better services, and the main opinion was that the public health service is low quality.

A wife's behaviour influences a man's perceptions of their health. Men from urban and rural areas we aware that their wives have essential roles in their families' health. "For me, the main point is my wife has a big role in our family's health. For example, she avoided the use of Mono Sodium Glutamate, and she preferred to cook 
brown rice rather than white rice" (E6). Women's big roles in the family encourage men to support their wives' health. However, wives have different reactions when facing health problems. This creates some difficulties for men to help them. Some men from urban and rural areas reported that even if their wives shared their health problems with them, their wives would still decline going to health services. "She talked likes bees and asked for my hand because she said her body is sore, but when I offered to take her to the hospital, she refused" (H7). Refusal or delaying treatment made men feel confused about what the appropriate action is.

A few urban men from the younger groups thought that women chose not to share their health issues with them, preferring to talk to other women, including sisters, mothers, or female friends. This lack of sharing was considered to be because of the women's character, or because they do not want to take medications. "She often keeps her health problem from me, and then only asks when it has deteriorated, or she is unable to control it anymore. She is a silent woman" (B2). Some men raised that it was a concern if women did not share with their husbands about their health. A man from the younger group said he is afraid that his wife could suffer from a dangerous disease like breast cancer and not share this with him. A wife's behaviour could be a burden for a man to apply his responsbility in protecting her from illness because sometimes the wife reports her problems but refuses to go to health services, or she hides her health problems from her husband.

Beside facility and service problems, low-income group participants shared that their family's financial situation is another problem for them to play their roles. They want accessible health services for low-income families, "If it is possible, we would like to have free services" (J4). In fact, when a family member is sick, they need additional money. Some hospitals require a down payment of fees before booking a room. In addition, money is needed when staying in a referral hospital.

Some people, I mean poor people, get health service facilities; medicines, inpatient rooms, and consultations free from the government subsidies, but relatives who accompany them in hospital, need food and transportation costs, so we need money. (F8) 
Financial challenges presented by men from rural and urban areas with low incomes regarding the demanding and expensive health service processes influenced their involvement in women's health.

In summary, based on the data, there are two types - internal and external - of barriers for men when applying for their roles in women's health. The internal barriers arise from family conditions and include wives' health behaviour and financial burdens. The external barriers are caused by the healthcare system. Rural and urban men with low incomes are likely to face more barriers than those with middle incomes in urban areas. Barriers identified by the low-income rural and urban men included limited health literacy of women's health and cancer, limited information of women's health from health services, complicated administrative requirements in health services, and extra spending when their wives were hospitalised.

\subsection{Husbands power and powerlessness reflects health services context}

Participants from rural and urban groups expressed their hopelessness because of the limited choice for female doctors and their expectations for good quality services from female health professionals. The men preferred female doctors for their wives, but access to them is limited. This opinion was shared by men from urban and rural areas. The majority of participants from urban areas with middle incomes reported that they always take their wives to female doctors, "There are many professional female doctors today, so why shouldn't their capabilities be the same as male doctors" (E4). The same comment was shared by one younger group participant from a rural area:

If there are choices, I preferred to go to a female doctor. For the male doctors, maybe it was common for them to assist female patients, but not for my wife, she would be awkward so that a female doctor may be better for her. (K3)

However, the majority of rural participants shared that most doctors in health services are male, and there are insufficient female doctors, especially in rural areas, as the following quote demonstrates. "Most of the specialist doctors are men. There are no female doctor specialists. It is the opposite with nurses and midwives” (J3). 
Some men, especially from the older groups with low incomes mentioned the gender of the health professional was not their focus.

Any doctors are okay for me. I have no special requirement, male or female is okay. If there is only a male doctor on standby in hospital, I will give my permission. The most important thing is the doctor can solve the problem. (B5)

For older groups, it is likely that the gender of health professionals is not important compared to younger groups, as for them their wives' health was paramount. Men from urban and rural areas have different experiences with regard to the avaiability of female doctors. The urban men confirmed that it is easy to find female doctors; however, it was difficult in rural areas.

Some reasons relating to men's opinions about how to choose female doctors were given. Several men consider their wives' feelings when choosing their health professionals. These included their wives' safety, their feelings of comfort, and being able to communicate freely. "Maybe it was safer with a female doctor and maybe my wife would be shy as the doctor needed to check by pressing her personal organ" (K6). However, in some conditions, for example, an emergency they would follow the hospital's regulations because they had no choice with regard to health professionals for their wives.

The male doctors helped her. In my opinion, it is taboo to show my wife's body to other men, but I could not do anything as this was an emergency situation and difficult to control. I felt confused about that situation but once again, I could not do anything. I gave up. (B1)

Participants explained their preference for female health professionals for their wives, but some conditions forced them to give their permission to male doctors because there were no other choices and their wives' health is precious.

Men reported other experiences of poor services from health professionals for their wives. Many men from urban and rural areas expect the health professionals to be responsive, communicative, respectful, informative, and "the most important thing is that they are friendly" (J5). They also expected that the husband and wife receive accurate information about the disease or treatment processes, so they can 
participate to improve the wife's health. Unfortunately, many had poor experiences of services from health professionals for their wives. For example, there was no clear explanation of her health problems, the service was slow, or the doctors were unfriendly.

When a woman came for treatment and discussed her health problems, the female doctor commented, 'aah it just mild pain don't over react like that'. So many women in Jambi [a region in Indonesia] were uncomfortable with her. (E1)

Besides professional behaviour, men also expected that their wives were seen by skilful and expert health professionals. "I am focused on the doctor's capability, and how he/she manages and gives service to the patient. Does he/she give excellent service? So if we need a doctor, he/she is available" (C6). However, one urban participant shared that the doctor who took care of his wife was not an expert but a student doctor and there was no privacy.

Another problem was the health providers who helped my wife were students, not experts, you know...many students in the delivery room. They watched the delivery process, weird...could you imagine? My wife was giving birth, and many people watched, but I could not do anything. (B1)

Participants from different groups presented their preferences and expectations of health professionals who provide services for their wives. However, the health professionals did not always meet their expectations, and the men were unable to do anything in these situations.

\subsection{Conclusion}

Overall, the discussion among 11 focus groups of Muslim husbands in rural and urban areas of West Java province in Indonesia, illustrated that Islamic teaching is important in guiding men when playing their roles in women's lives and health. Husband's roles in women's health, including cancer, vary. Their roles include providing resources and support for women's health, early detection, and disease treatments. Another role is collaborating with other sources to support their wives' 
health. In addition, the data indicated that men have limited knowledge of cancer, and this influences their perceptions of cancer.

Husbands from both the urban and rural groups apply Islamic teaching in their daily activities, including their behaviour in women's health and cancer. Husbands' health behaviour varied regarding their roles in women's health and cancer; participants in all groups reported their extensive roles in their wives' health. However, this study found a lack of husbands' roles in women health prevention, especially cancer, and many did not have any ideas about what they should do if their wives suffered from cancer. In addition, husbands face barriers when they want to support their wives' health. These barriers were reported particularly by rural, and low-income husbands and included: financial issues, women's characters, limited health facilities, and a lack of health programmes that enable men to support women's health. In terms of experience, the more experience husbands had of cancer, the more knowledge and awareness they had about women's health promotion, and disease treatments. However, apart from a few, most men did not understand about, the early detection of cancer. Some unexpected health services conditions including accessibility to health services, a lack of female doctors, and inadequate privacy for women, impact on the quality of women's health services. 


\section{Chapter 6. Women's Perspectives of Muslim Husbands' Roles in Women's Health and Cancer}

\subsection{Introduction}

This chapter details the findings from 20 interviews with married Muslim women. These interviews were conducted to answer the study's objective: to explore women's perspectives of Muslim husbands' roles in women's health and cancer. These interviews revealed, Muslim women's perspectives of their husbands' overall responsibility for the family included looking after their health. The characteristics of the women's participants are presented. The four themes which emerged from the analysis are based on comparisons between women from both rural and urban areas, older and younger women, women with middle and low incomes and those who have had experience with cancer and those who have not. The themes include: 1) Islamic teaching impacts on husbands' actions in women's health and cancer, 2) Husbands have extensive roles supporting family's health, 3) Family circumstances and social support influence Muslim husbands' roles in women's health and cancer, and 4) Husbands' limited health literacy influences their roles in women's health. Each theme includes explanations and participants' quotes in English. The final section summarises the findings.

\subsection{Characteristic of participants}

Women participants included 10 from urban and 10 from rural areas. For each area, I divided the participants into two groups of ages 41 years and over, and 40 years and under. Table 10 presents the characteristics of the women participants. The majority of participants were housewives; only two were employees and one a businesswoman. The older group had been married for an average of 27.8 years (range 11-38), and the younger group an average of 14.2 years (range 6-22). One urban participant had uteri cancer in 2013 and a rural participant had suffered from lymphatic cancer since 2010.

Five women had family members with cancer, including breast, cervical, and brain cancer. The rural women had 1-2 children, while most of the urban women had $2-3$ children. The majority of women attended nine years of compulsory education, and two participants attended elementary school only. There were different trends 
between rural and urban women who graduated from university. Two women from rural areas had graduated from university. One was working as a government officer and the other was an employee in a private company. Three urban women had graduated from university, two of them were housewives. The following four sections present the themes.

Table 10. Characteristics of married women participants

\begin{tabular}{|l|l|l|r|r|l|l|l|l|l|}
\hline No & Group & Age & $\begin{array}{c}\text { Child } \\
\text { No }\end{array}$ & $\begin{array}{c}\text { Years } \\
\text { Married }\end{array}$ & $\begin{array}{l}\text { History } \\
\text { Cancer }\end{array}$ & $\begin{array}{c}\text { Friends } \\
\text { with } \\
\text { Cancer }\end{array}$ & $\begin{array}{l}\text { Family } \\
\text { Cancer }\end{array}$ & Education & Occupation \\
\hline 1 & R1 & $>41$ & 2 & 34 & No & Yes & No & SHS & Housewife \\
\hline 2 & R2 & $>41$ & 2 & 31 & No & Yes & No & ES & Housewife \\
\hline 3 & R3 & $\leq 40$ & 1 & 6 & No & Yes & No & SHS & Housewife \\
\hline 4 & R4 & $\leq 40$ & 1 & 22 & No & Yes & No & SHS & Housewife \\
\hline 5 & R5 & $\leq 40$ & 2 & 17 & No & Yes & No & JHS & Housewife \\
\hline 6 & R6 & $\leq 40$ & 2 & 20 & Yes & Yes & No & SHS & Housewife \\
\hline 7 & R7 & $>41$ & 2 & 11 & No & Yes & Yes & UN & GO \\
\hline 8 & R8 & $>41$ & 1 & 35 & No & Yes & No & ES & Housewife \\
\hline 9 & R9 & $>41$ & 2 & 38 & No & Yes & No & SHS & Employee \\
\hline 10 & R10 & $\leq 40$ & 2 & 19 & No & Yes & No & UN & Employee \\
\hline 11 & U1 & $\leq 40$ & 2 & 13 & No & Yes & No & JHS & Housewife \\
\hline 12 & U2 & $\leq 40$ & 3 & 8 & No & Yes & No & UN & Housewife \\
\hline 13 & U3 & $\leq 40$ & 1 & 6 & No & Yes & No & SHS & Housewife \\
\hline 14 & U4 & $>41$ & 2 & 27 & No & Yes & No & JHS & Housewife \\
\hline 15 & U5 & $>41$ & 3 & 31 & No & Yes & Yes & SHS & Housewife \\
\hline 16 & U6 & $>41$ & 2 & 24 & No & Yes & Yes & UN & Housewife \\
\hline 17 & U7 & $\leq 40$ & 2 & 17 & No & Yes & No & JHS & Housewife \\
\hline 18 & U8 & $>41$ & 2 & 31 & No & Yes & No & SHS & Housewife \\
\hline 19 & U9 & $\leq 40$ & 3 & 15 & No & Yes & Yes & SHS & Housewife \\
\hline 20 & U10 & $>41$ & 3 & 27 & Yes & Yes & Yes & UN & $\begin{array}{l}\text { Business } \\
\text { women }\end{array}$ \\
\hline
\end{tabular}

R: Rural U: Urban

ES: Elementary School JHS: Junior High School SHS: Senior High School UN: University GO: Government Officer

\subsection{Islamic teaching impacts on husbands' actions in women's health and cancer}

Religious teaching underpins Muslim husbands' roles in women's health.

Women commented that husbands' behaviour was part of the application of Islamic teaching, including loving their spouse, being responsible for her in all her life aspects, and protecting her from any risks whether physical or psychological. Women shared that husbands showed their love for their wives in two ways; first, husbands provided support, and were faithful to their wives even if suffering from advanced stages of cancer. A woman from an urban downtown area described the love and close relationship she and her husband have, 
I think he loves me very much. The basis of this is the religious teaching. Sure, we are as one, my husband and I, as a verse from the Holy Quran, I am as my husband's clothes as he is for me, like that. (WU4)

Another urban middle-income participant shared her husband's behaviour when she was diagnosed with late-stage uteri cancer.

My husband told me that "I married you when you were healthy, and then you had cancer after marrying me for more than 20 years, I don't want to give up, maybe it is a test from Allah, and I want to pass the test, you are a 'sholehah' [good] woman, so submit it to Allah, and let's do our best to follow the cancer treatment". (WU10)

His love motivated her to follow the therapy processes. She added that because of her health, she was aware that she could not fulfil his sexual needs. So she provided money and told him to use the prostitution services, but he rejected it. He said that he did not want to do that because as a Muslim man he was not allowed to have sex with another woman, and he believed if he ignored the religious teaching, it could impact negatively on their family.

Women from urban and rural areas shared that Muslim husbands have to be responsible to their family, especially their nuclear family. Husbands' responsibilities are extensive. They are responsible for women physically and psychologically in sickness and in health. The physical aspect includes providing money, food, and other facilities, and the psychological aspect is the Muslim husband's responsibility to support his wife during her life, so she feels comfortable, supported, and protected.

When his wife is sick, as a husband he has to be responsible for taking his wife to a hospital or PHC. A husband is always ready for his wife, like that. He doesn't take her for granted. We have to stick together through thick and thin. (WR4)

The urban woman with a middle income who had cancer shared that her husband sold his rental car to pay for her medication in an overseas hospital. This was 
because the hospital in Bandung could not help her, and they referred her to an international hospital. Another middle-income woman also spoke of her husbands support for her health. She shared that her husband worked in a different city. He returned home and left his job because he wanted to send his wife to the hospital. Rural participants also shared that their husbands supported their health by ensuring they were comfortable by accompanying them to the health services and giving the advice to be close to God. A rural woman shared how her husband guided her to remember God when facing health issues," Be patient, everything is from Allah, so he will help you and always knows what humans do" (WR9). Allah is the centre of everything, including health but as a human, we must go to the hospital and take medication. Women from rural and urban areas with low incomes shared that husbands helped with household tasks to support them when they were sick. Further, they said husbands are responsible for women not only when they are sick, but also when they are healthy. Women from urban and rural areas shared that husbands supported them to improve their health, including providing support for social activities and participating in the care of their children.

Protecting women is part of husbands' actions that are guided by Islamic teaching. According to the interviews, husbands' protective actions include protecting women's aurat from male health professionals. The participants from both urban and rural areas reported that some husbands preferred female health professionals for them, and others had no concern about the health professionals' gender. The most important thing is the women's health. Women from urban areas shared that their husbands' reasons for choosing female health professionals, reflects religious teaching, "When the male doctor checked my body, automatically the doctor could see my 'aurat' (WU2). This happens when the problem is related to women's private organs.

The second reason shared by urban women is there are a lot of female health professionals in the city, so women have choices and can attend the best female doctors and avoid male doctors. "Both of us agreed to go to the female doctor. We discussed it and, for me personally, I chose the female doctor, and my husband said there are many female doctors, so there is no reason to choose the male doctor" (WU2). Even though not all female doctors were considered to provide the best service to their patients, many participants said they could talk freely to the female doctor about their health problems without shame. The next aspect is for women's 
safety. A few urban women mentioned that their husbands refused to allow them to see male doctors because of the possibility that doctors would behave unprofessionally. Likewise, a participant in a rural area preferred to go to a female health professional, a midwife, because she and her husband wanted to protect her body. However, not all women in rural areas went to female health professionals because of the aurat reason.

Yes, maybe it's true, some women don't go because of religious teachings, and it's the same for me. The religious factor is not the main reason. Many husbands do not know about women's aurat, so they choose female health professionals because of a funny reason such as being jealous of the male doctor. (WR3)

Many women from urban areas said that they went to a female doctor because their husbands demanded this. However, other women said that their husbands provided permission for the male doctor to treat them if they had an emergency. An example of this was given by an urban women who had vaginal bleeding and needed a curettage immediately. Her husband agreed that she see a male doctor. Another example reported by a woman from a downtown area was that the high-quality services from the doctor were the most important for her. These examples show that some husbands were more concerned with the women's lives rather than the gender of health professionals.

To conclude, women reported that Islamic teaching underpins husbands' health support for them. Husbands love their wives whether they are healthy or ill. In addition, as a couple, they complement each other. Further, husbands are responsible for all aspects of women's lives, including their health. Women perceived husbands provided full support to their wives physically and psychologically as part of their responsibility as Muslim husbands. Finally, husbands protected their wives from harm, and many followed Islamic teaching about protecting women's aurat and disallowed male doctors from treating their wives, and a few husbands allowed male doctors because of their individual reasons. 


\subsection{Husbands have extensive roles in supporting family health}

This section presents the two main categories of Muslim husbands' roles in women's cancer and their general health. These are their roles in women's health promotion and their active roles when women have health issues.

\subsubsection{Husbands' roles in women's health promotion}

Women's participants from rural and urban areas spoke of their husbands' extensive roles in promoting health and preventing their families from illness. Husbands' actions to improve their wives' health included providing opportunities for women to enjoy personal or social activities, giving attention to and reminders regarding healthy food, assisting with women's workloads, and family planning programmes. In addition, women shared that their husbands gave them considerable attention when women asked their husbands to discuss problems or to share their knowledge and experience. Further, husbands encouraged women to have regular medical check-ups.

According to urban and rural women information to enhance the women's health, husbands support women's activities as an individual as well as their roles as community members. Women from urban and rural areas shared information about two different activities including personal activities and social activities. The personal activities mean women's independent activities. A rural participant shared how her husband would accompany her going outside for a while to refresh her mind from her daily activities at home. An urban participant shared a similar experience. Her husband encouraged her to do the activities. "Mah [calling his wife] you should do like this, jogging, and avoid too much sleep in the morning (WU5). Another urban participant mentioned that her husband accompanied her for a morning walk. In contrast, the urban participant who has a history of cancer of uteri reported that her husband reminded her to control her daily activities at her work and at home. "Honestly, my husband is fussy. I mean he always says, please don't be too tired, like that" (WR10). He limited his wife's activities because she is a workaholic and has been since she was young, and the effect of her cancer treatments made her tire more quickly. In addition, other urban husbands reminded their wives to maintain their stamina, particularly in the rainy season, "Please wear your raincoat when [you] drop-off and picking your kids so it will protect you from any health problems" 
(WU1). Further, a few women said that their husbands supported them to join social and health activities in the community:

Alhamdulillah [thank God], he had positive responses, for example, I attended a full day workshop. He supported me. I knew other women sometimes experience difficulties getting permission from their husbands to join any activities, but it did not happen to me. (WR3)

The rural participant with lymphatic cancer shared because of her cancer her mood and physical condition fluctuated. Her husband encouraged her to meet her friends or attend a women's forum, 'When I gathered with friends like this, it refreshes my mind, because I met with friends, so I am happy, and it helps me to forget my disease a while" (WP2). Another rural participant shared some advantages of the social activity for women including women meeting their friends and talking about everything including their knowledge of health, health problems, and food management. Further, husbands paid attention to children's health, in particular, their young children. They advised their wives to keep the house clean and asked children to minimise playing outside especially in the rainy season.

Women from both urban and rural areas mentioned that their husbands were very concerned of healthy food for their families. They provided multivitamins to maintain women's health, and reminded them about eating habits, "Please don't eat spicy food. It's [not good] for your health, and no smoking please" (WU9).

Similarly, two urban participants said that their husbands reminded them about nutrition and selected food for them and their children. Husbands' actions were not only reminding women about healthy food, but they also provided money to buy the food. A few women said their husbands advised them to drink Jaти [traditional drink that Indonesian people believe to have a good effect when women drink it] regularly. "Mah [calling his wife] you have not drunk Jamu for a long time. Right? Let's go to the Jamu shop" (WR10). The women had a similar belief to their husbands regarding drinking Јати being good for women's health. The rural woman with a history of Myoma uteri shared that her husband believed herbal drinks prevented the recurrence of her disease, so he provided many types of leaves for his wife and asked her to cook them. Preventing a recurrence of disease was also reported by the urban woman with the history of uteri cancer: 
I still take the medicines regularly since the uterine surgery, sometimes Ifelt bored, and when it run out I did not tell my husband, one day my condition deteriorated, and he noticed there was no medicine. After that experience, he always controls my stock of medicines. (WU10)

To maintain their family's health, husbands advised their wives about eating healthy food and the importance of children eating well especially daughters, to prevent women's health issues, and children who are still growing and need nutritious food to improve their immune system. "My husband got information from his Chinese boss that young girls should eat vegetables and drink milk, then he suggested it to me and my daughter" (WU7). Many women mentioned that husbands were not only giving health advice to their wives or children, they are also enthusiastically involved in some women's health promotion activities. A cadre from a rural village reported that she knew many husbands who started to participate in the family planning programme as their real support to their wives' health. "As I knew there are men's contraception methods, some husbands in the Pamarican area joined a free vasectomy program from the BKKBN [National Population and Family Planning Board]” (WR9). In addition, three women from urban areas shared that they had medical check-ups regularly with their husband and that they visited the health service together.

Husbands participated in promoting women's health physically and psychologically. A rural participant shared that her husband actively supported her when she faced a problem in her workplace. He provided feedback related to my job, "I talked to him about everything, mostly about family or the children's school, like this or that" (WR10). Further, another rural participant reported that she talked to her husband about anything related to her health, especially about reproductive health. Urban participants received similar support. An urban participant from a downtown area reported that even when she had mild health issues, for example, fever or influenza, her husband called her mobile phone regularly to ask how she was.

Although husbands were supportive in promoting women's health, their behaviour varied regarding the early detection of cancer and some women did not take their husbands' advice about this. A few women, from middle-income urban areas, shared their husbands' advice about cancer screening, and two other women 
shared that their husbands provided facilities to support their health including screening. "I have two private health insurances. I do not know a lot about them, but they provide free cancer screening. I did have regular Pap smears and Mammograms" (WU5). However, several women from urban areas rejected their husbands' advice about their reproductive health. An urban woman whose husband works in a pharmacy company shared that he encouraged her to have early cancer detection tests because he obtained information about it from his colleagues but she did not immediately do as her husband advised. Another woman commented:

I had experience with abnormal vaginal discharge, Pak... [calling her husband] what do you think? [I asked my husband] I have vaginal discharge often, ah...Mah [calling his wife], please go for Pap smear, eeehm.. I am shy; my husband just smiles, he did not force me to do it. (WU7)

Similar behaviour was reported by an urban woman who had experience with cancer;

Yes, actually my husband reminded me about my health and gave attention when I had a health problem. My husband said, please go to the doctor immediately. I answered aah.. this is only a mild symptom don't worry. Maybe if I followed his advice and had gone to the health service, my condition would not be as bad as today. (WU10)

According to the above women's information, husbands paid attention to women's health, but not all women followed the husbands' advice. No rural participants reported their husbands' advice or support related to cancer screening.

To conclude, women perceived that Islamic teachings underpinned Muslim husbands' behaviour regarding women's health and cancer. The data highlights the similarities between rural and urban women's opinions with regard to how husbands applied their many roles in promoting their health, and supporting them when they were ill. However, only a few Muslim husbands were involved in women's cancer screening and prevention, especially in rural areas. 


\subsubsection{Husbands' roles in women with health issues}

Female participants from urban and rural areas shared the importance of husbands' roles in their health. They take extensive actions to help their wives with health issues, including paying attention to by listening to their health complaints and suggesting some health actions. Other actions included providing first aid before taking them to health services, taking over the household tasks when their wives were sick, and taking them to the health service.

Women talked to husbands when they had abnormal symptoms or health problems. Many participants from rural areas shared that their husbands listened to their health concerns.

When I faced a health problem, in particular my woman parts, breast or uterine, I talked to him freely. I never felt shy with my husband. I told him, I felt my "pranakan" [uterus] drop, maybe because I lifted something heavy. I often share my health problems with him. (WR3)

Husbands not only listened to their wives' complaints about their health, but they also paid attention to women's conditions, offered the women help, or provided advice to address the health issues.

Husbands were reported to pay full attention to women's health by rural and urban participants. An urban woman whose husband works in a different city shared that he called her regularly to ask about her health. Another urban woman said that her husband came home early from work when he knew that she was unwell and needed his help. Similarly, rural women felt that husbands paid attention to their health. "I always talk to him about my health issues, and then he offers some choices; take a rest at home or visit the health professional" (WR5).

Women shared when they were sick; husbands showed their support by taking over women's domestic responsibilities, including, washing the clothes, cooking food and taking care of children.

When I was sick, honestly, he was a good man. He helped me with household tasks, providing food and lunch boxes for the children, and dropping off and picking them up from school. I could take a rest because he handled 
everything. We don't have a washing machine, so he did the washing manually. (WR10)

An older rural woman mentioned that her husband took over all the household tasks when she was sick or fainted because of heart problems and their daughter could not help them because she had their own family. Similarly, urban participants shared that their husbands helped with household tasks, especially those related to food for families when their wives were sick.

Women shared that husbands provided money for women's treatment to solve women's health issues. A rural participant said that when she told her husband about her health issues he paid for her treatment because he is the breadwinner. According to the women's interviews, husbands did a lot to help women with their health issues. "Like this, when I told him that I felt unhealthy, he rubbed me or gave me a massage, and suggested I take a rest" (WU2). Husbands provided a rub or massage for mild health issues, and when this did not help, they took their wife to health services or an alternative therapist. The alternative treatments are done by a therapist, for instance, Orang pintar [traditional therapist], or Saman:

My husband, took me to alternative therapies in different cities such as Tasik, West Java or Cilacap, in Central Java. When he got information about an "orang pintar" in a region, he took me there. Sometimes I refused, but he said I have to recover and be healthy, so I followed him. (WR2)

The urban women with a history of uteri cancer shared that she and her husband visited the therapist as part their effort to solve her cancer. They wanted an alternative treatment and a second opinion besides the health services; unfortunately, it did not help her.

Taking medicine was the next action when traditional therapies could not help women. Women from urban and rural areas reported that it was common for rural people to take medicines provided at home or bought in a small shop near their home, and for urban people, to take medicines purchased in a minimarket. The medicines are typically analgesics or antipyretics, and a prescription is not needed to buy them. 
He consulted with a pharmacist about my health symptoms and bought medicines from the pharmacy, or he provided some medicines at home, including paracetamol. When I got a fever, he massaged me, then observed me for two days. If my condition deteriorated, he gave me paracetamol. (WU7)

When the common medicines were ineffective, most husbands in rural areas took their wives to the PHC, whereas urban husbands tended to take their wives to private health services, either a hospital or a doctor. Most women followed their husbands' advice to go to health services; however, a few of them refused. "I put my hand on my head, my husband was concerned and asked me "What's happen? Let's go to the doctor". No..eehm I just little bit tired, nothing bad, but he directly asked me to go to the doctor immediately. (WU10)

Husbands' behaviour differed when they took their wives to health services. The behaviour included accompanying their wives into the doctor's room, "Yes he went into the doctor's room. He then asked the doctor about my disease and the food he should provide for me" (WR1). A similar opinion was shared by a participant from an urban area.

Oh always, I mean he always accompany me, he never lets me go to the doctor by myself, except when he was away from Bandung. He is always there for me, even when he was working, he would come home immediately to take me to the doctor. (WU2)

Other husbands dropped their wives at the health services and remained outside while their wives visited the doctor. A few husbands also behaved like a taxi driver and just dropped their wives and left them. Others had different experiences; husbands let them go to the doctor, midwife, or Public Health Centre (PHC) by themselves. "He never dropped me to the doctor, maybe because I haven't experienced a serious illness" (WR3). In addition, an urban participant said her husband did not want to accompany her to the hospital because of some reasons, including personal experience with medical treatments, for example, he is afraid of needles. Another reason was that husbands felt sadness, pity, or regret about women's conditions, especially husbands whose wives had cancer. The urban participant who had a cancer history shared that her husband did not want to see her 
invasive treatment. He preferred to stay at home and support her with Doa [praying to Allah]. A different reason for not accompanying a women to hospital was shared by another urban women. She said that her husband trusted her choices because he knew she had a high concern for her health. "My husband was never fussy with my health. He only observed my actions to solve my health problem. That's how he supported me" (WU8). Some husbands fully supported the treatment processes and encouraged women to follow the health professional instructions. "The doctor said you need radiology assessment, eee... my husband supported me...let's Go for rontgen, he said" (WR4). However, other women had different experiences. A few women from rural areas were rarely ill, so they refused husbands' advice, especially when it related to being hospitalised.

Eeehhmm. How to say. Honestly, I did not want to be hospitalised when I had typhoid. I did not consider it a big problem. I thought it was just a mild disease, but my husband said, "Please... you have to recover and stay healthy, let's go to hospital". (WR10)

The woman from the urban area who suffered from lymphatic cancer mentioned that she refused the doctor's advice for surgery, even though her husband had tried to persuade her.

The majority of women considered their options for assistance when deciding on actions for their health. These included various sources such as immediate family, friends and community leaders. Even though women reported different sources who helped them to make decisions about their health, most followed their husband's advice particularly when their disease was not life-threatening. A few decided by themselves, and some women were helped by their children or community leaders. One woman explained why she followed her husband's advice and why husbands are dominant in a Muslim family. "I followed my husband's advice because he is the breadwinner. He is working for us. I don't have any jobs. He advised, provided money, then took me to the health services. We visited it together" (WR9). However, the data from the women participants generally revealed that those with a serious disease tended to make their own decisions regarding their treatment. 
Nobody in my family; children, sisters, had strength enough to sign the consent form for my uteri surgery. This also included my husband, so I signed it myself. That was my decision, so there would be no responsibility to anyone else if I die. My husband only supported me. He would not say anything. He surrendered to my decision, so there would be no regrets in the future.

(WU10)

The rural woman who suffered from myoma uteri had the same experience. She delayed the surgery because she was not ready even though the doctor and family advised her to have it. When the vaginal bleeding became severe and recurrent, she became afraid and decided on the surgery. The rural woman who suffered from lymphatic cancer also ignored the health professionals and her husband's advice to have surgery. She preferred to do alternative therapy, and her husband supported her.

\subsection{Family circumstances and social support influence Muslim husbands' roles in women's health and cancer}

\subsubsection{A particular situation in the family}

Women from urban and rural areas shared that their husbands' actions in taking care of their family's health were various and were influenced by changes within their family. These included having children, a new job, getting old, and developing a chronic disease. Younger women from rural areas said that since they had a baby or grandchildren, husbands paid more attention to the family's health. While an older woman from the urban area reported the opposite:

Eeehmmm... after our children grew up and had their own family; he rarely accompanied me to health services. I am independent, and it is quite different from when our children were young. He was beside me when I needed him.

(WU8)

In addition, a few older women from rural areas commented that their husbands' ages influenced their behaviour, "The older, the wiser to me, children, and community" (R7). However, an urban woman reported that her husband became 
childlike when he grew older. He asked me to accompany him everywhere and paid more attention to me particularly regarding my health. Moreover, husbands' occupations were identified by a few women as a factor that influenced men's behaviour:

Before he developed his own business, he was a caring dad. He worked in a pharmacy company and would take time off when a family member was sick. It is different today as he has his own pharmacy company and his clients need him. If he's absent from his business because of one of us is sick, who will cover the family expense? (WU7)

In contrast, a young woman from the rural area said that when husband did not have a permanent job, they spent a lot of time with their friends, but after he got a permanent job, he paid more attention to family health and had regular quality time with their children.

A family history of chronic or severe disease influenced husbands' behaviour towards their family. The rural woman who had had Myoma uteri surgery and also had diabetes shared her husband often reminded their children, especially their daughters, about living a healthy lifestyle.

Like this Ma'am, my daughter has a habit of adding condensed milk when eating sweet meals. My husband reprimanded her and said, "Don't overeat sweet food, it would prevent you from diabetes, you know your mom has diabetes". My blood sugar is not yet stable. (WR8)

Similar behaviour was mentioned by the urban woman who had experience with uteri cancer. Because of her history of illness, her husband was concerned about their daughters' reproductive health:

My husband and I gave the same advice to our daughters. We said "if you have irregular periods, don't delay to go to the OBGYN speciality and don't use any contraception. The intrauterine device (IUD) is dangerous because it could be rusty, pills or injections could influence your hormones and have 
many side effects. There are many high risks from contraception methods". (WU10)

Family dynamics influence husbands' behaviour and these can be positive or negative to the nuclear family members. The nature of family circumstances differed between young and older families, young and mature children, types of jobs, and those who had and those who had not had experienced severe diseases.

\subsubsection{Other sources which support husbands' roles.}

One woman's source of advice and support was from the community leaders who have large roles in communities and provide many services, including some relating to health. They take action when their community members suffer from lifethreatening diseases. Many women from rural areas postpone going to health services because they lack awareness, knowledge, and financial resources and rely on their community leader for guidance. As one interviewee related:

I thought about the hospital fee. I felt my money was not enough, but 'Pak

Kadus' [the community leader] said "let's go to the hospital. I will cover the hospital fees. The most important thing is your health". Another source was 'Forum Dusun' [a neighbourhood], who also helped with the hospital fees and mentioned that my health is the focus. (WR7)

In the low-income group, the roles of husbands were supported by community leaders and community organisations. The community leaders have a good understanding of the government health subsidy programmes and the administrative requirements in the referral hospitals. The final source of assistance was children, in particular, adult children. Adult children helped an urban woman to decide the best treatment for her in an emergency situation.

My children motivated me, and they decided to take me to an international hospital overseas because my condition was fragile and they found a doctor, a specialist in cancer. My children took me there, and my husband stayed at home. (WU10) 
A rural participant shared that her husband wanted to participate in women's therapy processes; however, he faced some burdens, so he delegated their children to take care of her;

Like this Mam, my husband is already old, and I could not imagine him accompanying me in a big referral hospital where he would not know the hospital areas, so we rely on our children who are more experienced and nimble. (WR8)

Female participants who had adult children involved them in their health, especially when they diagnosed with a deadly disease and their father was old and needed help himself.

Husbands play significant roles in their wives' health, especially in relation to their recovery. The support they gave included providing facilities, helping with household tasks, being psychologically supportive such as listening to women when they talk about their health problems, encouraging them to follow the doctor's instructions, and supporting women's decision. Family circumstances also affected husbands' roles in women's health. The severity of a woman's health issues influenced her husband's actions. Women with severe health problems tended to decide their medical treatment by themselves rather than discuss it with their husbands and husbands allowed their wives to decide on the most suitable treatment for themselves. Also, husbands were supportive by providing facilities. External sources and family members provided further support for women's health.

\subsection{Husbands' health literacy influence their roles in women's health}

The majority of women in urban and rural areas stated that they have never known a health education programme related to women's health that targeted Muslim husbands. There are almost no programmes related to women's health education that involved husbands. "Here, I think the health education for husbands is so rare or has never existed. I am not sure, but I never saw a husbands' gathering discussing women's health" (WR10). A few women said there was health information for husbands, but the topics were not related to women's health. 
As far as I know, there has never been any health education programmes for husbands in this village, but I recall a seminar about disaster management managed by PHC XX last year. Yes, there have not been any topics related to women's health. (WR4)

Furthermore, an urban participant shared that a PHC in their area organised a health education programme, but the topic was about elderly people's health. The PHC invited elderly couples, and most of the elderly attended the programme with their spouses.

Women from urban and rural areas have the opinion that women's health information for husbands is important because they perceived that husbands have overall responsibility for their wives and families and this included health. In addition, many woman described other advantages of husbands' knowledge related to women's health, including them deciding on the most effective actions for their wives. However, a few woman said that husbands give little support for women's health activities. This could be because of their limited knowledge of women's health. A participant who had had previous roles as a cadre commented:

Based on my experience as a cadre, many men did not care for their wives' health. It was very difficult to invite them to a health education event, such as a discussion forum. I faced many burdens when inviting them. Even when the committee provided money for them, they still did not come. (WU6)

In addition, women talked about the potential use of media to improve men's knowledge about women's health. Women from urban and rural areas had different preferences relating to media information for husbands. "Inviting men to the community hall, I think would be good. Men can talk to the health professional directly" (WR7). Rural women also described other potential media for their husbands, including TV programmes or getting health information via their wives, it means the health professional provide information to women, then women share the information with husbands. While women from urban areas preferred indirect media information: 
Maybe like this, the health professional joins in men's routine activities. For example, a weekly sports programme, so the health professional is proactively approaching men, and discusses health topics in general, and continues to women's health topics. (WU6)

Furthermore, urban women suggested other potential media to enhance husbands' knowledge of women's health, including providing a booklet that contains women's health information and informal discussions about husbands' health mixed with women's health information. Women reported a lack of health education programmes for husbands which affected husbands' roles in women's health. As a result, a few husbands did not pay attention to their wives' health. Women from rural areas suggested direct communication methods to improve husbands' knowledge, for example inviting husbands to the PHC for a health education program. While, urban women preferred indirect methods to encourage husbands to become involved in women's health, for example, TV programmes or internet news.

\subsection{Conclusion}

The data from the interviews with 20 married Muslim women from rural and urban areas of West Java showed that husbands' actions in many aspects of health were underpinned by the basic rules of Islamic teaching. Husbands are the main support for women and families in promoting health, and they are also the primary source of full support when their wives faced health issues. However, in rural areas, they were less supportive because of many limitations, for example, age, distance, and knowledge. Children, relatives, and community leaders provided secondary support. Husbands' actions with regard to women's health were influenced by the severity of women's illnesses and family circumstances. In addition, when supporting their wives, husbands faced burdens such as their limited knowledge of women's health and limited sources of information about women's health. 


\section{Chapter 7. Health Professionals' Perspectives of Muslim Husbands' Roles in Women's Cancer}

\subsection{Introduction}

This chapter presents the health professionals' opinions related to Muslim husbands' roles in women's health and cancer in rural and urban areas. Ten health professionals from different professions, including physicians, nurses, and midwives, took part in these interviews. They came from different health services, including Primary Health Centres (PHCs), hospitals, and Bidan Desa [the midwifery service that has the main responsibility to cover the community's health in a village, especially women's and children's health]. These interviews were undertaken to address the research objective: to explore health professionals' perspectives of Muslim husbands' roles in women's health and cancer. The health professionals' characteristic is also introduced in this chapter.

The analysis revealed four themes regarding the health professional's opinions about Muslim husbands' roles in women's health and cancer. The themes were: 1) Contextual factors influence husbands' behaviour in women's health and cancer; 2) Women's health conditions influence husbands' actions; 3) Family and health services impact on women's health decision; and 4) Level of health literacy affects husbands' actions in women's health and cancer.

\subsection{Characteristic of participants}

Of the health professionals who participate in this study, five were from urban areas (four midwives and a registered nurse) and five were from rural areas (two general practitioners, two midwives, and a registered nurse). The health professionals all had experience with health promotion, prevention, screening, and treatment. Table 11 presents the characteristics of the participating health professionals. The health professionals, all of whom were women, had different professional experience and education. The urban health professionals were two midwives who worked at a PHC, two midwives from outpatient services, and a specialist maternity nurse from a gynaecology ward of a national referral hospital in Bandung. The midwives graduated from the Academy of Midwifery with a level III diploma, and the nurse graduated from university with a master's degree. The 
sociodemographic characteristics show that the urban health professionals had been working in health services for an average of 5.7 years (range 2-10).

Table 11. Characteristics of health professional participants

\begin{tabular}{|l|r|l|l|l|}
\hline No & Years of work & Workplaces & Profession & Education \\
\hline HU1 & 4 & PHC & Midwife & Diploma III \\
\hline HU2 & 2 & PHC & Midwife & Diploma III \\
\hline HU3 & 4 & Hospital & Midwife & Diploma III \\
\hline HU4 & 8.5 & Hospital & Midwife & Diploma III \\
\hline HU5 & 10 & Hospital & Nurse & Master, Nurse specialist \\
\hline HR1 & 16 & PHC & Doctor & General Practitioner \\
\hline HR2 & 23 & PHC & Nurse & Diploma III \\
\hline HR3 & 17 & PHC & Doctor & General Practitioner \\
\hline HR4 & 11 & Community & Midwife & Diploma III \\
\hline HR5 & 17 & Community & Midwife & Diploma III \\
\hline
\end{tabular}

HU: Health provider from urban areas HR: Health provider from rural areas

The rural health professionals were two doctors, two midwives, and a nurse. The doctors and nurse worked in PHC, and the midwives worked as a Bidan Desa. The midwives and nurse graduated from the Academy of Midwifery and Nursing with a level III diploma, and the doctors graduated from university with a bachelors degree in medicine. They had been working in the rural health services for an average of 16.8 years (range 11-23). There is a difference between the rural and urban health professionals in the years they have worked in their professions. All health professionals in rural areas had worked for more than 11 years, whereas the urban health professionals had worked for less than 10 years. The majority of health professionals had limited experience of cervical cancer screening procedures. The following four sections present the themes.

\subsection{Contextual factors influence husbands' behaviour in women's health and cancer}

Health professionals identified age, jobs, culture, religion, and education as influencing men's behaviour in women's health. According to the health professionals, the behaviour between older and young men, when they accompanied their wives to health services or interacted with health professionals in the community, was different. Older men relied on their adult children to support their mothers' health, especially from rural areas. For example, when a wife goes to the PHC and is referred to a hospital in the city. "Older women in Indonesia, they would 
depend on their children, not their husband, maybe because the husband is also already old" (HR1). Reasons for this delegation, described by health professionals, included: older men's lack of familiarity with transportation to the capital of the district where referral hospital are usually located. Further, older men rarely went to the city because it is far away from home and they have no particular reason to go to the city, and so they are not familiar with the city's facilities.

The health professionals considered that husbands recognised that it was very important to assist a family member who was sick in a referral hospital. The health services, especially in a big referral hospital, have many facilities to support the diagnosis but, unfortunately, one service in the hospital may be located in a different block from the others, and family members have to move quickly between them. This is difficult for older men. Patients' families have significant roles in inpatient care, for example, when a patient needs a blood test, the nurse would take a blood sample from the patient, and the family is responsible for paying for it and taking the sample to the laboratory.

When we explain about their mother's conditions, commonly, young people quickly understood, and they had fast reactions, so the treatment or medical procedures for the patient were quickly decided. When we spoke to older people, we needed to explain several times, and unfortunately, sometime the treatment processes were complicated and difficult to follow by them. (HR2)

The third reason for adult children involvement is older men have had less experience in health procedures, especially in a big hospital, such as administration requirements, payment systems, laboratory or pharmacy services. Lastly, young people find it easier to understand and follow the health professional's instructions or health education.

Even though children took over their father's roles, the older men were reported to show more interest and care in their wives' health than the children or younger men.

Because older men had the experience related to their wives' health they asked detail questions related to their wives' condition, it was different with young men, maybe they were a shamed or didn't know exactly, eehhhmm...what's 
that...they rarely asked questions, when I tried to encourage them by asking whether they understood or not, then they gave their opinions, so I needed to stimulate the discussion, it is different with older men. (HU1)

A midwife from an urban area said that older men asked her about women's conditions, diet, and therapies. When they had different opinions to their wives, they could handle the interaction well. Young men were the opposite; they were passive in a discussion related to women's health. The health professionals said they tried to start the discussion by asking questions because they wanted to know the women's family understanding, especially about procedures and treatments.

Older men were reported as being faithful to their wife if she suffered from late-stage cancer. A maternity nurse who worked at a national referral hospital stated that older men tended to always be on the woman's side.

An older woman patient of mine said that she asked her husband about his sexual needs, she gave permission if her husband wanted to marry another or visit a prostitution service, because she was aware of her husband, respect him, and understood about men's sexual needs but the husband refused it. (HU5)

He said taking care of his wife was part of his responsibility and his sexual needs were not the priority. The priority was to support his wife and to stick together through "thick and thin". Although not all older men supported their wives, the health professionals reported that the majority did. One nurse shared that a man younger than 35 years old who had a wife with coitus bleeding preferred to divorce her rather than maintain their marriage.

The health professionals also considered that men's occupations were another factor that influenced husbands' actions regarding women's health, especially when their wives were sick. The majority of rural men are farmers while men from urban areas have various jobs, including being businessmen, private employees, soldiers, and government officers. Health professionals in rural areas mentioned that farm work could be a burden for a man who wished to assist in his wife's health, especially if their wives needed their help to take them to a health service. "I don't think these men would take their wives for treatment to a PHC because, in the 
village XXX, 80-90\% are farmers, they say they're too busy" (HR5). In rural areas, men go to the paddy field early in the morning and come back home at midday, and as the main health service in the rural area is a PHC with opening hours from 8 am to 12 noon, it is difficult for men to manage their time to take their wives to the PHC. "If a female patient is visiting the PHC and her husband dropped her off, commonly, he was not a farmer" (HR2). The men from rural areas who had time to take their wives to the PHC were usually a government officer or a trader in the traditional market.

Here, a trader in a traditional market, they are not going to the market every day, twice a week so that they can drop their wives to the health service, and an officer in the local government or other institutions but I rarely saw a wife of an officer with cancer. (HR2)

The health professionals from rural areas also reported that some farmers made time to take their wives to the PHC, and some government officers or even some jobless men did not take their wives to the PHC.

The urban health professionals shared different opinions about the type of jobs men did that could influence husbands' roles in women's health. Employees could not take their wives to the PHC or a hospital, as it would be difficult to get permission from their office. On the other hand, men who owned their business commonly had spare time to take their wives to health services. In addition, urban people have more choice of health services and open hours than rural people. In urban areas, there are a lot of private health services that open 24 hours so men can take their wives after they finish work. Men accompanied their wives mostly when their wives were pregnant, or their children needed immunisation. Furthermore, some men could not accompany their wives often because they were overseas or working in a different city.

Culture and religion also influence men's actions in women's health. A doctor from a rural area shared that older men and women's behaviour changed, for example, they often had separate bedrooms.

I think, it is part of the culture in this area, when people get older, wife and husband rarely did activities together, including sleep, maybe like that... while 
young couple still go everywhere together, including PHC, older people preferred to go somewhere with their children or relatives, some older people preferred to live alone, and would call their children or neighbour when there were sick. (HR1)

In addition, the health professional mentioned that tribal affiliation could influence a family and men's behaviour. A health professional from the Padang tribe who lives in the West Java province where the majority of people are from the Sundanese tribe shared her experience of the husband-wife relationship in the Sundanese and Padang cultures. She said that in Sundanese culture, men and women have equal roles in the family. They work together to take care of the family, respect each other, and men independently cater for their own needs. Even though the man is the family leader, he would discuss with his wife before making and acting on decisions, including health. Whereas, the Padang culture is very different. A woman provides and services all man's needs, including providing man's shoes before going to the office, preparing food, and taking off man's socks and shoes when they arrive from work. The man decides everything unilaterally, including making decisions related to his wife and children's health. In short, the man's position in a family is like being a king.

Religious beliefs play a major role in men's attitudes to women's health. Men who are religious treat and protect their wives properly. Health professionals from both areas said that religious men take care of their wives in the PHC or a hospital. They identified a religious man from his appearances, in particular, his clothes and beard. The man asked questions about women's health issues and everything related to disease, including diet, activities, and medications. The health professional considered that a religious man understood that this is part of his roles and responsibilities as a Muslim husband and a worshipper of Allah.

A husband has huge roles related to wife's care. In my opinion, it depends on the level of the husband's religiousness especially when dealing with a wife in a severe condition or dying. I said in a case of a severe disease, Ma'am, if the husband has a good understanding of Islamic teaching, he showed his love and actions as his responsibilities as a Muslim husband and tried to do the best actions to help his wife. (HU2) 
Based on Islamic teaching, it is a requirement for husbands to take care of their wives. The health professionals said that men who have a wife with cancer who is hospitalised in the women's surgical ward said that they did their roles because they believed marriage is not only for sexual purposes, but a responsibility to take care of each other. A speciality maternity nurse reported that a man whose wife had cancer said that fulfilling the sexual need is marital satisfaction for some men, but that the main purpose of marriage is for husbands and wives to take care of each other in good and bad times. However, there were a few cases; men preferred to divorce after their wives diagnosed with cancer.

Yes, because of culture, religion, and education level, as I knew a few Muslim men, who know that it is compulsory to look after their wives in all live aspects. Then, if they divorced their wives, it could be because of a specific reason. In a small percentage of cases, I knew they divorced after their wives diagnosed with cervical cancer. (HU5)

Men also believed in the social law, that is, when they did not take care of their sick wives, the family and community would label them as men who did not take responsibility for their family.

In term or the health professional gender, no health professionals from both areas shared experience about men requesting female health professionals for their wives. However, two health professionals from rural areas, a nurse and a doctor shared their concern about it. They shared that commonly, male health professionals in PHC referring a female patient with women's health issues, for example, vaginal bleeding or breast lump, would refer to a female health professional. Similarly, active roles of health professional related to the gender of health professionals were also reported by a midwife from a referral hospital in an urban area.

In this hospital... a public and a teaching hospital, no choices for patient about who will assess a woman patient, but I respect to a patient who has a look as a religious person, for example, she wearing "niqab” [a piece of cloth worn by some Muslim women to cover the whole face except the eyes]. I tell her that "no special [a woman] doctor" for you, then I provide information about the 
doctor who on duty, and she dicides whether she want to continue the service or not. (HU4)

According to the health professionals, the level of men's education influences their knowledge, understanding, and actions regarding women's cancer. They said when a man had a good understanding and a wide view related to women's health, it is easier for the health professionals to explain about his wife's disease and treatments. Men who have a high formal education pay more attention to their wife's illness compared with men with low education levels. A health professional from an urban area who works in an outpatient room speciality in women's cancer said that it was so difficult to explain about a medical procedure to a man with a low-level education.

Commonly, there is a husband who has great difficulty understanding our explanations. I said...Pak [Mister], you need to do this and that, "sorry Ma'am, I don't understand, what do you mean?" I explained, again and again, I then met my colleague, who asked me if I have explained to the patient's husband about the procedures. I replied that I had and asked why. Because she replied, he told me he doesn't know about the procedure...I am aware that his education was only elementary school, maybe my language was difficult to understand. (HU4)

Education also affects men's actions relating to women with cancer. A nurse from a rural area described the behaviour of a man to his sick wife.

Yeah. it depends on the education level...yeah economic status also, but education makes a big influence... Men who have had a high education have wide views about many things, including health, compared to those with a rudimentary education. I mean, the former shows their empathy, attention, and their caring for their wives differently. I had an experience with a woman patient, her condition was very weak, and she needed bed rest, but her husband forced her to go to the paddy field, it is true she could walk, but she was sick. (HR2) 
The health professionals shared that well-educated men had a positive behaviour; they took considerable interest in the diagnostic and treatment stages. They took care of their wives, and when the health professional explained a medical procedure for their wives, they could understand the meaning. They also provided an opportunity for their wives to give her opinion or decided what she wanted; they were aware of their wives' autonomy, and they were supporters.

The health professionals expressed that attitudes also influence men's behaviour. Different men's attitudes showed different actions with regard to women's cancer. A nurse from a rural area said she found some men who were ignorant. Similarly, an urban health professional shared a man denied the fact that his wife was really ill, even though he knew her condition, or he was selfish.

I had a woman patient with myoma uteri, and she had not had a child. She was 44 years old, the doctor advised surgery, but her husband really wanted a baby, so he refused and wouldn't let her have a hysterectomy, he wanted an alternative therapy for his wife. (HU3)

In contrast, a midwife in an urban area reported a positive outcome for a woman when her husband, a "caring man", paid high attention and actively engaged in her health. She had obtained a good recovery from breast cancer therapy achieving the maximum result from the treatment. A rural midwife stated that open-minded men were more empathetic to women's conditions. They paid attention and supported the treatment process. A midwife reported her experience of a man who was shocked about his wife's condition, he became an introvert or depressed, and was confused by the health professional's explanations, and didn't want to talk to others.

To conclude, the sociocultural factors, including age, occupations, cultural and religious backgrounds, and education reported by health professionals from urban and rural areas are factors that influence men's behaviour regarding women's cancer. Older men's physical condition, complicated health service systems, and geographical burdens are identified as men's reasons for delegating their roles in their wives' health to family members or other sources. However, the data revealed that children or others could not replace some older husbands' roles. The data showed that most rural men are farmers; this affected their roles, especially in relation to their participation in the health services, because their work hours differed 
from the PHC's opening hours, while urban men have various jobs and can often ask for time off to support their wives in the health services.

\subsection{Women's health conditions influence husbands' actions}

A woman's health condition influences her husband's behaviour. All health professionals stated that husbands actively participated when their wives were sick; however, they often do not provide attention when their wives are healthy. Husbands from both urban and rural areas took their sick wives to health services, and health professionals identified four different behaviours of husbands during these visits. First, husbands were like drivers of public transportation, "most of them like tukang ojek [driver for public transportation using motorcycle], they dropped their wives and then left her in the health services" (HR5). Second, husbands waited outside the doctor's room. Third, a few husbands accompanied their wives into the doctor room, but they did not get involved in discussion with the doctor or other health professionals. The fourth is husbands who accompanied their wives into the doctor's room and had an active discussion with the health professionals: nurses, midwives, and doctors.

I have experience with a woman cancer patient who has an amazing husband, he came to the hospital and told me about his wife who lost her appetite and weight. I educated the husband about the cancer diet, I asked him Pak [Mister], you should help your wife to eat properly. In my opinion, the first role of the husband is giving support, I saw the patient look comfortable when the husband accompanied her to the health procedure such as blood check or radiotherapy, and supported her psychologically. (HU3)

Providing psychological support is part of husbands' actions in the hospital. Other actions included husbands actively discussing with nurses or midwives in the ward about diet, medicines, or asking for strategies to keep their wives motivated during the long process of cancer therapies.

Urban men who accompanied their wives to a health service had significant roles in their wives' health. They accepted what they were told and agreed when the health professional explained about the best treatment for their wives, including 
referring her to the hospital. Health professionals also gave examples of how husbands behaved positively towards their wives in the hospital.

A husband who accompanied his wife for a blood check or her weekly chemotherapy told her to sit down in the waiting room, while he went to the nursing station and provided the nurse the results of the laboratory. Then he accompanied his wife to the therapy room for chemotherapy and other hospital services. (HU4)

The urban health professionals shared other roles husbands undertook when their wives were diagnosed with cancer. When their wives needed further treatment, they would come to the PHC weekly to process the paperwork. Husbands gave their permission for a medical procedure, supported their wives' needs in hospital, accompanied their wives to the hospital, and consulted with the health professional about their wives' health progress. Furthermore, urban husbands were able to easily understand the health professional's explanations about treatments and medical procedures.

According to the health professionals, husband's support is very important for the treatment processes because when a woman is hospitalised, she needs medications and laboratory tests, and when family members do not support her treatment, she will face many burdens. For example, when a woman needs medications, a family member would take the doctor's prescription to a pharmacy and purchase it. If there is no family support, she would be unable to get the medicines. Not all urban husbands support their wives when they are sick, some of them face obstacles, including working in a different region, and some husbands are afraid of medical procedures. A midwife explained that a woman with cancer who was not accompanied by her husband had support from her extended family and recounted a story of such a woman. "So the roles of the patient's wider family is huge here. A woman came to the hospital accompanied by her mother, aunt, and also her mother in law" (HU3). Other support for urban women came from a nongovernment organisation concerned with women's health.

Health professionals from rural areas told of how some husbands delegated their responsibilities to family members or external sources. One rural health professional working in the PHC noted that husbands rarely accompanied their wives 
for consultations or procedures, and stated "The majority of them [women] came to the PHC with someone other than their husband. These were often a neighbour, relatives, or cadre; few men accompanied their wives" (HR1). Other rural supporters are community leaders. These people are familiar with the health services and the administrative requirements in a referral hospital. HRI commented further and said:

A women patient in this area went to the PHC with a Bidan because commonly this is the first health professional she approached and people working here are informed about disease related to women's personal organ (vaginal bleeding for example), but when the health problem is related to breast problems, she will come by herself. (HR1)

According to a doctor at the PHC, women with vaginal bleeding from rural areas preferred to go to health services with another woman, and some attended with a local cadre. Cadres have essential roles in women's health in their areas and assist women with health problems and the administration procedures of health services. A midwife said that cadres are very important to support women's health. They are the front line of health services, and we have trained cadres about referral administration requirements. When a woman is sick and needs to be referred to the hospital, cadres help with the requirements. In addition, health professionals shared that adult children are often involved in their mother's health as they preferred to go to health services with their children because they feel more comfortable with them than they did with their husband. Most women who have cancer are 50 or older and so they commonly have adult children.

So when I advise some recommendations related to women's health, talking to adult children is easier than talking with the older husband as they are still fresh and understand my explanation. This was my consideration; another consideration is the financial aspect. The patient needs transport to visit the PHC, and as motorcycles are the cheapest mode, young people are more competent riders than older people. It is dangerous for older people because most of the roads are damaged. (HR1) 
The health professionals identified a health agent as another source who accompanies women in hospitals. Health agents are common in a big hospital. They are paid by the patients to escort them when they have to go to various services. Some agents follow the health professional's instruction, while others, because of their experience with cancer patients, do not. However, not all women want someone to accompany them when they visit health services. A midwife from an urban area said that young women preferred to go to health services by themselves, especially when the health problems related to their vagina or breasts as they felt that because the problems concerned their female parts, it was their responsibility as a woman. A similar opinion was shared by a nurse from a rural area. She mentioned that young women visit health services by themselves because they are still young and can cope with their problem by themselves.

Health professionals considered that there was a lack of support from men for women's illness prevention and early detection of cancer. As opposed to supporting then for cancer treatment, the interviews revealed that husbands are not active in illness prevention and early detection of women's cancer. Health professionals in rural areas said that husbands were not concerned with preventive actions or early detection actions for their wives' health. They think that as long as she does her daily activities, she is healthy.

My opinion, eehhmm.. Ma'am, rural men, most of them are not aware with early detection. You know in a rural area, as long as a woman can walk, it means everything is fine, or her husband think, she is only tired and needs a rest, but when the woman's illness became severe, the husband is confused, and he does not know what he should do. (HR3)

Furthermore, a rural midwife shared her opinion of a few men in rural areas. She said that a few rural husbands had the perception that women's bleeding was a common problem for women, so some husbands have no responses. Husbands also perceived that delivering a baby was their wives' responsibility. Another midwife from a rural area said that married men do not participate in family planning programmes, even though she encouraged them to come to family planning education with their wives, none come. They pay little attention to their wives' health when their wives do not complain about health issues, and when the husbands 
find women's health abnormalities, they sometimes ignore it.

Maybe, I can say, her husband did not care, I know they were always together, I mean he dropped his wife everywhere by motorcycle, so they were close to each other. I wondered why he did not know when his wife had coital bleeding, after the coitus and she experienced pain and cried. It was impossible for him not to know, and as a husband, he has to be concerned about his wife's condition, or think about wife's health symptom. She came to me with severe conditions. (HR5)

A midwife from an urban area recounted similar experiences. She noted that married men participated in women's health prevention activities, including family planning after they had their first child. And then after the second, the third, and maybe more than three children, the husband no longer took an active part and a woman usually came to the health service by herself. This was particularly evident among women whose husbands were working overseas or in a different region.

To conclude, husbands' roles depend on women's health conditions. They actively engaged in women's health when their wives were sick, but they were less engaged when their wives were healthy. Husbands who took their wives to health services displayed different behaviour. Some of them were very enthusiastic to be involved in the treatment processed, while others paid little attention. Further, some husbands provided material and psychological support for their wives' health. Urban married men were more supportive of their wives when they needed to go to the health services, whereas rural married men tended to delegate their roles to children, local leaders, cadres, or relatives. Furthermore, the health professionals from urban and rural areas reported a lack of support from married men in relation to prevention and the early detection of cancer. Also, married men commonly did not accept the health professionals' invitation to attend a health education with their wives.

\subsection{Family and health services impact on women's health decision}

According to the health professionals, husbands make the decisions about women's health, particularly about reproductive health, including pregnancy and delivery. There are four ways of making decisions about women's health. First, 
women rely on their husbands' decision. "I found in my private practice; a woman refers to her husband's decision for this or that, a woman asked their husband first" (HU1). A midwife from an urban area said that women talked to their husbands about their health and followed their husbands' advice. Secondly, some married couples discussed health treatments and decided together whether or not to follow the treatment. The third way is women made their own decisions.

I explained the medical procedure to the woman patient when her condition is reasonable, and then she talked to her husband, they discussed the options together, and the husband provided an opportunity to his wife to decide.

Finally the decision was made by the woman based on her and her husband's sound understanding of the procedure. (HU5)

The fourth way involves the patient and family who rely on the health professional's decisions. This happens when they cannot decide which actions to take.

The health professionals shared women's reasons to follow men's decisions. Rural health professionals said that most women in their areas are housewives and the man is the breadwinner in the family, so women respect their husband and follow their decision.

The decision maker is related to who is the breadwinner, if the husband is a provider of material support, a woman will ask him. If a woman knows that her husband has a financial problem, she will ask for help to the extended family; it could be parents, parents in law, children, and relatives. (HR1)

Similarly, urban health professionals said that women followed their husbands' decision because of financial reasons. Everything about women's health needs to be discussed with their husband because they are related to money. Women believe their husbands' decisions are the best ones because they are decided after discussions with the health professionals and also consider the Islamic teaching. A midwife offered the opinion that women followed their religious teaching which states that a woman has to follow a husband's advice because he is the family leader and is responsible for his family. While, another midwife said that it is part of the culture in this community, that although a woman understood the health professional's 
explanation, she still needs to ask for her husband's approval.

Two factors influence decision processes for women's health, especially when they are related to referring a woman to a hospital. These factors are finance and the community. All health professionals from rural areas shared that married men from rural areas took a long time to decide whether to permit health professionals to refer their wives to a referral hospital. This is because some married men have financial problems and they need to discuss with other people to get financial support. If a woman is suddenly diagnosed with a severe disease and needs to be referred to a hospital, it could be a disaster for a family. Men, as the family leader, might be shocked and realise that they need money for treatment, accommodation in the city, transportation to the hospital, and food for children who stay at home. Men, therefore, search for financial support from many sources, the main sources were family and relatives.

A problem happened when a woman needed to be referred to a hospital, I think it was not because of the difficulty of making the decision and getting permission, but it was because of financial problems. He [husband] then asked why and what would happen in the hospital. I explained $a, b$, c interventions, and he asked how long it would take. I told him it would probably take some time and maybe his wife will be referred to Bandung or Purwokerto. He then discussed with their family for quite a long time. (HR1)

A midwife from another rural area reported that married men who had a financial problem would come to local officers or community leaders and ask for a health subsidy programme or health insurance from the government. In contrast, affluent people, follow the health professional's advice and go directly to a referral hospital. Similarly, a midwife from an urban area noted the husband is the primary source of money in a family, so everything that related to money requires the husband's considerations.

The community factor includes who else influences and supports decisions relating to women's health. Others involved are extended family, cadre, community leaders, and ajengan (preacher). Involving community sources in the health decision was shared mostly by health professionals from rural areas. Health professionals also shared experiences of where husbands required time to talk with their extended 
family, including parents, parents in law, older brothers or sisters, children, or other relatives.

Quite a long time, yes a long time it took for the family to decide when I said this woman needed to be referred to hospital. The family's discussion took quite a long time. When the woman visited the PHC with her children, and I told them of my recommendation, the children said please wait a moment Ma'am I will ask my brother first, then the brother said I need to call my uncle and my father at home, I waited for their discussion but if an emergency situation I would take the patient by myself to the hospital. (HR1)

Another rural health professional added that maybe men felt hesitant when they had to ask someone who is respected in their extended family. Deciding an important thing involved an older brother. Even when the husband had already agreed to send his wife to the hospital, he sometimes thought asking his older brother was a necessity because if something bad happened, the older brother would help him. A rural midwife shared her opinions that married men in her area could not decide about their wives' health by themselves, they needed support from the father-in-law or grandfather, especially when the problem related to reproductive problems, women's cancer or delivering a baby. An urban midwife who had experience working in rural areas shared that, commonly, the final decision was taken by the husband with support from the extended family.

Community leaders helped married men make decisions. A health professional reported that men shared their wives' health conditions with community leaders because the community leader is the one who has a sound understanding of health services in hospitals. A midwife said that when she decided to refer a woman to the hospital, she preferred to ask the local community leader, then the leader could approach the husband using language that was easy to understand.

In fact like this Ma'am, when a woman patient needed to be referred to hospital, the one who played big roles was not the husband, but Pak Kadus [a local community leader], so I preferred to talk to him as he will process the referral letter from the PHC and other administrative stuffs. I don't know, maybe her husband is shy, or he doesn't know about the referral processes, so he delegated to Pak Kadus. In my opinion, becoming a local community leader 
in a rural area is a big job, as a community leader needs to understand everything, including referral procedures. (HR5)

A rural doctor shared that a lack of experience about the hospital services results in rural people being afraid when the doctor says a women needs to be referred to hospital. The word hospital scares them; they ask that the referral processes be delayed as they want to discuss with somebody who can help them, including Pak Kadus

Husbands, especially those in rural areas, involved religious leaders in the health decisions for their wives. Two types of involvement were identified. First, they rely on the ajengan (preacher) to decide women's health. It happens in isolated rural areas.

In rural areas there were many pesantren [an Islamic boarding school]. When a woman patient is from the pesantren needed to refer to a hospital, her family asked permission to the ajengan. When he disagrees it means as the health professional should delay the referral processes. (HR1)

Second, men talk to the religious leader about their wives' condition because they respect them. A midwife from a rural area said that in her area, the roles of religious leaders are significant, they are not the decision makers. "He shared his wife's health problem with the ajengan. He said your wife needs medical treatment soon, so his [preacher] role is a motivator to the husband and the husband took his wife to the hospital" (HR2). The religious leaders were reported to have open minds, and the majority of them support the health professional's decision, they watch television and read health information, and are flexible. Health professionals considered that the non-Muslim man who lives in the rural area was more independent when deciding for his wife than a Muslim man with an extended family. A doctor from a rural area who had experience with a non-Muslim patient mentioned that the man decide faster than a Muslim husband when referring his wife to the hospital. Perhaps, this is because the non- Muslim man is an immigrant and has no extended family close by.

To conclude, women involved their husbands in deciding a health action for them. Two factors influence the health decision for women, including the financial factor and the community factor. Woman depend on their husband's decision 
because they husbands are the breadwinners for their family. Furthermore, married men involve community sources to support their decision about women's health.

\subsection{Level of health literacy affects husbands' actions in women's health and cancer}

Health professionals from both areas agree that married men have limited understanding about women's cancer and this might influence their actions. They shared information that husbands offered little support for their wives' health. They also shared that there is limited health education programmes about women's health, especially women's cancer that involves the participation of men. A midwife from a rural married men did not accept the midwife's invitation to attend a health education about women's health, including a family planning programme. Further, husbands did not take their wives to the health services for illness preventions or early detection of women's cancer, nor were they interested in accompanying their wives for a health check. They let their wives go into health professionals' room by themselves. "They preferred smoking outside the health services' room rather than accompany their wives into the doctor room and get information about her health from the health professionals" (HR2). Married men's behaviour indicated that they had a lack of knowledge about women's cancer. This was also shared by health professionals from the urban areas. A midwife in a referral hospital said that husbands tend to rely on the health professionals' decision about women's treatment without any clarification about the treatment purposes or procedures. "Commonly they said I don't know the best one for my wife; I follow your [health professionals] decision (HU3)". Information from a midwife from a rural area about early detection of cancer was similar to that of a midwife from the urban area who said that women visited the hospital for a Pap smear by themselves.

Health professionals from rural areas said that no health education programmes had been developed by the PHC or the health department about women's cancer, especially prevention and early detection for the community. One rural health professional commented: 
I attended a health education programme at the district level delivered by the health department. We were trained in surveillances, but there was no training or workshops relating to how to do early detection or use the early detection tools for cancer detection". (HR2)

In addition, a doctor from a rural PHC commented similarly about the lack of health education programmes for both men and women in the community.

We did a Pap smear event. It was a health education programme for prevention and early detection and a free Pap smear test in collaboration with a third party, a women's organisation. It is the one we have done because the budget is limited and it is difficult to develop health education programmes about women's cancer without a budget. (HU1)

Health education relating to women's cancer is not a priority for PHC. A midwife from a rural area shared that there is a health prevention and promotion department in each PHC, yet the focus of this department is about clean and healthy lifestyle and HIV AIDS. Sometimes they do health education in a school about drug abuse, or in the community about tropical diseases, including malaria and dengue fever. A similar opinion was shared by two PHC midwives from urban areas. They said there were no specific health education programmes about women's cancer for men, but they invited husbands to their prenatal class. Different opinions were shared by health professionals who work in a referral hospital. These health professionals care for many women with cancer. As they had recognised that women needed support from their husbands, they developed a health education programme in the hospital. The content was not about preventions or early detection but mainly about medications, side effects, and other treatments. This programme was developed for women's families including spouses, children, and parents.

The health professionals agreed that knowledge about women's cancer is important for married men because, as a couple, men and women need to respect and protect each other, including in their health. An experienced health professional from the rural areas mentioned that married men need to know about women's health, including cancer, because they have to know the women's health conditions, so they can take appropriate actions to help their wives. 
Yes, it is necessary for men to know, so if somethings happen to their wives, if cancer detected and already in the advance stages, how come? So he needs to know, maybe he can support his wife when she is sick, or if there are symptoms of a health problem, he recognises it and can respond quickly. (HR4)

In addition, the two midwives who work in an outpatient service in a gynaecology department in an urban hospital said that it is important for husbands to know their wives' health conditions. The wife's health is the husband's health, so a health education programme should cover both of them, especially to support survival from an early cancer diagnosis. The midwives shared that it would be difficult for a referral hospital to develop a service for husbands that focused on the health promotion and prevention of cancer patients. This is because hospitals faced some challenges, including negative responses from the management of hospitals about providing room for health education activities in outpatient services and husbands found it difficult to understand the health education explanations from the health professionals. Also, the majority of patients referred to the hospital were in the late stages, so prevention and early detection materials were not suitable for their needs.

Different experiences were shared by a nurse who managed women's cancer patients in a women's ward; she told of a health education programme she developed for cancer patients and families. Her programme involved all health professionals from different professions who were responsible for the patients in the wards. She stated husbands obtained information about women's cancer from their peers who had a family member as a patient who had been hospitalised for a long time and was accompanied by their husband. These husbands would share their experience with husbands of new patients.

Involving the media was proposed by a health professional to enhance husbands' knowledge of women's cancer. In addition, a doctor in a rural area mentioned that the religious leaders, cadres, community leaders or local leaders are some sources who are close to the community and could potentially improve husbands' knowledge. 
The most effective source is the local government leaders, there is a monthly meeting for all local leaders in this region, where they address to introduce the government programmes. We can use the monthly forum for a health education, and the local leaders can share the health information with the people in their areas, even though they are not able to inform all people, but it better rather than nothing. (HR1)

Other rural health professionals indicated that flyers, television programmes, short movies were other media alternatives for husbands' health education. In addition, two rural midwives shared that inviting husbands to a community centre and talking to them in a friendly atmosphere could be a good venue for a health education programme. Health professionals from urban areas who work in the PHC preferred to do counselling by visiting the patient's home or inviting women and men to a discussion forum. Health professionals in the referral hospital mentioned several methods of health education including a pamphlet about cancer, empowering nursing or midwifery students who worked in the hospital to develop a health education event, and personally approach the patient and family.

Overall, these study findings show husbands lack knowledge of women's cancer because of internal and external factors. An internal factor is husbands' lack of motivation for action. For example, their disinclination to attend health education. External factors include lack of health education programmes and facilities from health services.

\subsection{Conclusion}

Health professionals identified husbands' contextual backgrounds as a factor that influences their behaviour towards women's cancer. The background includes age, job, tribe, religion, and education. Older husbands, especially from a rural area, delegated some roles to other sources because they faced some burdens. Husbands from urban areas have various type of jobs and have more flexibilities in work hours so they can fully support their wives' health. Health professionals had the initiative to provide a female health professional for a female patient if it is possible, even though no patients' husbands asked about it in the public health services. Husbands 
who are highly educated exhibit more empathy to women's health than those with low or no education.

Husbands have essential roles to play in women's health, especially in relation to the health treatments in the health services, while they have fewer roles in the prevention and early detection of cancer. To facilitate their wives' health, husbands provide material support for the treatments of disease as well as psychological support. In addition, most women ask for and accept husbands' decision about their health because they believe that the husband is the family leader who is responsible for all women's life aspects, including their health. Husbands' decisions were supported by their extended family and other external sources, including community, religious and local leaders as well as cadres. Health professionals assumed that husbands had lack of women's cancer knowledge. Some internal and external factors contributed to men's limited understanding of women's cancer. 


\section{Chapter 8 Discussion}

\subsection{Introduction}

The previous three chapters have reported the detailed findings from the married Muslim men, Muslim women and health professionals in Indonesia. This chapter presents and discusses the key findings that emerged from the triangulation of the 13 themes from these three data sources. This study was designed to address the following objectives: 1) to uncover Muslim husbands' roles in women's health, and breast and cervical cancer, including prevention, early detection, and treatment; 2) to explore women's perspectives of Muslim husbands' roles in women's health, and cancer; 3) to explore health professionals' perspectives of Muslim husbands' roles in women's health and cancer; and 4) to identify whether there are different perspectives of husbands' roles related to geographical location, age or other social, health or cultural characteristics. The study's key findings were 'Islamic teachings influence husbands' roles in women's health and cancer'; 'husbands have multiple and variable roles in women's health and cancer'; and 'personal, family and health service factors influence husbands' roles and experiences in women's health'. These are illustrated in Figure 7.

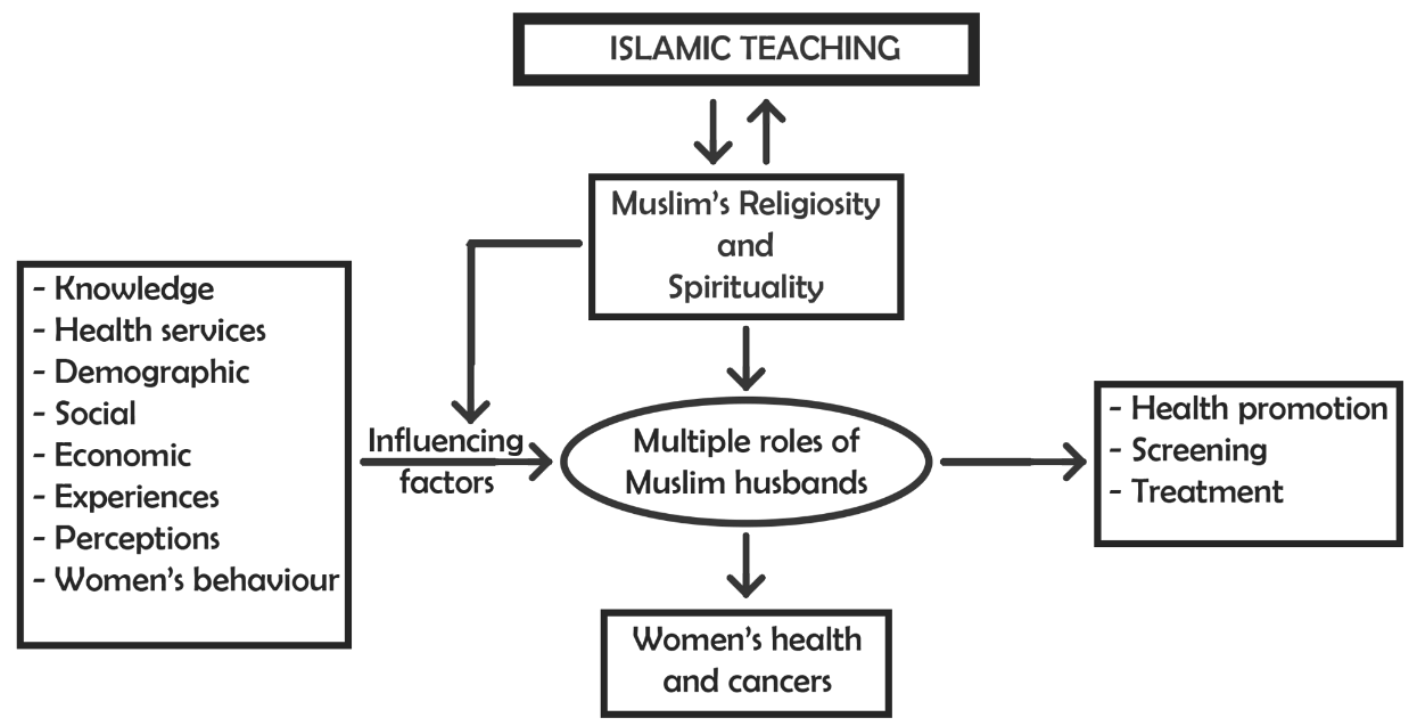

Figure 7. Key findings of Muslim husbands' roles in women's health and cancer 
Figure 7 presents the interconnection between Islamic teaching and the belief that Islam is a way of life for Muslims. Muslims accept God's rules, including husbands' roles in their family, and they follow Islamic guidelines when they perform their roles. Husbands were found to be very involved and played multiple roles in women's health and cancer, including being influential and involved in health promotion, and funding and supporting treatment. Many factors influenced their roles in women's health and cancer, including personal factors such as knowledge, experience, perceptions, and demography. Other factors were social factors (family, community leaders) and health professionals.

The findings identified similarities and differences of themes among the sample groups. Themes from each group were related to Islamic teaching, husbands' roles in maintaining women's health, men's actions in supporting women with health issues, men's knowledge about women's cancer, and other supports that involved women's health. There were two themes from the married men's data that differed from those of the married women and health professionals: the influence of the husbands' experience and knowledge on their perceptions and actions of cancer, and the sense of powerlessness in health service situations. In addition, the health professionals' findings specifically describe the influence of contextual factors on husbands' roles. Table 12 presents the three categories headings and 13 themes by participant group.

The first category describes how Islamic teaching underpins husbands' roles in women's health. The findings from the married men and married women revealed that Islamic teaching informs husbands' actions. Islamic teaching is their guide when they are developing families, being responsible for their wives' health, and taking care of their wives' health issues. Women shared that their husbands' actions demonstrate the application of Islamic teaching, they assisted and advised based on the directives from Allah. The health professionals had a slightly different view, Islamic teaching was not the main factors that underpin Muslim husbands' behaviour. They considered that many other factors, especially husbands' health knowledge and awareness, had a greater influence on husbands' actions.

The second category is the husbands' multiple roles in women's health. This category was revealed on all themes of the three participants groups. Husbands were reported as carrying out essential and various roles in maintaining their wives' health and had extensive roles in the treatment of illness. Of significance to the topic of 
cancer, they had a limited role related to early detection of cancer. The third category

explains the multiple factors influencing husbands' roles in women's health and cancer. In general, the factors include personal, family, and health services. The following section elaborates on these categories and discusses each in relation to theories and literature.

Table 12. Categories and themes from three data sources

\begin{tabular}{|c|c|c|c|}
\hline Categories & Men's themes & Women's themes & $\begin{array}{c}\text { Health Professionals' } \\
\text { themes }\end{array}$ \\
\hline $\begin{array}{l}\text { Islamic teachings } \\
\text { influence husbands' } \\
\text { roles in women's } \\
\text { health and cancer }\end{array}$ & $\begin{array}{l}\text { Islamic teaching } \\
\text { shapes husbands' roles } \\
\text { in women's health and } \\
\text { cancer }\end{array}$ & $\begin{array}{l}\text { Islamic teaching } \\
\text { impacts on husbands' } \\
\text { actions in women's } \\
\text { health and cancer }\end{array}$ & \\
\hline $\begin{array}{l}\text { Husbands have } \\
\text { multiple and variable } \\
\text { roles in women's } \\
\text { health and cancer }\end{array}$ & $\begin{array}{l}\text { Husbands' roles are } \\
\text { primary in many } \\
\text { aspects of women's } \\
\text { health and cancer }\end{array}$ & $\begin{array}{l}\text { Husbands have } \\
\text { extensive roles } \\
\text { supporting the } \\
\text { family's health }\end{array}$ & $\begin{array}{l}\text { Women's health } \\
\text { condition influences } \\
\text { husbands' actions }\end{array}$ \\
\hline $\begin{array}{l}\text { Personal, family and } \\
\text { health service factors } \\
\text { influence husbands' } \\
\text { roles and experiences } \\
\text { in women's health }\end{array}$ & $\begin{array}{l}\text { Experience and } \\
\text { knowledge influences } \\
\text { husbands' perceptions } \\
\text { and awareness of } \\
\text { cancer } \\
\text { Barriers exist in } \\
\text { husbands' roles in } \\
\text { women's health and } \\
\text { cancer } \\
\text { Husbands' power and } \\
\text { powerlessness reflects } \\
\text { health service context }\end{array}$ & $\begin{array}{l}\text { Family circumstances } \\
\text { and social support } \\
\text { influence Muslim } \\
\text { husbands' roles in } \\
\text { women's health and } \\
\text { cancer } \\
\text { Husbands' limited } \\
\text { health literacy } \\
\text { influences their roles } \\
\text { in women's health }\end{array}$ & $\begin{array}{l}\text { Contextual factors } \\
\text { influence husbands' } \\
\text { behaviour in women's } \\
\text { health and cancer } \\
\text { Family and health } \\
\text { services impact on } \\
\text { women's health } \\
\text { decisions } \\
\text { Level of health } \\
\text { literacy affects men's } \\
\text { actions in women's } \\
\text { health and cancer }\end{array}$ \\
\hline
\end{tabular}

\subsection{Islamic teachings influence husbands' roles in women's health and cancer}

This study revealed multiple perspectives of the influence of Islamic teaching to husbands' behaviour in women's health and cancer. Islamic teaching is the basic value for building a family. The findings revealed Muslim husbands believe Islamic teaching and accept the Islamic rules as Imam [head of the family] with broad responsibilities, including to their wives, in this world and also for preparing for life after death. Their married purpose is to build a family with Sakinah Mawaddah wa Rahmah [tranquillity, affection, and mercy] as part of worshipping Allah. Limited 
studies were located that particularly assessed Muslim husbands' fundamental values in their families related to health. The findings link to verses of the Holy Quran. In describing their actions, the married men's words were Sakinah, Mawaddah, wa Rahmah which is the main intent in surah Ar Rum verse 21. The husbands' beliefs also demonstrate the verses of the Quran that assert it is their responsibilities as Muslim husbands to support their wives in this world, and prepare them for life after death (At Tahrim verse 6; Surah Al Baqarah verse 233). In addition, the Muslim husbands' responsibility to take care of women is supported by a policy of the Republic of Indonesia government through the Ministry of Regulation Edict No.3, 1953, an agreement between husbands and wives that aims to protect the wife from the husband's violations.

This finding indicates that Islamic teaching has an extremely important position for Muslim husbands in guiding them in their family roles. Muslim husbands are committed to Islamic teaching as their guides, even though in this era, women can be more empowered, educated, and independent financially (Kementerian Pemberdayaan Perempuan, 2012, 2013; Priherdityo, 2016). Through observation, there is the possibility that Muslim husbands' roles are learnt from generation to generation, as some men did not automatically link to religious teaching. The husband and wife believed Allah is the one who determines the destiny of a human being, including illness. The study's findings revealed the husbands and wives believed that a disease comes from Allah and as Muslims, they need to exert every possible effort to solve their health problems. The previous studies that have explored Muslims' perspectives and behaviour in women's health and cancer have reported similar findings. A study of Malaysian Muslim couples with breast cancer found that Allah has an important role in this disease and both wives and their husbands believed that this disease is a test from Allah and they have to accept it (Yusoff, Taib, \& Ahmad, 2011). Similar findings are presented in other studies in different religions (Allen et al., 2014; Kumar, Shaikh, Khalid, \& Masood, 2010; Thombre, Sherman, \& Simonton, 2010). Allen et al. (2014) who studied religious beliefs and cancer screening behaviours among Catholic communities in the USA found that participants believed God showers blessings on Catholic believers as well as testing them. They also believed that God influences their health as well as making them suffer in sickness and that he cures them. However, my findings go further than this; they show that Islamic teachings influence how married men live 
their daily lives in addition to their actions related to health and their responses to ill health. In contrast, Allen et al.'s participants said that being healthy and actively caring for their health is a part of humans' responsibilities. Although my study and the other studies' participants came from different religious background: Muslim, Catholic, and Hinduism, all the studies show that religious beliefs uphold God's role in human's health and especially in illness. This finding is important information for health professionals as it means that they should consider involving patients' religious beliefs when they offer interventions for patients, especially those with a terminal disease, for example, cancer.

Islamic teaching was found to shape Muslim husbands' behaviour in women's health and cancer in multiple ways. These ways will be elaborated in the next section. Husbands' support to women's daily activities is in line with the Hadith that describes Prophet Muhammad's behaviour to his wife (Al-Shammari, 2016;

Maqsood, 1995). Muslim couples typically complement each other, and each of them has particular responsibilities, as mentioned in the Holy Quran Surah Al Baqarah verse 187. Muslim women also use Islamic teaching as their guide in family and couples' relationship as written in the Holy Quran surah An-Nisa verse 34.

Islam is not only religious dogma but also a way of life for many people. Most of Muslims' behaviour cannot be separated from Islamic teaching and links to their belief that this is part of worshipping to Allah. Beliefs are part of the human's identity. Considering patients' beliefs and viewing people holistically, including their spiritual aspect, needs to be part of health professionals' practice, as human needs are not only physical but also spiritual. These considerations link to the WHO (2006) definition of health; health is "a state of complete physical, mental, and social well-being and not merely the absence of disease or infirmity".

The study's findings show that Muslim couples are bonded and influence each other. The influence can have positive and negative impacts on spouses' behaviour. As the World Health Organization (2017b) identified, social support and networks, including family members, are a barrier to accessing high-quality health services for women. Involving and educating husbands and wives in spouses' health will have a positive impact on couples' health. The influence of Islamic teaching on husbands' behaviour in women's health found in this study is also an opportunity for health researchers to study the relationship between Islam and Muslims' health further. 
The relationship between Islamic teaching and health contributes to the body of knowledge that has examined religion/spirituality and health (Aldwin, Park, Jeong, \& Nath, 2014; Bahar et al., 2005; Banning, Hafeez, Faisal, Hassan, \& Zafar, 2009; Benjamins, Ellison, Krause, \& Marcum, 2011; Cotton, Zebracki, Rosenthal, Tsevat, \& Drotar, 2006; Hileli, Weyl Ben Arush, Hakim, \& Postovsky, 2014; Koenig, 2012; Labun \& Emblen, 2007; Lee \& Newberg, 2005; Levin, 1996; Maqsood, 1995; Salmoirago-Blotcher et al., 2011; Thombre et al., 2010). The majority of studies have found that religion/spirituality is strongly linked with better health behaviour. Aldwin et al. (2014) showed that good health was linked to religious or spiritual experience. Their findings, supported by other studies, found performing religious teachings were health-related, including health promotion (Benjamins et al., 2011; Levin, 1996; Maqsood, 1995). The positive and negative effects of religion on health described by Koenig (2012) and Lee and Newberg (2005) include decreasing incidence and prevalence of disease, better outcomes after medical procedures, good behaviour and lifestyles, promoting access to healthcare resources, and positive feeling and character. The negative effects are mostly related to mental problems, including depression, suicide, anxiety, and psychotic disorders (Koenig, 2012). My study's findings contribute to this knowledge particularly regarding Muslims' religiosity and health behaviour in Indonesia.

In my study, Muslim husbands shared that their support and influence on women's health included accompanying them to health services, and providing facilities. These findings are in alignment with the BMRH theory. This theory argues that religiosity and spirituality influence people's health outcomes via behaviour, social support, and psychological aspects (Masters, 2008). To date, there has not been a publication about the application of Masters' theory to a specific religion including Islam.

The study findings also confirmed Masters' (2008) theory in that Islamic teaching as Muslims' religiosity influenced Muslim husbands' roles in women's health and cancer. Masters argues there are three main pathways related to the influence of religiosity and spirituality on health outcome. Of these three, two pathways (R/S - Behaviour-Health Outcomes, and R/S - Social Support-Health Outcomes) are relevant to this section of the discussion. The R/S - Behaviour-Health Outcomes is evident as Muslims' religiosity and spirituality were shown to be reflective in the choices people made regarding their general health (e.g., the types of 
food they ate and who and how they engaged with health professionals) and this behaviour impacted on women's health outcomes. The R/S - Social Support-Health Outcomes relationship was demonstrated in that the people who were generally sought for social support were determined by Islamic teaching, and this influenced health outcomes. The third pathway of Masters' theory is also relevant to the discussion, but this pathway is not discussed until the third category is discussed. The interconnections between Islamic teaching and Muslims' religiosity and spirituality and the latter's influence on behaviours and husband' roles is illustrated in Figure 8.

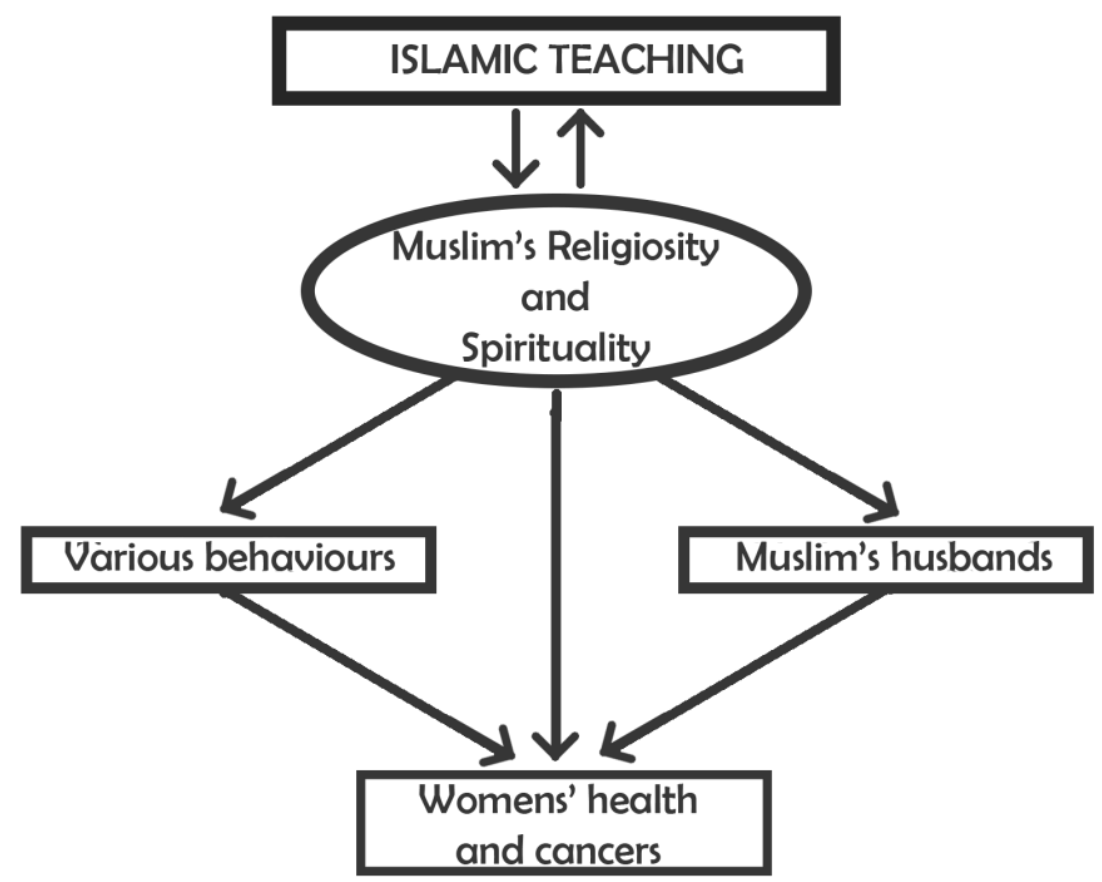

Figure 8. The relationship between Islamic teaching and Muslim's religiosity and spirituality

According to the findings, the majority of Muslims believe that Islam provides rules for a Muslim husband to his family. This study showed that when a Muslim man marries, he accepts his roles, including responsibility for his wife's well-being. When he applies his roles as a husband, he follows Islamic teaching which provides guidelines. This interconnection did not appear in Masters' (2008) diagram, as the theory is not Muslim-specific. However, Masters wrote that the application of the $\mathrm{BMRH}$ theory is not as simple as the diagram of the theory. This finding shows that 
the BRMH theory is applicable to frame Muslims' R/S; however, the connection between Islam and Muslim's spirituality is specific and may differ from other religions. I found the relationship between Islam and Muslim husbands affected their behaviour, and this influenced women's health and cancer.

Although the Islamic teaching influence on husbands' behaviour is very evident in the men's and women's findings, it barely appeared in the health professionals' findings. Health professionals captured several factors that influence husbands' behaviour in women's health through their observations when they cared for Muslim female patients in the PHC or hospitals. These factors included sociodemographics, knowledge, attitude, culture, and religion. The health professionals reports of Islam were about people's appearances (e.g., long beards) and the role of ustadz (e.g., to help people access services), as opposed to people's religious beliefs. These reports indicate that Islam is possibly viewed as cultural and not something that is the business of health professionals. The health professionals did note, however, that the Muslims they presumed to be more religious, as evidenced by their clothing and beards were more caring. They saw linkage with Islam through health service requirements. However, this study's evidence of how Islamic teaching guides Muslim husbands, and the important influence of Islamic teaching for Muslim men and women's health behaviour is significant information for health professionals. Health professionals should be aware that understanding patients' R/S and the influence of religiosity on patients' behaviour is part of comprehensive care. The influence of Islamic teaching on health behaviour is challenging as unlike physical observation religiosity and spirituality concerns personal beliefs and values. Health professionals need to develop ways to assess and understand patients' religiosity and spirituality. Such developments will contribute to comprehensive assessments of patients and enable delivery of holistic care or a biopsychosocial (World Health Organization, 2006).

\subsection{Husbands have multiple and variable roles in women's health and cancer}

The finding that the three main roles for Muslim husbands in women's health and cancer: promoting women's health, supporting cancer screening, and engaging in women's treatments were not uniformly carried out is important. The majority of 
husbands from urban and rural areas were involved in women's health promotion, and they also engaged in supporting treatment of women's diseases. In contrast, the findings revealed minimum involvement by Muslim husbands in cancer screening. In discussing Muslim husbands' roles, I begin with their roles in health promotion, followed by cancer screening, and finally their roles in treatment. The finding is illustrated in Figure 9, which depicts the emphasis of the husbands' focus in the three areas.

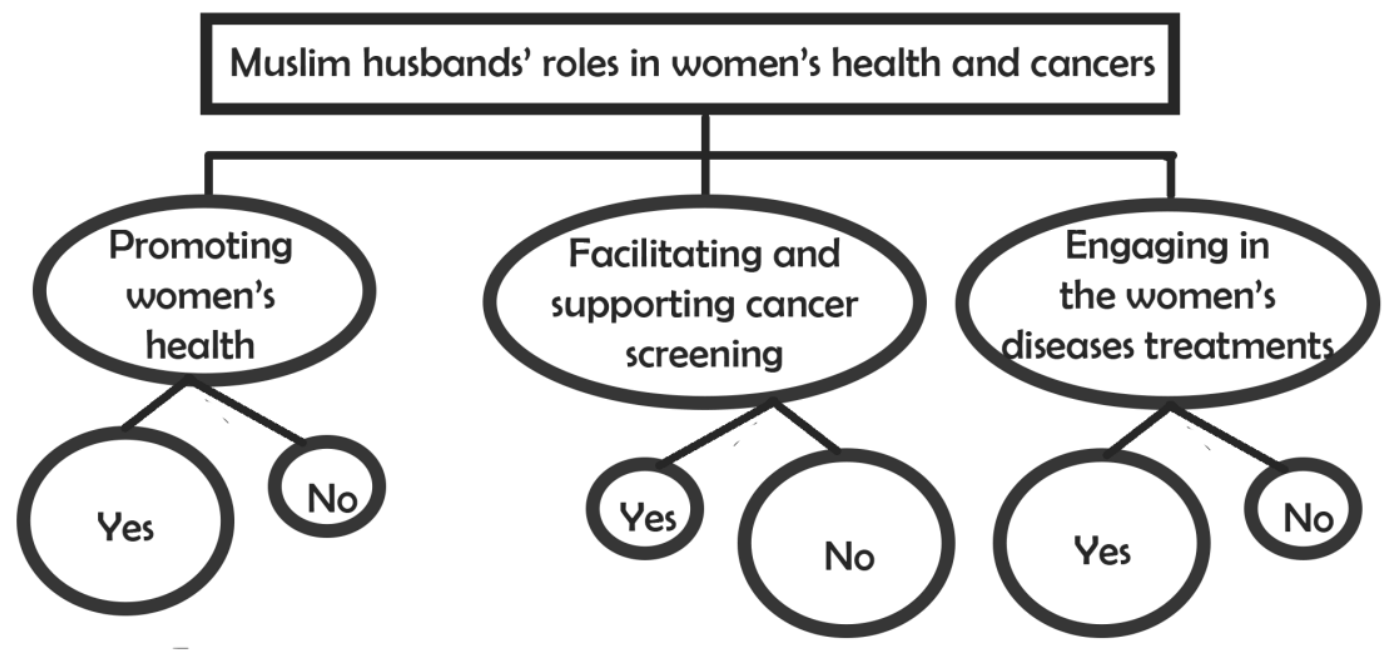

Figure 9. Muslim husbands' roles in women's health and cancer

\subsubsection{Women's health promotion}

Regarding health promotion, the findings revealed that husbands had broad roles in promoting women's health, including physical and emotional support. Both men and women shared similar information about health promotion. Also, women added information about their husbands' participation in family planning. The health professionals' opinions about married men's roles in promoting women's health differed slightly from the married men's and married women's perspectives. The health professionals shared limited information about married men's participation in promoting women's health. This finding possibly reflects that health promotion activities are mostly done at home which health professionals would not see.

The study's findings revealed that the husband's concern for healthy food for the family involved them cooking organic food, avoiding chemical substances, and providing money to buy food. They shared that food containing chemical substance 
may cause the causes of dangerous diseases such as cancer. This finding is in contrast to a qualitative study of eating behaviours of Chilean women which found that although husbands were concerned about their family's nutrition, their actions as the controller of what foods were purchased meant that unhealthy food, for example, fatty foods, which are detrimental to the health of all in the family, were regularly purchased (Galvez, Valencia, Palomino, Cataldo, \& Schwingel, 2015). For Muslims, eating good food is linked to Islamic teaching. This finding captured husbands' awareness of the importance of healthy food for human beings, as mentioned in Maslow's theory that food is a basic human need (McLeod, 2016). The Muslim husbands were aware that one way to maintain family health is by providing healthy food and that unhealthy food is a risk to family health.

Regarding husbands' involvement in family planning, my study found two different behaviours. Some husbands were actively involved in family planning programmes, and there were others whose participation was limited. This is not a new finding, as many previous studies have found husbands' support in women's family planning programmes (Abhilasha, 2003; Fortunati \& Floerchinger-Franks, 2001; Grady, Tanfer, Billy, \& Lincoln-Hanson, 1996; Ijadunola et al., 2010; MacDonald et al., 2013; Mistik, Nacar, Mazicioglu, \& Cetinkaya, 2003; Orji, Ojofeitimi, \& Olanrewaju, 2007). Unsupportive husbands are also identified in Onyongo et al.'s (2010) study. Their study conducted in Kenya found that men do not understand their family planning responsibilities because, culturally, family planning is a woman's responsibility (Onyango, Owoko, \& Oguttu, 2010). These different attitudes indicate that Muslim husbands may have a different understanding and awareness of the importance of their involvement in family planning. Unsupportive husbands in the family planning programme contribute to the stagnancy of a programme in Indonesia (Rawayan, 2014). The Indonesian government established family planning programmes nationally in Indonesia in 1969 (48 years ago) (Badan Kependudukan dan Keluarga Berancana Nasional, 2017); however, the government still faces many challenges, including a lack of support from many aspects, such as husbands' support (Rawayan, 2014). There is a need for alternative methods of approaching communities, including husbands that will improve and support men and women's participation in family planning programmes. 
The findings that the majority of husbands support their wives' personal and social activities demonstrate how married men follow Prophet Muhammad's behaviour as written in a Hadith narrated by Al Bukhari. The personal activities that married men assisted with included household tasks and engagement in sport. The social activities married men supported including permitting their wives to engage in the community such as attending health workshops or regular religious events and taking on the role of health cadre. This study demonstrated that the majority of Muslim married men play a huge role in supporting their wife. However, the study's findings also confirmed those of other studies which found that not all husbands support women's activities at home. This is thought to be because the husbands think that household tasks are culturally women's responsibilities (Ferree, 1991; Young, Wallace, \& Polachek, 2015), demanding for both men and women, and these activities are not on a household's lists of priorities (Robinson \& Spitze, 1992; Schooler, Miller, Miller, \& Richtand, 1984).

In my study, only a very few husbands were found to limit women's engagement in health promotion. These husbands were reported by the women as not giving them permission to women attending social events that included health education. These particular men were spoken of as having overall control of all their wives' activities, which some consider unjustifiably restricts women's mobility (Mainuddin, Ara Begum, Rawal, Islam, \& Shariful Islam, 2015; Qureshi \& Shaikh, 2007). Raising husbands' awareness in regard to the positive impact of social activities for women will be useful in enhancing women's welfare and also women's health knowledge if the activities are about the health aspect.

Regarding women's empowerment, the findings revealed that husbands had different behaviours; some husbands encouraged women to become more independent, empowered, and confident to make decisions while other husbands were dominant and tended to lead in many aspects of women's life, including decision making in women's health. There are no published findings in Indonesia about husbands, health and women empowerment. A study in Bangladesh found that only $12 \%$ of women participants were empowered to make health-seeking decisions autonomously (Mainuddin et al., 2015). While it is not known how empowerment impacts on Indonesian women's health outcomes, a study in Pakistan has identified the positive effect of women's empowerment to women's health (Qureshi \& Shaikh, 2007). Qureshi and Shaikh argue that empowering women is significant in 
improving their health status and social reform. It is possible that if women are more empowered in Indonesia, their health may improve. Motivating husbands to support women's personal and social activities will give positive impact to women's empowerment, and empower women will have wide effect including health.

\subsubsection{Facilitating and supporting cancer screening}

One method of primary prevention to protect women from cervical cancer is the HPV vaccine (Andrijono, 2007). My study's finding that no man, woman, or health professional spoke about this method, nor did they share much related to husbands' roles in preventing women's cancer or other specific disease prevention although not surprising, is a concern. The lack of mention of the HPV vaccine maybe because this method is still new in Indonesia, and the supply is limited (Fadhila, 2017). The vaccine price is high 1,500,000-3,000,000 rupiah (approx. $\$ N Z 150-300$ ) for Indonesians (Sari, 2016); minimum monthly wages in West Java province for example are 1,450,000 rupiah. Even though it is expensive for most Indonesians, there is a need to increase information and facilities related to the HPV vaccine, especially to adolescents. While I do not support health inequalities, I do believe that those who can afford it, such as those in middle income and higher bracket should know about it as preventing even one cancer is important.

The presence of two patterns - not being aware of the importance of screening and being fully supportive of screening - that was revealed about husbands' roles in women's screening for cancer is new. Many previous studies have found that obtaining support from spouses motivated women to have screening (Baheiraei, Mirghafourvand, Charandabi, \& Mohammadi, 2013; Keating, O'Malley, Murabito, Smith, \& Christakis, 2011; Su-I, 2006; Taha, Al-Qutob, Nystrom, Wahlstrom, \& Berggren, 2012; Thiel de Bocanegra, Trinh-Shevrin, Herrera, \& Gany, 2009), but little is reported about the lack of knowledge. The finding that the majority of the married men and married women did not seem to be aware screening enables the early detection of cancer and that the earlier abnormalities are picked up the greater the chance of a positive health outcome may reflect the limitations of Indonesia's cancer screening programmes. Although screening programmes in Indonesia are still developing, and only $7.6 \%$ of 9422 PHCs provide this service (Pusat data dan informasi, 2015), it is imperative that an increased focus on health education is implemented, as well as an expansion of screening services. Educating husbands and 
women about the importance of screening will have a positive impact on women's screening behaviour. Other factors that may influence husbands' roles in women's health are presented in part three of this chapter.

\subsubsection{Engaging in women's disease treatment}

The study highlighted various husbands' actions regarding their roles when their wives were sick. The actions are divided into three groups: paying attention and providing support to women's complaints about their health; doing first aid or taking temporary actions to cope with women's health issues, and taking women to health services. Husbands' behaviour in caring for their wives is linked to the Holy Quran teaching written in Surah Al Baqarah verse 233. This finding is not new; a qualitative study in Egypt found husbands' support for seeking health and that they help with household tasks when their wives are sick (Ohashi et al., 2014). The importance of husbands in women's health is also identified in a Spanish study (Thiel de Bocanegra et al., 2009). Husbands are also reported as the main source of support for women suffering from reproductive health issues, including cancer (Maree \& Wright, 2010). A husband has also been identified as the best person with whom a wife should share her abnormal symptoms, as the husband can send his wife to the hospital early to avoid a late diagnosis of cancer (Gyenwali, Pariyar, \& Onta, 2013; Liou, Ling, Feng, Guo, \& Chen, 2009).

The health professionals' observation that husbands accompanied some women and other women visited health services by themselves or with another woman when they have women related or reproductive issues provides insight into how some women are able to identify the type of support they require. This finding is consistent with Gyenwali et al.'s (2013) study of Nepali women with cervical cancer where women were found to talk about their illness symptoms to female family members, or they kept them to themselves (Maree \& Wright, 2010). A Kenyan study found men rarely accompanied women on health service visits because they felt over powered by women, which is contrary to cultural norms (Onyango et al., 2010). However, Indonesian research reports husbands' involvement in women's health is significant in enhancing women's health as good support from spouses can be a precursor to better women's health and physical function (Kim, Chopik, \& Smith, 2014). 
Regarding husbands' roles in women's cancer, husbands performed various activities to help women in cancer treatments. The married men's perspectives were supported by the three women who had experience with cancer and other severe reproductive health issues. Health professionals' experiences were that some husbands were fully supportive, while others did not support their wives. This finding is in line with previous studies (Maree \& Wright, 2010; Taha et al., 2012). Husbands' awareness of women's health needs to be improved so when women face a serious or terminal illness; men can provide maximum support. Such support makes a significant contribution to the daily emotional and physical welfare of women, including women with cancer (Gremore et al., 2011).

Couples' behaviour differed, from very conservative to very relaxed or liberal behaviour. When husbands provided opportunities for their wives to choose their health actions, they appeared to feel they needed to support her choices, even if they did not agree with them. The consequence of not challenging their wives' decisions meant some women did not seek assistance until they had advanced stages of cancer. This finding illustrate that unless there is an intensive interaction between husbands and wives to discuss and negotiate about women's health, especially when a woman has a serious disease that delays can occur. The married men were also shown to prefer medical treatments, yet women with initial cancer preference were for traditional therapy. This female behaviour is in line with women's health-seeking behaviour for cervical cancer in a study in Ethiopia (Birhanu et al., 2012).

Traditional therapy is important, but more needs to be done to ensure this is adopted in conjunction with conventional healthcare where there is evidence effectiveness.

No one single behaviour of husbands and wives related to women's health highlights the challenges health professionals face when covering a community with different characteristics. Although a few husbands showed limited involvement in women's health, and a few husbands' behaviour was a barrier to women's health activities, the majority of Muslim husbands indicated their various roles in women's health and cancer, including health promotion, screening and early detection, and disease treatments. They were very involved in their wives' health. For a Muslim wife, her husband is the closest person with whom to share women's health issues. This study's findings found there were comprehensive Muslim husbands' roles in women's health. Knowing about the extensive roles of husbands is important information for health professionals as they can use this knowledge and encourage 
increased involvement of husbands as husbands are a potential help to improve women's health.

\subsection{Personal, family and health service factors influence husbands' roles and experiences in women's health and cancer}

This section discusses factors that influence husbands' roles in women's health and cancer. The factors cluster into three main areas: personal, family, and health services factors. The personal factors are knowledge, perceptions, sociodemographic characteristics and experience. The family factors are the actions and behaviour of parents, children, relatives and women towards the husbands/men. Finally, the health services factors include the impact of health professionals, facilities, services, and programmes on the husbands/men. These factors are presented in Figure 10.

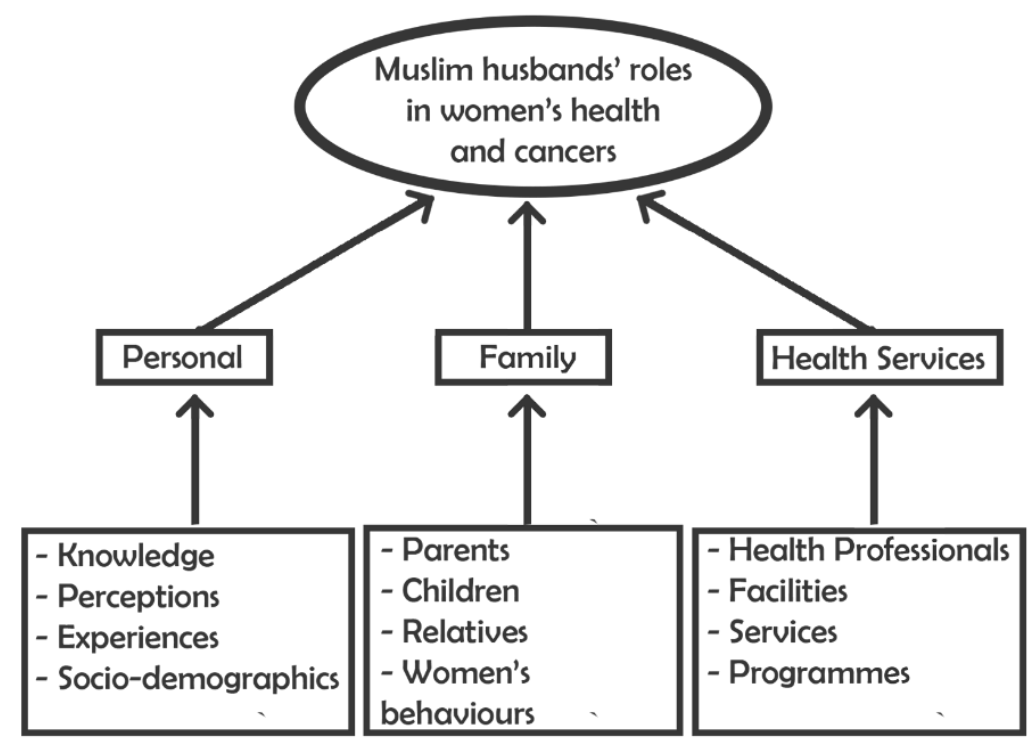

Figure 10. Factors that influence Muslim husbands' roles in women's health and cancer

The majority of factors contained in the theoretical frameworks HBM and HSBIFF presented in Chapter 2 were evident in this study. One factor that was not present in my findings is husbands' emotional responses to their wives' cancer. This factor was absent largely because my study did not particularly target husbands whose wives had cancer. A few husbands expressed their emotional response related to their perceptions of women's cancer. They expressed being afraid of women's cancer. In addition, the women's behaviour factor was not present in HBM and HSBIFF 
theories. In my study, women's behaviour was shown to impact men's behaviour. This aspect of family is probably present because I recruited both men and women and asked them about their own and each other's behaviour. Previous studies that utilised the HSBIFF theory only researched women (O'Mahony, Hegarty, \& McCarthy, 2011; O'Mahony, McCarthy, Corcoran, \& Hegarty, 2013). My finding, therefore, indicates that more research involving multiple perspectives is needed to verify this theory. The theory, however, is helpful in explaining aspects of husbands' roles in women's health. The following section discusses each influencing factor.

\subsubsection{Personal factors}

\section{Limited knowledge of women's health and cancer}

This study's finding that the majority of husbands had limited health literacy about cancer prevention, early detection, and treatments is significant. All three participant groups reported a lack of husbands' knowledge about women's cancer. Most husbands had no understanding regarding the causes of cancer, signs and symptoms, screening and the differences between cancer stages. The rural husbands, in particular, did not know how to prevent or identify the early detection of cancer. However, the few husbands from both rural and urban areas who had experience of cancer in their family, extended families, or communities had some understanding of women's cancer, including the symptoms and treatments. It was evident to me while researching that the rural and urban men and women who participated in the research were keen to learn more about women's cancer; they actively asked me questions after the focus groups.

Men's limited health literacy about women's health, especially cancer, is not a new finding. Studies conducted in other Muslim countries such as Saudi Arabia and Malaysia had similar findings (Al-Amoudi, Eldeek, Ayuob, Alzhrani, \& Alahwal, 2012; M. Al-Amoudi \& Abduljabbar, 2012; Al-Naggar, Bobryshev, Abdulghani, Rammohan, \& Al-Jashamy, 2012). A Latino study also found the majority of men had little knowledge about cancer and were unfamiliar with screening (Trevino, Jandorf, Bursac, \& Erwin, 2012). In contrast, an exploratory study of 24 Muslim married men in Jordan found the men understood that early detection is the best way to control breast cancer, and they encouraged women to do that (Taha, Al-Qutob, Nystrom, Wahlstrom, \& Berggren, 2013). Men in Jordan may know more about 
women's cancer than those in Indonesia for two reasons; the first is population size, Jordan has approximately 7,594,000 people and Indonesia 257,564,000 (WHO Country data - 2015). Getting a shared message to a smaller population will be easier. Secondly, Jordan spent 798 international dollars on health per capita in 2014 whereas Indonesia only spent 299 international dollars per capita (WHO Country data). The expenditure difference in Jordan is likely to contribute to increased health education. In addition, unlike Jordan, Indonesia does not maintain a cancer registry.

According to the HSBIFF theory, knowing health and illness influences health seeking (O'Mahony et al., 2011; O'Mahony et al., 2013). The lack of husbands' knowledge could be a contributing factor to the low uptake by women of cancer screening and treatment, given the Muslim husband's significant position in the family. In the absence of such knowledge, people are unlikely to seek to screen when well or seek assistance when they have symptoms as they do not understand what they mean. Addressing the knowledge gap will require health education programmes in Indonesia not only to encourage screening but also to teach people that early diagnosis of abnormality can improve health outcomes. Providing a variety of health education for men and women is very important given the various backgrounds of the men regarding knowledge, experience, and socio-demographics. Developing men's health centres and men's health forums such as fairs or peer group discussions that also provide information about women's health may be a way forward.

The reason for the delay in presenting to health services in the presence of abnormal symptoms also indicates a lack of knowledge and awareness regarding the type of symptoms and that woman should see health professionals about. This women's behaviours are similar to other studies (Gould, Fitzgerald, Fergus, Clemons, \& Baig, 2010; Granek \& Fergus, 2012; Gyenwali et al., 2013; Lu, Lin, \& Lee, 2010; O'Mahony \& Hegarty, 2009; Taib, Yip, \& Low, 2011). Women and men need to appreciate that health professionals would rather see women and be able to advise that her condition is normal or mild, rather than having her present very late with advanced or serious illness.

\section{Experience shapes husbands' actions regarding women's cancer}

The findings that few husbands from urban and rural areas had a personal experience related to women with cancer may reflect the incidence and prevalence of cancer. Of the 12 husbands who did have experience, their main knowledge and 
experience related to treatments. Given their knowledge of the multiple steps of cancer therapy and the cost of cancer treatment, these men considered they were more attentive to their wives' and daughters' health. They encouraged the female family members to have screening, even though some of them did not know what screening involved. In addition, they also reminded other men to pay attention to women's reproductive issues. These findings provide support for two concepts in the Health Belief Model theory (Hayden, 2009). The first concept is the modifying variable, which states that people change from unhealthy to healthy behaviour because of many different variables, including experiences. Having experience also aligns with the HSBIFF theory (O'Mahony et al., 2011). The second concept concerns are receiving cues to act. This describes how an individual's behaviour can be influenced by social or interpersonal factors, including the media, awareness of an ill family member, advice from others, a reminder letter from health services, or a warning sentence on a product. Men in the focus groups picked up on the advice (the cues) from the men with experience.

Health programmes could utilise the finding that experience of cancer impacts on husbands' health behaviour by finding ways to share such experiences. Indonesia could explore the strategies used in other countries such as New Zealand where many forums for sharing knowledge about cancer are used. These forums include newspaper articles, stories in women's magazines, stories about celebrities with cancer, television series such as Shortland Street which is set in a hospital, and radio and television documentaries. While such strategies may not reach the many millions of people in rural areas given the often limited media resources in these communities, they could impact on people living in urban areas. In addition, husbands who have experience of women's cancer should be encouraged by the health services to share their knowledge with other husbands.

\section{Various interpretation of breast and cervical cancer}

The married men's perceptions that women's cancer is dangerous, scary, deadly or fatal diseases, are likely to be attributed to the participants having limited knowledge of people being successfully treated for cancer (Widiasih, Nelson, \& Skinner, 2016). These perception of cancer in my study are not new. Daher (2012) also found his participants believed that cancer is a fatal disease because they viewed it as being unpreventable. Given that the majority of women present late with cancer 
in Indonesia (Maharani, 2015), they have an increased risk of dying because of the stage of their illness. Cancer will only become less scary when more people are known to survive it. This study's findings are in alignment with the HBM theory (Hayden, 2009), especially perceived of seriousness concept that describes a person's perceptions about the severity of diseases because of their beliefs about the disease's effect on their life. Men perceive that women's cancer is a dangerous, fatal, and deadly disease because their experience is that most women with cancer have passed away. Health education programmes, therefore, also need to showcase and provide examples of people who have been successfully treated for cancer and draw attention to their early diagnosis.

There is an urgent need in Indonesia to convey messages that cancer is often preventable and that early detection increases the likelihood of cancer not being terminal. Until more people understand these points, women will not routinely attend screening and cancer will continue to be a mainly deadly disease. Improved health literacy about preventing cancer and early diagnosis should impact on husbands' behaviour in supporting their wives' screening, and daughters' HPV vaccine.

\section{Demographic characteristics shape husbands' actions}

The findings that the husbands' ages, occupations, and places of abode influenced their actions in supporting women's health and cancer are not new. This study identified different actions and attitudes by older and younger husbands in women's health and cancer. Types of jobs, whether they were farmers, employees, or businessmen, influenced husbands' behaviour, especially in accompanying their wives when sick. Living in rural or urban areas influenced men's accessibility to health services and information about women's health and cancer. There were also different behaviour and responses to diseases between older and younger people. Hasson-Ohayon's et al.'s (2014) findings highlighted significant differences in levels of depression in older and younger women with breast cancer and with their spouses. In addition, a prospective cohort study of urban and rural women in regions of Lithuania investigated the prevalence, persistence, and risk factors of HPV exposure and found that young and poorly educated women were more exposed than old and more highly educated women (Kliucinskas, Nadisauskiene, \& Minkauskiene, 2006). The impact of geographical location is present in the HSBIFF theory. Through my 
personal experience, living in rural areas is a struggle because of limited health facilities, human resources, and bad infrastructures, for example, damaged roads, electricity issues, and transportation problems. In contrast, urban areas have greater access to any facilities, including health. For example, the Pap smear service in urban areas is open every day and easily accessed by urban women. While in rural areas the service is only provided if there is a special event. The absence of a regular Pap smear service means rural women need to go to the city to get a smear which takes time and costs money. Living rurally is not only a problem for the employed, older husbands reported not supporting their wives in the hospital because hospitals are mostly located in the district or the provincial capital. The access issues raised and the experience of the burden of hospitalisation provide additional information for the Indonesian government about the wide impact of gaps between urban and rural, including health and especially women's health.

\section{Low income as a barrier in supporting women's health}

Financial barriers were identified when rural or downtown participants discussed the expense of cancer treatments or other health issues. Considerable expense is incurred when a family member is hospitalised. This barrier aligns with the men's perception of cancer that cancer treatments are expensive. The barrier to receiving treatment is the high financial cost of treatment; as with other developing countries, there is a lack of affordable and accessible health services in low to middle-income areas in Indonesia. There is also limited access to cancer diagnosis, few facilities and a dearth of health professionals all of which are burdens for optimal cancer treatments (Hoen, 2014; Samiei', 2013).

The high cost of cancer treatments, especially cancer medication, is an international issue for low to middle-income countries, including Indonesia (Hoen, 2014). The cost issues also related to health promotion, prevention, and the early detection of women's cancer (Ackerson \& Gretebeck, 2007; Baheiraei et al., 2013; Farooqui et al., 2013). Financial issues also affect minorities receiving cancer services (Bowen et al., 2013; Brown, Wilson, Boothe, \& Harris, 2011; Dempsey \& Davis, 2006; Ndukwe, Williams, \& Sheppard, 2013; Ogedegbe et al., 2005). For women who live in a developing country, there are several burdens related to health services. These are challenged with transport issues, cultural barriers, language, 
health facility issues and low interest by health professionals, long waiting times for appointments, and difficulties with work schedules all of which are delaying factors for cancer treatments (Bowen et al., 2013; Marlow, McGregor, Nazroo, \& Wardle, 2013).

In terms of cancer screening, most women in rural or downtown areas with low income had not had a regular Pap smear or mammography experience. However, having an income that funds screening, or private insurance to access private health services improves access, meant the women from urban areas with middle incomes attended cancer screening services. These results are in line with previous studies which found that higher family incomes influence awareness of cancer screening (Su-I, 2006; Witharana, Wijesiriwardhana, Jayasekara, Kumari, \& Rodrigo, 2015). Income inequality impacts on health behaviour. Although the Indonesian government provides a healthcare security programme for Indonesian citizens, including poor communities, many technical issues occur for low-income people (Ady, 2016). People on low incomes need additional money when a family member is sick, as hospital services are expensive in Indonesia. Low-income family need increased support from the government, including accessible, cheap or free health services, especially for women with terminal illness like cancer.

\subsubsection{Family factors}

Family, nuclear and extended, and external supports were important in supporting husbands' roles in women's health especially husbands from rural areas and downtown areas. Family and external supports include children, parents, siblings, relatives, cadres, community leaders, and religious leaders. Support from family and community in women's health has been reported in many studies in Indonesia and elsewhere. A qualitative study as part of the pilot breast and cervical cancer screening programme in Karawang identified several facilitating factors. The study found that free screening, social support especially from health volunteers, encouraged women to attend the pilot programme (Kim et al., 2012). On the other hand, a lack of motivation from parents, friends, and spouses influenced women's practise of BSE in Terangganu, Malaysia (Rosmawati, 2010). The family is important to Indonesians and can be a motivator or a burden regarding health.

The HSBIFF theory, social factors including family is a factor that influences help-seeking behaviour in women's health. The family factor in my study 
highlighted more detailed information related to supports and the role of each support than what is conveyed in the HSBIFF theory. This finding adds knowledge that Muslim husbands from rural areas and downtown areas need support from others to apply their roles in women's health and cancer. The support needed by men is the same as what women were found to receive in previous studies (O'Mahony et al., 2011; O'Mahony et al., 2013). This includes extended family and other support to help them when their wives experience health issues. When people are sick, health professionals need to advise extended family and others how they can help.

Showcasing the role of extended family and community supports also needs to be presented in health education programmes.

\subsubsection{Health services factors}

\section{Health professional}

In line with Islamic teaching, the majority of husbands preferred female health professionals to take care of their wives when they were sick. They also wanted a high-quality service from the doctor for their wives. Little is known about how people balance health professional gender preferences in health. A USA-based study of Arab Muslim immigrants found that women preferred female health professionals to help them because they felt comfortable with them performing extensive examinations (Zeilani \& Seymour, 2012). However, the preference for female doctors in Indonesia is difficult for several reasons. First, the number of doctors in Indonesia is limited. According to WHO (2017b), the density of physicians should be one physician per 1000 population, yet in Indonesia, on average, the density of doctors is one physician for 2320 population (Anugrapaksi, 2016). There are also gaps among provinces related to the doctors' density, for example in Jakarta, the capital, there is one doctor for 608 population, while other provinces, for example, Sulawesi Barat, there is only one doctor for 10,417 population (Anugrapaksi, 2016). West, Central, and East Java also lack doctors because of their large population (Anugrapaksi, 2016).

Second, female doctor numbers and distribution are not the focus of the health development, the focus is fulfilling the number of doctors, and improving the quality of medical education (Anna, 2017). Given this scenario, other solutions need to be explored especially for rural areas. In addition to training more doctors, urgent attention could be given to expanding the roles of nurses. This would involve special 
training, but this could be done in a much shorter time than the six years it takes to train a doctor. Nurses also need to become more aware that they can help women, by accompanying female patients when being cared for by male doctors.

Besides gender, the low quality of the doctors' services is also mentioned by husbands, especially the lack of communication skills. Health professionals' poor communication skills were identified in previous studies in developing countries (Augusto, Rosa, Cavalcanti, \& Oliveira, 2013; Thomas, Saleem, \& Abraham, 2005). Lack of communication from health professionals is not only found in studies from developing countries and among ethnic minorities, but it was also found in a study of a developed country like Germany (Wegwarth \& Gigerenzer, 2011). A good quality service from health professionals for women is another important aspect that men expect from health professionals for their wives. Improving health professionals' services and communication skills are needed, especially for teaching hospitals, the patient right and safety should be a priority.

The powerlessness and distress that some men experienced when their wives were treated by a male doctor or seen by some student doctors have not been reported before. These experiences happened in the emergency room and teaching hospitals. Miklance (2007) did, however, find that Muslim women felt very uncomfortable when they were examined by male health professionals. To anticipate these situations health professionals should have some alternative actions that they can adopt. Where possible, this should include changing doctors to have a female doctor, but where this is not possible, discuss with the woman and her husband why a man needs to perform the assessment and show how they will respect the women. For example, women in New Zealand are typically offered the choice of having a female nurse present if a male doctor is examining their private parts. During all assessments, where possible, cover the private parts of the body with a cloth. Finally, minimising the number of students that any women is examined by. Providing clear guidelines and regulations for health students so that they can obtain knowledge and experience without harm to patients. Developing "women centre services" that provide high-quality health services for women could become an alternative action to improve women's health services will also assist women. 


\section{Health facilities and programmes}

It was evident from the findings that access and availability of health services varied. In particular, there are limited cancer screening facilities in rural areas and often no trained health professionals who can undertake screening. Health professionals added that information for men about women's cancer was not a priority for health programmes in the PHCs although health professionals understood the advantages of health education for men. Until health professionals show more support in educating men about women's health, especially prevention and early detection of women's cancer, progress may be limited. The current health programmes in PHCs and hospitals are developed based on the $\mathrm{MOH}$ guidelines, and these guidelines will need to change to recognise the role of the husband.

The lack of resources is in line with a review of cervical cancer screening in developing countries which indicated that the main barriers to screening programmes were poverty, a lack of healthcare infrastructures, and few trained practitioners (Catarino, Petignat, Dongui, \& Vassilakos, 2015). Similar obstacles have been identified by the WHO in its report of cervical cancer screening in developing countries (World Health Organization, 2002). This finding provides information to the Indonesia government about the health services situation in rural areas. Even though this information may not be new, giving additional information about the rural health situation, especially about husbands as women's health support system and limited health services related to women's cancer, may be useful for future health programmes.

\subsection{Reflection}

The use of an Islamic ontological approach has not been reported in the literature. Using this approach required me to strengthen my Islamic culture and what I thought as a person. Even though Islam is my hereditary religion, when I began this research I felt my understanding of Islamic teaching was limited. In reading and writing the Islamic ontological approach (Chapter 2), I learnt a lot and was conscious of my responsibility to convey the concept of Islam correctly. As part of addressing my responsibility, I sent my writing about Islam to the Head of the Kilbirnie Mosque, Wellington. He is a scholar of Islam from Cairo, Egypt. Following a discussion I modified aspects, especially regarding the Hadiths. For 
Muslim, the Hadith sources are large, I wanted to make sure I referred to them correctly.

The data collection stage was the most exciting process in my research journey. Unlike Mohamed (2010) who found recruiting participants difficult, my experience with recruitment was positive. In rural areas, I collected my data at the border areas between West and Central Java provinces where the participants communicated in two different indigenous languages: Javanese and Sundanese. I can speak Javanese well because I am Javanese, and I can understand Sundanese because I live in West Java where the majority of the population is Sundanese, and I learned that language from people around me. I met many people who supported my study in the recruitment stage, including my family, colleagues, students, local government and institutional leaders, community and religious leaders, and people in urban and rural communities. Prospective participants welcomed the opportunity to join my study; they actively engaged in the focus groups and interviews, were excited when I met them, and they wanted to learn more about women's health and cancer. After the focus groups and interviews, participants wanted me to talk more about breast and cervical cancer. I enjoyed having interactions with them, listening to their opinions related to the study's topic and learnt a lot from their experiences. There is clearly a place for health professionals to lead health forums in community settings.

From the data collection, I learnt that as a Muslim woman researcher I need to be more open-minded. Before I started my data collection in rural areas, I was worried that men in the rural area would not accept me. I had the view that rural men are more religious than urban men, and maybe they would not want to talk about their matters to me as a woman and a guest. However, the reality was different, they were very supportive and openly shared their daily actions and at times intimate details related to their marriage, their behaviour and how this linked to women's health and cancer. Given the variability in what people shared, the lack of a robust discussion does not limit the credibility of the findings.

As a researcher, I learnt to be flexible in fieldwork. I had not anticipated that woman participants would prefer a group setting rather than a one-on-one interview. In the rural setting, I, therefore, had to adapt the interview schedule so that women could, if they chose, share their experience in pairs. Eight chose to be interviewed in pairs. I explained to the women that the questions were of a personal nature, and they said it would be fine because they are friends. I do not consider interviewing in pairs 
influenced the quality of the data gathered, and I obtained data that addressed my study's aims. In regard to site permission processes, I am happy that my country is improving its public service processes. It took only one day for me to receive permission to visit the sites from the provincial and district governments. I also had immediate responses from community leaders who were willing for me to contact potential participants.

Analysing the huge amount of qualitative data was an overwhelming experience. It took me almost a year to find the meanings and messages in what was shared. I began with transcribing the data from the focus groups and interviews. From this process, I faced problems with several Sundanese terms. To address this translation issue, I discussed the terms with a Sundanese friend who clarified them for me. It was an interesting experience for me to stay in a community that spoke different indigenous languages. The focus groups were conducted in Bahasa Indonesia and participants gave their opinions in three languages, Bahasa Indonesia, Sundanese, and Javanese. Translating from Bahasa Indonesia to English was difficult because both languages have different sentence structures. Bahasa Indonesia uses word by word to express or explain things, while English has specific grammar and sentences to achieve this. I translated all the transcriptions from the focus groups which was extremely time consuming, and a lot of the translation included conversations that did not relate to the topic under study. I altered my strategy for women and health professionals by analysing the data in Bahasa Indonesia and then translating those findings into English using only participants' words that had a direct link to the research topic.

Finding appropriate methods to analyse the data took long discussions with supervisors. There were no published approaches for analysing descriptive exploratory data that included comparing the data between groups, such as rural and urban participants, younger and older participants, and those who have and have not had cancer experience. I, therefore, created my approach to achieve this by integrating three sources (F Rabiee recommendation, Content Analysis in Nursing Research, and the Qualitative Analysis Guide of Leuven). I specifically named the analysis methods as the Comparative Analysis for Focus Group and the Comparative Analysis for Interviews so others can more easily replicate them. These methods were useful for guiding the step-by-step analysis of the vast amount of data, including taking account of the participants' different demographics. Overall, the 
study's design achieved the research objectives. Lastly, writing up the research results and elaborating the whole thesis was particularly challenging; I not only had to learn to write and argue in English, but I also needed to focus on my study objectives and ensure chapter by chapter congruence.

\subsection{Study Limitations}

This study included a purposive sample of 11 focus groups of 73 Muslim husbands, 20 interviews with Muslim wives, and 10 interviews with health professionals. The sample does not represent the millions of Muslims in Indonesia as the sample came from one region, and Muslim husbands in other regions may have different roles. However, this study does provide insights into Javanese Muslim husbands' roles in women's health and cancer and the factors that influence these roles. This information will be useful for nurses and the government, especially the Ministry of Health, to develop future health programmes as information about Muslim men roles and behaviours is limited. Given the topic of Muslim husbands' roles in women's health and cancer has not been explored before, I consider the findings will also be useful for other countries where Muslim people live.

A second limitation is that the health professional participants were all female. Male health professionals' perspectives of their role in women's health and how they work with husbands and what they consider are husbands' roles may differ. Only female health professionals participated because they were the health professionals mainly responsible for women's health and cancer services in the area in the PHC and villages where the research was conducted. The health professionals were recommended by the heads of the PHCs and were considered experts in their field. The information they provided was comprehensive and suitable for the study.

In the focus groups, the interaction among participants and myself as moderator was more like a group interview. The men participants tended to listen to the question, one would answer it, and other participants would add their experience: if it was the same or they would describe a different experience or opinion, but no one disagreed or openly argued with other men's views. This behaviour is perhaps influenced by their Islamic or cultural background. For example, the older men in the group were given priority to answer first, and it is also a way of showing respect to these older persons by listening correctly. 
In this study, the use of community leaders to approach participants to participate was adopted in line with Islamic and community values and practices. The numbers of people who participated in the study indicate these leaders did an excellent job. However, there is a possibility that participants who were chosen by the community leaders were the person who actively engaged in the community, and because of that they maybe have a better understanding about health than other community members. Others in the communities, perspectives on the roles of husbands in women's health and cancer may differ.

Although the use of the theoretical frameworks to guide the focus groups and interview schedules could be viewed as a limitation as the topics related to these theories were used as prompts during data collection, I do not consider this to be the case. The factors extracted from the tools were integrated. Also, the theories had not been applied to Muslim people, nor used in the Indonesian context before. Participants' responses reflected their day-to-day realities as opposed to addressing theoretical answers.

\subsection{Implications and recommendations for nursing}

\subsubsection{Nursing Theory}

Several nursing theories provide a comprehensive approach to frame nursing care that includes a religious or spiritual component, for example, the Health Promotion Model by Nola Pender (Pender, Murdaugh, \& Parsons, 2016). However, my research contributes a new perspective on how a religion can be recognised as a critical influence and driver in health and health behaviour. The model in Figure 7 has links with the Basic Model of Religiosity and Health (Masters, 2008). What it illustrates is that religious influence can be overarching, not unlike culture. In relation to a dominant majority religion that influences society, nurses need to recognise and incorporate religion and religious practices into their nursing care and health education and value its role in health outcomes. This research identifies that the role of religion needs to be stronger or strengthened, in nursing theory, particularly where religion is also a way of life, such as Islam, and in some Hindi and Catholic populations. 


\subsubsection{Nursing Practice}

As part of their roles in their families, Muslim husbands were very engaged in women's health and cancer, especially in maintaining women's health, and helping women when they were sick. However, the role of the husbands in cancer screening was almost absent. Their limited health literacy of women's cancer influenced this. Given that the husbands had a strong interest to learn more about women's cancer, this is an opportunity for nursing. Nurses can take the lead in improving Muslim husbands' understanding in women's health and cancer, raising their awareness of women's cancer and screening, and enhancing the quality of health services for women. This will require nurses to provide health education programmes informed by Islamic teachings for Muslim husbands about women's cancer.

The Islamic approach means approaching men via their Islamic activities, for example, providing flyers about women's cancer and screening in the Mosque because it is compulsory for Muslim men to attend the weekly Friday prayer. Flyers could help men access information about cancer and screening, including their roles in supporting and encouraging women to attend health services. Other methods for distributing information are visiting men communities groups, including sports clubs and farmers association. Nurses can also make time to talk to men about women's cancer, including running group discussions involving husbands with women's cancer experience in their family. Modern technology, such as developing a cell phone application with content information about women's cancer, is also possible. Developing a centre for men's health education to enhance men's understanding of the importance of disease prevention, including women's cancer prevention using the HPV vaccine, should also be explored.

To increase the awareness of women's health and cancer, nurses can use Islamic teaching to approach men and women, as both follow the teaching. Motivating married men to be proactive in supporting women's health by reminding them that taking care of their wives' health is part of worshipping God will also assist. In addition, this religious approach may also be useful for women, as many women believe that following their husband's advice is compulsory for Muslim wives. The nursing profession could lead the development of "a women's health day" programme that could be used for NCDs generally and screening for cancer in particular. 
Nurses also have a role in assisting men and families in rural areas to overcome the obstacles faced when attending hospitals in main centres. Developing outreach clinics as well as appointment systems that mean the first people present get seen is a burden for rural people. Rural families also need people to assist them to navigate the hospital system. Nurses, for example, could teach administrators to orientate people. There is also a potential role for community volunteers.

Nurses also need to use a cultural safety framework (Polaschek, 1998; Richardson, 2011) in their assessment of patients. The aim is to establish their expectations of health services and to understand patients' needs related to such matters as the need for a female health professional, as well as the role of different family members regarding their health. Health professionals need to be aware of the influence of Islamic teaching and its impact on power and powerlessness of husbands regarding their wives' health. Given that the desire for a female health doctor for female patients is not possible in many areas (especially rurally), health professionals, especially nurses, need to do more to minimise the distress felt by men (and perhaps women) whose wives have to be seen by male health doctors. Strategies nurses can use include ensuring a woman is appropriately draped, staying with women while the doctor examines the women, and acknowledging the men's distress.

\subsection{Implications and recommendations for the Indonesia health system}

This research draws attention to the urgent need for more Muslim female health professionals, especially female doctors in rural areas. Incentives may be required for female doctors to work in rural areas, in addition to training more women doctors. As breast and cervical screening services and programmes are not available in all rural areas in Indonesia, the government should consider a major expansion of services. Early detection of women's cancer is crucial because it increases the possibility of successful treatment (WHO, 2017). Further, there is no clear cancer target for the PHC (health services in rural areas), and few rural health professionals provide screening procedures. Some actions to enhance women's health services in rural areas could include improving health facilities, expanding nursing roles and clarifying the technical requirements for rural health professionals. 
These should comprise a target for women's screening and more training for rural health professionals.

It is also apparent from the research that women's health and cancer programmes in Indonesia need to recognise the role of Islamic teachings, especially the significance of Muslim husbands' roles. Husbands have the potential to help women enhance their health. Health education programmes are required that will increase both men's and women's health literacy and awareness of disease prevention and cancer screening. Such programmes need to be clear about the role of early diagnosis and also the nature of symptoms for which people should seek assistance.

Married men from rural areas also face burdens when their wives were hospitalised. Among these, and one which should be a priority is accommodation. Providing more family rooms or accommodation for rural patients could improve husbands' and families' support. In addition, reforming procedures for services in referral hospitals, especially inpatient rooms and patients' care, should be the full responsibility of the health professionals. A family's role is to support the patient emotionally and mentally, not to be facilitators in health procedures, for example, dropping blood or urine samples to the laboratory.

\subsection{Further research}

Recommendations for future study include developing a study that compares Muslim husbands' roles in women's health in different provinces in Indonesia to provide a wider picture and more information about this topic. This became apparent in this study in the West Java province where the majority of residents are from the Sundanese tribe. Indonesia is a multi-ethnic country, and as other provinces have similar characteristics, they are dominated by different tribes and therefore may have differing attitudes to women's health.

A more specific study is required to better understand of the burdens rural people face in accessing health services. Such a study could also include examining the difficulties faced by health professionals in rural areas.

Understanding more about why men and women do not respond to abnormal symptoms of women's health issues is essential. Early detection of women's health 
abnormality, especially women's reproductive organs, is key to successful treatments.

A study to explore the impact of men's powerlessness in regard to women's health and health services would be useful information in helping health services to evaluate their services, to inform husbands and wives' expectations of health services, and to evaluate teaching hospital management about student health fieldwork in hospitals or PHCs. There is a need to study Muslim husbands' roles in patient cancer care as only a few men in this study had specific experience of women's cancer.

Research into the perspectives of external supports, including community leaders, cadres, relatives and religious leaders, and how they influence men's roles in women's health would provide nurses with useful information when they are involved with these sources relating to men's roles in women's health. Finally, more comparative studies are needed to find the specific needs of rural and urban men so an appropriate approach can be developed to improve their roles in women's health. This would be helpful as urban and rural men exhibited different roles with regard to women's health and there is a paucity of information comparing men's demographic factors in this area. These include the difference between older and younger men, whether they have children, different types of employment, whether they live in rural or urban areas, the variation in education levels and the diversity of ethnic groups.

\subsection{Conclusion and Contribution}

This study provides a broad understanding of Muslim husbands' roles in women's health and cancer. The findings indicate that Islamic teaching is significant to guiding Muslim husbands' activities in their roles in women's health and cancer from urban and rural areas. The three data sources provided perspectives that Muslim husband's roles in women's health and cancer are comprehensive and that there is variability in how Muslim husbands apply these roles. This variability is influenced by personal, family, and health services factors. Muslim husbands have significant roles in women's health, especially health promotion and facilitating health treatments. However, most husbands have a more limited role in the prevention and early detection of cancer. Rural husbands and those with low 
incomes faced barriers in accessing women's health and cancer information, and health services for their wives.

The findings contribute to health knowledge and nursing practices, including providing fundamental knowledge about Muslim husbands' roles in women's health and cancer in urban and rural areas of a low to middle-income country: Indonesia. They provide considerable information related to the need to improve Muslim husbands' understanding of women's health and cancer that would encourage husbands' involvement in women's health, especially their roles in women's disease prevention and screening. The findings highlight the need to enhance women's health services in rural areas and referral hospitals.

Methodologically the research provides three key contributions. Firstly, that it is possible for a Muslim woman to research a project focused on Muslim men. Secondly, the development and explication of the comparative analysis techniques for focus groups and interviews make a useful contribution to the descriptive exploratory methodology. Thirdly, through the use of an Islamic ontological framework I have been able to acknowledge the teachings and their influence on the life of Muslims. This framework allowed me to uncover the significant influence of Allah and the Hadith's words on the health and health-seeking behaviour of Muslims. The impact of Islamic teachings on health behaviour is not only an influencing component but is a main determinant. 


\section{Appendices}

Appendix 1: Introductory letter form supervisor

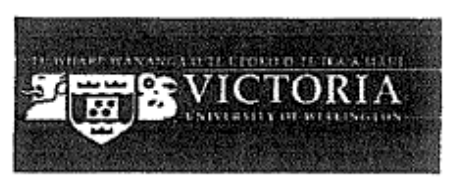

GRADUATE SCHOOL OF NURSING, MIDWIFERY \& HEALTH

VICTORIA UNIVERSITY OF WELLINGTON, PO Box 7625, Newtown, Wellington 6242, New Zealand Phone +64-4-4635363/0800 108005 Fax +64-4-4635442 Email nmh@ivww.ac.nz Websito wew.victoria.acnz/nmh

$28^{\text {th }}$ November 2014

To whom it may concern

As Restuning Widiasih's primary supervisor I am writing in support of her research in Indonesia. Restuning has a New Zealand Scholarship to undertake doctoral studies at Victoria University of Wellington. This is a three year scholarship that includes some support for students to return to their home country for data collection so that the research they undertake has relevance to their home country as well as international significance.

Restuning is now in Indonesia to undertake her ficld work. Her research is exploring the perspectives of married Muslim men's roles related to women's cancer in Indonesia. Her project has been formally accepted by the Graduate School of Nursing, Midwifery \& Health where she is located. She has received ethical approval from the Human Ethics Committee, Victoria University of Wellington. This process required Restuning to identify ethical issues and strategies to address these for her research.

I would appreciate any support you can give Restuning over the next three months while she undertakes data gathering. I will be in regular contact with her over this time. Restuning is using a descriptive qualitative design and will be carrying out interviews of women and of health professionals and focus groups of married men in both a rural and urban area of Indonesia. She has pre-tested her methods with Indonesian immigrants in New Zealand. Victoria University has password protected computers and all offices are locked. This will ensure the safety of her material on return to New Zealand.

Please do not hesitate to contact me for further information. My email address is Kathy.Nelson@vuw.ac.nz if you require further information.

Dr Katherine Nelson

Senior Lecturer and Deputy Head of School

Graduate School of Nursing, Midwifery \& Health 
Appendix 2: Recommendation letter from Dean of Nursing Faculty, Universitas Padjadjaran for site permissions to BKBP West Java Province

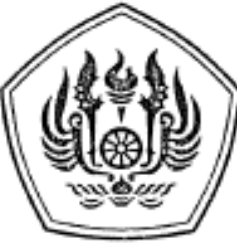

Nomor

Perihal
KEMENTERIAN PENDIDIKAN DAN KEBUDAYAAN

UNIVERSITAS PADJADJARAN

FAKULTAS KEPERAWATAN

Jl.Raya Bandung - Sumedang Km. 21 Jatinangor - Sumedang 45363 Telp./Fax.022 - 7795596 Email: keperawatan@unpad.ac.id

\author{
: 3266/UN6.L/PP/2014 \\ 8 Desember 2014
}

Yth. Kepala Badan Kesatuan Bangsa dan

Pemberdayaan Masyarakat

Provinsi Jawa Barat

Sehubungan dengan staf pengajar Fakultas Keperawatan Universitas Padjadjaran yang saat ini sedang melaksanakn studi S3 di Graduate School of Nursing. Midwifery and Health, Victoria University of Wellington, New Zealand, dengan ini kami sampaikan permohonan izin bagi :

$$
\begin{array}{ll}
\text { Nama } & \text { : Restuning Widiasih } \\
\text { NIP } & : 197504172006042001
\end{array}
$$

Untuk melakukan penelitian dengan judul "Perspectives of Married Muslim Men's Roles Related to Women's cancer in Indonesia"

Adapun penelitian ini akan dilaksanakan di wilayah Kota Bandung dan Kabupaten Pangandaran pada Bulan Desember 2014 - Maret 2014. Sebagai bahan pertimbangan, bersama ini kami lampirkan proposal kegiatan penelitian.

Besar harapan kami Bapak dapat memberikan izin penelitian bagi staf kami tersebut. Atas perhatian, bantuan dan kerjasamanya, kami ucapkan terima kasih.

Dekan,

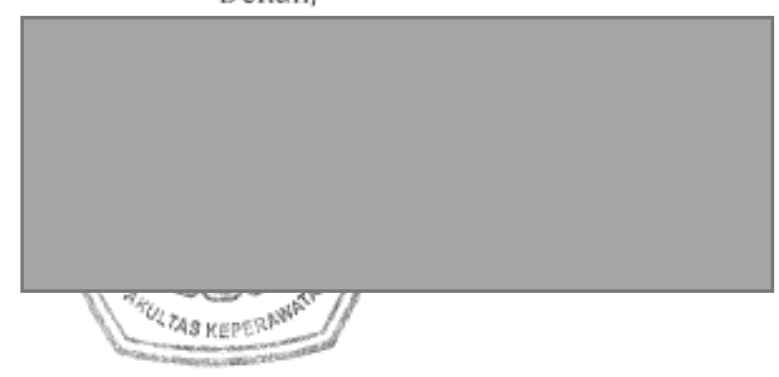

Tembusan :

Yth. Wadek I \& II FKep Unpad 


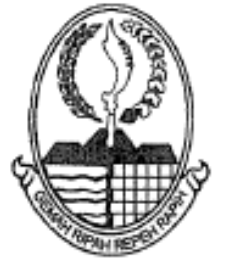

\title{
PEMERINTAH PROVINSI JAWA BARAT BADAN KESATUAN BANGSA DAN POLITIK
}

Jalan Supratman No. 44 Telp. (022) $7206174-7205759$

Faksimil : (022) 7106286 website : www.bakesbangpolinmasda.jabarprov.go.id e-mail : bakesbangpolinmasda@jabarprov.go.id B ANDUNG

\section{SURAT KETERANGAN \\ Nomor : 070/1492/Rekomlit/KESBAK/2014}

4. Yang bertanda tangan di bawah ini :

\section{Kepala Badan Kesatuan Bangsa dan Politik Provinsi Jawa Barat}

\author{
Berdasarkan surat dari : Dekan Fakultas Keperawatan Universitas Padjadjaran \\ Nomor : 3266/UN6.L/PP/2014 \\ Tanggal : 8 Desember 2014 \\ Menerangkan bahwa :
}

\begin{tabular}{|l|l|l|l|}
\hline a. & N a m a & $:$ & Restuning Widiasih \\
\hline b. & HP/Email & $:$ & 082115858896 \\
\hline c. & Tempat/tgl lahir & $:$ & Banyumas, 17-04-1975 \\
\hline d. & Agama & $:$ & Islam \\
\hline e. & Pekerjaan & $:$ & Dosen \\
\hline f. & Alamat & $:$ & Jl. BKM Tengah No.17Cibeunying Kidul Bandung \\
\hline g. & Peserta & $:$ & - \\
\hline h. & Maksud & $:$ & Penelitian \\
\hline i. & Untuk Keperluan & $:$ & $\begin{array}{l}\text { Studi S3 Dengan Judul : "Perspectives of Married Muslim Me'n Roles Related } \\
\text { to Women's cancer in Indonesia" }\end{array}$ \\
\hline j. & Lokasi & $:$ & Kota Bandung dan kab. Pangandaran \\
\hline k. & $\begin{array}{l}\text { Lembaga/Instansi } \\
\text { Yang Dituju }\end{array}$ & $:$ & $\begin{array}{l}\text { 1. Kantor Pemberdayaan Masyarakat, Pemerintahan Desa dan Kesbang } \\
\text { KotaBandung }\end{array}$ \\
\hline
\end{tabular}

5. Sehubungan dengan maksud tersebut, diharapkan agar pihak yang terkait dapat memberikan bantuan/fasilitas yang diperlukan

6. Demikian Surat Keterangan ini dibuat untuk dipergunakan sebagaimana mestinya, dan berlaku sampai dengan 31 Maret 2015

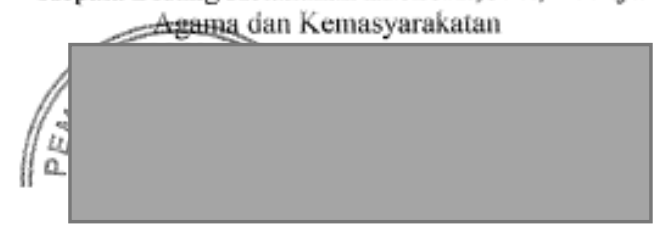


Appendix 4: Site permission letter from BKBP Bandung city

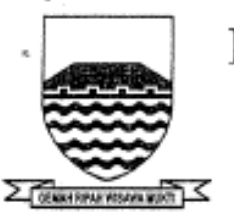

\section{PEMERINTAH KOTA BANDUNG BADAN KESATUAN BANGSA DAN PEMBERDAYAAN MASYARAKAT}

Jalan Wastukencana No. 2 Tlp. 022 4230393, 4230097 - Bandung

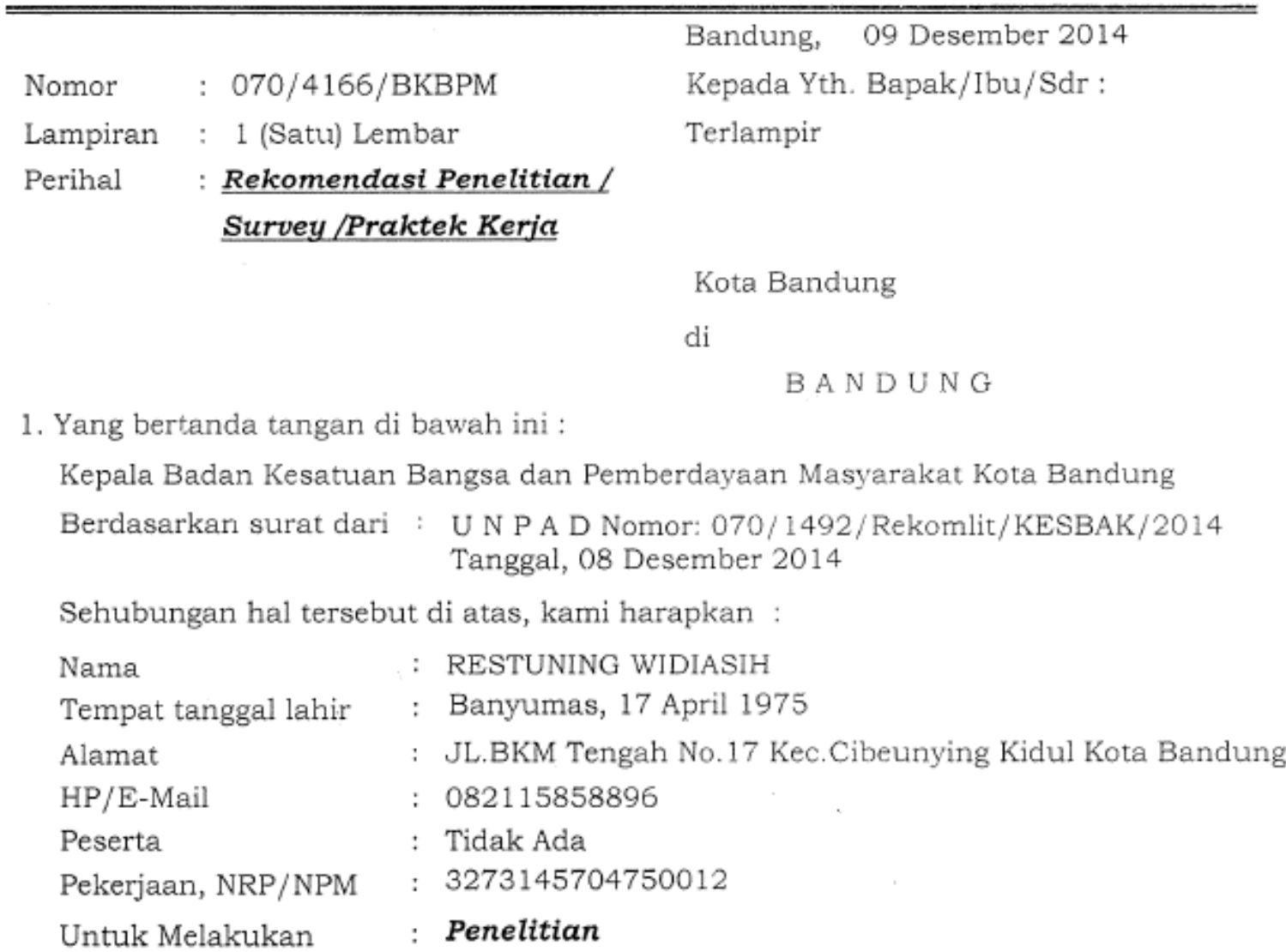

\section{Dengan Judul "Perspectives of Married Muslim Men's Roles Related to Women's Cancer in Indonesia".}

2. Yang bersangkutan telah menghadap kami tanggal 09 Desember 2014 dan Surat Pemberitahuan ini berlaku sampai dengan tanggal 09 Juni 2015

3. Dengan memperlihatkan Identitas serta untuk kelancaran memperoleh bahan yang diperlukan, pada prinsipnya kami tidak keberatan yang bersangkutan melaksanakan Penelitian/Survey/Praktek Kerja, sepanjang tidak mengganggu tugas yang menyangkut rahasia jabatan masing-masing Instansi/SKPD.

4. Demikian atas kerjasamanya kami haturkan terimakasih.

a.n. KEPALA BADAN KESATUAN BANGSA DAN PEMBERDAYAAN MASYARAKAT KOTA BANDUNG Sekretaris 
Appendix 5: Site permission letter from BKBP Pangandaran district

\section{PEMERINTAH KABUPATEN PANGANDARAN KANTOR KESATUAN BANGSA, POLITIK}

Jalan Balandongan Nomor 18 Tlp/Pax (0265) 2641259 Parigi-Kab. Pangandaran

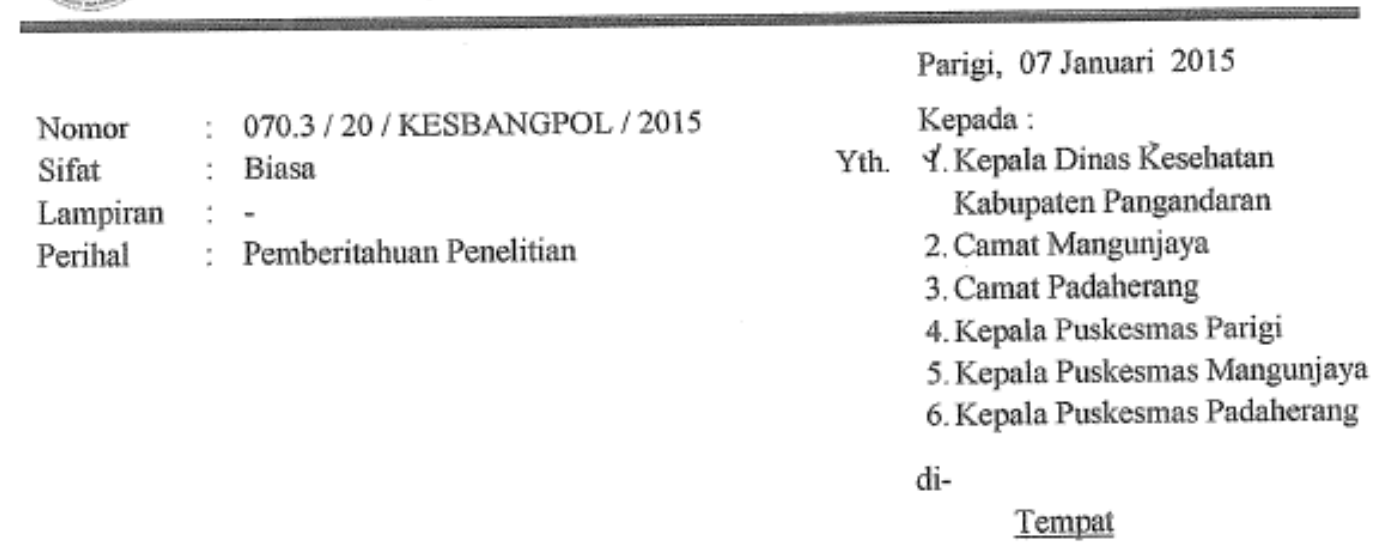

Sehubungan surat dari Badan Kesatuan Bangsa dan Politik Provinsi Jawa Barat Nomor : 070/1492/Rekomlit/KESBAK/2014, Perihal Permohonan Izin Penelitian

Setelah dilakukan penelitian terhadap kelengkapan administrasi dan wawancara langsung dengan yang bersangkutan, dengan ini kami sampaikan bahwa :

Nama

RESTUNING WIDIASIH

HP/Email

082115858896

Tempat tanggal lahir

Bayumas, 17-04/1975

Alamat

Jl. BKM Tengah No. 17 Komplek Bojong Koneng Makmur, Rt.004/Rw.011 Desa Sukapada Kecamatan Cibeunying Kidul Kota Bandung

Pekerjaan : Dosen

Judul Penelitian : Perspectives Of Married Muslim Men's Roles Related To Women's Cancer In Indonesia

Waktu Pelaksanaan : 07 Januari s.d 31 Maret 2015

Telah memenuhi syarat untuk dapat dibantu kelancaran kegiatan dimaksud.

Demikian agar maklum, atas perhatiannya kami ucapkan terima kasih.

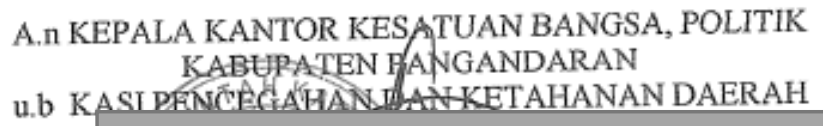




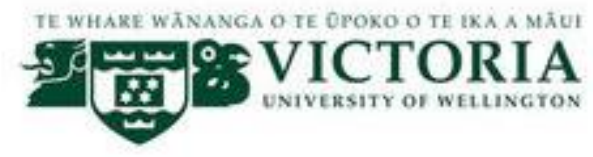

Graduate School of Nursing, Midwifery, and Health

Focus Group Questions for Married Muslim men

Project title: Perspectives of Muslim husbands' roles related to women's cancer in Indonesia

\section{Review ground rules}

- Respect for each other's opinions

- Confidentiality

- One speaker at a time

- Aim is to understand there are no correct ways to answer any of the questions

Note: Prompts as bulleted will only be used as required

1. Please share with the group a little bit about yourself; your name, occupation, how long you have been of married, any children?

2. Please share what your involvement in your wife's health generally

$\circ$ E.g., Not involved

- What kind (if any) of health issues do you discuss together?

- To what extent are you involved in whether your wife sees a health professional

- Do you accompany her to appointments?

- Has your involvement in your wife's health changed over time, and why?

- What has influenced or where did you learn about this role

- Your wife (expects it; her health dictates it); How brought up (your own family experience); Teachings of Allah about husband's role about health;

3. Now to move to the focus of breast and cervical cancer.

- Please share with the group whether you have had any experience with either of these. (Your wife, child, your mother, sister, neighbour, work colleague)

4. What do you know about breast cancer?

$\circ$ How is it screened, diagnosed, and treated?

5. What do you know about cervical cancer?

$\circ$ How is it screened, diagnosed, and treated?

6. In what way does the fact that these women's cancer concern the private parts of your wife's body influence what happens to her participation in screening and treatment of breast and cervical cancer?

- How important is the gender of the health provider?

- What are your expectations of women's health services? 
7. If your wife was or has been diagnosed with one of these cancer how do (or did) you imagine you would respond, and why?

- Embarrassed; accept as a test from Allah

- Wait and see how it develops

- Seek out services

- Fund care

- Accompany to care

8. Do you consider that health programmes should do more about husbands" roles in screening and treatment of breast and cervical cancer?

$\circ$ Why? Why not?

○ For those who say they should do more ask for examples of what should be done?

Thank you for your time today. If you have any questions or queries about the research, please feel free to contact me on $\underline{\text { Restu.Widiasih@vuw.ac.nz }}$ 


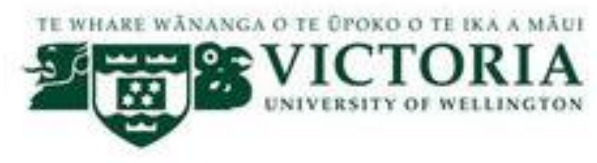

\section{Graduate School of Nursing, Midwifery, and Health}

The interview questions for married women

\section{Project title: Perspectives of Muslim husbands' roles related to women's cancer in Indonesia}

Note: Prompts as bulleted will only be used as required

1. Could you tell me a little bit about yourself; your name, occupation/activities, and how long you have been of married, any children?

2. Tell me about how you manage your health generally and the type of role your husband has in this
$\circ \quad$ E.g., Not involved
- What kind (if any) of health issues do you discuss together?
- Who decides whether you see a health professional
- Does anyone accompany you to appointments, and why?
- Has your husband's role in your health changed over time and why?

3. This research is about women's cancer especially breast and cervical cancer

$\circ$ What is your experience of these? Own health; child, mother, grandmother, sister, neighbour, colleague

$\circ$ Expand on the experience

4. What do you know about breast cancer?

- How is it screened, diagnosed, and treated?

- Do you participate in screening, what is your husband's response to this?

5. What do you know about cervical cancer?

○ How is it screened, diagnosed, and treated?

- Do you participate in screening, what is your husband's response to this?

6. In what ways does the fact that these women's cancer concern the private parts of your body influence what your husband expects related to your participation in screening and treatment of breast and cervical cancer?

$\circ$ How important is the gender of health providers?

7. If you were or have been diagnosed with one of these cancer how did or do you imagine your husband would respond to this and why?

- Embarrassed; accept as a test from Allah

$\circ$ Wait and see how it develops

- Seek out services 
- Fund care

- Accompany to care

8. Do you consider that health programmes should do more about husbands" roles in screening and prevention of breast and cervical cancer?

$\circ$ Why? Why not?

- For those who say they should do more ask for examples of what should be done?

Thank you for your time today. If you have any questions or queries about the research, please feel free to contact me on Restu.Widiasih@vuw.ac.nz 


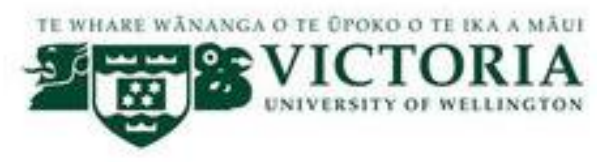

\author{
Graduate School of Nursing, Midwifery, and Health
}

The interview questions for health professionals

Project title: Perspectives of Muslim husbands' roles related to women's cancer in Indonesia

Note: Prompts as bulleted will only be used as required

1. Please tell me about yourself? How long have you been working as health providers in this community?

2. What do you think about women's cancer in your area?

○ Incidence, severity, actions

3. What are the programmes of cancer prevention and treatment for breast and cervical cancer in the institution?

○ Programmes, facilities, sources, targets, implementations, burdens

4. In recalling the last two women that you saw regarding screening/or ?diagnostic testing for breast cancer -

- What was the role of their husbands in this?

- Why did they have this role?

- How typical is this role?

- Give different examples of husband's roles

5. In recalling the last two women that you saw who had been diagnosed with breast cancer

- What was the role in their care and decision making?

$\circ$ Why did they have this role?

$\circ$ How typical is this role?

- Give different examples of husband's roles and decision making

6. In recalling the last two women that you saw regarding screening for cervical cancer or diagnostic testing?

- What was the role of their husbands in this?

- Why did they have this role?

- How typical is this role?

- Give different examples of husband's roles

7. In recalling the last two women that you saw who had been diagnosed with cervical cancer

- What was the role in their care and decision making? 
- Why did they have this role?

- How typical is this role?

- Give different examples of husband's roles and decision making

8. Do you consider that health programmes should do more about husbands" roles in screening and prevention of breast and cervical cancer?

$\circ$ Why? Why not?

- For those who say they should do more ask for examples of what should be done?

Thank you for your time today. If you have any questions or queries about the research, please feel free to contact me on Restu.Widiasih@vuw.ac.nz 
Appendix 9: Example of demography survey

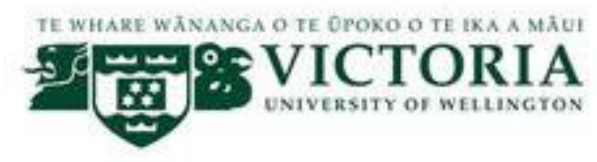

\section{Graduate School of Nursing, Midwifery, and Health \\ SOCIO- DEMOGRAPHICS QUESTIONNAIRE}

Project title: Perspectives of Muslim husbands' roles related to women's cancer in Indonesia

1. What is your gender?

Female

$\square \quad$ Male

2. What is your age?

Less than 40 years

More than 40 years

3. How many children do you have?

4. How long have you been married?

5. Have you had cancer?

Y Yes

$\square$ No

6. Has anyone in your family had cancer?
1] Yes
No

7. What is the highest level of education you have completed?

Elementary school

Junior high school

Senior high school

University

8. Which of the following categories best describes your primarily area of employment (regardless of your actual position)?
Civil servant
aRMY
Private employee
$\square$ Entrepreneur 
Appendix 10: Example of note taking form

\section{FOCUS GROUP NOTE TAKING FORM}

Please specify which focus group you are recording:

Rural areas

Aged 40 years and less

Pre-test 6-12 participants in a group

Pre-test aged 40 years and less
Urban areas

Aged more than 40 years

Pre-test 3-4 participants in a group

Pre-test aged more than 40 years

Date of Focus Group

Location of Focus Group

Name of Note Taker

Note: This note taking form is confidential, please respect participants' opinion. Use this form to record the process of the focus group. Please write extensively and accurately to describe the discussion process, either verbal or nonverbal expression of participants.

\begin{tabular}{|l|}
\hline Question 1 \\
\hline Question 2 \\
\hline \\
\hline Question 3 \\
\hline
\end{tabular}


Question 4

Question 5

Question 6

Question 7

Question 8 
Appendix 11: Example of pre-test focus group guide used for Muslim men

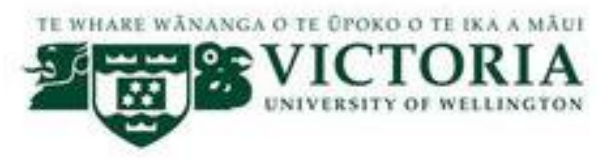

Graduate School of Nursing, Midwifery, and Health

Pre-Test

The focus group questions

Project title: Perspectives of Muslim husbands' roles related to women's cancer in Indonesia

Focus Group Questions for Married Muslim men

\section{Review ground rules}

- Respect for each other's opinions

- Confidentiality

- One speaker at a time

- Aim is to understand, there are no correct ways to answer any of the questions

Note: Prompts as bulleted will only be used as required

1. Please share with the group a little bit about yourself; your name, occupation, how long you have been of married, any children?

2. Please share your involvement in your wife's health generally

$\circ$ E.g., Not involved

- What kind (if any) of health issues do you discuss together?

- To what extent are you involved in whether your wife sees a health professional

- Do you accompany her to appointments?

- Has your involvement in your wife's health changed over time, and why?

- What has influenced you or where did you learn about this role

- Your wife (expects it; her health dictates it); How brought up (your own family experience); Teachings of Allah about husband's role about health;

3. Now to move to the focus of breast and cervical cancer.

- Please share with the group whether you have had any experience with either of these. (Your wife, child, your mother, sister, neighbour, work colleague)

4. What do you think about breast cancer?

- Curable disease, preventable disease, trial from the God

○ Affecting family members' roles

5. What do you thing about cervical cancer?

- Curable disease, preventable disease, trial from the God

○ Affecting family members' roles 
6. In what ways does the fact that these women's cancer concern the private parts of your wife's body influence what happens to her participation in screening and treatment of breast and cervical cancer?

a. How important is the gender of the health provider?

b. How are your expectations of women's health services?

7. If your wife was or has been diagnosed with one of these cancer how do (or did) you imagine you would respond, and why?
a. Embarrassed; accept as a test from Allah
b. Wait and see how it develops
c. Seek out services
d. Fund care
e. Accompany to care

8. Do you consider that health programmes should do more about husbands" roles in screening and treatment of breast and cervical cancer?
a. Why? Why not?
b. For those who say they should do more ask for examples of what should be done?

9. Could you tell me, what gender you prefer as moderator in this focus group?

Thank you for your time today. If you have any questions or queries about the research, please feel free to contact me on Restu.Widiasih@vuw.ac.nz 
Appendix 12: Example of pre-test interview guide used for Muslim women

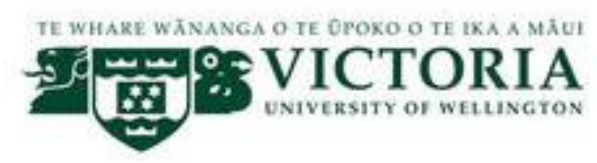

Graduate School of Nursing, Midwifery, and Health

Pre-Test

The interview questions

Project title: Perspectives of Muslim husbands'roles related to women's cancer in Indonesia

\section{The interview questions for married women}

Note: Prompts as bulleted will only be used as required

1. Could you tell me a little bit about yourself; your name, occupation/activities, and how long you have been of married, any children?

2. Tell me about how you manage your health generally and the type of role your husband has in this

$\circ$ E.g., Not involved

- What kind (if any) of health issues do you discuss together?

- Who decides whether you see a health professional

$\circ$ Does anyone accompany you to appointments, and why?

- Has your husband's role in your health changed over time and why?

3. This research is about women's cancer especially breast and cervical cancer

$\circ$ What is your experience of these? Own health; child, mother, grandmother, sister, neighbour, colleague

- Expand on the experience

4. What do you know about breast cancer?

$\circ$ How is it screened, diagnosed, and treated?

- Do you participate in screening, what is your husband's response to this?

5. What do you know about cervical cancer?

$\circ$ How is it screened, diagnosed, and treated?

- Do you participate in screening, what is your husband's response to this?

6. In what way does the fact that these women's cancer concern the private parts of your body influence what your husband expects related to your participation in screening and treatment of breast and cervical cancer?

○ How important is the gender of health providers? 
7. If you were or have been diagnosed with one of these cancer, how did or do you imagine your husband would respond to this and why?

- Embarrassed; accept as a test from Allah

- Wait and see how it develops

- Seek out services

- Fund care

- Accompany to care

8. Do you consider that health programmes should do more about husbands" roles in screening and prevention of breast and cervical cancer?

$\circ$ Why? Why not?

- For those who say they should do more ask for examples of what should be done?

Thank you for your time today. If you have any questions or queries about the research, please feel free to contact me on $\underline{\text { Restu.Widiasih@vuw.ac.nz }}$ 
Appendix 13: Example of pre-test of Socio-demographics survey

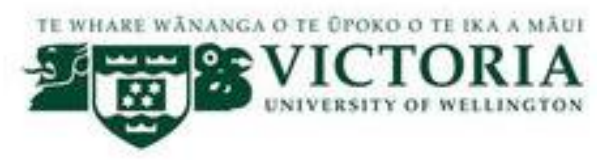

Graduate School of Nursing, Midwifery, and Health

SOCIAL DEMOGRAPHICS QUESTIONNAIRE

Project title: Perspectives of Muslim husbands' roles related to women's cancer in Indonesia

1. What is your gender?

Female

Male

2. What is your age?

3. How many children do you have?

4. How long have you been married?

5. Have you had cancer?
Yes
No

6. Has anyone in your family had cancer?
1] Yes
No

7. What kind of cancer did you or your family members have?
Breast cancer
Cervical cancer

8. What is the highest level of education you have completed?

Elementary school

Junior high school

- Senior high school

$\square \quad$ University

9. What is your occupation? 
Appendix 14: Example of pre-test of qualitative survey of women's knowledge

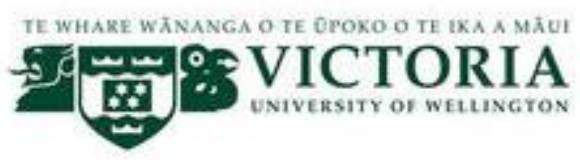

\section{Graduate School of Nursing, Midwifery, and Health}

Survey of Women's Cancer Knowledge

Project title: Perspectives of Muslim husbands' roles related to women's cancer in

\section{Indonesia}

\section{Breast Cancer}

1. What do you know about breast cancer?

2. Please name as many warning signs and symptoms of breast cancer that you know?

3. What are the things that influence a woman's chance of developing breast cancer?

4. What can be done to protect a woman from breast cancer?

5. Is there a breast cancer screening programme in Indonesia? If yes, could you name it?

6. When is the appropriate time to have breast cancer screening?

7. What should women do after diagnosis with breast cancer?

8. Can breast cancer be treated? If yes, please provide names of some treatments you know about? 


\section{Cervical Cancer}

1. What do you know about cervical cancer?

2. Please name as many warning signs and symptoms of cervical cancer that you know?

3. What are the things that influence a woman's chance of developing cervical cancer?

4. What can be done to protect a woman from cervical cancer?

5. Is there cervical cancer screening or prevention programmes in Indonesia? If yes, could you name it?

6. When is the appropriate time to have cervical cancer screening or prevention?

7. What should women do after diagnosis with cervical cancer?

8. Can cervical cancer be treated? If yes, please provide names of some treatments you know about? 
Appendix 15: An example of translation

\section{Pengalaman selama ini, istri mengeluh sakit, biasanya yang bapak-bapak lakukan apa? mungkin ada yang memulai berpendapat silahkan}

XX: kalo istri sakit, kalo saya suka saya suruh kedokter langsung, jangan beli obat diwarung ato dimana saja yaa, langsung saja saya suruh ke dokter misalnya sakit lambung ato masuk angina, tapi istri mah sukanya minta di kerok, sama saya ga pernah diturutin kalo saya, nanti dia nyuruh adiknya, sering dia itu teh bu, udah kedokter saja langsung saya bilang gitu, kalo sakit minta kerok, saya suka bilang jangan, kan ga boleh yaa, kalo keseringan dikerok kan yaah, jadinya kalo sudah sakit rada lama gitu bu, bisa seminggu, disuruh ke dokter ga mau

\section{Kapan terakhir ke dokter istrinya?}

XX: kapan yaa sudah lumayan lama lah

\section{Apa dianterin?}

XX: Ga lah, jarang, seringnya sendiri, saya kerja bu

Based on your experience, what have you done so far, when your wife reported some health issues? Any of you wants to share about this?

$X X$ : When my wife was sick, I took her to the doctor quickly, I avoided to buy medicine at the little shops near home as other people did, I told her to go to the doctor but sometimes, she refused it. For example, she had ulcer or cold; she preferred to get "kerok" (a traditional Indonesian therapy), I did not want to do that because, for me, it is unhealthy behaviour. And then she went to her young sister and asked for "Kerok." So sometimes, she needed around a week to recover from a mild health issue because she did not want to go to the doctor.

When was the last time your wife went to the doctor?

XX: Its already quite a long time ago.

Did you accompany her to the doctor?

$X X:$ Not really, she went to the doctor by herself, because I am busy with my job 


\section{Kalo bapak yang lain bagaimana pengalamanya?}

XX: emang sie sama saja, kesimpulan dari P Hendra juga, kalo misalnya ada gejalagejala sakit, cepet aja ke dokter, kalo misalnya keadaan darurat terkecuali, penanggulangan darurat kita pake obat-obat herbal yang bisa kita minum dulu sebelum ke dokter, itu pun kalo misalkan darurat, tapi kalo bisa cepet ke dokter yaa ke dokter untuk periksa, kita kan ga tahu penyakit apa, kadang-kadang kalo istri kita sakit, kitu nyak, kadang-kadang kalo kita lagi sibuk, kadang cuek ato bagaimana gitu, kurang perhatian terhadap istri yaa, tapi yaa pada dasarnya memperhatiin istri soalnya kesehatan itu sangat berharga, lebih baik menjaga dari pada mengobati, gitu aja

XX: kalo saya, kalo istri sakit dilihat dulu gejalanya kalo ringan cuman minta dikerokin ato dipijat, saya akan lakukan untuk menyembuhkan sementara, kalo merasa berat, nah ini mah harus ke dokter, ya saya langsung bawa ke dokter keluarga, untuk mencegahnya jadi makin berat,

\section{Jadi P XX anterin?}

XX: saya lagi kerja kalo ditelpon istri sakit juga langsung saya anterin, kadang masuk ikut nememin sampai kedalam klinik, kadang ngater ajah

\section{Anyone else?}

$X X$ : Well its quite similar to my experience, I summarized from Hendra's opinion. For example, when my wife reported symptoms of health issues. I took her to the doctor immediately. For the first aid, I suggested her to take herbal medicines first, before my wife and I visited the doctor. But, once again, I preferred to go to the doctor for a check, because we didn't know what the disease was. Honestly, sometimes I was too busy with my jobs, so I lacked attention to her health, but I am aware that I need to pay attention to my wife's health because her health is precious, it is better to do health prevention rather than treatments. That's all.

$X X$ : In my opinion, when my wife said any health problem, first, I observed the symptoms, when it was mild symptoms, I did "kerok" as a temporary action, then no 
significant changed of her health, I took her to the family doctor. The aim was to prevent the condition deteriorate. My wife's health is my priority.

\section{Did you accompany her?}

XX: When she called me via her cell phone and said that she had sick, I would back home and accompany her to the doctor, even though I was working. Sometimes, I went into the doctor room, but when I was too busy, I did not accompany her.

XX: hampir sama sie, kalo misal sakit pinggang, pertama biasanya pake obat warung dulu, kalo sakitnya masih bisa pake obat warung yaa obat warung, Alhamdulillah sejauh ini sakitnya ga parah, mungkin dulu pernah waktu hamil gitu ngerasa sakit, dia kalo ada yang dirasa ditahan dulu, nanti misalnya emang sudah banget dan merasa ga kuat dia baru bilang ke saya, saya sie seperti itu bukannya apa yaa, bukan cuek ato ga perhatian lebih ya memang istri sendiri sifatnya seperti itu, jadi kalo memang saya paksain dah langsung ke rumah sakit, kadang dia sendiri kadang takut yaa sama yang namanya rumah sakit bu yaa jadi kalo sekiranya sakitnya masih bisa ditahan yaa dia tahan, kalo ga tahan langsung ke dokter, dulu pernah malam2 jam 1 malam, tiba-tiba nyeri hamil, terus sudah sakit sampe ga kuat, terus dirawat, selama ini istri juga sakit wajar, bisa pake obat warung, kalo misalnya sendirinya ngerasa ga kuat dia pasti bilang ke saya

$X X:$ Almost similar to Una's opinion. For example when my wife had sore on her hip, first I suggested her to buy a painkiller from the small shop near our home. Then, she was fine after an hour. Alhamdulillah, as far as I know, she never had serious health problems. As I remembered, she only had sick when she was pregnant. However, she rarely talked to me about her health; I am worried something. I think the problem is her personality, she is a quite woman, and she afraid with "the hospital" term. So, at that time, when she had sore with her pregnancy she held by herself. Suddenly, she had severe pain at 1 am; then I took her to the hospital. Finally, she hospitalized. Fortunately, she is a healthy woman, no severe disease, and only a mild health problem. It solved by taking common medicines such as painkillers. 


\section{Ada yang ingin menambahkan? P XX?}

XX: sama dengan bapak-bapak yang lain, yaa mungkin kalo istri sakit, penanggulangannya, saya Tanya sakit apa dulu yaa? Kalo masuk angin yaa paling dikerokin, mungkin itu tradisi kayaknya orang Indonesia yaa, walaupun kata dokter ga boleh, yaa kalo tradisi mo gimana, kalo sudah dikerokin, terus minum obat, tergantung apa gejala penyakitnya, tapi kebanyakan orang kebiasanya sakitnya sakit kepala, batuk pilek, kayak gitu, jarang yang berat, biasanya sakitnya yaa gitu-gitu aja jadi biasanya obatnya sudah disiapin dirumah, aklo ga kuat mungkin ke dokter langsung gitu yaa, kalo keadaan saya kerja, paling yaa dia sendiri, seringnya sendiri, soalnya pagi kerja, saya kan jauh gitu yaa, paling pulangnya kalo dia ga kuat, dia sendiri ke dokter, kalo sudah ke dokter pulangnya paling dia ngobrol, itu ajah paling, soalnya kita punya aktivitas kerja yaa namanya kerja yaa susah juga , kalo darurat banget yaa wajib saya pulang, gitu...

\section{Anyone want to add your experience? P XX?}

$X X:$ My experience is quite similar to others, when my wife was sick, first, my action was asked her what's the problem? I did "kerok" when she was catching a cold; I think it is an Indonesian habit, even though she knows that doctors forbade it. And then, I bought a standard medicine for her; it depends on her symptoms, the most common problem was a headache, influenza, something like that. She rarely had severe symptoms; her health problem was a mild health issue. I provided common medicines at home. When she was sick and needed to visit the doctor, while I was working, she went to the doctor by herself. My workplace is far away from home, so I go early every morning. When I had times, I picked her up from the doctor. You know, I just an employee, it is difficult to have a free time, but for an emergency situation, it is compulsory for me to back home and help her immediately, like that. 


\section{Appendix 16: Ethics approval from Human Ethic Committee Victoria University of Wellington}

TE WHARE WĀNANGA O TE OPOKO O TE IKA A MĀUI

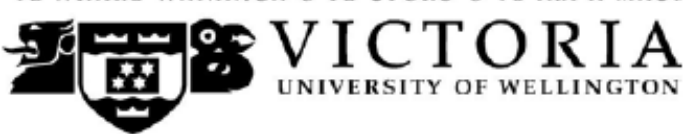

MEMORANDUM

Phone $\quad 0-4-4635676$

Fax $\quad 0-4-4635209$

Email Allison.kirkman@vuw.ac.nz

\begin{tabular}{l|l}
\hline TO & Restuning Widiasih \\
\hline COPY TO & Kathy Nelson \\
\hline FROM & Dr Allison Kirkman, Convener, Human Ethics Committee \\
\hline
\end{tabular}

\begin{tabular}{l|l}
\hline DATE & 27 September 2014 \\
\hline PAGES & 1 \\
\hline
\end{tabular}

SUBJECT

Ethics Approval: 21192

Perspectives of married Muslim men's roles related to women's cancer in Indonesia

Thank you for your application for ethical approval, which has now been considered by the Standing Committee of the Human Ethics Committee.

Your application has been approved from the above date and this approval continues until 30 September 2016. If your data collection is not completed by this date you should apply to the Human Ethics Committee for an extension to this approval.

Best wishes with the research.

Allison Kirkman

Human Ethics Committee 
Appendix 17: Information sheet

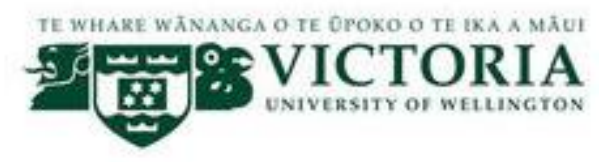

\section{Graduate School of Nursing, Midwifery, and Health \\ Research Information}

\section{Project title: Perspectives of Muslim husbands' roles related to women's cancer in Indonesia}

\section{The research aims}

My research proposes to explore the understandings, perceptions, and expectations of married Muslim men regarding prevention and treatment of breast and cervical cancer. The research will be located in rural and urban areas of the Sumedang district. It will provide new knowledge about what married Muslim men know about the screening and treatment of breast and cervical cancer and what their expectations are for their wives. It will also describe what some married women and some health professionals understand about the role of husbands for these women's cancer. The study findings will be used to inform health services for women in Indonesia.

\section{The research team}

My name is Restuning Widiasih, and I am a NZAS scholarship student in the Graduate School of Nursing, Midwifery, and Health at Victoria University of Wellington (VUW), New Zealand. I am presently on leave from my position as a nursing lecturer in the Maternity Nursing Department at Nursing Faculty, Padjadjaran University to undertake a PhD. My research is being carried out under the supervision of two academic supervisors (Dr. Katherine Nelson and Dr. Joan Skinner) and has received approval from the VUW Human Ethics Committee and from the local government of Sumedang district.

\section{The research process}

This research will involve three groups of participants: married Muslim men, married Muslim women, and health providers.

- The men will be invited to participate in one of eight focus groups (four groups for the under 40 years and four groups over 40 years). The focus group will be led by a male facilitator and attended by myself. It will ask men to discuss what they know about women's cancer, and their role and actions regarding their wives' participation in the prevention and treatment of cancer. The focus groups will consist of 6-10 men and will take 60-90 minutes and take place at a time and venue negotiated with the community leader. Those participating in the group will be asked to agree on group ground rules such as one person speaks at a time and all views acceptable. The focus groups will be audiorecorded and later transcribed for analysis purposes. Refreshments will be served.

- The women will be interviewed by myself and asked about their experience of men's role regarding the treatment and prevention of women's cancer. The interviews will last 45-60 minutes, and take place at a mutually agreed time and venue, and with the women's consent will be audio-recorded and later transcribed for analysis purposes.

- The health providers will be interviewed about their experience of the role of husbands in the screening and prevention of breast and cervical cancer. The interview will also ask about the women's cancer programmes that are provided. The interviews will last 45-60 
minutes and take place at a mutually agreed time and venue and with the health provider's consent will be audio-recorded and later transcribed for analysis purposes.

- The focus groups and interviews will be transcribed and later translated into English. Translators will sign agreements that guarantees to maintain confidentiality of all information collected.

- Each focus group and interview will initially be analysed, then all focus groups and interviews from each setting will be looked at as a group, finally all the data will be examined together to establish the overall findings.

\section{Participant's rights regarding participation}

- All participants will be invited to ask questions about the research and will be asked to sign a written consent form stating they are participating voluntarily in the research.

- The married men can choose not to comment on all topics in the focus group. If a man wishes to leave the focus group they can without giving a reason, but what they have shared will remain part of the group data.

- The married women can decline to answer any question or ask me to have the recorder switch off at any time during the interview. Women can bring a support person to the interview if they wish.

- Health providers can decline to answer any question or ask me to switch off the recorder at any time during the interview.

- Direct quotations from the interviews and focus groups will be reported in the results. However, no participant's name, family members or their place of employment will be included, rather participants will be referred to as Focus Group under 40s, rural; Women 36 years, urban, Health Provider rural so forth.

- Only my supervisors and I will read the transcripts from the focus groups and interviews.

- All data will be kept confidential and stored in a password protected computer. All data will be destroyed two years after the end of the study.

\section{Dissemination of the findings}

The results of this research will be presented in my thesis and subsequent publications. The data will be used for my $\mathrm{PhD}$ thesis, journal articles, and for presentation at relevant conferences. Presentations will be given to the communities from which participants are recruited. A copy of my completed thesis will be deposited in the library of Victoria University of Wellington, and will be available electronically in the institutional repository. A copy of my completed thesis will also be deposited in the library of Padjadjaran University in Indonesia.

\section{Contact Person}

If you have any questions or would like to receive further information about this research, please contact me or my supervisors at the information below. 


\section{Researcher:}

\section{Restuning Widiasih}

PhD student

Graduate School of Nursing, Midwifery, and

Health

Victoria University of Wellington

PO Box 7625

Wellington, New Zealand

Email: Restu.Widiasih@vuw.ac.nz

Phone: +64-4-4636662 (New Zealand)

+62 2288883861 (Indonesia)

Under supervision of:

\section{Dr Katherine Nelson}

Primary Supervisor

Deputy Head of School

Graduate School of Nursing, Midwifery,

$\&$ Health

Victoria University of Wellington

PO Box 7625

Wellington, New Zealand

Email: kathy.nelson@vuw.ac.nz

Phone: +64-4636138

\section{Dr Joan Skinner}

Secondary Supervisor

Senior Lecturer (Midwifery)

Graduate School of Nursing, Midwifery, \& Health

Victoria University of Wellington

PO Box 7625

Wellington, New Zealand

Email: joan.skinner@vuw.ac.nz

Phone: +64-463 6654 
Appendix 18: Informed consent sheet

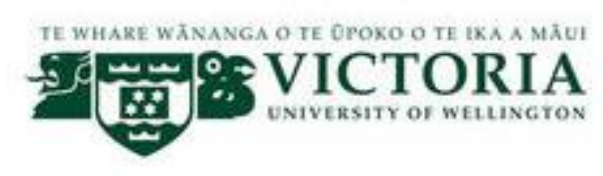

Graduate School of Nursing, Midwifery, and Health

Consent Form for Focus Groups

Project title: Perspectives of Muslim husbands' roles related to women's cancer in Indonesia

I have read and agree with the following statements:

- I have read the information sheet for this study and understand the explanation given.

- I have had the opportunity to ask questions and have had them answered to my satisfaction.

- I understand that I have the right to ask further questions at any time.

- I understand that focus group rules will be discussed and agreed upon before the focus group commences.

- I agree to keep the identity of other focus group participants confidential.

- I understand that the focus group will be audio-recorded.

- I understand that my name will not be used in any reports or publications of the study, and the information that I provide will not be used in any way that will identify me.

- I understand that the data I provide will be kept secure at all times, and will be kept confidential to the researcher and the researcher's supervisors and it will be destroyed five years after the conclusion of the project.

- I understand the data will only be used for the researcher's $\mathrm{PhD}$ thesis, journal articles or conference presentations. Any further use will require my written consent.

Participant's Name

Participant's Signature

Date

THANK YOU 


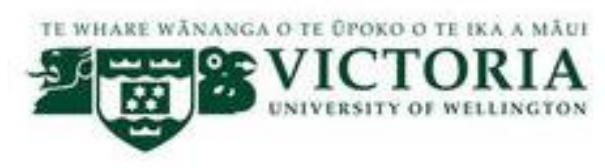

Graduate School of Nursing, Midwifery, and Health

Consent for interviews

Project title: Perspectives of Muslim husbands' roles related to women's cancer in Indonesia

I have read and agree with the following statements:

- I have read the information sheet for this study and understand the explanation given.

- I have had the opportunity to ask questions and have had them answered to my satisfaction.

- I understand that I have the right to ask further questions at any time.

- I agree to the interview being audio-recorded.

- I understand the data will only be used for the researcher's PhD thesis, journal articles or conference presentations. Any further use will require my written consent.

- I understand that neither my name nor the name of my organisation will be used in any reports or publications of the study, and the information that I provide will not be used in any way that will identify me.

- I understand that the data I provide will be kept secure at all times, and will be kept confidential to the researcher and the researcher's supervisors and it will be destroyed five years after the conclusion of the project.

Participant's Name

Participant's Signature

Date

THANK YOU 
Appendix 19: Example of the moderator agreement for pre-test

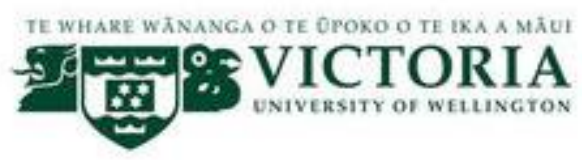

Graduate School of Nursing, Midwifery, and Health

MODERATOR CONFIDENTIALITY AGREEMENT

Project title: Perspectives of Muslim husbands' roles related to women's cancer in Indonesia

I agree to maintain total confidentiality as a moderator in focus groups for the above named.

I will not disclose any information relating to the focus group, to any person aside from the Principal Researcher, Restuning Widiasih.

I agree to keep all material safely stored while I am moderating and will destroy all copies of material once I have confirmation that the principal researcher has received it.

Signed

Print Name

:

Date 
Appendix 20: Pre-test Information sheet

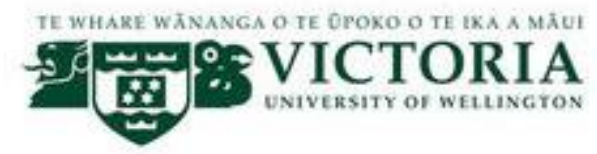

\section{Graduate School of Nursing, Midwifery, and Health \\ Pre-test Information}

Project title: Perspectives of Muslim husbands' roles related to women's cancer in Indonesia

\section{The pre-test aims}

The pre-test is part of my $\mathrm{PhD}$ research project. The research project purposes to uncover the understandings, perceptions, and expectations of married Muslim men regarding prevention and treatment of breast and cervical cancer from three different perspectives: married men, married women, and health providers. Focus groups and interviews will use as methods of data collection. The aim of this pre-test is to anticipate issues related to focus group and interview processes, such as encouraging participants, developing questions in a focus group or interviews, and moderating Muslim men. This pre-test will be used to inform the data collection process in Indonesia.

\section{The pre-test team}

My name is Restuning Widiasih, and I am a NZAS scholarship student in the Graduate School of Nursing, Midwifery, and Health at Victoria University of Wellington (VUW), New Zealand. I am presently on leave from my position as a nursing lecturer in the Maternity Nursing Department at Nursing Faculty, Padjadjaran University to undertake a PhD. The pre-test is being carried out under the supervision of two academic supervisors (Dr. Katherine Nelson and Dr. Joan Skinner) and has received approval from the VUW Human Ethics Committee. One of moderator in the focus group pre-test is Marko Hermawan, an Indonesian male $\mathrm{PhD}$ candidate from School of Accounting and Commercial Law VUW who has experience in conducting focus groups.

\section{The process of pre-test}

I will do pre-test involving men and female from the Indonesian Muslim community in New Zealand. The pre-test will be conducted with two groups of Muslim men, and two interviews of Muslim women, using the sample criteria. The pre-test process will be recorded.

\section{Focus Group}

- The men will be invited to participate in one of two focus groups (a group of males aged less than 40 years and a group of male aged over 40 years).

- One of focus group pre-tests will be led by a male facilitator and another group will be led by myself. It will ask men to discuss what they know about women's cancer, and their role and actions regarding their wives participation in the prevention and treatment of cancer.

- The focus groups pre-test will consist of 6-10 men and will take approximately 60-90 minutes and take place at a time and venue negotiated with participants.

- Those participating in the group will be asked to agree on group ground rules such as one person speaks at a time and all views acceptable. 
- The focus group pre-test will be audio-recorded and used to inform the data collection process in Indonesia.

- Refreshments will be served.

\section{Interviews}

- Two Indonesian married Muslim women will be invited to participate in interviews

- The women will be interviewed by myself and asked about their experience of men's role regarding the treatment and prevention of women's cancer.

- The interviews will take approximately 45-60 minutes, and take place at a mutually agreed time and venue, and with the women's consent will be audio-recorded and later transcribed for analysis purposes.

- Refreshments will be served.

\section{Participant's rights regarding pre-test participation}

- All participants will be invited to ask questions about the pre-test and will be asked to sign a written consent form stating they are voluntarily participating in the pre-test.

- The married men can choose not to comment on all topics in the focus group. If a man wishes to leave the focus group they can without giving a reason, but what they have shared will remain part of the group data.

- The married women have the opportunity to ask questions and have the right to withdraw from the pre-test.

- No pre-test participant's name, family members or their place of employment will be included; rather participants will be referred to as Focus Group under or above 40.

- Only my supervisors and I will read the transcripts from the pre-test result.

- All data will be kept confidential and stored in a password protected computer. All data will be destroyed two years after the end of my study.

\section{Contact Person}

If you have any questions or would like to receive further information about this pretest, please contact me or my supervisors at the information below.

\section{Researcher:}

\section{Restuning Widiasih}

$\mathrm{PhD}$ candidate

Graduate School of Nursing, Midwifery, and

Health

Victoria University of Wellington

PO Box 7625

Wellington, New Zealand

Email: Restu.Widiasih@vuw.ac.nz

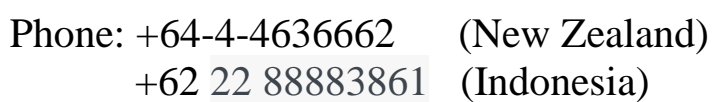

Under supervision of:

Dr Katherine Nelson

Primary Supervisor

Deputy Head of School

\section{Dr Joan Skinner}

Secondary Supervisor

Senior Lecturer (Midwifery) 
Graduate School of Nursing, Midwifery, Graduate School of Nursing, Midwifery, $\&$ Health

Victoria University of Wellington

\& Health

PO Box 7625

Wellington, New Zealand

Victoria University of Wellington

PO Box 7625

Email: kathy.nelson@vuw.ac.nz

Phone: +64-4636138

Wellington, New Zealand

Email: joan.skinner@vuw.ac.nz

Phone: +64-463 6654 
Appendix 21: Example of the informed consent for pre-test

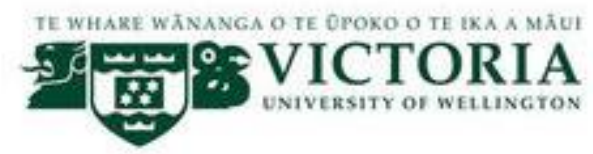

Graduate School of Nursing, Midwifery, and Health

Pre-test consent for interviews

Project title: Perspectives of Muslim husbands' roles related to women's cancer in Indonesia

I have read and agree with the following statements:

- I have read the information sheet for this pre-test and understand the explanation given.

- I have had the opportunity to ask questions and have had them answered to my satisfaction.

- I understand that I have the right to ask further questions at any time.

- I agree to the interview being audio-recorded.

- I understand that I can withdraw myself (or any information I have provided) from this pre-test and all information related to me will be destroyed

- I understand the data will only be used to inform the data collection process in Indonesia.

- I understand that neither my name nor the name of my workplace will be used in any reports of the pre-test, and the information that I provide will not be used in any way that will identify me.

- I understand that the data I provide will be kept secure at all times, and will be kept confidential to the researcher and the researcher's supervisors and it will be destroyed two years after the conclusion of the project.

Participant's Name

Participant's Signature

Date

THANK YOU 
Appendix 22: All instrument in Bahasa Indonesia

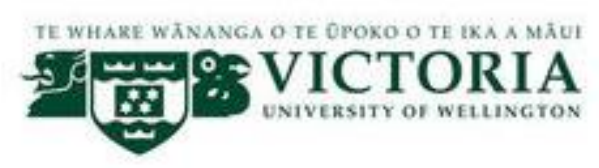

\section{Graduate School of Nursing, Midwifery, and Health}

\section{Lembar Informasi}

\section{Judul Penelitian: Perspektif peran pria Muslim yang menikah berhubungan} dengan penyakit kanker perempuan di Indonesia

\section{Tujuan Penelitian}

Penelitian ini bertujuan untuk mengeksplore pemahaman, persepsi, dan harapan pria muslim menikah berkaitan dengan pencegahan dan pengobatan kanker payudara dan kanker leher Rahim. Penelitian ini akan dilakukan didaerah perdesaan dan perkotaan di wilayah kabupaten Sumedang. Penelitian ini akan memberikan informasi dan pengetahuan baru tentang apa yang diketahui oleh pria muslim yang menikah tentang pencegahan dan pengobatan kanker, dan harapan mereka terhadap pelayanan kesehatan bagi istrinya. Penelitian ini juga akan menjelaskan tentang pemahaman istri dan petugas kesehatan tentang peran suami dalam kesehatan istri khususnya berhubungan dengan kanker. Penelitian ini diharapakan akan memberi manfaat pada pelayanan kesehatan perempuan di Indonesia.

\section{Team peneliti}

Nama saya Restuning Widiasih, saya adalah Phd candidate di Graduate School of Nursing, Midwifery, and Health di Victoria University of Wellington (VUW), New Zealand, atas beasiswa New Zealand Award for Asean. Saya adalah dosen di bagian keperawatan Maternitas Fakultas Keperawatan Universitas Padjadjaran Bandung. Penelitian saya dibawah supervise Dr Kathy Nelson dan Dr Joan Skinner, dan telah mendapat persetujuan dari Komite Human Ethic dari Victoria University of Wellington dan dari pemerintah Kabupaten Sumedang.

\section{Proses Penelitian}

Penelitian ini akan melibatkan tiga grup partisipan yaitu pria muslim menikah, perempuan muslim menikah, dan petugas kesehatan.

- Pria muslim akan diundang untuk berpartisipasi dalam satu dari minimal delapan grup diskusi (empat grup pria usia 40 th atau kurang, dan empat grup pria usia lebih dari 40 th). Fokus grup tersebut akan dimoderatori oleh moderator pria atau saya sendiri. Diskusi akan mendiskusikan tentang apa yang mereka pahami tentang kanker pada perampuan, peran, dan tindakan mereka berkaitan dengan partisipasi istri dalam pencegahan dan pengobatan kanker. Dalam satu grup akan terdiri sekitar 6-10 pria dan akan berdiskusi sekitar 60-90 menit, untuk tempat dan waktu akan didiskusikan kemudian, Dalam berpartisipasi pria akan diminta 
persetujuan awal, dan menyepakati tata tertib dalam diskusi seperti berbicara bergantian, dan semua pendapat diterima, tidak ada jawaban benar atau salah. Diskusi ini akan di rekam dan kemudian hasil rekaman akan ditranskip untuk keperluan analisa data. Konsumsi akan disediakan.

- Perempuan muslim akan diwawancara oleh saya sendiri, wawancara akan mendiskusikan tentang pengalaman mereka berkaitan dengan peran suami terhadap pencegahan dan pengobatan kanker. Wawancara akan dilakukan kurang lebih selama 45-60 menit, tempat dan waktu akan didiskusikan sesuai kesepakatan. Wawancara akan di rekam berdasar persetujuan dan kemudian akan di traskipsikan untuk tujuan analisa data.

- Petugas kesehatan akan diwawancara tentang pengalaman mereka berkaitan dengan peran suami dalam pencegahan dan pengobatan kanker. Wawancara juga akan bertanya tentang program pencegahan dan pengobatan kanker yang ada di pelayanan kesehatan. Wawancara akan dilakukan kurang lebih selama 45-60 menit, tempat dan waktu akan didiskusikan sesuai kesepakatan. Wawancara akan di rekam berdasar persetujuan dan kemudian akan di traskipsikan untuk tujuan analisa data.

- Fokus data dan wawancara akan di terjemahkan dalam Bahasa inggris. Penterjemah anak menandatangani persetujuan yang akan menjamin kerahasiaan darai semua informasi yang telah dikumpulkan.

- Setiap focus grup dan wawancara akan dianalisa dengan menggunakan inisial, kemudian data focus grup dan interview akan di analisa dalam satu grup per area, dan pada tahap akhir akan di analisa bersama untuk mendapatkan hasil secara keseluruhan.

\section{Hak-hak partisipan}

- Semua partisipan yang diundang akan diminta persetujuan dan dijelaskan tentang riset ini, serta diminta untuk menandatangani persetujuan tertulis yang menyatakan bahwa partisipasi mereka adalah sukarela dalam penelitian ini.

- Pria muslim menikah dapat memilih untuk tidak menjawab pertanyaan pada semua topic yang di diskusikan. Partisipan boleh meninggalkan grup diskusi tanpa menjelaskan apa sebabnya, namun data dan informasi yang telah diberikan akan tetap menjadi bagian dari data grup diskusi tersebut.

- Perempuan dapat menolak untuk menjawab pertanyaan atau meminta alat perekam dimatikan selama wawancara. Perempuan boleh mengajak teman atau saudara untuk mensupport dia saat wawancara jika dia menginginkan.

- Petugas kesehatan dapat menolak untuk menjawab pertanyaan atau meminta alat perekam dimatikan selama wawancara.

- Dalam hasil penelitian, petikan pendapat dari partisipan dari diskusi dan wawancara akan langsung di tuliskan, namun semua akan ditulis tanpa nama partisipan, keluarga, atau tempat kerja partisipan, penulisan akan merujuk pada grup dari diskusi seperti grup usia kurang dari 40 th, pedesaan, wanita 36 tahun, perkotaan, petugas kesehatan dari pedesaan atau perkotaan.

- Hanya saya dan supervisor yang akan membaca hasil focus grup dan wawancara. 
- Semua data akan dijaga kerahasiaannya dan disimpan dalam computer yang dilindungi dengan password. Semua data akan dimusnahkan setelah dua tahun masa study berakhir.

\section{Penyebarluasan hasil}

Dari penelitian ini akan dihasilkan tesis dan beberapa publikasi. Data hasil penelitian akan digunakan untik $\mathrm{PhD}$ tesis saya, artikel ilmiah, dan presentasi pada konferen yang sesuai dengan topic penelitian. Berbagai presentasi juga akan dilakukan dikomunitas dimana data dikumpulkan. Kopi dari tesis akan ditempatkan di perpustakaan Victoria University of Wellington new Zealand, Universitas Padjadjaran Indonesia, dan juga akan tersedia secara electronic di katalog universitas tersebut.

\section{Alamat peneliti}

Jika ada pertanyaan atau ingin mendapatkan informasi lain tentang penelitian ini, silahkan menghubungi saya atau supervisor saya, dengan alamat dibawah ini

\section{Peneliti:}

\section{Restuning Widiasih}

PhD Candidate

Graduate School of Nursing, Midwifery, and

Health

Victoria University of Wellington

PO Box 7625

Wellington, New Zealand

Email: Restu.Widiasih@vuw.ac.nz

Phone: +64-4-4636662 (New Zealand)

+62 2288883861 (Indonesia)

Dibawah supervisi dari:

\section{Dr Katherine Nelson}

Primary Supervisor

Deputy Head of School

Graduate School of Nursing, Midwifery,

$\&$ Health

Victoria University of Wellington

PO Box 7625

Wellington, New Zealand

Email: kathy.nelson@vuw.ac.nz

Phone: +64-4636138

\section{Dr Joan Skinner}

Secondary Supervisor

Senior Lecturer (Midwifery)

Graduate School of Nursing, Midwifery, \& Health

Victoria University of Wellington

PO Box 7625

Wellington, New Zealand

Email: joan.skinner@vuw.ac.nz

Phone: +64-463 6654 


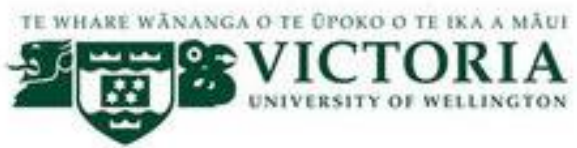

\section{Graduate School of Nursing, Midwifery, and Health \\ Lembar Persetujuan}

Judul Penelitian: Perspektif peran pria Muslim yang menikah berhubungan dengan penyakit kanker perempuan di Indonesia.

Saya telah membaca dan setuju dengan pernyataan dibawah ini:

- Saya telah membaca lembar informasi penelitian dan memahami penjelasan yang diberikan.

- Saya diberi kesempatan untuk bertanya dan mendapatkan jawaban yang memuaskan.

- Saya mengerti bahwa saya mempunyai hak untuk bertanya pada kesempatan yang lain diluar kegiatan focus grup.

- Saya mengerti bahwa tata tertib dalam focus grup akan dibicarakan dan disetujui sebelum focus grup berjalan.

- Saya setuju untuk menjaga kerahasiaan identitas peserta focus grup yang lain

- Saya mengerti bahwa proses focus grup akan di rekam.

- Saya mengerti bahwa saya dapat meninggalkan kegiatan focus grup, namun pendapat yang telah saya sampaikan tetap menjadi bagian dari data focus grup.

- Saya mengerti bahwa nama saya tidak akan digunakan pada laporan atau publikasi apapun berkaitan dengan riset ini, dan informasi yang saya sampaikan tidak akan digunakan dalam bentuk apapun yang akan mengidentifikasi diri saya.

- Saya mengerti bahwa data yang saya berikan akan terjaga kerahasiaannya setiap saat, dan hanya saya dan supervisors yang mengetahui, serta semua data akan dihancurkan dua tahun setelah penelitian ini diambil kesimpulan.

- Saya mengerti bahwa data-data yang saya berikan hanya akan digunakan untuk keperluan tesis PhD dari peneliti, artikel ilmiah, atau presentasi dalam konferensi. Penggunaan data untuk hal lain dapat dilakukan berdasarkan persetujuan saya secara tertulis.

Nama

Tanda tangan :

Tanggal

Terima Kasih 


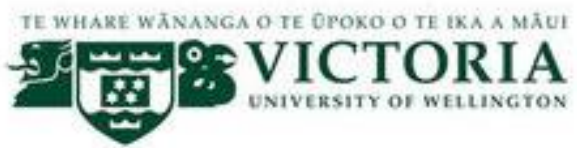

\section{Graduate School of Nursing, Midwifery, and Health}

\section{Lembar Persetujuan Wawancara}

Judul Penelitian: Perspektif peran pria Muslim yang menikah berhubungan dengan penyakit kanker perempuan di Indonesia.

Saya telah membaca dan setuju dengan pernyataan dibawah ini:

- Saya telah membaca lembar informasi penelitian dan memahami penjelasan yang diberikan.

- Saya diberi kesempatan untuk bertanya dan mendapatkan jawaban yang memuaskan.

- Saya mengerti bahwa saya mempunyai hak untuk bertanya pada kesempatan yang lain diluar kegiatan wawancara.

- Saya mengerti bahwa proses wawancara ini akan di rekam.

- Saya mengerti bahwa saya dapat mengundurkan diri dari wawancara beserta data yang telah diberikan dalam dua minggu setelah wawancara dan semua informasi yang telah diberikan akan dihancurkan.

- Saya mengerti bahwa data-data yang saya berikan hanya akan digunakan untuk keperluan tesis PhD dari peneliti, artikel ilmiah, atau presentasi dalam konferensi. Penggunaan data untuk hal lain dapat dilakukan berdasarkan persetujuan saya secara tertulis.

- Saya mengerti bahwa nama saya tidak akan digunakan pada laporan atau publikasi apapun berkaitan dengan riset ini, dan informasi yang saya sampaikan tidak akan digunakan dalam bentuk apapun yang akan mengidentifikasi diri saya.

- Saya mengerti bahwa data yang saya berikan akan terjaga kerahasiaannya setiap saat, dan hanya saya dan supervisors yang mengetahui, serta semua data akan dihancurkan dua tahun setelah penelitian ini diambil kesimpulan.

Nama

Tanda tangan :

Tanggal

Terima Kasih 


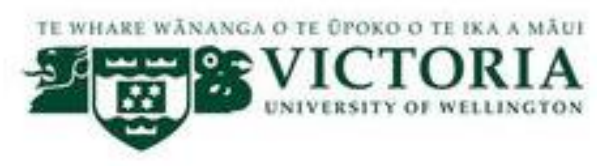

\section{Graduate School of Nursing, Midwifery, and Health \\ Pertanyaan Sosial Demographi}

Judul Penelitian: Perspektif peran pria Muslim yang menikah berhubungan dengan penyakit kanker perempuan di Indonesia

1. Apakah jenis kelamin anda?

$\square$ Laki-laki

Perempuan

2. Berapa umur anda?

40 tahun atau kurang dari 40 tahun

Lebih dari 40 tahun

3. Berapa jumlah anak saat ini?

4. Berapa lama telah menikah?

5. Apakah saat ini menderita penyakit kanker?

Ya

Tidak

6. Apakah ada keluarga yang menderita kanker?

$\square$ Ya

Tidak

7. Apakah pendidikan terakhir anda?

$\square$ SD

$\square$ SMP

$\square$ SMA

$\square$ Universitas

8. Berdasakan kategori dibawah ini, apa pekerjaan anda?

Pegawai Negeri

Karyawan Swasta

ABRI

Pengusaha

Ibu rumah tangga 


\section{Graduate School of Nursing, Midwifery, and Health}

\section{Pertanyaan untuk Focus Group dan Wawancara}

\section{Judul Penelitian: Perspektif peran pria Muslim yang menikah berhubungan dengan penyakit kanker perempuan di Indonesia}

\section{Pertanyaan untuk Fokus Grup}

\section{Tata tertib}

- Saling menghargai terhadap pendapat orang lain

- Menjaga kerahasaiaan

- Pada saat satu orang berbicara, peserta lain menyimak, dan bergantian untuk memberikan pendapat

- Tujuan dari focus grup ini adalah untuk mengetahui sebanyak-banyaknya pendapat peserta, dan tidak ada jawaban benar atau salah

Catatan : Point-point dalam setiap pertanyaan hanya digunakan apabila dibutuhkan

1. Bagaimana bapak-bapak menjaga kesehatan selama ini?

2. Bapak-bapak, di mohon menyampaikan pendapatnya, Bagaimana dan apa peran serta bapak selama ini berkaitan dengan menjaga kesehatan istrinya

- Tidak pernah ikut-ikutan urusan kesehatan istri

- Jika ada masalah kesehatan, apakah berdiskusi bersama?

- Dalam hal apa bapak berperan atau terlibat ketika istri akan pergi ke pelayanan kesehatan

- Apakah bapak mendampingi istri?

- Apakah peran serta bapak dalam kesehatan istri ada perubahan?mengapa?

- Apakah yang mempengaruhi anda dalam berperan terhadap kesehatan istri?dari mana bapak belajar tentang peran tersebut (keinginan istri, pengalam sebelumnya misal keluarga ada yang sakit, bagian dari mengamalkan ajaran agama berkaitan dengan tanggung jawab akan kesehatan istri)

3. Kita mulai fokuskan diskusi kita tentang kanker payudara dan leher Rahim Mari bapak-bapak, kita saling berbagi tentang, apakah ada diantara bapak-bapak disini yang mempunyai pengalaman dengan kanker tersebut? (bisa pengalaman istri, anak, ibu, saudara perempuan, tetangga, teman kerja, teman sekolah, atau keluarga dekat lain)

4. Mendengar cerita pengalaman bapak-bapak, Apa pendapat bapak-bapak tentang kanker payudara dan leher Rahim? Apa tanda-tanda yang dapat dilihat?Apakah bisa dicegah atau dideteksi dini? Jika iya dengan cara apa? Berdasarkan yang bapak ketahui apakah ada program-program pencegahan atau deteksi dini di Indonesia? Perempuan seperti apa yang lebih berisiko terkena cancer tersebut?Apakah penyakit kanker pada perempuan bisa diobati?Berdasarkan yang 
bapak ketahui,dengan cara-cara apa Kanker dapat diobati, dan dimana bisa mengobatinya?

5. Pada kenyataan,payudara dan leher Rahim adalah bagian yang pribadi bagi istri, hal-hal apa yang dapat mempengaruhi atau menjadi pertimbangan suami berkaitan dengan partisipasi istri dalam pencecegahan, deteksi dini, atau pengobatan kanker?

- Bagaimana pentingnya dokter atau petugas kesehatan yang sama jenis kelaminnya?

- Bagaimana harapan bapak-bapak terhadap pelayanan kesehatan perempuan di Indonesia?

6. Tindakan seperti apa yang telah bapak lakukan selama ini berkaitan dengan deteksi dini atau pengobatan kanker?

7. Jika misalnya istri bapak-bapak terdiagnosa kanker, bagaimana bapak membayangkan akan berespon? Dan mengapa berespon seperti itu?

- Malu, merasa ini cobaan dari Allah swt

- Melihat dulu perkembangannya sebelum memutuskan untuk berobat

- Mencari pengobatan

- Membiayai pengobatan dan perawatan

- Menemani istri untuk pengobatan dan perawatan

8. Apakah bapak-bapak pernah berpikir bahwa program-program kesehatan yang ada di Indonesia khususnya berhubungan dengan pencegahan dan pengobatan kanker lebih melibatkan suami-suami?

- Mengapa perlu melibatkan, mengapa tidak perlu?

- Apa yang harus dilakukan pemerintah terhadap suami-suami, atau program apa untuk para suami?

Terimakasih atas waktunya. Jika ada pertanyaan tentang riset ini, bisa ditanyakan ke alamat : Restu.Widiasih@vuw.ac.nz

\section{Pertanyaan wawancara untuk Ibu}

Catatan : Point-point dibawah pertanyaan, hanya digunakan jika dibutuhkan

1. Mohon di jelaskan sedikit tentang latar belakang ibu, nama, pekerjaan/aktivitas, berapa lama telah menikah, dan jumlah anak?

2. Ibu mohon diceritakan, bagaimana ibu menjaga kesehatan secara umum, dan bagaimana peran suami dalam hal ini

- Tidak pernah ikut-ikutan urusan kesehatan istri tentang kanker

- Jika ada masalah kesehatan, masalah seperti apa yang didiskusikan dengan suami?

- Apakah ibu ditemani oleh bapak apabila ke pelayanan kesehatan?

- Apakah peran serta bapak dalam kesehatan istri ada perubahan?mengapa?

3. Penelitian ini tentang kanker payudara dan leher Rahim? 
- Apakah ada pengalaman dengan kedua kanker ini?ibu sendiri, anak, orangtua, nenek, saudara perempuan, teman, tetangga

- Perluas berkaitan dengan pengalaman tersebut

4. Apa yang ibu pahami tentang kanker payudara?

- Apakah ibu berpartisipasi dalam pencegahan kanker payudara, bagaimana respon bapak dengan yang ibu lakukan?

5. Apa yang ibu pahami tentang kanker leher Rahim?

- Apakah ibu berpartisapasi dalam pencegahan atau imunisasi kanker leher Rahim, dan bagaimana tanggapan suami dengan hal tersebut?

6. Pada kenyataan,payudara dan leher Rahim adalah bagian yang pribadi bagi ibu, hal-hal apa yang dapat mempengaruhi atau menjadi pertimbangan suami berkaitan dengan partisipasi istri dalam pencegahan kanker? Pengobatan kanker?

- Bagaimana peran/ jenis kelamin petugas kesehatan?apakah jenis kelamin sama penting buat ibu?

7. Jika misalnya ibu terdiagnosa kanker, bagaimana ibu membayangkan bapak akan berespon? Dan mengapa berespon seperti itu?

- Malu, merasa ini cobaan dari Allah swt

- Melihat dulu perkembangannya sebelum memutuskan untuk berobat

- Mencari pengobatan

- Membiayai pengobatan dan perawatan

- Menemani istri untuk pengobatan dan perawatan

8. Apakah ibu berpikir bahwa program-program kesehatan yang ada di Indonesia khususnya berhubungan dengan pencegahan dan pengobatan kanker perlu melibatkan suami-suami?

- Mengapa perlu melibatkan, mengapa tidak perlu?

- Apa yang harus dilakukan pemerintah terhadap suami-suami, atau program apa untuk para suami?

Terimakasih atas waktunya. Jika ada pertanyaan tentang riset ini, bisa ditanyakan ke alamat : Restu.Widiasih@vuw.ac.nz

\section{Pertanyaan untuk Petugas Kesehatan}

Catatan : Point-point dibawah pertanyaan, hanya digunakan jika dibutuhkan

1. Mohon dijelaskan tentang diri anda? berapa lama anda telah bekerja menjadi petugas kesehatan di wilayah ini?

2. Bagaimana menurut anda kanker payudara dan kanker leher Rahim di wilayah ini

- Jumlah kasus, keparahan/stadium, tindakan 
3. Apakah ada program pencegahan dan pengobatan kanker payudara dan leher Rahim pada institusi dimana anda bekerja?

- Program, fasilitas, sdm, target, pelaksanaan, hambatan

4. Mengingat kembali 2 pasien terakhir yang melakukan pencegahan atau test laboratorium kanker payudara dan leher rahim

- Apakah peran suami dalam hal ini?

- Menurut anda, mengapa mereka berperan seperti itu?

- Menurut pengalaman anda, bagaimana tipe-tipe peran suami?

- Berilah contoh peran-peran suami dalam kesehatan istri yang pernah anda lihat

5. Mengingat kembali 2 pasien terakhir yang terdiagnosa kanker payudara dan leher rahim

- Bagaimana peran suami dalam perawatan dan pengambilan keputusan

- Menurut anda, mengapa mereka berperan seperti itu?

- Menurut pengalaman anda, bagaimana tipe-tipe peran suami?

- Berilah contoh peran-peran suami dalam kesehatan istri yang pernah anda lihat

6. Mengingat kembali 2 pasien terakhir yang melakukan pencegahan atau test laboratorium kanker leher Rahim

- Apakah peran suami dalam hal ini?

- Menurut anda, mengapa suami berperan seperti itu?

- Menurut pengalaman anda, bagaimana tipe-tipe peran suami?

- Berilah contoh peran-peran suami dalam kesehatan istri yang pernah anda lihat

7. Mengingat kembali 2 pasien terakhir yang terdiagnosa kanker leher rahim Apakah anda berpikir bahwa program-program kesehatan yang ada di Indonesia khususnya berhubungan dengan pencegahan dan pengobatan kanker perlu melibatkan suami-suami?

- Mengapa perlu melibatkan, mengapa tidak perlu?

- Apa yang harus dilakukan pemerintah terhadap suami-suami, atau program apa untuk para suami?

Terimakasih atas waktunya. Jika ada pertanyaan tentang riset ini, bisa ditanyakan ke alamat : Restu.Widiasih@vuw.ac.nz 


\section{References}

Abdel-Khalek, A. M. (2011). Islam and mental health: A few speculations. Mental Health, Religion \& Culture, 14(2), 87-92. doi:10.1080/13674676.2010.544867

Abhilasha, S. (2003). Male involvement in reproductive health: Women's perspective. The Journal of Family Welfare, 49(1).

Ackerson, K., \& Gretebeck, K. (2007). Factors influencing cancer screening practices of underserved women. J Am Acad Nurse Pract, 19(11), 591-601. doi:10.1111/j.1745-7599.2007.00268.x

Ady. (2016). 8 masalah penghambat jaminan kesehatan nasional. Retrieved from http://www.hukumonline.com/berita/baca/lt57bd0ba444be5/8-masalahpenghambat-jaminan-kesehatan-nasional

Aggraeni, B. (2016). Dukungan suami terhadapt deteksi diki kanker serviks pada pasangan usia subur di Dusun Ngasem, Desa Timbulharjo sewon, Bantul, Sleman. Media Ilmu Kesehatan, 5(3), 184-192.

Ajzen, I. (1991). The theory of planned behavior. Organizational Behavior and Human Dicision Processes, 50.

Al-Amoudi, Eldeek, B. S., Ayuob, N. N., Alzhrani, W., \& Alahwal, M. S. (2012). Knowledge about breast cancer among male medical students, Jeddah, 2011 Life Science Journal, 9(3), 166-170.

Al-Amoudi, M., \& Abduljabbar, H. S. (2012). Men's knowledge and attitude towards breast cancer in Saudi Arabia: A cross-sectional study. Saudi Med J, 33(5), 547-550.

Al-Hilali, M. T.-u.-D., \& Khan, M. M. (1998). The Noble Quran. Madinah, Saudi

Al-Jauziyah, I. I. Q. (2003). Healing with the medicine of the prophet. USA: Fordham University.

Al-Mubarakfuri. (2011). Ar-rahiq, Al-makhtum (A. Suwandi, Trans. 1 ed.). Jakarta: Ummul Qura.

Al-Naggar, R. A., Bobryshev, Y. V., Abdulghani, M. A., Rammohan, S., \& AlJashamy, K. (2012). Knowledge and perceptions of cancer and cancer prevention among Malaysian traditional healers: A qualitative study. Asian Pac J Cancer Prev, 13(8), 3841-3850.

Al-Shammari, G. (2016). The Prophet Muhammad the best of all husbands. Retrieved from Kalamullah.com website:

Aldwin, C. M., Park, C. L., Jeong, Y.-J., \& Nath, R. (2014). Differing pathways between religiousness, spirituality, and health: A self-regulation perspective. Psychology of Religion and Spirituality, 6(1), 9-21. doi:10.1037/a0034416

Allen, J. D., Leyva, B., Torres, A. I., Ospino, H., Tom, L., Rustan, S., \& Bartholomew, A. (2014). Religious beliefs and cancer screening behaviors among Catholic Latinos: Implications for faith-based interventions. J Health Care Poor Underserved, 25(2), 503-526. doi:10.1353/hpu.2014.0080

Amalia, A. (2015). Pengetahuan dan sikap suami terhadap istri dalam pemeriksaan Pap smear di Desa Dukuhagung, Kecamatan Tikung, Kabupaten Lamongan Surya, 7(3).

Amnesty International. (2010). Left without a choice : Barrier to reproductive health in Indonesia Amnesty International, 1.

Andrijono. (2007). Vaksinasi HPV merupakan pencegahan primer kanker serviks. Majalah Kedokteran Indonesia, 57(5). 
Anggraeni, \& Benedikta. (2016). Dukungan suami terhadap deteksi dini kanker serviks pada pasangan usia subur (PUS) di dusun Ngasem, desa Timbulharjo, Sewon, Bantul. Media Ilmu Kesehatan, 5(3), 184-192.

Anna, L. K. (2017). Jumlah dokter di Indonesia cukup, tetapi menumpuk di Kota Besar. Retrieved from http://lifestyle.kompas.com/read/2016/05/10/093908423/Jumlah.Dokter.di.In donesia.Cukup.tetapi.Menumpuk.di.Kota.Besar

Anugraheni, A. (2010). Minat melakukan Pap smear ditinjau dari persepsi tentang kesehatan pada wanita usia dewasa madya. (Thesis), UNIKA

Soegijapranata, Semarang. Retrieved from http://repository.unika.ac.id/5621/

Anugrapaksi. (2016). Apakah Indonesia butuh tambahan dokter? Retrieved from http://www.kompasiana.com/egharap/apakah-indonesia-butuh-tambahandokter 56b74491a2afbd93134b37fd

Aqni, S. N. (2013). Faktor yang mempengaruhi keterlambatan deteksi dini penderita kanker rahim. (Sarjana Mini Thesis), Universitas Jember, Jember. Retrieved from http://repository.unej.ac.id/bitstream/handle/123456789/4987/Sukmawan\%20 NA 1.pdf?sequence $=1$ (052110101048)

Arkiang. (2016). Hubungan dukungan suami dengan motivasi ibu dalam melakukan pencegahan serviks di Puskesmas Kendal Sari, Malang. (Thesis), Universitas Muhammadiyah Malang, Malang.

Artiningsih. (2011). Hubungan antara tingkat pengetahuan dan sikap wanita usia subur dengan pemeriksaan IVA dalam rangka deteksi dini kanker serviks di Puskesmas Bloto Kecamatan Prajurit Kulon Mojokerto. Universitas Sebelas Maret.

Arya. (2016). Biaya Pap smear Prodia terbaru. Retrieved from https://inspiratips.com/biaya-pap-smear-prodia-terbaru/

Assad, S., Niazi, A. K., \& Assad, S. (2013). Health and Islam. J Midlife Health, 4(1), 65. doi:10.4103/0976-7800.109645

Augusto, E. F., Rosa, M. L., Cavalcanti, S. M., \& Oliveira, L. H. (2013). Barriers to cervical cancer screening in women attending the Family Medical Program in Niteroi, Rio de Janeiro. Arch Gynecol Obstet, 287(1), 53-58. doi:10.1007/s00404-012-2511-3

Australian Indonesia Partnership of Health System Strengthening. (2015). Health Insurance-National Social Security System (JK-SJSN)at a glance. Retrieved from http://aiphss.org/health-insurance-national-social-security-system-jksjsnat-a-glance/

Aydemir, M., Özkeskin, E. E., \& Akkurt, A. A. (2015). A theoretical framework on open and distance learning. Procedia - Social and Behavioral Sciences, 174, 1750-1757. doi:http://dx.doi.org/10.1016/j.sbspro.2015.01.833

Babu, G. R., Samari, G., Cohen, S. P., Mahapatra, T., Wahbe, R. M., Mermash, S., \& Galal, O. M. (2011). Breast cancer screening among females in Iran and recommendations for improved practice: A review. Asian Pac J Cancer Prev, 12(7), 1647-1655.

Badan Kependudukan dan Keluarga Berancana Nasional. (2017). Sejarah BKKBN. Retrieved from https://www.bkkbn.go.id/pages/sejarah-bkkbn

Bahar, Z., Okcay, H., Ozbicakci, S., Beser, A., Ustun, B., \& Ozturk, M. (2005). The effects of Islam and traditional practices on women's health and reproduction. Nurs Ethics, 12(6), 557-570. 
Baheiraei, A., Mirghafourvand, M., Charandabi, S. M., \& Mohammadi, E. (2013). Facilitators and inhibitors of health-promoting behaviors: The experience of Iranian women of reproductive age. Int J Prev Med, 4(8), 929-939.

Balitbangkes Kementerian Kesehatan RI. (2013). Riset kesehatan dasar. Retrieved from Jakarta, Indonesia:

www.depkes.go.id/resources/download/general/Hasil\%20Riskesdas\%202013 .pdf

Banerjee, A. T., Strachan, P. H., Boyle, M. H., Anand, S. S., \& Oremus, M. (2014). Attending religious services and its relationship with coronary heart disease and related risk factors in older adults: A qualitative study of church pastors' and parishioners' perspectives. J Relig Health, 53(6), 1770-1785. doi:10.1007/s10943-013-9783-1

Banning, M., Hafeez, H., Faisal, S., Hassan, M., \& Zafar, A. (2009). The impact of culture and sociological and psychological issues on Muslim patients with breast cancer in Pakistan. Cancer Nurs, 32(4), 317-324. doi:10.1097/NCC.0b013e31819b240f

Benjamins, M. R., Ellison, C. G., Krause, N. M., \& Marcum, J. P. (2011). Religion and preventive service use: Do congregational support and religious beliefs explain the relationship between attendance and utilization? J Behav Med, 34(6), 462-476. doi:10.1007/s10865-011-9318-8

Birhanu, Z., Abdissa, A., Belachew, T., Deribew, A., Segni, H., Tsu, V., . . . Russell, F. M. (2012). Health seeking behavior for cervical cancer in Ethiopia: A qualitative study. Int J Equity Health, 11, 83. doi:10.1186/1475-9276-11-83

Bowen, S. A., Williams, E. M., Stoneberg-Cooper, C. M., Glover, S. H., Williams, M. S., \& Byrd, M. D. (2013). Effects of social injustice on breast healthseeking behaviors of low-income women. Am J Health Promot, 27(4), 222230. doi:10.4278/ajhp.110505-QUAL-189

Brown, D. R., Wilson, R. M., Boothe, M. A., \& Harris, C. E. (2011). Cervical cancer screening among ethnically diverse black women: Knowledge, attitudes, beliefs, and practices. J Natl Med Assoc, 103(8), 719-728.

Bustreo, F. (2015). Ten top issues for women's health. Retrieved from http://www.who.int/life-course/news/commentaries/2015-intl-womens$\underline{\text { day/en/ }}$

Carpi, A., Egger, A. (2008). Comparison in scientific research. Retrieved from http://www.visionlearning.com/en/library/Process-ofScience/49/Comparison-in-Scientific-Research/152/reading

Carreno, J., Vyhmeister, G., Grau, L., \& Ivanovic, D. (2006). A health promotion programme in Adventist and non-Adventist women based on Pender's model: A pilot study. Public Health, 120(4), 346-355. doi:10.1016/j.puhe.2005.08.023

Carter, N., Bryant-Lukosius, D., DiCenso, A., Blythe, J., \& Neville, A. J. (2014). The use of triangulation in qualitative research. Oncol Nurs Forum, 41(5), 545-547. doi:10.1188/14.onf.545-547

Casciotti, D. M., \& Klassen, A. C. (2011). Factors associated with female provider preference among African American women, and implications for breast cancer screening. Health Care Women Int, 32(7), 581-598. doi:10.1080/07399332.2011.565527

Catarino, R., Petignat, P., Dongui, G., \& Vassilakos, P. (2015). Cervical cancer screening in developing countries at a crossroad: Emerging technologies and 
policy choices. World Journal of Clinical Oncology, 6(6), 281-290. doi:10.5306/wjco.v6.i6.281

Chang, H. J., Chen, W. X., Lin, E. C., Tung, Y. Y., Fetzer, S., \& Lin, M. F. (2013). Delay in seeking medical evaluations and predictors of self-efficacy among women with newly diagnosed breast cancer: A longitudinal study. Int J Nurs Stud. doi:10.1016/j.ijnurstu.2013.10.024

Christian, T., \& Guell, C. (2015). Knowledge and attitudes of cervical cancer screening among Caribbean women: A qualitative interview study from Barbados. Women Health, 55(5), 566-579. doi:10.1080/03630242.2015.1022816

Cotton, S., Zebracki, K., Rosenthal, S. L., Tsevat, J., \& Drotar, D. (2006). Religion/spirituality and adolescent health outcomes: A review. J Adolesc Health, 38(4), 472-480. doi:10.1016/j.jadohealth.2005.10.005

Creswell, J. W. (2014). Research design (4th ed.). Los Angeles: Sage.

Daher, M. (2012). Cultural beliefs and values in cancer patients. Ann Oncol, 23 Suppl 3, 66-69. doi:10.1093/annonc/mds091

Dempsey, A. F., \& Davis, M. M. (2006). Overcoming barriers to adherence to HPV vaccination recommendations. Am J Manag Care, 12(17 Suppl), S484-491.

Departemen Komunikasi Eksternal dan Hubungan Masyarakat. (2017). Kabupaten Tanah Datar integrasikan program Jamkesda ke JKN-KIS. Retrieved from http://bpjs-kesehatan.go.id/bpjs/index.php/arsip/categories/Mjg/siaran-pers

Desanti, Sunarsih, \& Supriyanti. (2010). Persepsi wanita berisiko kanker payudara tentang pemeriksaan payudara sendiri di kota Semarang, Jawa Tengah. Berita Kedokteran Masyarakat, 26(3), 152.

Dewan Perwakilan Rakyat Republik Indonesia. (2016). Implementasi BPJS masih masalah. Retrieved from http://www.dpr.go.id/berita/detail/id/10536

Dewi, R., \& Arma, A. J. A. (2013). Perubahan pengetahuan sikap wanita yang memiliki pasangan terhadap pemeriksaan Pap smear sebelum dan sesudah diberikan penyuluhan tentang deteksi dini kanker serviks dengan pemeriksaan Pap smear dikelurahan Glugur Kecamatan Medan Timur Kota. Gizi, Kesehatan Reproduksi dan Epidemiologi, 2(3).

Dieng, M., Trevena, L., Turner, R. M., Wadolowski, M., \& McCaffery, K. (2013). What Australian women want and when they want it: Cervical screening testing preferences, decision-making styles and information needs. Health Expect, 16(2), 177-188. doi:10.1111/j.1369-7625.2011.00707.x

Dierckx de Casterle, B., Gastmans, C., Bryon, E., \& Denier, Y. (2012). QUAGOL: A guide for qualitative data analysis. Int J Nurs Stud, 49(3), 360-371. doi:10.1016/j.ijnurstu.2011.09.012

Dillard, A. J., Couper, M. P., \& Zikmund-Fisher, B. J. (2010). Perceived risk of cancer and patient reports of participation in decisions about screening: The decisions study. Med Decis Making, 30(5 Suppl), 96s-105s.

doi:10.1177/0272989x10377660

Doi, A. R. I. (2015). Marriage. Retrieved from http://www.islamawareness.net/Marriage/marriage_article002.html

Donnelly, T. T., Al Khater, A. H., Al-Bader, S. B., Al Kuwari, M. G., Al-Meer, N., Malik, M., .. . Fung, T. (2013). Beliefs and attitudes about breast cancer and screening practices among Arab women living in Qatar: A cross-sectional study. BMC Womens Health, 13, 49. doi:10.1186/1472-6874-13-49 
Duran, E. T. (2011). Examination with the health belief model of women's attitudes to cervical cancer and early diagnosis in Turkey: A qualitative study. Asian Pac J Cancer Prev, 12(5), 1179-1184.

Eheman, C. R., Berkowitz, Z., Lee, J., Mohile, S., Purnell, J., Rodriguez, E. M., . . Morrow, G. (2009). Information-seeking styles among cancer patients before and after treatment by demographics and use of information sources. J Health Commun, 14(5), 487-502. doi:10.1080/10810730903032945

Ekanita, P., \& Khosidah, A. (2013). Hubungan antara pengetahuan dan sikap WUS terhadap perilaku pemeriksaan payudara sendiri Jurna Bidan Prada, 4(2).

El-Hammasi, K., Samir, O., Kettaneh, S., Al-Fadli, A., \& Thalib, L. (2009). Use of and attitudes and knowledge about Pap smears among women in Kuwait. Journal Of Womens Health, 18(11), 1825-1832. doi:10.1009/jwh.2008.1227

Eric, D. (2016). Pertumbuhan asuransi di 2016 dan prediksi 2017. Retrieved from http://www.mauasuransi.com/artikel/2016/pertumbuhan-asuransi-di-2016dan-prediksi-2017

Fadhila, R. (2017). Sekilas tentang vaksin HPV. Retrieved from http://www.idai.or.id/artikel/klinik/imunisasi/sekilas-tentang-vaksin-hpv

Farooqui, M., Hassali, M. A., Knight, A., Shafie, A. A., Farooqui, M. A., Saleem, F., ... Aljadhey, H. (2013). A qualitative exploration of Malaysian cancer patients' perceptions of cancer screening. BMC Public Health, 13, 48. doi:10.1186/1471-2458-13-48

Fauziah. (2016). Kecemasan pada penderita kanker (Undergraduate Mini thesis), Universitas Muhammadiyah Surakarta, Surakarta. Retrieved from http://eprints.ums.ac.id/43931/12/NASKAH\%20PUBLIKASI.pdf (F.100124015)

Ferree, M. M. (1991). The gender division of labor in two-earner marriages dimensions of variability and change. Journal of Family Issues, 12(2), 158180.

Forster, A. S., Forbes, L. J., Abraham, C., Warburton, F. G., Douglas, E., \& Ramirez, A. J. (2014). Promoting early presentation of breast cancer: A preliminary evaluation of a written intervention. Chronic Illn, 10(1), 18-30. doi:10.1177/1742395313484071

Fortunati, L. N., \& Floerchinger-Franks, G. (2001). Men and family planning: What is their future role? J Am Acad Nurse Pract, 13(10), 473-479.

Frasure-Yokley, L. (2015). Focus group protoclos and data collection prosedures. Cambridge: Cambridge University Press.

Friedman, A. M., Hemler, J. R., Rossetti, E., Clemow, L. P., \& Ferrante, J. M. (2012). Obese women's barriers to mammography and pap smear: The possible role of personality. Obesity (Silver Spring), 20(8), 1611-1617. doi:10.1038/oby.2012.50

Galvez, P., Valencia, A., Palomino, A. M., Cataldo, M., \& Schwingel, A. (2015). Communicating about eating behaviors. A qualitative study of Chilean women and their health-care providers. Int J Qual Stud Health Well-being, 10, 25979. doi:10.3402/qhw.v10.25979

Gibson, B. G., Morgan. (1979). Sociological paradigmns and organisational analysis: Elements of the sociology of corporate life. London: Heinemann.

Ginting, F. (2014). Persepsi pasien kanker payudara terhadap pengobatan alternative. (Undergraduate Mini Thesis), Universitas Gajah Mada, Yogyakarta. Retrieved from 
http://etd.repository.ugm.ac.id/index.php?mod=penelitian_detail\&sub=Peneli tianDetail\&act=view\&typ=html\&buku id $=76172$

Gonzales, K. L., Harding, A. K., Lambert, W. E., Fu, R., \& Henderson, W. G. (2013). Perceived experiences of discrimination in health care: A barrier for cancer screening among American Indian women with type 2 diabetes. Womens Health Issues, 23(1), e61-67. doi:10.1016/j.whi.2012.10.004

Gould, J., Fitzgerald, B., Fergus, K., Clemons, M., \& Baig, F. (2010). Why women delay seeking assistance for locally advanced breast cancer. Can Oncol Nurs J, 20(1), 23-29.

Grady, W. R., Tanfer, K., Billy, J. O., \& Lincoln-Hanson, J. (1996). Men's perceptions of their roles and responsibilities regarding sex, contraception and childrearing. Fam Plann Perspect, 28(5), 221-226.

Graneheim, U. H., \& Lundman, B. (2004). Qualitative content analysis in nursing research: Concepts, procedures and measures to achieve trustworthiness. Nurse Educ Today, 24(2), 105-112. doi:10.1016/j.nedt.2003.10.001

Granek, L., \& Fergus, K. (2012). Resistance, agency, and liminality in women's accounts of symptom appraisal and help-seeking upon discovery of a breast irregularity. Soc Sci Med, 75(10), 1753-1761. doi:10.1016/j.socscimed.2012.07.016

Grbich, C. F. (1999). Qualitative research in health. Australia: Allen and Unwin Pty Ltd.

Green, J., \& Thorogood, N. (2004). Qualitative Methods in Health Research. London: Sage Publication.

Gremore, T. M., Baucom, D. H., Porter, L. S., Kirby, J. S., Atkins, D. C., \& Keefe, F. J. (2011). Stress buffering effects of daily spousal support on women's daily emotional and physical experiences in the context of breast cancer concerns. Health Psychol, 30(1), 20-30. doi:10.1037/a0021798

Gyenwali, D., Pariyar, J., \& Onta, S. R. (2013). Factors associated with late diagnosis of cervical cancer in Nepal. Asian Pac J Cancer Prev, 14(7), 43734377.

Hadad, A. K. E. (2007). The prophet as a husband. Retrieved from http://rasoulallah.net/index.php/en/articles/article/239

Hakim, L., Heldy, \& Fauzi. (2013). Analisis managemen dan intervensi bagi pasien terhadap upaya Promosi Kesehatan Rumah Sakit (PKRS) Di Rumah Sakit Umum Pusat Haji Adam Malik Medan. Kebijakan, Promosi Kesehatan dab Biostatistik, 2(1).

Hamdan-Mansour, A. M., Malkawi, A. O., Sato, T., Hamaideh, S. H., \& Hanouneh, S. I. (2016). Men's perceptions of and participation in family planning in Aqaba and Ma'an governorates, Jordan. East Mediterr Health J, 22(2), 124132.

Harandy, T. F., Ghofranipour, F., Montazeri, A., Anoosheh, M., Bazargan, M., Mohammadi, E., .. . Niknami, S. (2010). Muslim breast cancer survivor spirituality: coping strategy or health seeking behavior hindrance? Health Care Women Int, 31(1), 88-98. doi:10.1080/07399330903104516

Harumawati, D. (2012). Gambaran dukungan suami dalam antenatal care ibu hamil. (Diploma III Mini Thesis), Universitas Muhammadiyah Ponorogo, Ponorogo. (0962081)

Hasbiah. (2004). Faktor-faktor yang berhubungan dengan perilaku pemeriksaan PAP Smear oleh pegawai negeri sipil wanita di Poltekes Palembang. Retrieved from 
http://repository.ui.ac.id/contents/koleksi/16/ada1d7444b326685135b710e1b c87b225736063e.pdf

Hasson-Ohayon, I., Goldzweig, G., Dorfman, C., \& Uziely, B. (2014). Hope and social support utilisation among different age groups of women with breast cancer and their spouses. Psychol Health, 29(11), 1303-1319. doi:10.1080/08870446.2014.929686

Hayden, J. (2009). Health Behavior Theory Introduction to Health Behavior Theory London: Jones and Bartlett.

Hernandez, B. (2006). Institute of medicine (USA) committee on assessing interactions among sosial, behaviour and genetic factor in health. Washington: National Academies Press.

Hileli, I., Weyl Ben Arush, M., Hakim, F., \& Postovsky, S. (2014). Association between religious and socio-economic background of parents of children with solid tumors and DNR orders. Pediatr Blood Cancer, 61(2), 265-268. doi:10.1002/pbc. 24712

Hoen, E. t. (2014). Access to cancer treatment. Retrieved from https://www.ciaonet.org/attachments/27387/uploads

Hooker, S. A., Masters, K. S., \& Carey, K. B. (2014). Multidimensional assessment of religiousness/spirituality and health behaviors in college students. The International Journal for the Psychology of Religion, 24(3), 228-240.

Houghton, C., Casey, D., Murphy, D., \& Shaw, K. (2013). Rigour in qualitative case-study research. Nurse researcher, 20(4).

Hunt, M. R. (2009). Strengths and challenges in the use of interpretative descriptive: reflections arising from a study of the moral experience of health professionals in humanitarian work. Qual Health Research, 19(9).

Husain, I., \& Soetjipto, H. P. (2006) The number and quality health staff of Health Center, a distribution study village-urban area and region analyes of Data SAKERTI in 2000. Yogyakarta: Magister Kebijakan dan Pelayanan Managemen, Universitas Gajah Mada

Hussain, M. (2012). What Islam teaches about healthy life style. Retrieved from http://www.musharrafhussain.com/2012/11/28/what-islam-teaches-abouthealthy-life-style/

Ibrahim, I. (1997). A brief illustrated guide to understanding Islam (2 ed.). Houston, Texas, USA: Darussalam.

Ibrahim, K. (2009). Cultural care for people living with HIV/AIDS in Muslim communities in Asia: A literature review. Thai Journal of Nursing Research, $13(2)$.

Idward. (2012). Seberapa besar manfaat pengobatan alternative. Retrieved from http://www.gizikia.depkes.go.id/archives/artikel/seberapa-besar-manfaatpengobatan-alternatif

Ijadunola, M. Y., Abiona, T. C., Ijadunola, K. T., Afolabi, O. T., Esimai, O. A., \& OlaOlorun, F. M. (2010). Male involvement in family planning decision making in Ile-Ife, Osun State, Nigeria. Afr J Reprod Health, 14(4 Spec no.), 43-50.

Indonesia Cancer Foundation. (2014). Tentang YKI. Retrieved from http://yayasankankerindonesia.org/tentang-ykia01/\#a02

Informasi BPJS. (2016). Inilah daftar operasi yang ditanggung BPJS Kesehatan. Retrieved from http://infobpjs.net/inilah-daftar-operasi-yang-di-tanggungbpjs-kesehatan/ 
Jordan, K. D., Masters, K. S., Hooker, S. A., Ruiz, J. M., \& Smith, T. W. (2014). An Interpersonal Approach to Religiousness and Spirituality: Implications for Health and Well-Being. Journal of personality, 82(5), 418-431.

Keating, N. L., O'Malley, A. J., Murabito, J. M., Smith, K. P., \& Christakis, N. A. (2011). Minimal social network effects evident in cancer screening behavior. Cancer, 117(13), 3045-3052. doi:10.1002/cncr.25849

Kementerian Kesehatan Republik Indonesia. (2004). Kebijakan dasar pusat kesehatan masyarakat. Jakarta: Kementerian Kesehatan Retrieved from http://pelayanan.jakarta.go.id/download/regulasi/keputusan-menterikesehatan-nomor-128-menkes-sk-ii-2004-tentang-kebijakann-dasar-pusatkesehatan-masyarakat.pdf.

Kementerian Kesehatan Republik Indonesia. (2007). Permenkes no. 1109 tahun 2007: Penyelenggaraan pengobatan komplementer alternatif. Jakarta: Kementerian Kesehatan Republik Indonesia Retrieved from http://www.hukumonline.com/pusatdata/detail/lt4dc8cc65764b8/node/lt50ed 170e2a71c/peraturan-menteri-kesehatan-no-1109_menkes_per_ix_2007tahun-2007-penyelenggaraan-pengobatan-komplementer-alternatif-difasilitas-pelayanankesehatan.

Kementerian Kesehatan Republik Indonesia. (2010). Profil Kesehatan Indonesia Tahun 2009 Retrieved from Jakarta: http://perpustakaan.depkes.go.id:8180/handle/123456789/1409

Kementerian Kesehatan Republik Indonesia. (2012). Profil Data Kesehatan tahun 2011 Retrieved from Jakarta, Indonesia: http://www.depkes.go.id/resources/download/pusdatin/profil-kesehatanindonesia/profil-kesehatan-indonesia-2011.pdf

Kementerian Kesehatan Republik Indonesia. (2015). Rencana strategis Kementerian Kesehatan Republik Indonesia tahun 2015-2019. Jakarta: Kementerian Kesehatan Retrieved from www.depkes.go.id/resources/download/infopublik/Renstra-2015.pdf.

Kementerian Kesehatan Republik Indonesia. (2016). Peraturan Menteri Kesehatan Republik Indonesia nomor 43 tahun 2016 tentang standar pelayanan minimal bidang kesehatan. Jakarta: Kementerian Kesehatan Retrieved from http://www.indonesian-publichealth.com/download-permenkes-nomor-43tahun-2016-tentang-spm-bidang-kesehatan.

Kementerian Pemberdayaan Perempuan. (2012). Profil perempuan Indonesia 2012. Retrieved from Jakarta: http://www.kemenpppa.go.id/index.php/page/read/26/1020/profileperempuan-indonesia-tahun-2012

Kementerian Pemberdayaan Perempuan. (2013). Profil perempuan Indonesia 2013. Retrieved from Jakarta: http://www.kemenpppa.go.id/index.php/page/read/26/1021/profileperempuan-indonesia-tahun-2013

Kessler, T. A. (2017). Cervical cancer: Prevention and early detection. Semin Oncol Nurs, 33(2), 172-183. doi:10.1016/j.soncn.2017.02.005

Khan, M. M. (2011). The hadith of the Prophet Muhammad. Retrieved from https://sunnah.com/

Kim, Ati, A., Kols, A., Maria, F., Lambe., Soetikno., . . Megan. (2012). Influencing women's actions on cervical cancer screening and treatment in Karawamg district, Indonesia. Asian Pasific Journal of Cancer Prevention, 12, 29131921. 
Kim, Chopik, W. J., \& Smith, J. (2014). Are people healthier if their partners are more optimistic? The dyadic effect of optimism on health among older adults. J Psychosom Res, 76(6), 447-453.

doi:10.1016/j.jpsychores.2014.03.104

Kim, Lambe, F. M., Soetikno, D., Wysong, M., Tergas, A. I., Rajbhandari, P., . . . Lu, E. (2013). Evaluation of a 5-year cervical cancer prevention project in Indonesia: Opportunities, issues, and challenges. J Obstet Gynaecol Res, 39(6), 1190-1199. doi:10.1111/jog.12052

Kivistik, A., Lang, K., Baili, P., Anttila, A., \& Veerus, P. (2011). Women's knowledge about cervical cancer risk factors, screening, and reasons for nonparticipation in cervical cancer screening programme in Estonia. BMC Womens Health, 11(1), 43. doi:10.1186/1472-6874-11-43

Kliucinskas, M., Nadisauskiene, R. J., \& Minkauskiene, M. (2006). Prevalence and risk factors of HPV infection among high-risk rural and urban Lithuanian women. Gynecol Obstet Invest, 62(3), 173-180. doi:10.1159/000093572

Koenig, G. H. (2012). Religion, spirituality, and health: The research and clinical implications. SRN Psychiatry, 2012(2012), 33.

Kumar, S., Shaikh, A. J., Khalid, S., \& Masood, N. (2010). Influence of patient's perceptions, beliefs and knowledge about cancer on treatment decision making in Pakistan. Asian Pac J Cancer Prev, 11(1), 251-255.

Kusmindari, Zinaida, Pasmawati, \& Saputra. (2016). Peran pria dalam program keluarga berencana di Kota Palembang, Sumatra Selatan. Jurnal Keluarga Berencana, 1(1).

Kutty, A. (2004). Is marriage obligatory. Marriage. Retrieved from http://www.islamawareness.net/Marriage/fatwa_16.html

Kyle, R. G., Forbat, L., \& Hubbard, G. (2012). Cancer awareness among adolescents in Britain: A cross-sectional study. BMC Public Health, 12, 580. doi:10.1186/1471-2458-12-580

Labun, E., \& Emblen, J. D. (2007). Spirituality and health in Punjabi Sikh. J Holist Nurs, 25(3), 141-148; 149-150. doi:10.1177/0898010106293592

Laher, S. (2014). An overview of illness conceptualizations in African, Hindu, and Islamic traditions: towards cultural competence. South African Journal of Psychology, 44(2), 191-204.

Lambert, V. A., Lambert, C. E. (2012). Qualitative descriptive research: An acceptable design. Pacific Rim International Journal of Nursing Research, $16(4), 255-256$.

Lantu, \& Saraswati. (2013). Gambaran pengetahuan dan sikap ibu tentang pap smear di desa Pulubala Kabupaten Gorontalo. KIM Fakultas ilmu-ilmu kesehatan dan keolahragaan, 1(1).

Lee, B. Y., \& Newberg, A. B. (2005). Religion and health: A review and critical analysis. Zygon ${ }^{\circledR}, 40(2), 443-468$. doi:10.1111/j.1467-9744.2005.00674.X

Lee, H. Y., Stange, M. J., \& Ahluwalia, J. S. (2014). Breast cancer screening behaviors among Korean American immigrant women: Findings from the health belief model. J Transcult Nurs. doi:10.1177/1043659614526457

Levin, J. S. (1996). How religion influences morbidity and health: Reflections on natural history, salutogenesis and host resistance. Soc Sci Med, 43(5), 849864.

Lewis, N., Martinez, L. S., Freres, D. R., Schwartz, J. S., Armstrong, K., Gray, S. W., . . Hornik, R. C. (2012). Seeking cancer-related information from media and family/friends increases fruit and vegetable consumption among cancer 
patients. Health Commun, 27(4), 380-388.

doi:10.1080/10410236.2011.586990

Lincoln, Y. S. (1985). Naturalistic inquiry. Beverly Hills, Calif.: Beverly Hills, Calif. : Sage Publications.

Liou, H. I., Ling, X. M., Feng, M. X., Guo, Y. L., \& Chen, M. Y. (2009). Responses, actions and health-promoting behavior among rural Taiwanese women with abnormal Papanicolaou test. Public Health Nurs, 26(2), 134-143. doi:10.1111/j.1525-1446.2009.00764.x

LitBang Rumah Sakit Kanker Dharmais. (2012). Registrasi kanker berbasis Rumah Sakit di Rumah Sakit Kanker Dhamais 2003-2007. Retrieved from Jakarta: http://dharmais.co.id/srikandi/2-pbcr-rsk-dharmais/6-publikasi/

Lor, M., Khang, P. Y., Xiong, P., Moua, K. F., \& Lauver, D. (2013). Understanding Hmong women's beliefs, feelings, norms, and external conditions about breast and cervical cancer screening. Public Health Nurs, 30(5), 420-428. doi:10.1111/phn.12043

Lu, M. H., Lin, H. R., \& Lee, M. D. (2010). The experiences among older Taiwanese women facing a new diagnosis of breast cancer. Cancer Nurs, 33(5), 398405. doi:10.1097/NCC.0b013e3181d72c45

Ma, G. X., Gao, W., Lee, S., Wang, M., Tan, Y., \& Shive, S. E. (2012). Health seeking behavioral analysis associated with breast cancer screening among Asian American women. Int J Womens Health, 4, 235-243. doi:10.2147/ijwh.s30738

MacDonald, L., Jones, L., Thomas, P., Thu, L. T., FitzGerald, S., \& Efroymson, D. (2013). Promoting male involvement in family planning in Vietnam and India: HealthBridge experience. Gender \& Development, 21(1). doi:10.1080/13552074.2013.767498

Mackenzie, N., \& Knipe, S. (2006). Research dilemmas: Paradigms, methods, and methodology. Issues in Educational Reseach, 16(2).

Maharani, D. (2015). Banyak pasien kanker payudara datang terlambat karena pengobatan alternatif. Retrieved from http://lifestyle.kompas.com/read/2015/12/18/174500823/Banyak.Pasien.Kan ker.Payudara.Datang.Terlambat.Karena.Pengobatan.Alternatif

Maharani, D. (2016). Mesti ditanggung BPJS biaya berobat pasien kanker tetap tinggi. Retrieved from http://health.kompas.com/read/2016/04/11/172300823/Meski.Ditanggung.BP JS.Biaya.Berobat.Pasien.Kanker.Tetap.Tinggi

Maharsie, L. (2012). Hubungan Pengetahuan Ibu Tentang Kanker Serviks dengan Keikutsertaan Ibu Melakukan IVA Test Di Kelurahan Jebres Surakarta. Gaster| Jurnal Ilmu Kesehatan, 9(2), 46-54.

Mainuddin, A., Ara Begum, H., Rawal, L. B., Islam, A., \& Shariful Islam, S. M. (2015). Women empowerment and its relation with health seeking behavior in Bangladesh. J Family Reprod Health, 9(2), 65-73.

Maqsood, R. W. (1995). The Muslim married guide. Cambridge: Quillam Press.

Maqsood, R. W. (2012). Need to know? Islam. London, United Kingdom: HarperCollins Publishers.

Maree, J. E., Mosalo, A., \& Wright, S. C. (2013). 'It depends on how the relationship was before you became ill': Black South African women's experiences of life partner support through the trajectory of cervical cancer. Eur J Cancer Care (Engl), 22(4), 459-467. doi:10.1111/ecc.12051 
Maree, J. E., \& Wright, S. C. (2010). How would early detection be possible? An enquiry into cancer related knowledge, understanding and health seeking behaviour of urban black women in Tshwane, South Africa. Eur J Oncol Nurs, 14(3), 190-196. doi:10.1016/j.ejon.2009.10.009

Marlina, E. (2015). Hubungan dukungan suami dengan perilaku istri melakukan pemeriksaan Pap smear di Puskesmas Umbulharjo II Kota Yogyakarta. (Undergraduate Mini thesis), STIKES Aisyiyah, Yogyakarta.

Marlow, L. A., McGregor, L. M., Nazroo, J. Y., \& Wardle, J. (2013). Facilitators and barriers to help-seeking for breast and cervical cancer symptoms: A qualitative study with an ethnically diverse sample in London. Psychooncology. doi:10.1002/pon.3464

Masters, K., S. (2008). Mechanism in the relation between religion and health with emphasis on cardiovascular reactivity to stress. Research in the Social Scientific Study of Religion, 19(91-116).

McAlearney, A. S., Oliveri, J. M., Post, D. M., Song, P. H., Jacobs, E., Waibel, J., . . . Paskett, E. D. (2012). Trust and distrust among Appalachian women regarding cervical cancer screening: A qualitative study. Patient Educ Couns, 86(1), 120-126. doi:10.1016/j.pec.2011.02.023

McLeod, S. (2016). Maslow's hierarchy of needs. Retrieved from https://www.simplypsychology.org/maslow.html

Menteri Kesehatan Republik Indonesia. (2010). Pedoman teknis pengendalian kanker payudara dan kanker leher rahim. Jakarta: Author Retrieved from http://www.hukor.depkes.go.id/up_prod_kepmenkes/KMK\%20No.\%20796\% 20ttg\%20Kanker\%20Rahim.pdf.

Misgiyanto, \& Susilawati. (2014). Hubungan antara dukungan keluarga dengan tingkat kecemasan penderita kanker serviks Jurnal Keperawatan Universitas Muhammadiyah Malang, 5(1).

Mistik, S., Nacar, M., Mazicioglu, M., \& Cetinkaya, F. (2003). Married men's opinions and involvement regarding family planning in rural areas. Contraception, 67(2), 133-137.

Mohamed, C. R. (2010). The educational needs of home-based Stroke patients and family care givers in Malaysia. (Doctoral), Victoria University of Wellington, New Zealand.

Monsonego, J., Cortes, J., da Silva, D. P., Jorge, A. F., \& Klein, P. (2011). Psychological impact, support and information needs for women with an abnormal Pap smear: Comparative results of a questionnaire in three European countries. BMC Womens Health, 11, 18. doi:10.1186/1472-6874$11-18$

Montazeri, A., Vahdaninia, M., Harirchi, I., Harirchi, A. M., Sajadian, A., Khaleghi, F., . . Jarvandi, S. (2008). Breast cancer in Iran: Need for greater women awareness of warning signs and effective screening methods. Asia Pac Fam Med, 7(1), 6. doi:10.1186/1447-056x-7-6

Morais, R. J. (2010). Refocusing focus groups: A practical guide. New York: Paramount Market Publishing.

Murtini. (2012). Hubungan Antara factor predisposisi, pendukung dan pendorong dengan cakupan IVA (Master Thesis), Universitas Udayana, Denpasar. Retrieved from http://www.pps.unud.ac.id/thesis/pdf_thesis/unud-3861506654570-bagian\%20depan.pdf (0992162047)

Musyriqoh, S. (2013). Hubungan dukungan suami dengan perilaku pencegahan terhadap kanker serviks pada wanita dewasa awal di Desa Balung Lor, 
Kecamatan Balung, Kabupaten Jember. (Undergraduate Mini Thesis), Universitas Jember, Jember.

Nagler, R. H., Gray, S. W., Romantan, A., Kelly, B. J., DeMichele, A., Armstrong, K., ... Hornik, R. C. (2010). Differences in information seeking among breast, prostate, and colorectal cancer patients: Results from a populationbased survey. Patient Educ Couns, 81 Suppl, S54-62. doi:10.1016/j.pec.2010.09.010

Ndukwe, E. G., Williams, K. P., \& Sheppard, V. (2013). Knowledge and perspectives of breast and cervical cancer screening among female African immigrants in the Washington D.C. metropolitan area. J Cancer Educ, 28(4), 748-754. doi:10.1007/s13187-013-0521-x

Ningrum, R. D., Fajarsari, Dyah. (2012). Faktor-faktor yang mempengaruhi motivasi ibu mengikuti deteksi di kanker serviks melalui merode inspeksi visual asam asetat (IVA) di kabupaten Banyumas. Journal Bidan Prada, 4(1).

Nissen, M. J., Tsai, M. L., Blaes, A. H., Swenson, K. K., \& Koering, S. (2013). Effectiveness of treatment summaries in increasing breast and colorectal cancer survivors' knowledge about their diagnosis and treatment. J Cancer Surviv, 7(2), 211-218. doi:10.1007/s11764-012-0261-7

Noh, H. I., Lee, J. M., Yun, Y. H., Park, S. Y., Bae, D. S., Nam, J. H., . . Chang, Y. J. (2009). Cervical cancer patient information-seeking behaviors, information needs, and information sources in South Korea. Support Care Cancer, 17(10), 1277-1283. doi:10.1007/s00520-009-0581-y

Norsa'adah, B., Rahmah, M. A., Rampal, K. G., \& Knight, A. (2012). Understanding barriers to Malaysian women with breast cancer seeking help. Asian Pac J Cancer Prev, 13(8), 3723-3730.

O'Mahony, M., \& Hegarty, J. (2009). Factors influencing women in seeking help from a health care professional on self discovery of a breast symptom, in an Irish context. J Clin Nurs, 18(14), 2020-2029. doi:10.1111/j.13652702.2008.02564.x

O'Mahony, M., Hegarty, J., \& McCarthy, G. (2011). Women's help seeking behaviour for self discovered breast cancer symptoms. Eur J Oncol Nurs, 15(5), 410-418. doi:10.1016/j.ejon.2010.10.011

O'Mahony, M., McCarthy, G., Corcoran, P., \& Hegarty, J. (2013). Shedding light on women's help seeking behaviour for self discovered breast symptoms. Eur J Oncol Nurs, 17(5), 632-639. doi:10.1016/j.ejon.2013.03.012

Ogedegbe, G., Cassells, A. N., Robinson, C. M., DuHamel, K., Tobin, J. N., Sox, C. H., \& Dietrich, A. J. (2005). Perceptions of barriers and facilitators of cancer early detection among low-income minority women in community health centers. J Natl Med Assoc, 97(2), 162-170.

Ohashi, A., Higuchi, M., Labeeb, S. A., Mohamed, A. G., Chiang, C., \& Aoyama, A. (2014). Family support for women's health-seeking behavior: A qualitative study in rural southern Egypt (Upper Egypt). Nagoya J Med Sci, 76(1-2), 1725.

Ompusungu, F. (2012). Karakteristik hambatan wanita usia subur melakukan Pap smear di Puskesmas Kedai Duria. Journal Keperawatan Klinis, 1(1).

Onyango, M. A., Owoko, S., \& Oguttu, M. (2010). Factors that influence male involvement in sexual and reproductive health in western Kenya: A qualitative study. Afr J Reprod Health, 14(4 Spec no.), 32-42. 
Orji, E. O., Ojofeitimi, E. O., \& Olanrewaju, B. A. (2007). The role of men in family planning decision-making in rural and urban Nigeria. Eur J Contracept Reprod Health Care, 12(1), 70-75. doi:10.1080/13625180600983108

Park, C. L., Masters, K. S., Salsman, J. M., Wachholtz, A., Clements, A. D., Salmoirago-Blotcher, E., ... Wischenka, D. M. (2017). Advancing our understanding of religion and spirituality in the context of behavioral medicine. J Behav Med, 40(1), 39-51. doi:10.1007/s10865-016-9755-5

Park, S., Song, H. Y., Hur, H. K., \& Kim, G. (2009). Effects of a cognition-oriented breast self-examination intervention for Korean women and their spouses. Public Health Nurs, 26(3), 259-268. doi:10.1111/j.1525-1446.2009.00778.x

Pathan, M. S. K. (2003). Every illness has a cure: The Islamic perspective Retrieved from http://www.fiqh.org/2009/04/every-illness-has-a-cure-the-islamicperspective/

Pender, N., Murdaugh, C., \& Parsons, A. M. (2016). Health Promotion in Nursing Parctice (6th ed.). Boston: Pearson.

PewResearch Center. (2012). The global religious landscape: Muslims. Retrieved from http://www.pewforum.org/2012/12/18/global-religious-landscapemuslim/

Polaschek, N. R. (1998). Cultural safety: A new concept in nursing people of different ethnicities. J Adv Nurs, 27(3), 452-457.

Polit, D. F., \& Beck, C. (2014). Essentials of nursing research (Vol. 8 ed). Philadelphia: Wolters Kluwer.

Potrata, B. (2011). Cultures, subcultures and late presentation with breast cancer. Asian Pac J Cancer Prev, 12(6), 1609-1613.

Pratami. (2016). Pengalaman suami dalam memberikan dukungan ASI eksklusif pada ibu primipara di wilayah kerja Puskesmas Semplak Kelurahan Curug Mekar Kota Bogor. (Undergraduate Mini Thesis), Universitas Islam Negeri Syarif Hidayatullah, Jakarta. Retrieved from http://repository.uinjkt.ac.id/dspace/handle/123456789/33028

Priherdityo, E. (2016). Wanita kerier Indonesia terbanyak keenam di dunia. Retrieved from http://www.cnnindonesia.com/gaya-hidup/20160308121332277-116053/wanita-karier-indonesia-terbanyak-keenam-di-dunia/

Purnomo, A. (2009). Sekitar 50\% PUSKESMAS belum memenuhi standart minimal pelayanan. Retrieved from www.tempo.co/read/news/2009/12/06/058212102/siktar-50-PersenPuskesmas-Belum-Memenuhi-Standar-Minimal

Pusat data dan informasi. (2015). Situasi penyakit kanker. Buletin Jendela Data dan Informasi Kesehatan, 1.

Pusat Komunikasi Publik. (2012). Penderita kanker diperkirakan menjadi penyebab utama beban ekonomi terus meningkat. Retrieved from http://www.depkes.go.id/index.php?vw=2\&id=1937

Pusat Komunikasi Publik. (2013). Pemerintah targetkan 80\% perempuan dapat deteksi dini kanker payudara dan kanker serviks. Retrieved from http://www.depkes.go.id/index.php?vw=2\&id=SNR.13100003

Puspitasari, Indrawati, \& Pujiati. (2012). Hubungan tingkat pendidikan dan pengetahuan ibu tentang kanker serviks dengan pemeriksaan Pap smear. Journal Kebidanan Universitas Muhammdiyah Semarang, 1(1). 
Putri. (2012). Inilah program pengendalian kanker di Indonesia. Retrieved from http://lifestyle.okezone.com/read/2012/05/04/482/623937/inilah-programpengendalian-kanker-di-indonesia-i

Qureshi, N., \& Shaikh, B. T. (2007). Women's empowerment and health: The role of institutions of power in Pakistan. East Mediterr Health J, 13(6), 1459-1465.

Rabiee, F. (2004). Focus-group interview and data analysis. Proc Nutr Soc, 63(4), 655-660.

Radina, M. E., Ginter, A. C., Brandt, J., Swaney, J., \& Longo, D. R. (2011). Breast cancer patients' use of health information in decision making and coping. Cancer Nurs, 34(5), E1-12. doi:10.1097/NCC.0b013e3181faab7c

Radji, M., Aldrat, H., Harahap, Y., \& Irawan, C. (2010). Penggunaan obat herbal pada pasien kanker serviks. Jurnal Ilmu Kefarmasian, 8(1), 33-39.

Rafidah, I., Wibowo, A. (2012). Pengaruh dukungan suami terhadap kepatuhan akseptor melakukan KB suntik. Jurnal Biometrika dan Kependudukan, 1(1), 72-78.

Ramanakumar, A. V., Balakrishna, Y., \& Ramarao, G. (2005). Coping mechanisms among long-term survivors of breast and cervical cancers in Mumbai, India. Asian Pac J Cancer Prev, 6(2), 189-194.

Rawayan. (2014). Hambatan KB di Indonesia. Retrieved from http://bk2bn.blogspot.co.nz/2014/05/anggapan-banyak-anak-banyakrezeki.html

Reid-Arndt, S. A., \& Cox, C. R. (2010). Does rurality affect quality of life following treatment for breast cancer? J Rural Health, 26(4), 402-405. doi:10.1111/j.1748-0361.2010.00295.x

Richardson, F. (2011). What is cultural safety and why does it matter? Retrieved from http://www.nursingreview.co.nz/issue/august-2011/what-is-culturalsafety-and-why-does-it-matter/\#.WSKdp7h95pg

Robinson, J., \& Spitze, G. (1992). Whistle while you work? The effect of household task performance on women's and men's weil-being. Social Science Quarterly, 73(4), 844-861.

Rosmawati, N. H. (2010). Knowledge, attitudes and practice of breast selfexamination among women in a suburban area in Terengganu, Malaysia. Asian Pac J Cancer Prev, 11(6), 1503-1508.

Rosser, J. I., Zakaras, J. M., Hamisi, S., \& Huchko, M. J. (2014). Men's knowledge and attitudes about cervical cancer screening in Kenya. BMC Womens Health, 14, 138. doi:10.1186/s12905-014-0138-1

Sabrida, H. (2015). Peranan deteksi dini kanker untuk menurunkan penyakit kanker stadium lanjut. Buletin Jendela Data dan Informasi Kesehatan, 1, 16-24.

Saha, K. B., Singh, N., Chatterjee Saha, U., \& Roy, J. (2007). Male involvement in reproductive health among scheduled tribe: experience from Khairwars of central India. Rural Remote Health, 7(2), 605.

Salmoirago-Blotcher, E., Fitchett, G., Ockene, J. K., Schnall, E., Crawford, S., Granek, I., . . . Rapp, S. (2011). Religion and healthy lifestyle behaviors among postmenopausal women: The women's health initiative. J Behav Med, 34(5), 360-371. doi:10.1007/s10865-011-9322-z

Samiei', M. (2013). Challenges of making radiotherapy accessible in developing countries. Retrieved from http://globalhealthdynamics.co.uk/cc2013/wpcontent/uploads/2013/04/83-96-Samiei-varian-tpage-incld-T-page_2012.pdf 
Sandelowski, M. (2000). Whatever happened to qualitative description? Res Nurs Health, 23(4), 334-340.

Sandelowski, M. (2010). What's in a name? Qualitative description revisited. Res Nurs Health, 33(1), 77-84. doi:10.1002/nur.20362

Saraswati, L. K. (2009). Pengaruh Promosi Kesehatan Terhadap Pengetahuan Tentang Kanker Serviks Dan Partisipasi Wanita Dalam Deteksi Dini Kanker Serviks (Di Mojosongo Rw 22 Surakarta). Universitas Sebelas Maret.

Sari, N. (2016). Harga vaksin kanker serviks bisa capai Rp 1,2 juta. Retrieved from http://megapolitan.kompas.com/read/2016/11/22/12541001/harga.vaksin.kan ker.serviks.bisa.capai.rp.1.2.juta

Sarihati, A., . Yulianti,. (2013). Analisis faktor yang mendorong masyarakat melakukan Pap smear di Kota Denpasar. Jurnal Skala Husada, 10(1), 100104.

Satitvipawee, P., Promthet, S. S., Pitiphat, W., Kalampakorn, S., \& Parkin, D. M. (2009). Factors associated with breast self-examination among Thai women living in rural areas in Northeastern Thailand. J Med Assoc Thai, 92 Suppl 7, S29-35.

Schooler, C., Miller, J., Miller, K. A., \& Richtand, C. N. (1984). Work for the household: Its nature and consequences for husbands and Wives. American Journal of Sociology, 90(1), 97-124.

Setiadi, I. (2015). Pengambilan keputusan penggunaan alat kontrasepsi istri dalam keluarga. Populasi, 23(1), 20-35.

Shaluhiyah. (2007). Socio-cultural and socio-sexual factors influence the premarital sexual

behaviour of Javanese youth in the era of HIV/AIDS. Jurnal Promosi Kesehatan Indonesia, 2(2).

Shenton, A. K. (2004). Strategies for ensuring trustworthiness in qualitative research projects. Education for information, 22(2), 63-75.

Shinoda, E. (2016). Pengembangan jamu sebagai warisan budaya. Retrieved from http://biofarmaka.ipb.ac.id/biofarmaka/2013/Lomba\%20Blog\%2050\%20Pen gembangan\%20Jamu\%20Sebagai\%20Warisan\%20Budaya.pdf

Sinaga, N. (2012). Akutualisasi kehidupan berbangsa dan bernegara. Retrieved from http://pemberdayaanperempuan.demokrat.or.id/2012/12/bagimu-negerijiwa-raga-kami-aktualisasi-kehidupan-berbangsa-dan-bernegara/

Stacey, A. (2008). Health in Islam. A holistic approach. Retrieved from http://www.islamreligion.com/articles/1878/health-in-islam-part-1/

Stewart, B. W., \& Wild, C. P. (2014). World cancer report 2014. Retrieved from Lyon: http://www.who.int/cancer/publications/WRC_2014/en/

Stewart, D., \& Shamdasani, P. N. (2015). Focus group theory and practice (Vol. 20). California: SAGE Publications Inc.

Su-I, H. (2006). Perceived spousal support and beliefs toward cervical smear screening among Chinese women. Californian Journal of Health Promotion, 4(3), 157-164.

Sudaryanto, Mahmudah, \& Sukraeny. (2016). Hubungan dukungan keluarga dengan tingkat stres pasien kanker servik yan menjalani kemoterapi di ruang Rajawali RSUP Dr. Kariadi Semarang. Keperawatan, 1(2).

Sulistiowati, \& Sirait. (2014). Pengetahuan tentang faktor risiko, perilaku dan deteksi dini kanker serviks dengan Inspeksi Visual Asetat (IVA) pada wanita 
di Kecamatan Bogor Tengah, Kota Bogor. Buletin Penelitian Kesehatan, 42(3).

Suryana, S. (2010). Pelaksanaan promosi kesehatan masyarakat rumah sakit di RSUD Liwa kabupaten Lampung Barat. (Undergraduate), Universitas Diponegoro, Semarang. Retrieved from eprints.undip.ac.id/17301/3805.pdf (E2A308046)

Suryanto. (2013). Persentase jumlah umat Islam berbagai daerah di Indonesia. Retrieved from http://www.dokumenpemudatqn.com/2013/07/persentasejumlah-umat-islam-berbagai.html\#.U5gF9nKSx-Y

Taha, H., Al-Qutob, R., Nystrom, L., Wahlstrom, R., \& Berggren, V. (2012). "Voices of fear and safety" women's ambivalence towards breast cancer and breast health: A qualitative study from Jordan. BMC Womens Health, 12, 21. doi:10.1186/1472-6874-12-21

Taha, H., Al-Qutob, R., Nystrom, L., Wahlstrom, R., \& Berggren, V. (2013). "Would a man smell a rose then throw it away?" Jordanian men's perspectives on women's breast cancer and breast health. BMC Womens Health, 13, 41. doi:10.1186/1472-6874-13-41

Taib, N. A., Yip, C. H., \& Low, W. Y. (2011). Recognising symptoms of breast cancer as a reason for delayed presentation in Asian women--the psychosocio-cultural model for breast symptom appraisal: Opportunities for intervention. Asian Pac J Cancer Prev, 12(6), 1601-1608.

Tan, A. S., Moldovan-Johnson, M., Gray, S. W., Hornik, R. C., \& Armstrong, K. (2013). An analysis of the association between cancer-related information seeking and adherence to breast cancer surveillance procedures. Cancer Epidemiol Biomarkers Prev, 22(1), 167-174. doi:10.1158/1055-9965.epi-120781

Thiel de Bocanegra, H., Trinh-Shevrin, C., Herrera, A. P., \& Gany, F. (2009). Mexican immigrant male knowledge and support toward breast and cervical cancer screening. J Immigr Minor Health, 11(4), 326-333. doi:10.1007/s 10903-008-9161-3

Thomas, V. N., Saleem, T., \& Abraham, R. (2005). Barriers to effective uptake of cancer screening among Black and minority ethnic groups. Int J Palliat Nurs, 11(11), 562, 564-571.

Thombre, A., Sherman, A. C., \& Simonton, S. (2010). Religious coping and posttraumatic growth among family caregivers of cancer patients in India. $J$ Psychosoc Oncol, 28(2), 173-188. doi:10.1080/07347330903570537

Thorburn, S., Keon, K. L., \& Kue, J. (2013). Sources of breast and cervical cancer information for hmong women and men. Women Health, 53(5), 468-478. doi:10.1080/03630242.2013.796305

Thorne, Kirkham, \& Emes. (1997). Interpretive description: A noncategorical qualitative alternative for developing nursing knowledge. Res Nurs Health, 20.

Thorne, \& Sally. (2000). Data analysis in qualitative research. Evid Based Nurs, 3.

Tiwari, A., \& Kishore, J. (2011). Perceptions and concerns of women undergoing Pap smear examination in a tertiary care hospital of India. Indian J Cancer, 48(4), 477-482. doi:10.4103/0019-509x.92261

Torres, E., Erwin, D. O., Trevino, M., \& Jandorf, L. (2013). Understanding factors influencing Latina women's screening behavior: A qualitative approach. Health Educ Res, 28(5), 772-783. doi:10.1093/her/cys 106 
Tresnawati. (2012). Faktor-faktor yang mempengaruhi ibu untuk melakukan deteksi dini kanker serviks. (Diploma III Mini Thesis), STIKES 'Aisyiyah Yogyakarta, Yogyakarta. (98640502874)

Trevino, M., Jandorf, L., Bursac, Z., \& Erwin, D. O. (2012). Cancer screening behaviors among Latina women: The role of the Latino male. J Community Health, 37(3), 694-700. doi:10.1007/s10900-011-9501-4

Triutomo, N. (2014). Fikih ringkasan nikah. Retrieved from https://buletin.muslim.or.id/fiqih/fikih-ringkas-pernikahan

Underhill, M. L., Lally, R. M., Kiviniemi, M. T., Murekeyisoni, C., \& Dickerson, S. S. (2012). Living my family's story: Identifying the lived experience in healthy women at risk for hereditary breast cancer. Cancer Nurs, 35(6), 493504. doi:10.1097/NCC.0b013e31824530fa

United Nations Population Fund. (2011). Social-cultural influences on the reproductive health of migrant women. Retrieved from Vietnam:

United Nations Population Fund. (2016). Religion, women's health and rights: Points of contention and paths of opportunities. Retrieved from New York:

Usamah, A. H. (2013). Anjuran untuk menikah. Retrieved from https://almanhaj.co.id

Vaismoradi, M., Turunen, H., \& Bondas, T. (2013). Content analysis and thematic analysis: Implications for conducting a qualitative descriptive study. Nursing \& Health Sciences, 15(3), 398-405. doi:10.1111/nhs.12048

Villafuerte, B. E., Gomez, L. L., Betancourt, A. M., \& Cervantes, M. L. (2007). Cervical cancer: A qualitative study on subjectivity, family, gender and health services. Reprod Health, 4, 2. doi:10.1186/1742-4755-4-2

Wahyuni. (2013). Faktor-faktor yang mempengaruhi perilaku deteksi dini kanker serviks di kecamatan Ngampel kabupaten Kendal Jawa Tengah. Jurnal Keperawatan Maternitas, 1(1).

Wahyuni, S. (2011). Efektifitas edukasi metode "Wish and Drive" terhadap perilaku deteksi dini kanker serviks di Kecamatan Ngampel Kabupaten Kendal Jawa Tengah. (Master), Universitas Indonesia, Jakarta. Retrieved from $\underline{\text { http://lontar.ui.ac.id/file?file=digital/20282604-T\%20Sri\%20Wahyuni.pdf }}$ (08064853582)

Waller, J., Robb, K., Stubbings, S., Ramirez, A., Macleod, U., Austoker, J., . . . Wardle, J. (2009). Awareness of cancer symptoms and anticipated help seeking among ethnic minority groups in England. Br J Cancer, 101 Suppl 2, S24-30. doi:10.1038/sj.bjc.6605387

Watts, L., Joseph, N., Velazquez, A., Gonzalez, M., Munro, E., Muzikansky, A., . . . Del Carmen, M. G. (2009). Understanding barriers to cervical cancer screening among Hispanic women. Am J Obstet Gynecol, 201(2), 199.e191198. doi:10.1016/j.ajog.2009.05.014

Watts, L., Joseph, N., Wallace, M., Rauh-Hain, J. A., Muzikansky, A., Growdon, W. B., \& del Carmen, M. G. (2009). HPV vaccine: A comparison of attitudes and behavioral perspectives between Latino and non-Latino women. Gynecol Oncol, 112(3), 577-582. doi:10.1016/j.ygyno.2008.12.010

Weeks, B. E., Friedenberg, L. M., Southwell, B. G., \& Slater, J. S. (2012). Behavioral consequences of conflict-oriented health news coverage: The 2009 mammography guideline controversy and online information seeking. Health Commun, 27(2), 158-166. doi:10.1080/10410236.2011.571757 
Wegwarth, O., \& Gigerenzer, G. (2011). "There is nothing to worry about": Gynecologists' counseling on mammography. Patient Educ Couns, 84(2), 251-256. doi:10.1016/j.pec.2010.07.025

Widianto, W. (2013). Komnas Perempuan: Segera tetapkan RUU Perlindungan Pekerja Luar Negeri. Retrieved from http://www.tribunnews.com/nasional/2013/05/16/komnas-perempuan-segeratetapkan-ruu-perlindungan-pekerja-luar-negeri

Widiasih, R., Nelson, K., \& Skinner, J. (2016). Cancer is a fatal disease; Perspectives among Muslim married men in Indonesia. International Journal of Health and Medicine, 1(1), 5.

Winkler, J., Bingham, A., Coffey, P., \& Handwerker, W. P. (2008). Women's participation in a cervical cancer screening program in Northern Peru. Health Educ Res, 23(1), 10-24. doi:10.1093/her/cyl156

Witharana, C., Wijesiriwardhana, P., Jayasekara, K., Kumari, P., \& Rodrigo, C. (2015). Awareness of female malignancies among women and their partners in Southern Sri Lanka and implications for screening: A cross sectional study. BMC Public Health, 15, 1179. doi:10.1186/s12889-015-2531-6

World Health Organization. (2002). Cervical cancer screening in developing countries: report of a WHO consultation: World Health Organization.

World Health Organization. (2006). Constitution of the World Health Organization [Press release]. Retrieved from http://www.who.int/governance/eb/who_constitution_en.pdf

World Health Organization. (2017a). Breast cancer: Prevention and control. Breast cancer control. Retrieved from http://www.who.int/cancer/detection/breastcancer/en/index3.html

World Health Organization. (2017b) Density of physicians. New York: Wold Health Organization.

World Health Organization. (2017c). Women's health. Retrieved from http://www.who.int/topics/womens_health/en/

Yanty, \& Vidi. (2013). Hubungan tingkat pengetahuan ibu tentang kanker serviks dengen perilaku ibu dalam melakukan tes Pap smear di Kelurahan Tugu Utara UIN Syarif Hidayatullah, Jakarta. Retrieved from http://repository.uinjkt.ac.id/dspace/bitstream/123456789/26411/1/Novita\%2 0Vidi\%20Yanty-FKIK.PDF

Yin, R. K. (2003). Case study research: Design and methods (3rd ed.). London: SAGE Publication.

Young, M., Wallace, J. E., \& Polachek, A. J. (2015). Gender differences in perceived domestic task equity. Journal of Family Issues, 36(13), 1751-1781. doi:10.1177/0192513x13508403

Yuliwati. (2012). Faktor-faktor yang berhubungan dengan perilaku WUS dalam deteksi dini kanker leher rahim mertode IVA di wilayah Puskesmas Prembun, Kebumen. (Sarjana Mini Thesis), Universitas Indonesia, Jakarta. Retrieved from http://lontar.ui.ac.id/file?file=digital/20318324-S-Yuliwati.pdf (1006822555)

Yusoff, N., Taib, N. A., \& Ahmad, A. (2011). The health seeking trajectories of Malaysian women and their husbands in delay cases of breast cancer: A qualitative study. Asian Pac J Cancer Prev, 12(10), 2563-2570.

Zeilani, R., \& Seymour, J. E. (2012). Muslim women's narratives about bodily change and care during critical illness: A qualitative study. J Nurs Scholarsh, 44(1), 99-107. doi:10.1111/j.1547-5069.2011.01427.x 